\title{
ELEFANT
}

C. Thieulot

\section{ELEFANT: a user-friendly multipurpose geodynamics code}

\section{Thieulot ${ }^{1,2}$}

${ }^{1}$ Department of Earth Sciences, University of Utrecht, Budapestlaan 4, 3584 CD, Utrecht, the Netherlands

${ }^{2}$ Centre for Earth Evolution and Dynamics (CEED), Postbox 1048, Blindern 0316 Oslo, Norway

Received: 19 June 2014 - Accepted: 30 June 2014 - Published: 29 July 2014

Correspondence to: C. Thieulot (c.thieulot@uu.nl)

Published by Copernicus Publications on behalf of the European Geosciences Union.

Back

Full Screen / Esc

Printer-friendly Version

Interactive Discussion

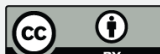




\section{Abstract}

A new finite element code for the solution of the Stokes and heat transport equations is presented. It has purposely been designed to address geological flow problems in two and three dimensions at crustal and lithospheric scales. The code relies on the Marker-

5 in-Cell technique and Lagrangian markers are used to track materials in the simulation domain which allows recording of the integrated history of deformation; their (number) density is variable and dynamically adapted. A variety of rheologies has been implemented including nonlinear thermally activated dislocation and diffusion creep and brittle (or plastic) frictional models. The code is built on the Arbitrary Lagrangian Eulerian free surface while the computational domain remains of constant width in the horizontal direction. The solution to the large system of algebraic equations resulting from the finite element discretisation and linearisation of the set of coupled partial differential equations to be solved is obtained by means of the efficient parallel direct solver AGMG iterative solvers. The code accuracy is assessed by means of many geodynamically relevant benchmark experiments which highlight specific features or algorithms, e.g., the implementation of the free surface stabilisation algorithm, the (visco-)plastic rheology implementation, the temperature advection, the capacity of the code to handle large viscosity contrasts. A two-dimensional application to salt tectonics presented as case study illustrates the potential of the code to model large scale high resolution thermo-mechanically coupled free surface flows.

\section{Introduction}

The use of numerical modelling in geosciences has transformed our understanding of the planet Earth. The constant improvement of numerical methods, the widespread availability of geophysical data and the evolution of ever more powerful computers keep
SED

6, 1949-2096, 2014

ELEFANT

C. Thieulot

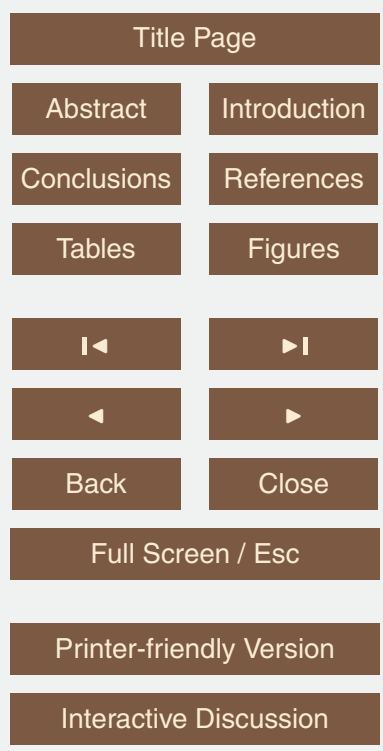


pushing its range of applications (from crustal deformation to deep mantle convection, from surface processes to planetology). Recently, two textbooks were dedicated to this topic (Gerya, 2010a; Ismail-Zadeh and Tackley, 2010).

The computational geodynamics community has traditionally been split in the mantle 5 convection and the crustal/lithospheric communities. This can be explained by a difference in dynamic regimes (different gouverning physical processes), and in terms of characteristic time and length scales. In light thereof, different codes have been custom-built to address the challenges faced by each community. As it is now clear that surface processes have a non negligible impact on deep processes (and vice versa), therefore aim at bridging the time and length scale differences.

Many thermo-mechanically coupled visco-(elasto-)plastic codes have been developed in the course of the past three decades. Due to limited computational resources, two-dimensional codes first came to light. Many have been upgraded over the years, 15 some have appeared recently. One can cite PARAVOZ (Poliakov et al., 1993a), SOPALE (Fullsack, 1995), ADELI (Hassani et al., 1997), I2ELVIS (Gerya and Yuen, 2003, 2007), SLOMO (Kaus, 2005), LAPEX2D (Babeyko et al., 2002), FANTOM (Thieulot, 2011), SULEC (Quinquis et al., 2011) and Fluidity (Davies et al., 2011) to name a few.

The vast majority of these codes has been developed by the geophysical community around the plane strain approach (vertical cross section). A noticeable exception is the plane stress approach (plan form, thin sheet) by England (1982) or Houseman and England (1993) (see also Willett and Pope, 2003, and references therein for a discussion on this approach). Plane strain approximation-based codes are not capable of modelling strain partitioning resulting from 3-D effects such as oblique convergence on a plate boundary and plane stress approximation provides a vertically integrated description of deformation and therefore cannot model the details of thrust and normal faulting.

With the increase of computational power of desktop stations and the wider availability of clusters, three-dimensional codes were developed in the mid-nineties (Braun,

\section{SED}

6, 1949-2096, 2014

\section{ELEFANT}

C. Thieulot

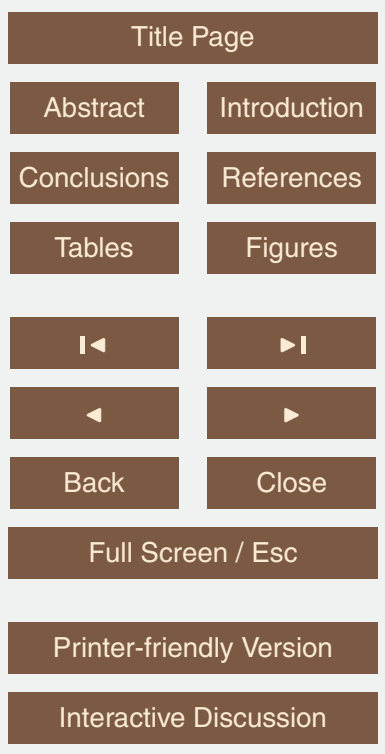


1993, 1994; Braun and Beaumont, 1995; Dunbar and Sawyer, 1996). Yet, 3-D tools offering a sufficient spatial resolution as well as comparable physics as their 2-D counterparts only appeared in the late 2000's. One can cite UNDERWORLD (Moresi et al., 2007), ELLIPSIS (O’Neill et al., 2006; Moresi et al., 2007), DOUAR (Braun et al., 2008), 5 MILAMIN (Dabrowski et al., 2008), LAMEM (Schmeling et al., 2008), SLIM3D (Popov and Sobolev, 2008), I3ELVIS (Zhu et al., 2009), and GALE ${ }^{1}$.

Some of these codes are based on the Finite Element Method, others on Finite Differences, others on FLAC and a great majority of them track materials by means of markers ("marker-in-cell" technique). Note that other methods have also been pro- posed, such as the Element Free Galerkin Method (Hansen, 2003), or the Discrete Element Method (Egholm, 2007; Egholm et al., 2007; Virgo et al., 2013) D

Two-dimensional codes have been used (for instance) to study lithospheric extension (Huismans and Beaumont, 2003, 2007), subduction (Gerbault et al., 2009; Schmeling et al., 2008; Kaus et al., 2008; Yamato et al., 2008; Gerya, 2011), small-scale sub15 lithosheric convection (van Wijk et al., 2010; Ballmer et al., 2007), underplating (Currie et al., 2007), Archean plate tectonics (Gray and Pysklywec, 2010), normal fauting (Lavier et al., 2000), burial and exhumation of ultrahigh-pressure rocks (Butler et al., 2013), wedge models of convergent orogens (Willett, 1999) or crustal scale convection (Babeyko et al., 2002).

20 Three-dimensional codes have been applied to the evolution of basins (Petrunin and Sobolev, 2008; Moresi et al., 2007; Allken et al., 2011, 2012), indentation problems (Thieulot et al., 2008), subduction (OzBench et al., 2008; Yamato et al., 2009; Loiselet et al., 2010; Yoshida et al., 2012; Li et al., 2013; Faccenda, 2014), crustal wedges (Braun and Yamato, 2009), oblique orogen convergence (Whipp et al., 2014), thrust wedges Ruth et al. (2014), transform faults at mid-ocean ridges (Gerya, 2010b; Choi et al., 2008; Püthe and Gerya, 2014) and have recently been coupled to absolute plate motion models (Chertova et al., 2014).

\footnotetext{
${ }^{1}$ http://www.geodynamics.org/cig/software/gale
}

\section{SED}

6, 1949-2096, 2014

\section{ELEFANT}

C. Thieulot

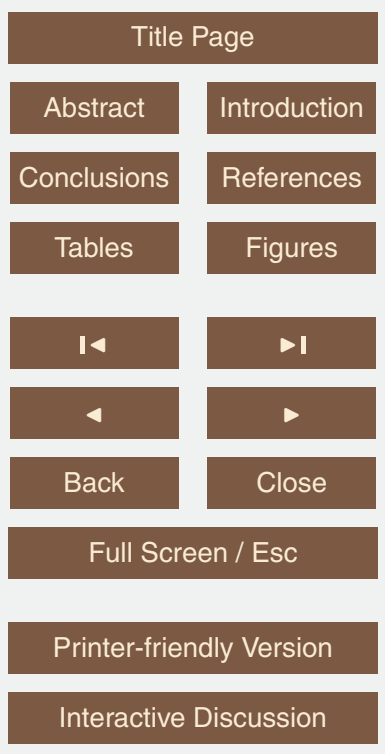


I present here the code coined ELEFANT ${ }^{2}$ which is a general nonlinear fluid Arbitrary Lagrangian-Eulerian (ALE) code primarily designed to solve two- and threedimensional large deformation visco-plastic flows at the lithospheric scale.

ELEFANT is a code which draws from the experience gained of co-developing DOUAR 5 (Braun et al., 2008) and writing FANTOM (Thieulot, 2011). In a sense, ELEFANT is an attempt to square the circle: I set out to write a code that would be the most user-friendly possible (i.e. usable by students with little computational background) while retaining the capacity to be used as a research tool. In a way, MILAMIN (Dabrowski et al., 2008), while being a very different code follows a similar philosophy. Further, not only had its use to be simple, but its structure had to be readable and self-explanatory. Writing the code was therefore a balance experiment between two seemingly unreconcilable poles: on the one hand, real user-friendliness and clarity, on the other hand some level of high performance, and completeness. At a very practical level, ELEFANT had to be simple to install too, compile seamlessly with all standard fortran compilers, and had to run on a variety of machines and operating systems (at the time of writing, the code has been installed on various laptops, multi-core desktops and supercomputers). Routine names are self-explanatory (e.g. smooth_pressure, or compute_timestep) and it was purposely chosen that a certain level or redundancy in the code would be allowed for a clearer structure (in the lines of: "one routine - one task").

20 The purpose of this work is two-fold: introducing the code and the implemented algorithms and techniques, as well as exposing the code to a rigorous series of relevant benchmarks.

The outline of this paper is as follows: in Sect. 2, the equations gouverning the physical processes are introduced; in Sect. 3, the numerical algorithms implemented in the 25 code are presented in detail. Section 4 showcases all the benchmark experiments carried out with the code. Section 5 presents a two-dimensional application of the code to

${ }^{2}$ ELEments Finis Appliqués a la simulation Numérique en Tectonique.

\section{SED}

6, 1949-2096, 2014

ELEFANT

C. Thieulot

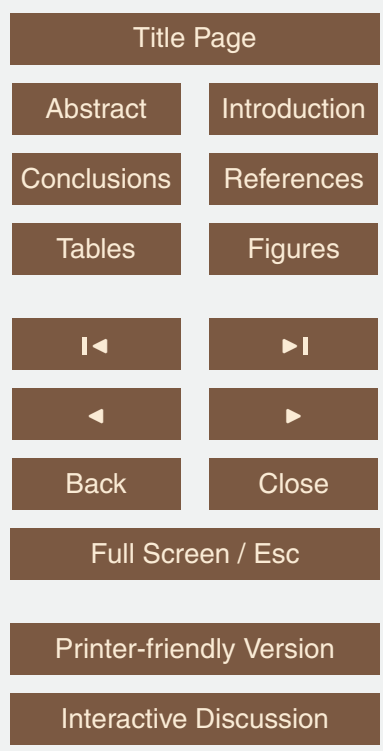


salt tectonics. Section 6 illustrates the performance of the solver, and finally, general conclusions on the present work are given in Sect. 7.

\section{Gouverning equations}

In what follows, the assumption is made that geological materials can be treated as 5 fluids (with special properties) within the realm of continuum fluid mechanics (Karato, 2008).

For convenience, the notation, meaning and dimension of used quantities throughout this work are shown in Table 1. The mechanical behavior of Earth materials which compose the crust and the mantle is described by means of the following equations:

$$
\begin{aligned}
\boldsymbol{\nabla} \cdot \boldsymbol{\sigma}+\rho \boldsymbol{g} & =\mathbf{0} \\
\boldsymbol{\nabla} \cdot \boldsymbol{v} & =0 \\
\boldsymbol{\sigma} & =-p \mathbf{1}+\boldsymbol{s} \\
\boldsymbol{s} & =2 \mu \dot{\boldsymbol{\epsilon}} \\
\dot{\boldsymbol{\epsilon}} & =\frac{1}{2}\left(\boldsymbol{\nabla} \boldsymbol{v}+(\boldsymbol{\nabla} \boldsymbol{v})^{T}\right) .
\end{aligned}
$$

Equation (1) is the momentum conservation equation and Eq. (2) is the mass conservation equation for incompressible fluids. One can resolve the stress tensor $\sigma$ into its spherical part $-p 1$ and its stress deviation $s$ (see Eq. 3), where the deviatoric stress tensor is proportional to the strain rate tensor $\dot{\boldsymbol{\epsilon}}$ (see Eq. 4) through the dynamic vis-
Equations (1)-(5) all together lead to the following form of the Stokes equations:

$\boldsymbol{\nabla} \cdot(\mu \boldsymbol{\nabla} \boldsymbol{v})-\boldsymbol{\nabla} p+\rho \boldsymbol{g}=\mathbf{0}$

$$
\boldsymbol{\nabla} \cdot \boldsymbol{v}=0 .
$$

\section{SED}

6, 1949-2096, 2014

\section{ELEFANT}

C. Thieulot

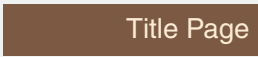

Abstract

Introduction

Conclusions

Tables

References

Figures

14

$\rightarrow 1$

4

Back

Close

Full Screen / Esc

Printer-friendly Version

Interactive Discussion

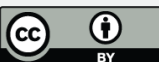


Equation (6) is an elliptic equation characterized by the fact that changes in buoyancy and constitutive relationships anywhere in the domain have an immediate influence on the entire domain.

Rock material properties such as density and viscosity depend on temperature. It 5 is therefore necessary to compute the temperature field within the deforming system. One then must solve the energy or heat transport equation:

$\rho c_{\mathrm{p}}\left(\frac{\partial T}{\partial t}+\boldsymbol{v} \cdot \boldsymbol{\nabla} T\right)=\boldsymbol{\nabla} \cdot(k \nabla T)+H_{\mathrm{r}}+H_{\mathrm{s}}$

where $H_{\mathrm{r}}$ is the internal heat production due to radioactive decay and $H_{\mathrm{s}}$ is the heat production due to dissipative or shear heating (Schott et al., 2000; Hartz and Podlachikov, 2008; Thielmann and Kaus, 2012) given by $H_{\mathrm{s}}=\sigma: \dot{\boldsymbol{\epsilon}}$.

At low temperature, rocks deform by brittle failure. In the context of continuum mechanics, it is approximated by a viscous deformation following a plasticity criterion (Kachanov, 2004). Viscosity values are locally adapted to limit the stress that is generated during deformation.

These criteria usually take the form of a yield criterion $F$ that is expressed in terms of the stress tensor, the accumulated strain, and of material dependent parameters

$F(\sigma, c, \phi, \epsilon, \ldots)=0$.

At high temperature, rocks deform by creep, a non-linear form of viscous deformation that is commonly approximated by defining a stress or strain rate dependent and thermally activated viscosity. This power-law rheology is described by the following equation:

$\dot{\epsilon}=A \sigma^{n} \exp \left(-\frac{Q+V p}{R T}\right)$

where $\dot{\epsilon}$ is a measure of the strain rate $\dot{\boldsymbol{\epsilon}}, \sigma$ is a measure of the flow stress, $A$ is a material constant, $n$ is the stress exponent, $Q$ is the creep activation energy, $R$ is 1955

\section{SED}

6, 1949-2096, 2014

\section{ELEFANT}

C. Thieulot

\section{Title Page}

Abstract

Introduction

Conclusions

Tables

References

Figures

14

$>$ I

4

Back

Close

Full Screen / Esc

Printer-friendly Version

Interactive Discussion

$>$

C 
the gas constant, $V$ is the activation volume. $A, n$ and $Q$ are empirically determined material-dependent constants assumed not to vary with stress and $(p, T)$ conditions.

The mass density $\rho$ varies as a function of temperature according to:

$\rho(T)=\rho_{0}\left(1-\alpha\left(T-T_{0}\right)\right)$

5 where $\alpha$ is the coefficient of thermal expansion which depends on pressure (Čížková et al., 2012), and $\rho_{0}$ is the value of the density at $T=T_{0}$.

The Oberbeck-Boussinesq approximation is adopted: it consists of assuming the density of the medium constant, except that the vital buoyancy term involving $\alpha$ is retained in the momentum equation (see Hetényi et al., 2011, for a discussion on the consequences of this approximation in the context of geodynamic models).

Physical properties of Earth materials also depend strongly on the accumulated strain, i.e. their history. Strain is therefore computed, stored and advected with the materials in the system.

A local accumulation of strain causes changes in the brittle properties of materials 15 and it is assumed that both cohesion and angle of friction decrease linearly with strain. If $\epsilon$ is less than threshold value $\epsilon_{1}, \phi=\phi_{0}$. For $\epsilon_{1}<\epsilon<\epsilon_{2}, \phi(\epsilon)$ is given by:

$\phi=\phi_{0}+\left(\phi_{\infty}-\phi_{0}\right) \frac{\epsilon-\epsilon_{1}}{\epsilon_{2}-\epsilon_{1}}$.

When $\epsilon$ reaches $\epsilon_{2}, \phi$ remains constant and is set to $\phi_{\infty}$. The cohesion $c$ follows a similar law, so that when fully strain-weakened the material cohesion is $c_{\infty}$.

Note that viscous strain softening is also taken in account so that the material properties can also weaken with accumulated strain in the viscous regime (Huismans and Beaumont, 2003; Warren et al., 2008).

Numerical and analogue modelling have shown that surface processes are very important factors in the study of the Earth. Not only do they shape the observable geological record on Earth, but they also provide feedback to deep tectonic processes through mass transport and deposition and asymmetric weathering (Thieulot et al.,
SED

6, 1949-2096, 2014

ELEFANT

C. Thieulot

\section{Title Page}

Abstract

Introduction

Conclusions

Tables

References

Figures

14

$>1$

4

Back

Close

Full Screen / Esc

Printer-friendly Version

Interactive Discussion 
2014c). Currently, two surface processes models are implemented: a simple diffusion law (see for instance Burov and Cloetingh, 1997), and an empirical law by Montgomery and Brandon (2002).

\section{Numerical implementation}

\section{$5 \quad 3.1$ The computational domain}

ELEFANT relies on a regular grid made of quadrilaterals in two-dimensions and hexahedrons in three-dimensions. The size of the elements is typically assigned at startup as being the ratio of the length in a given dimension divided by the number of elements in this same dimension. However, in the case when the user knows a priori where most 10 of the deformation is going to occur (e.g. the deformation is seeded in a given part of the domain, or crustal deformation is to be focused on at the expense of the mantle), the user can stretch the grid by either using pre-defined functions or implementing his own.

This is illustrated for instance in Fig. 1 where the grid has been stretched so that 15 a higher resolution is achieved at towards the center of the domain. The stretching is controlled by a simple function which is either selected from the provided ones in the code or written by the user. This approach has of course its limitation since elements with too high an aspect ratio are sources of numerical error. Nevertheless, it allows for a substantial gain of performance compared to a regular grid which would have the

\subsection{The penalty formulation}

In order to impose the incompressibility constraint, two widely used procedures are available, namely the agrange multiplier method and the penalty method (Bathe, 1982; Hughes, 2000, he latter is implemented in ELEFANT, which allows for the elim- 
ination of the pressure variable from the momentum equation (resulting in a reduction of the matrix size).

Mathematical details on the origin and validity of the penalty approach applied to the Stokes problem can for instance be found in Cuvelier et al. (1986), Reddy (1982) or 5 Gunzburger (1989).

The penalty formulation of the mass conservation equation is based on a relaxation of the incompressibility constraint and writes

$\boldsymbol{\nabla} \cdot \boldsymbol{v}+\frac{p}{\lambda}=0$

where $\lambda$ is the penalty parameter, that can be interpreted (and has the same dimension) 10 as a bulk viscosity. It is equivalent to say that the material is weakly compressible. It can be shown that if one chooses $\lambda$ to be a sufficiently large number, the continuity equation $\boldsymbol{\nabla} \cdot \boldsymbol{v}=0$ will be approximately satisfied in the finite element solution. The value of $\lambda$ is often recommended to be 6 to 7 orders of magnitude larger than the shear viscosity (Donea and Huerta, 2003; Hughes et al., 1979).

15 Equation (13) can be used to eliminate the pressure in Eq. (6) so that the mass and momentum conservation equations fuse to become:

$\boldsymbol{\nabla} \cdot(\mu \boldsymbol{\nabla} \boldsymbol{v})+\lambda \boldsymbol{\nabla}(\boldsymbol{\nabla} \cdot \boldsymbol{v})+\rho \boldsymbol{g}=0$.

Malkus and Hughes (1978) have established the equivalence for incompressible problems between the reduced integration of the penalty term and a mixed Finite Element approach if the pressure nodes coincide with the integration points of the reduced rule.

In the end, the elimination of the pressure unknown in the Stokes equations replaces the original saddle-point Stokes problem (Benzi et al., 2005) by an elliptical problem, which leads to a symmetric positive definite (SPD) FEM matrix. This is the major benefit of the penalized approach over the full indefinite solver with the velocity-pressure variables. Indeed, the SPD character of the matrix lends itself to efficient solving strage-

SED

6, 1949-2096, 2014

\section{ELEFANT}

C. Thieulot

\section{Title Page}

Abstract Introduction

Conclusions

Tables

References

Figures

14

$>1$

Back

Printer-friendly Version

Interactive Discussion
4

Close

Full Screen / Esc

$>$ 
gies and is less memory-demanding since it is sufficient to store only the upper half of the matrix including the diagonal (Golub and van Loan, 2013).

\subsection{Iterative solution technique}

The implemented method is related to artificial compressibility methods which them5 selves go back to Chorin (1967) (see Glowinski, 2003, for a mathematically rigorous overview of such techniques applied to viscous incompressible flows). The penalised system is solved by means of the following iterative method (see Sect. 8.1 of Benzi et al., 2005) which is related to the so-called Uzawa method.

Briefly, the iterative algorithm is given as follows:

1. Choose $p_{0}$ as an arbitrary initial pressure.

2. Let $k$ be the iteration number. Then solve for $k \geq 1$ the following problem

$$
\boldsymbol{\nabla} \cdot\left(\mu \boldsymbol{\nabla} \boldsymbol{v}^{k}\right)+\lambda \boldsymbol{\nabla}\left(\boldsymbol{\nabla} \cdot \boldsymbol{v}^{k}\right)+\rho \boldsymbol{g}=-\boldsymbol{\nabla} p^{k-1} .
$$

3. Correct the pressure approximation with (new descent direction)

$$
p^{k}=p^{k-1}+\lambda \boldsymbol{\nabla} \cdot \boldsymbol{v}^{k}
$$

4. Repeat steps 2 and 3 until the divergence of the ve y is sufficiently small.

It is then obvious that the traditional penalty method corresponds to the case where $p_{0}$ is zero and steps 2 and 3 are performed only once. Note that a pressure gradient term is now present on the right hand side which is absent in the penalty method. Starting from a code using the penalty method, these similarities make the implementation of this method rather trivial: all the terms appearing in step 2 are already available in any penalty formulation, except for the pressure gradient term which is usually recovered once the velocity is obtained.

\section{SED}

6, 1949-2096, 2014

\section{ELEFANT}

C. Thieulot

\section{Title Page}

Abstract Introduction

Conclusions

Tables

References

Figures

14

$\rightarrow 1$

4

Back

Close

Full Screen / Esc

Printer-friendly Version

Interactive Discussion
$>$ 
The strength of this method lies in its ability to produce a divergence-free velocity field even for very poorly conditioned problems such as flows where fluid properties vary by several orders of magnitude. It was shown to perform consistently better than the penalty based formulation (see Sect. 4.4).

$5 \quad$ As observed by Dabrowski et al. (2008), it was found beneficial in the presence of large viscosity variations to relate the penalty factor to the elemental viscosity to improve the condition number of the global matrix. In this case, a dimensionless coefficient $\lambda^{\star}$ is used so that the value of $\lambda$ in a given element $e$ is given by $\lambda(e)=\lambda^{\star} \mu_{\text {eff }}(e)$ where $\mu_{\text {eff }}(e)$ he effective viscosity in the element (see Sect. 3.13).

\subsection{Finite element formulation}

Introduced in the late 1950s, the finite element method (FEM) has emerged as one of the most powerful numerical methods so far devised (Hughes, 2000; Zienkiewicz and Taylor, 2002).

The physical domain $\Omega$ is broken up into elements, and a set of finite element basis 15 functions is defined for each element so that functional representations of the independent variables can be constructed.

Quadrilateral/hexahedral $Q_{1} P_{0}$ elements (bi/tri-linear velocity, piecewise constant pressure) are used in ELEFANT. Despite the fact that they violate the Ladyzhenskaya, Babouska and Brezzi (LBB) stability condition (Donea and Huerta, 2003), they remain a popular practical choice in mixed finite element approximation of incompressible materials.

This popularity can be explained by factors such as local mass conservation and simple and uniform data structures, algebraic problems with manageable sizes and small bandwidths of the resulting matrix.

25 The theory and implementation of the Finite Element method applied to viscous incompressible flows has been rigorously exposed in Donea and Huerta (2003), Gunzburger (1989) or Glowinski (2003) and the theory and implementation of the heat

\section{SED}

6, 1949-2096, 2014

\section{ELEFANT}

C. Thieulot
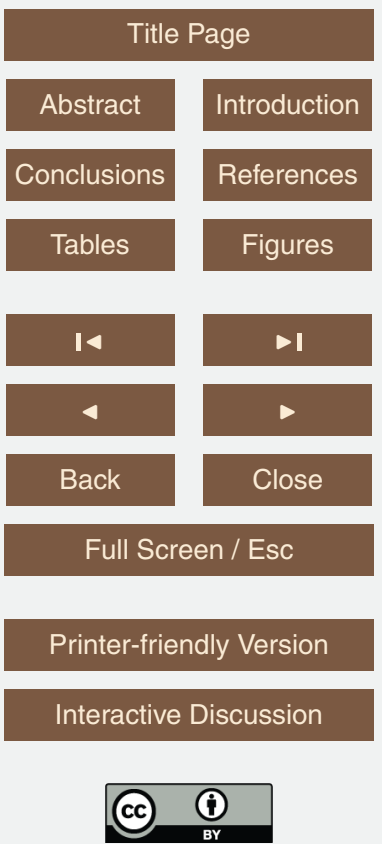
transport equation is to be found in Lewis et al. (2004). The FEM formulation of Eqs. (14) and (8) is presented succinctly in Appendix A.

Even though Eqs. (14) and (8) are coupled through the viscosity and density dependence on temperature and/or velocity, these equations are traditionally not solved in 5 a coupled manner. The obtention of a new set of variables $(\boldsymbol{v}, p, T)$ at a given time is the product of a three-stage process:

1. solve for velocity field

2. recover pressure field from velocity field

3. solve for temperature.

10 Note that steps 1 and 2 may need to be iterated out due to the nonlinear character of the equations to be solved (so called outer iterations).

The finite element discretisation of Eq. (15) yields the following matrix system:

$K \cdot V=G$

where $K$ is a large sparse SPD matrix, $\boldsymbol{V}$ is the vector of unknowns (the velocity degrees of freedom) and $G$ is the right hand side containing the buoyancy and correcive pressure gardient terms.

In order to reduce the condition number of the matrix $K$, the system is conditioned by means of a diagonal matrix $P=(\operatorname{diag}(K))^{-1 / 2}$ (Komzsik and Poschmann, 1993; Wathen and Silvester, 1993) so that the following system is in fact solved:

${ }_{20} \quad K^{\prime} \cdot V^{\prime}=G^{\prime}$

with $K^{\prime}=P K P, V^{\prime}=P^{-1} \cdot V$ and $G^{\prime}=P \cdot G$. This simple approach allows for a substantial reduction in iterations within the linear solver, effectively decreases the condition number (measured by means of the DSYEVD ${ }^{3}$ routine provided by LAPACK) and has the

\section{SED}

6, 1949-2096, 2014

\section{ELEFANT}

C. Thieulot

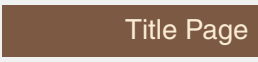

Abstract

Introduction

Conclusions

Tables

References

Figures

14

4

Back

Full Screen / Esc

Printer-friendly Version

Interactive Discussion

${ }^{3}$ http://www.netlib.org/lapack/lapack-3.1.1/html/dsyevd.f.html 
added advantage of scaling down the coefficients of the matrix towards values close to one which decreases round-off errors. Note that this simple preconditioner was found to be remarkably efficient in the case a Conjugate Gradients method is used (Pini and Gambolati, 1991).

\section{$5 \quad 3.5$ Boundary conditions}

Boundary conditions on the domain boundaries can be

- no-slip (no flow at the boundary);

- free slip (impermeable but tangential flow allowed);

- open to some form of through-flow;

- user defined in- and outflow;

- periodic.

Free slip is the most commonly used boundary condition while prescribed in- and outflow are also common (Ellis et al., 2011; Leng and Gurnis, 2011; Jammes and Huismans, 2012).

15 So-called open boundaries, for which the horizontal in- and outflow are defined by a fully internally developed flow, have hardly been used in the published geodynamical modeling literature, with the noticeable following exceptions: Quinteros et al. (2010), Chertova et al. $(2012,2014)$ and Ismail-Zadeh et al. (2013). The hydrostatic pressure condition is prescribed on the boundary and thereby prevents the model from collapsfor incompressible flows are studied by Gresho and Sani (1987).

Among the range of boundary conditions used, open boundaries may fit best to real-mantle flow conditions surrounding subduction zones, and lead to more consistent model results (especially when the computational domain aspect ratio is changed) than prescribed in/outflow boundary conditions (Chertova et al., 2012).

1962

\section{SED}

6, 1949-2096, 2014

\section{ELEFANT}

C. Thieulot

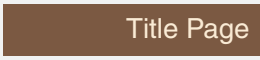

Abstract

Introduction

Conclusions

Tables

References

Figures

14

$>1$

4

$>$

Back

Close

Full Screen / Esc

Printer-friendly Version

Interactive Discussion 
Figure 2 shows the simple case of a Stokes sphere simulation with and without open boundary conditions on the side walls. In the case of free slip the flow is parallel to the walls while in the case of open boundaries the velocity field is almost perpendicular to the sides and shows an in- and outflow, consequence of the internal flow dynamics.

Another type of (stress) boundary conditions commonly used in the literature concerns the bottom of the domain (see Sect. 7.4 of Gerya, 2010a and references therein or Brune and Autin, 2013). It is a hydrostatic boundary condition where a normal stress (equal to the hydrostatic pressure at the bottom boundary) and zero shear stress is applied. Similarly to the open boundary conditions, it allows for an in- and out-flow

10 through the boundary based on the internal dynamics of the model. Figure 3 illustrates how this boundary condition works.

\subsection{Linearisation and convergence}

In the case of Newtonian fluid flow, a few iterations are normally required to bring the system to convergence and obtain a truly incompressible flow with the implemented 15 iterative scheme (the number depends strongly on the value of the penalty parameter).

While for Newtonian materials the viscosity $\mu$ in Eq. (6) is the dynamic viscosity of these materials, for non-Newtonian materials it is an effective viscosity $\mu_{\text {eff }}$ which depends on the velocity field (through the strain rate and the pressure) and on temperature. This makes Eq. (14) a strongly nonlinear equation. Following Appendix F of 20 Thieulot (2011), noplingar Picard-type iterations are carried out until convergence of the computed fields

The stopping criterion for the iteration process is based on three metrics: the first one is very similar to the one in Thieulot (2011) but has been expanded. Let us consider a scalar field $f$, which can represent nodal values such as the velocity components and 25 the temperature or elemental values such as pressure or strain rate. The normalised correlation of the field between two consecutive nonlinear iterations $i$ and $i+1$ is given

\section{SED}

6, 1949-2096, 2014

\section{ELEFANT}

C. Thieulot

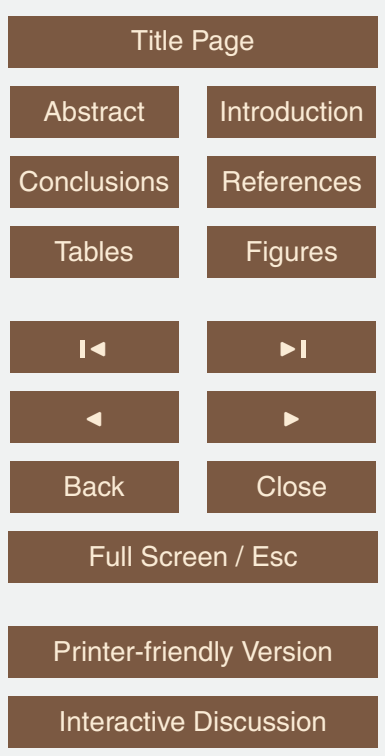


by:

$R_{f}^{i, i+1}=\frac{\left\langle\left(f^{i}-\left\langle f^{i}\right\rangle\right) \cdot\left(f^{i+1}-\left\langle f^{i+1}\right\rangle\right)\right\rangle}{\sqrt{\sigma^{i} \sigma^{i+1}}}$

SED

6, 1949-2096, 2014

where the means $\left\langle f^{i}\right\rangle,\left\langle f^{i+1}\right\rangle$, and the variances $\sigma^{i}, \sigma^{i+1}$ of the signals $f^{i}$ and $f^{i+1}$ are computed.

5 Since the correlation is normalised, it takes values between 0 (very different fields) and 1 (identical fields). The following convergence criterion, formulated in terms of the variable $\chi_{\mathrm{f}}=1-R_{f}^{i, i+1}$ has been implemented: convergence is reached when

$\chi_{\mathrm{f}}<t o I_{\mathrm{f}}$

The value of $t o l_{\mathrm{f}}$ for each field $f$ is set by default to $10^{-6}$.

10 The second metric is based on the residual of the linear system. The residual at iteration $i$ is given by

$r^{i}=\left|K^{i-1} \cdot \boldsymbol{V}^{i}-\boldsymbol{G}^{i-1}\right|$

where the matrix $K^{i-1}$ and the right hand side $G^{i-1}$ have been computed using the fields obtained at the previous $i-1$ iteration. It can be normalised by the norm of the 15 right hand side $G$, so that it takes value 1 at startup and decreases towards zero when the solution is converged. The criterion then reads:

$\frac{r^{i}}{|G|}<t o l_{\mathrm{r}}$.

The third metric is based on the velocity divergence and is used in Dabrowski et al. (2008) and Schmalholz et al. (2008). This criterion simply checks that the velocity divergence (normalised by the background strain rate $\dot{\epsilon}_{\text {ref }}$ ) is less than a given value $t o l_{\mathrm{d}}$ :

ELEFANT

C. Thieulot

Title Page

Abstract

Introduction

Conclusions

References

Tables

Figures

14

$>1$

4

Back

Close

Full Screen / Esc

Printer-friendly Version

Interactive Discussion

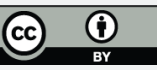


$\frac{\max |\boldsymbol{\nabla} \cdot \boldsymbol{v}|}{\dot{\epsilon}_{\mathrm{ref}}}<t o I_{\mathrm{d}}$

Convergence is reached when all three here above criteria are true-The stringency of the convergence criterion is determined by the choice of the $t o l_{\mathrm{f}}$ parameters for the $5 f$ fields, $t o I_{\mathrm{r}}$ and $t o l_{\mathrm{d}}$. Depending on the nonlinear character of the flow, these values can be adjusted, albeit with care since poor convergence will lead to error accumulation over time.

Note that a cap can be set by the user on the maximal number of nonlinear iterations

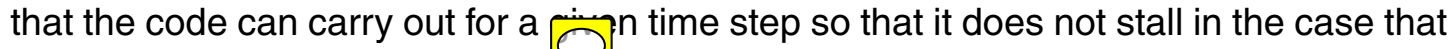

\subsection{Time stepping}

The chosen time step $\mathrm{d} t$ used for time integration is chosen to comply with the CourantFriedrichs-Lewy condition (Anderson, 1995):

$\mathrm{d} t=C \min \left(\frac{h}{|\boldsymbol{V}|_{\infty}}, \frac{h^{2}}{\kappa}\right)$

15 where $h$ is a measure of the smallest element size, $k=k / \rho c_{\mathrm{p}}$ is the thermal diffusivity and $C$ is the Courant number chosen in $[0,1]$.

\subsection{The ALE algorithm}

Crustal and lithospheric numerical simulations are characterised by the presence of a free surface at the top of the domain. There are several ways to deal with this open boundary.

One is called "Eulerian" and implies that the materials flow through a fixed computational grid. This requires the fluid above the free surface (i.e. the air) to be included in the model.

\section{SED}

6, 1949-2096, 2014

\section{ELEFANT}

C. Thieulot

\section{Title Page}

Abstract

Introduction

Conclusions

Tables

References

Figures

14

$\rightarrow 1$

Back

Close

Full Screen / Esc

Printer-friendly Version

Interactive Discussion

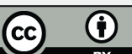


Another is coined "Lagrangian" and means that the grid deforms with the flow, which in the case of large strains can lead to a very distorted mesh (and even inverted elements) unsuited for accurate computations. Remeshing is then necessary but this procedure introduces interpolation errors and can be very costly (especially in 3-D).

5 ELEFANT implements the so-called Arbitrary Lagrangian-Eulerian method (Donea et al., 2004) which has been widely used in the numerical geodynamics community. The key idea resides in the use of a computational mesh which can move and deform with a velocity independent of the velocity carried by the material particles. Concretely, the lateral extent of the box remains constant, while the grid adapts vertically to span the o domain elevation dynamically produced by the flow. The technique and the associated interpolation algorithms used in ELEFANT are identical to those described in detail in Thieulot (2011).

\subsection{Markers advection}

The computational grid is underlain by a cloud of markers. Apart from its position in 15 space and its integer coordinates in the FE grid, each marker carries two fields: the type of material it tracks, and the accumulated strain $\epsilon$. At start-up, $n^{e}$ points are placed in each element $e$ (either regularly or randomly distributed). Once a new solution (converged velocity field) has been obtained, the finite element shape functions can be used to interpolate the velocity field on each marker, which is then advected.

20 The simplest approach is a first-order scheme which consists of two steps:

1. Interpolate velocity on marker $M$ at location $\boldsymbol{x}_{M}$.

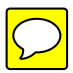

2. Advect the marker and compute its new position by

$$
\boldsymbol{x}_{M}(t+\delta t)=\boldsymbol{x}_{M}(t)+\boldsymbol{v}\left(\boldsymbol{x}_{M}, t\right) \delta t .
$$

This algorithm can also be called a first-order Runge-Kutta algorithm. Runge-Kutta algorithms are an important family of implicit and explicit iterative methods for the approximation of solutions of ordinary differential equations developed around 1900 by 1966

\section{SED}

6, 1949-2096, 2014

\section{ELEFANT}

C. Thieulot

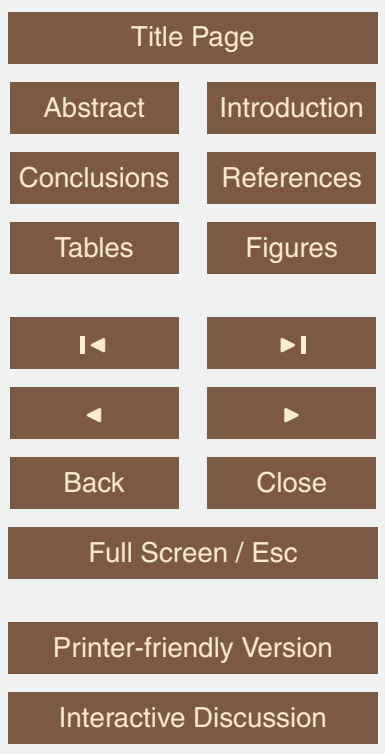

Interactive Discussion

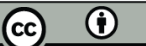


the German mathematicians C. Runge and M.W. Kutta (Hoffman, 1992). Chapter 8 of Gerya (2010a) presents a nice overview of advection schemes and related issues in the context of the Marker-in-Cell technique.

The first-order scheme is very appealing due to its simplicity but it is not very accu5 rate. Higher-order schemes are more accurate but introduce more calculations (intermediary advection steps). A few of them have therefore been implemented in ELEFANT:

- Runge-Kutta 1st, 2nd, 3rd, 4th order,

- Dormand-Prince 5th order (Prince and Dormand, 1981; Dormand and Prince, 1986). This method is currently the default method in MATLAB and GNU Octave's ode45 solver,

- Fehlberg 7th order (Fehlberg, 1985) which is frequently used in all high precision computations.

The implementation of these methods was tested by means of the classical Zalesak disk test (Zalesak, 1979) which is also found in many articles such as Battaglia et al. (2008), Pietro et al. (2006) or Sussman and Puckett (2000).

The setup of this experiment is shown in Fig. $4 \mathrm{a}$ and the velocity field anywhere in the domain is prescribed as follows:

$u(x, y)=2 \pi(y-L / 2)$

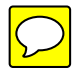

$v(x, y)=-2 \pi(x-L / 2)$.

After a $2 \pi$ rotation, markers should be back to their initial location, and it is logically observed that the position error decreases with the order of the employed Runge-Kutta scheme. However, while higher order methods prove to be more accurate, their additional costs become prohibitive compared to the gain in accuracy, so that the standard 4th-order Runge-Kutta constitutes the default method in ELEFANT.

SED

6, 1949-2096, 2014

\section{ELEFANT}

C. Thieulot
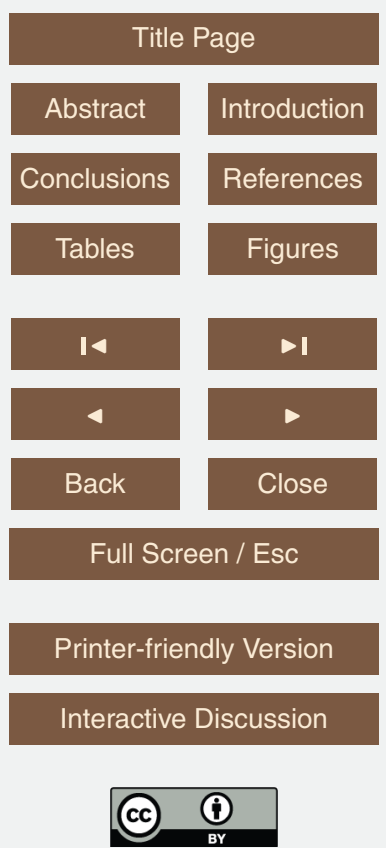


\subsection{Markers and population control}

Once the advection process is completed, the points which have been advected outside of the computational domain are removed, and the number of cloud points $n^{e}$ is again computed in each element. This number is then checked against two user-defined 5 limits: $n_{\min }^{e}$ and $n_{\max }^{e}$.

If $n^{e}<n_{\min }^{e}$, the nature of the flow has led to a situation where the local density of cloud points is below the threshold $n_{\min }^{e}$. In this case, $n_{\min }^{e}-n^{e}$ points need to be injected. Each injection is performed by randomly injecting a given number of test points inside the element among which only one is kept (this selection is based on a maximi10 sation of the distance between the new one and the preexisting points). This approach, also used in DOUAR (Braun et al.. 2008), represents an alternative to the splitting approach of Moresi et al. (2003). $\Omega$

If $n^{e}>n_{\text {max }}^{e}$, the local density of cloud points has become too high. Keeping overnumerous points in the system ultimately leads to excessive memory usage, and slows 15 the routines handling the cloud. Therefore $n^{e}-n_{\max }^{e}$ points are removed. As in the injection case, removal of points is performed in connection with the local density of points within the element.

\subsection{Marker projection}

At a given time, every element $e$ contains $n^{e}$ markers. During the FE matrix building 20 process, viscosity and density values are needed at the quadrature points. One therefore needs to project the values carried by the markers at these locations. Several approaches are currently in use in the community and the topic has hespinvestigated by Deubelbeiss and Kaus (2008) and Duretz et al. (2011) for instance.

ELEFANT adopts a simple approach: viscosity and density are considered to be ele-

mental values, i.e. all the markers within a given element contribute to assign a unique constant density and viscosity value to the element by means of an averaging scheme.

\section{SED}

6, 1949-2096, 2014

\section{ELEFANT}

C. Thieulot
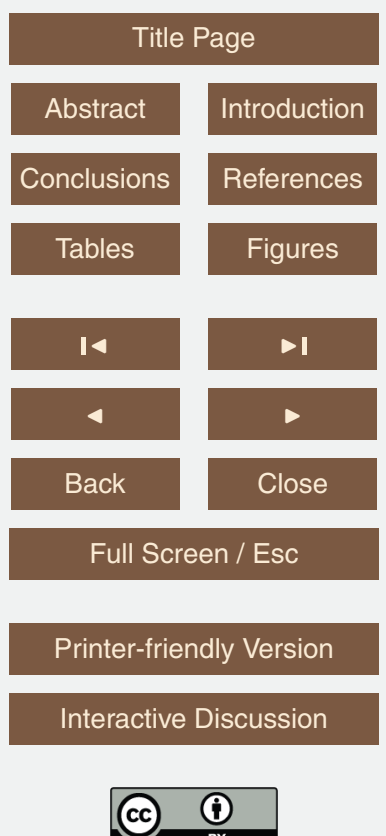
While it is common in the literature to treat the so-called arithmetic, geometric and harmonic means as separate averagings, I hereby wish to introduce the notion of generalised mean, which is a family of functions for aggregating sets of numbers that include as special cases the arithmetic, geometric and harmonic means.

5 If $p$ is a non-zero real number, we can define the generalised mean (or power mean) with exponent $p$ of the positive real numbers $a_{1}, \ldots a_{n}$ as:

$M_{p}\left(a_{1}, \ldots a_{n}\right)=\left(\frac{1}{n} \sum_{i=1}^{n} a_{i}^{p}\right)^{1 / p}$

and it is trivial to verify that we then have the special cases:

$M_{-\infty}=\lim _{p \rightarrow-\infty} M_{p}=\min \left(a_{1}, \ldots, a_{n}\right) \quad$ (minimum)

${ }_{10} \quad M_{-1}=\frac{n}{\frac{1}{a_{1}}+\frac{1}{a_{2}}+\cdots+\frac{1}{a_{n}}} \quad$ (harm. avrg.)

$$
M_{0}=\lim _{p \rightarrow 0} M_{p}=\left(\prod_{i=1}^{n} a_{i}\right)^{1 / n} \quad \text { (geom. avrg.) }
$$

$M_{+1}=\frac{1}{n} \sum_{i=1}^{n} a_{i} \quad$ (arithm. avrg.)

$M_{+2}=\sqrt{\frac{1}{n} \sum_{i=1}^{n} a_{i}^{2}} \quad$ (root mean square)

$M_{+\infty}=\lim _{p \rightarrow+\infty} M_{p}=\max \left(a_{1}, \ldots, a_{n}\right) \quad$ (maximum).

Note that the proofs of the limit convergence are given in Bullen (2003).

An interesting property of the generalised mean is as follows: for two real values $p$ and $q$, if $p<q$ then $M_{p} \leq M_{q}$. This property has for instance been illustrated in Fig. 20 of Schmeling et al. (2008).

SED

6, 1949-2096, 2014

\section{ELEFANT}

C. Thieulot

Title Page

Abstract

Introduction

Conclusions

Tables

References

Figures

14

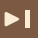

4

Back

Close

Full Screen / Esc

Printer-friendly Version

Interactive Discussion

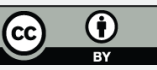


One can then for instance look at the generalised mean of a randomly generated set of 1000 viscosity values within $10^{18} \mathrm{~Pa}$ and $10^{23} \mathrm{Pas}$ for $-5 \leq p \leq 5$. Results are shown in Fig. 5 and the arithmetic, geometric and harmonic values are indicated too. The function $M_{p}$ assumes an arctangent-like shape: very low values of $p$ will ultimately 5 yield the minimum viscosity in the array while very high values will yield its maximum. In between, the transition is smooth and occurs essentially for $|p| \leq 5$.

The default projections for density and viscosity in the code are respectively arithmetic and geometric.

\subsection{Solver and assembly process}

10 Large-scale high-resolution finite element computations generate large sets of coupled algebraic equations. Solving this system, if naively implemented, can prove to be irrealistically time- and cpu-consuming so that an external solver needs to be coupled to the code.

In principle, the solution to these equations can either be obtained using an iter15 ative/multigrid solver or a direct solver $\mathrm{A}$ succinct overview of the pros and cons of direct solvers is given by Braun et al. (2008) and comparative properties, ease of use and performance studies across sparse direct symmetric solvers have been studied by Scott and $\mathrm{Hu}$ (2005) and Gould et al. (2005).

If one uses a penalty parameter many orders of magnitude larger than the dy20 namic viscosity, convergence of the nonlinear/outer iterations is expected to be fast and will bring the velocity divergence to computer precision values (see Sect. 4.4). This is indeed observed with direct solvers. However, such ill-conditioned systems will have iterative solvers fail unless dedicated appropriate preconditioners are implemented (Moresi and Solomatov, 1995; Chen and Phoon, 2009; May and Moresi, 2008;

At the time of writing four solvers are coupled with ELEFANT: the direct solver MUMPS, the iterative solver library SPLIB, the Krylov subspace iterative solver WISMP and the algebraic multigrid solver AGMG.

SED

6, 1949-2096, 2014

\section{ELEFANT}

C. Thieulot
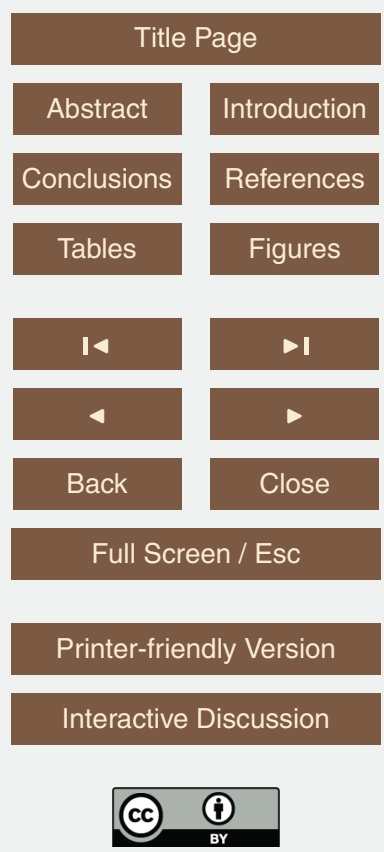
Note that since ELEFANT uses a regular grid, the connectivity of the grid nodes is fixed, and solver(s)-related arrays can be allocated once and for all at the beginning of the run. The code standardly builds both FEM matrices in Compressed Row Storage (CSR) format. The prominence of this format among available solver libraries makes 5 the code easy to be coupled to virtually any solver.

\subsubsection{Direct solver}

While FANTOM relied on WSMP ${ }^{4}$ (Gupta et al., 2009; Gupta, 2000), and PARDISO ${ }^{5}$ (Schenk et al., 2007, 2008), ELEFANT relies on MUMPS ${ }^{6}$ (Amestoy et al., 2001, 2006). All these solvers implement algorithms for efficiently solving large systems of linear solvers, or as scalable parallel solvers in a message-passing environment.

In the context of ELEFANT, MUMPS was chosen for several reasons: (a) it is simple to obtain and to install on any machine; (b) it is Fortran based; (c) it is public domain; (d) aside from a standard so-called coordinate matrix format, it is the only one which offers to carry out the assembly of the FEM matrix from the elemental matrices (Thieulot and L'Excellent, 2014). This last feature enables a very compact and clean implementation, albeit slightly more expensive in memory compared to the fully assembled case. Both formats and their associated performances are tested in Sect. 6.

Also, note that the METIS ${ }^{7}$ ordering library should be linked with MUMPS for maximal

\subsubsection{Iterative solvers}

Several iterative solvers are currently coupled with ELEFANT:

\section{SED}

6, 1949-2096, 2014

\section{ELEFANT}

C. Thieulot

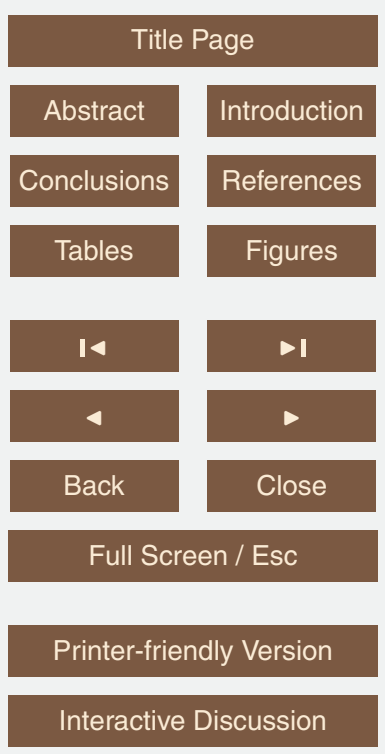

\footnotetext{
${ }^{4}$ http://www-users.cs.umn.edu/ agupta/wsmp.html

${ }^{5}$ http://www.pardiso-project.org/

${ }^{6}$ http://graal.ens-lyon.fr/MUMPS/

${ }^{7}$ http://glaros.dtc.umn.edu/gkhome/metis/metis/overview
} 
- Released in the second half of the 90's, SPLIB (Bramley and Wang, 1995) is a library of sparse iterative solvers, with preconditioners, for rapid prototyping of solvers for nonsymmetric linear systems. It was developed with the intent that it be useful for comparing iterative methods and preconditioners in a uniformly coded implementation. It is freely available ${ }^{8}$ and is written in portable Fortran77.

The code is heavily instrumented to provide information about the convergence history, memory usage, and CPU time used. SPLIB implements thirteen iterative solvers (CG-like methods, GMRES, Jacobi, Gauss-Seidel, Successive OverRelaxation ...) and seven preconditioning methods (ILU-like methods, Symmetric Successive Over-Relaxation, ...). All of the preconditioners are parameterised, providing a rich variety of preconditioning strategies.

SPLIB uses the Compressed Sparse Row format (CSR) for the matrix but unfortunately cannot exploit the (potential) symmetry of the matrix. Further, it is performing sequentially only but due to its use of the CSR format it can nevertheless handle large matrices of several hundreds of thousands of degrees of freedom.

SPLIB is essentially used for small tests and prototyping.

- $\mathrm{AGMG}^{9}$ is an algebraic multigrid solver (Notay, 2010, 2012; Napov and Notay,

AGMG is purely algebraic; that is, no information has to be supplied besides the system matrix and the right-hand-side. Both a sequential and a parallel FORTRAN 90 implementations are provided, as well as an interface allowing to use the software as a Matlab function. AGMG is available at no cost for academic Desearch and teaching.

At the time of writing, no domain decomposition algorithm is implemented in ELE25 2012 ) is the default solver for the heat transport equation in ELEFANT.

\section{SED}

6, 1949-2096, 2014

\section{ELEFANT}

C. Thieulot

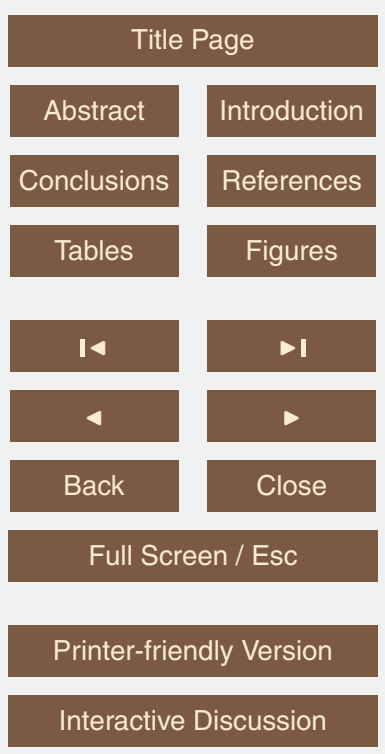

${ }^{8}$ http://wotug.org/parallel/nhse/rib/repositories/hpc-netlib/catalog/Asset/splib.html

${ }^{9}$ http://homepages.ulb.ac.be/ ynotay/AGMG

1972 
the parallel capabilities of AGMG are not investigated (these are however documented elsewhere ${ }^{10}$ ).

- WISMP is part of the Watson Sparse Matrix Package, WSMP ${ }^{11}$ (Gupta, 2007) which is a high-performance, robust, and easy to use software package for solving large sparse systems of linear equations. WSMP is comprised of three parts. Part I uses direct factorization for solving symmetric systems without numerical pivoting. Part II sparse LU factorization with pivoting for numerical stability to solve general systems. Part III deals with the iterative solution of sparse systems of linear equations and is coined WISMP in what follows.

WISMP can work either on a single CPU or on multiple CPUs with a shared address space (current efforts include distributed memory implementation). This package can be used for solving sparse linear systems using preconditioned Krylov subspace methods (CG, GMRES, TFQMR, BiCGStab), for performing sparse matrix-vector multiplication, and for generating and solving with respect to incomplete factorization based preconditioners.

WISMP currently supports Jacobi (diagonal), Gauss-Siedel (SSOR with relaxation $\omega=1$ ), and Incomplete Cholesky/LDL ${ }^{\top}$ preconditioners for symmetric positive definite and mildly indefinite (with very few negative eigenvalues) matrices. It supports Jacobi, Gauss-Siedel, and Incomplete LU factorization based preconditioners for general matrices.

Note that this is a commercial software that can be downloaded and tried freely for evaluation and benchmarking.

\footnotetext{
${ }^{10} \mathrm{http} / / /$ homepages.ulb.ac.be/ ynotay/AGMG/numcompsolv.pdf

${ }^{11}$ www.research.ibm.com/projects/wsmp
}

\section{SED}

6, 1949-2096, 2014

\section{ELEFANT}

C. Thieulot

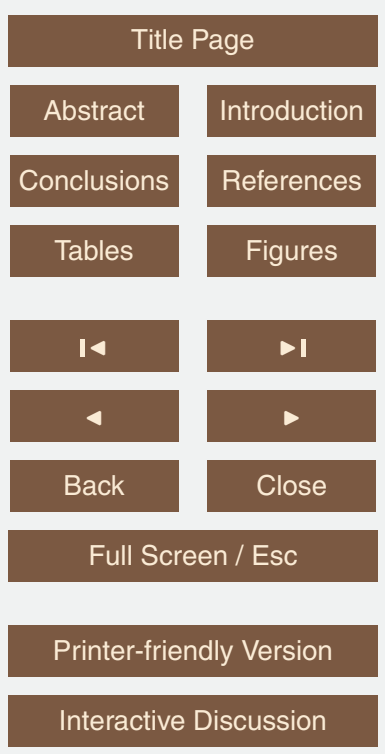




\subsection{Implementation of nonlinear rheologies}

Earth materials are parameterised in the code by a visco-plastic rheology. Which of the plastic or viscous branch is used to compute the effective viscosity at the location of a given marker is a function of the local pressure, temperature, and strain rate fields.

The viscous branch is itself a blend of diffusion and dislocation creep mechanisms and the effective viscosity is then given by

$\mu_{\text {eff }}=\frac{1}{2}\left(\frac{d^{p}}{A C_{\mathrm{OH}}^{r}}\right)^{1 / n} E_{2}^{\prime \frac{1-n}{2 n}} \exp \left(\frac{Q+p V}{n R T}\right)$

where $E_{2}^{\prime}$ is the second invariant of the deviatoric strain rate tensor $\dot{\boldsymbol{\epsilon}}, A$ is a material constant, $n$ is the power law stress exponent, $d$ the grain size, $p$ the grain size expo10 nent, $C_{\mathrm{OH}}$ the water content, $r$ the water content exponent, $Q$ the activations energy, $V$ the activation volume and $R$ the molar gas constant.

In he case of diffusion creep, $p>0$ and $n=1$ while in the case of dislocation creep $p=0$ and $n>1$.

Note that since $A$ is usually measured experimentally using uni-axial stress condi15 tions it has to be converted to invariants that are independent of the coordinate system by multiplying it by $3^{(n+1) / 2} / 2$ (Ranalli, 1995).

Numerically, an effective value for each mechanism is computed and the two are averaged in a composite viscosity as follows:

$\mu_{\text {eff }}^{\text {comp }}=\left(\frac{1}{\mu_{\text {eff }}^{\text {disl }}}+\frac{1}{\mu_{\text {eff }}^{\text {diff }}}\right)^{-1}$.

20 The code contains a database of various materials, such as wet and dry quartz, wet and dry olivine, diabase, salt, ...

In the case of the plastic branch, the implemented method is an alternative to the radial return method proposed in many textbooks (Zienkiewicz and Taylor, 2002; Owen

SED

6, 1949-2096, 2014

\section{ELEFANT}

C. Thieulot

\section{Title Page}

Abstract

Introduction

Conclusions

Tables

References

Figures

14

$\Delta$

4

Back

Close

Full Screen / Esc

Printer-friendly Version

Interactive Discussion
$>$ 
and Hinton, 1980); instead of computing the normal to the yield surface in the principal stress space, and projecting any predicted stress state outside the surface onto this surface along the normal, one simply rescales the viscosity so that the point falls back on the surface.

5 Practically, during the FE matrix building process, the yield function $F$ is computed in each element and for every marker, using the velocity solution obtained from the previous iteration:

$F=\sqrt{J_{2}^{\prime}}-\sigma_{p}(p, \dot{\boldsymbol{\epsilon}}, \epsilon)=2 \mu \sqrt{E_{2}^{\prime}}-\sigma_{\mathrm{p}}(p, \dot{\boldsymbol{\epsilon}}, \epsilon)$

where $J_{2}^{\prime}$ is the second invariant of the deviatoric stress and $\sigma_{\mathrm{p}}$ is the yield value (which 10 can depend on pressure, strain rate and accumulated strain).

If $F>0$ then the point under consideration is outside the yield surface, and rescaling the viscosity to

$\mu_{\text {eff }}=\frac{\sigma_{\mathrm{p}}(p, \dot{\boldsymbol{\epsilon}}, \epsilon)}{2 \sqrt{E_{2}^{\prime}}}$

insures that the nonlinear (plastic) relationship between strain rate and stress is re-

spected. This method is commonly referred to as the Viscosity Rescaling Method (VRM) (Kachanov, 2004; Willett, 1992).

As the yield criterion should be independent of the orientation of the coordinate system employed, it is only a function of the stress tensor invariants: $J_{1}, J_{2}^{\prime}$, and $J_{3}^{\prime}$. The two plasticity failure criteria (Mohr-Coulomb and Drucker-Prager) and their implementation are given in Appendix B of Thieulot (2011).

The code distinguishes between three rheologies: viscous, (rigid-)plastic and viscoplastic. In the first case, the viscosity $\mu$ used in Eq. (14) is the average elemental viscosity (see Sect. 3.11).

If the element is rigid-plastic, the yield $\sigma_{\mathrm{p}}$ is computed, and the viscosity is obtained

\section{SED}

6, 1949-2096, 2014

\section{ELEFANT}

C. Thieulot

\section{Title Page}

Abstract

Introduction

Conclusions

Tables

References

Figures

14

$\Delta$

4

Back

Close

Full Screen / Esc

Printer-friendly Version

Interactive Discussion 
sure $\sqrt{E_{2}^{\prime}}$ is small and therefore predicts a high value of $\mu_{\text {eff. }}$ Likewise, in regions where the deformation is localised, $\sqrt{E_{2}^{\prime}}$ is large and the resulting effective viscosity is low. Ultimately this leads to an untractable stiffness matrix due to its poor conditioning. In order to alleviate this problem, two user-defined viscosity values $\mu_{\min }$ and $\mu_{\max }$ are 5 used to enforce

$\mu_{\min } \leq \mu_{\text {eff }} \leq \mu_{\max }$

The lower bound is chosen as being the value predicted by Eq. (37) in the (hypothetical) case where all the deformation would be concentrated on a shear zone of one element width. The higher bound is obtained in a similar manner, assuming that the system is in pure shear (no localisation). Since the width of an element varies with the used computational grid, these values have to be calculated for every simulation.

Note that the value of $\mu_{\max }$ is bounded by the value of the incompressibility parameter $\lambda$ (bulk viscosity), so that ultimately the following relationship has to hold:

$\mu_{\min } \leq \mu_{\text {eff }} \leq \mu_{\max }<\lambda$

\section{$15 \quad 3.14$ Material memory}

It is now accepted that the realistic generation of plates in convection simulations requires some sort of strain or strain rate-weakening mechanism (e.g. Tackley, 1998), and as briefly summarized by Huismans and Beaumont (2003), frictional-plastic faults and brittle shear zones may be weakened by high transient or static fluid pressures or by gouge formation or mineral transformation, which is approximated by strain weakening.

Strain is therefore accumulated on the markers over time. Considering the $i$-th marker, the second invariant $E_{2}^{\prime}(t)$ of the deviatoric strain rate tensor $\dot{\boldsymbol{\epsilon}}(t)$ is computed at the point location by means of the spatial derivatives of the finite element shape functions. Let $\epsilon(t)$ be the accumulated strain on a given marker at time $t$. The accumulated

SED

6, 1949-2096, 2014

\section{ELEFANT}

C. Thieulot

\section{Title Page}

Abstract Introduction

Conclusions

Tables

References

Figures

14 $\Delta 1$

4

Back

Close

Full Screen / Esc

Printer-friendly Version

Interactive Discussion
$>$

ion

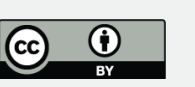


strain on this marker at time $t+\mathrm{d} t$ is then computed as follows :

$\epsilon(t+\mathrm{d} t)=\epsilon(t)+\sqrt{E_{2}^{\prime}(t)} \mathrm{d} t$

This strain value can then be used to strain-weaken the plastic parameters (decreasing the cohesion and/or angle of friction) or the composite viscosity of the creep models.

\section{3.15 Free surface stabilisation}

Typical densities of rocks are $\sim 3000 \mathrm{~kg} \mathrm{~m}^{-3}$, whereas typical density differences between the lithosphere and mantle, which drive lithospheric-scale processes, range between a few $\mathcal{O}\left(10^{1}\right)$ to $\mathcal{O}\left(10^{2}\right) \mathrm{kg} \mathrm{m}^{-3}$, i.e. the driving force from the topography of the lithosphere-mantle interface is thus up to a few hundred times smaller than that of the air-lithosphere interface (Kaus et al., 2010).

Since the stress $\sigma$ is proportional to $A \Delta \rho g$ (where $A$ is the amplitude of the topography), one can conclude that changing $A$ by $1 \mathrm{~m}$ at the free surface induces stresses that are up to a hundred times larger than those caused by moving the bottom of the lithosphere by $1 \mathrm{~m}$. It has been observed that using too large a time step results in 15 a system out of isostatic equilibrium with respect to the rest of the model and yields a fast growing numerical instability.

This instability is commonly suppressed by using extremely small time steps and/or a larger value for mantle viscosity, but a more robust solution has been presented in detail in Kaus et al. (2010) and succinctly in Quinquis et al. (2011). In its simplest form, it consists of the addition of a simple extra term to the FEM matrix which takes into account the incremental change in normal forces across density interfaces during each time step:

$F_{y}=\Delta \rho g_{y} \mathrm{~d} t v$

where $F_{y}$ is the extra vertical force term across the interface and $\Delta \rho$ is the change in density across the interface and $v$ is the vertical velocity of the interface. 
I have carried out the Rayleigh-Taylor instability experiment described in Kaus et al. (2010) where a dense fluid overlays another fluid in a square domain with their initial interface being of sinusoidal shape.

When the time step $\delta t$ is small, the simulation evolves smoothly (Fig. 6a), but too 5 large a time step leads to a sloshing instability, also called "drunken sailor effect" in the community (Fig. 6b).

The position $y(t)$ of the free surface point situated at $x=L_{x}$ is monitored and plotted in Fig. 7. The stabilisation algorithm is first switched off and up to a time step of $\delta t \sim 3800 \mathrm{yr}$, the free surface does not develop any instability (all curves are superim10 posed). For a time step of $3900 \mathrm{yr}$ and above, a clear oscillation develops (green seesaw curve on the figure). Turning the algorithm on, time steps larger than $\mathrm{d} t \sim 10000 \mathrm{yr}$ can be used and no oscillation is observed. Note that (a) the presence of the stabilisation algorithm with small time steps does not introduce a significant difference in the outcome (less than a meter of deviation after $1 \mathrm{Myr}$ ); (b) the time step was increased up to $\delta t=20000 \mathrm{yr}$ and the simulation remained stable (the vertical deviation differed by approximately $4 \mathrm{~m}$ from the one obtained with a very small time step, which remains a remarkable result since it only represents $\sim 0.2 \%$ of the element size); (c) time steps up to $\delta t=50000 \mathrm{yr}$ remain stable but lead to oscillations at the beginning and deviate in the end by about $5 \mathrm{~m}$.

\subsection{Dynamic pressure}

To counteract the lack of LBB stability (see Sect. 3.4), $Q_{1} P_{0}$ elements are usually supplemented by stabilisation or postprocessing procedures which allow to remove spurious pressure modes (see Sani et al. (1981a) and Fortin (1981) for details on the origin of these modes). The latter approach is implemented in DOUAR, FANTOM and ELEFANT.

The total dynamic pressure is recovered at the end of the outer iterations process as illustrated in Sect. 3.3 but can display spurious pressure modes which manifest themselves by the presence of a so-called element-by-element checkerboard mode as shown in Fig. 18 in Thieulot et al. (2008) and in Fig. 36d of the lid driven cavity

\section{SED}

6, 1949-2096, 2014

\section{ELEFANT}

C. Thieulot
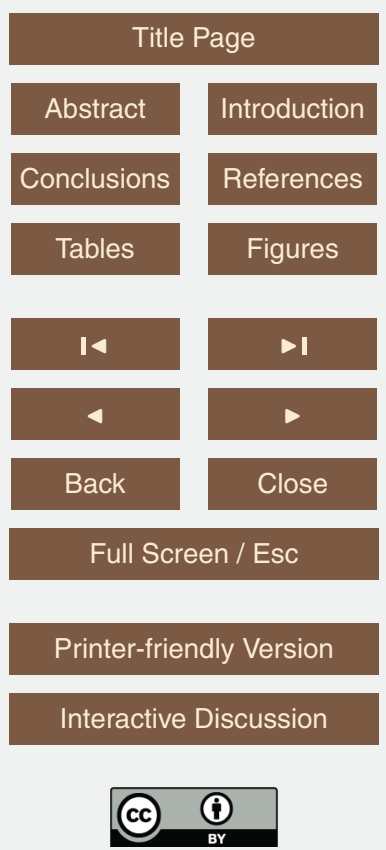
experiment. If the pressure field is not of importance, these modes are not problematic. However, in the context of geodynamical simulations, pressure is a quantity which needs to be computed as accurately as possible since (a) it appears in the creep law expression for viscosity and in the yielding criterion for frictional materials (b) it can also 5 be recorded over time for a later analysis of $P-T$ paths. Smoothing/filtering is therefore needed.

While many schemes have been proposed (e.g. Sani et al., 1981a, b), ELEFANT resorts to the same as the one present in DOUAR (Thieulot et al., 2008) and FANTOM (Thieulot, 2011): the pressure is smoothened by performing a double interpolation of 10 the elemental pressure onto nodes and then back onto elements. The element-to-node interpolation is performed by averaging the elemental values from elements common to each node; the node-to-elen interpolation is performed by averaging the nodal values element-by-element.

\subsection{The lithostatic pressure}

15 The difference between the computed dynamic pressure and the lithostatic pressure is called the overpressure. Its importance has for instance been highlighted by Schmalholz and Podlachikov (2013) in the context of the exhumation of high-pressure rocks.

The lithostatic pressure should therefore be computed but in most cases it cannot simply be computed analytically: indeed, it is a direct function of the material geometry and their density, which itself may depend on temperature.

The lithostatic pressure is also used in the context of open boundary conditions where it is prescribed on the sides of the model so that only the overpressure drives in- and outflow. Its calculation is succinctly explained in what follows.

In the absence of a velocity field, the Stokes equation reduces to

$25-\nabla p_{1}+\rho \boldsymbol{g}=\mathbf{0}$

\section{SED}

6, 1949-2096, 2014

\section{ELEFANT}

C. Thieulot

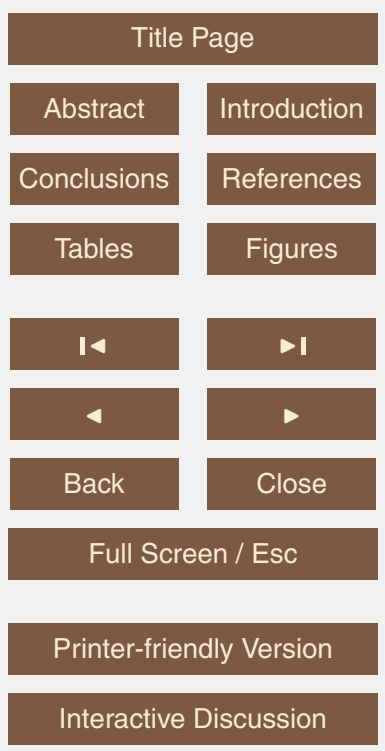


where $p_{1}$ the lithostatic pressure. A FEM discretisation similar to the one applied to the full Stokes equation yields the following linear system:

$$
\left(\int_{\Omega} \boldsymbol{N}^{T} \cdot B d \Omega\right) \cdot \boldsymbol{P}=\int_{\Omega} \boldsymbol{N}^{T} \cdot \rho g d \Omega
$$

where $\boldsymbol{P}$ is the vector of nodal pressures and $\boldsymbol{N}$ and $\boldsymbol{B}$ are the FEM shape function and shape function derivatives matrices (see Appendix A). Supplemented with a boundary condition (typically $p_{1}=0$ at the free surface) the system can be solved (note that the obtained matrix is not symmetric).

\subsection{Parallelism}

At the time of writing, ELEFANT is mostly a sequential code and the parallelism is only achieved through the MUMPS solver. Indeed, even though the matrix is built and assembled on one thread, MUMPS can solve the matrix using the message passing interface, without adding any complexity to the code (Thieulot and L'Excellent, 2014). Its performance is documented in Sect. 6.

This choice is primarily justified by the fact that the Stokes matrix solve in such a code 15 is the most cpu intensive task (up to $80 \%$ of the wall time as shown in Thieulot, 2011). The code will be parallelised in the near future, and both MPI and OpenMP paradigms are currently considered. An implementation of the PETSc library ${ }^{12}$ is also envisaged.

\subsection{Visualisation}

ELEFANT outputs data in binary format. These are later read and post-processed by

means of a set of visualisation tools distributed with the code and produces postscripts and VTK files, the latter being processed with Paraview ${ }^{13}$.

\footnotetext{
${ }^{12}$ http://www.mcs.anl.gov/petsc/

${ }^{13}$ http://www.paraview.org/
}

\section{SED}

6, 1949-2096, 2014

\section{ELEFANT}

C. Thieulot
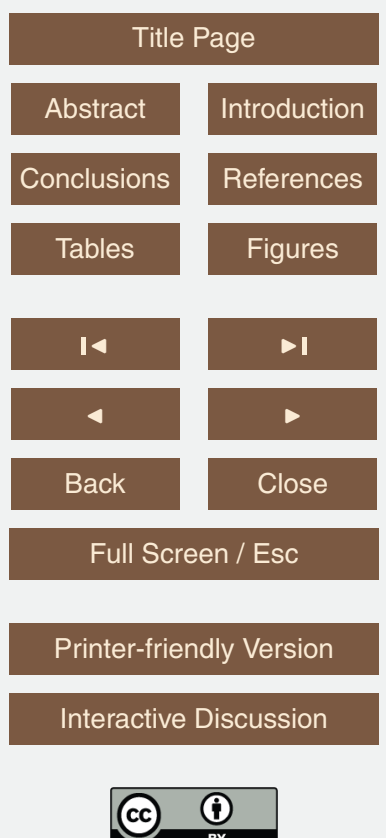


\subsection{Recording deformation}

Additional sets of markers and triangulated surfaces can be included in the model domain. These are passively advected with the computed velocity and can be used to record pTt-paths or simply visually illustrate accumulated deformation.

\section{Benchmarks}

Given the growing complexity of the geodynamics codes currently in use, it is customary to subject any new or updated code to a series of benchmark experiments to verify that it performs as expected by comparing the outcome to an analytical solution or to results obtained with other existing codes.

10 Given that ELEFANT is based on very similar algorithms as DOUAR and FANTOM, I have decided not to showcase the numerical sandbox experiment (Buiter et al., 2006), the instantaneaous Rayleigh-Taylor instability benchmark (Ramberg, 1968; Deubelbeiss and Kaus, 2008) and the falling block (Gerya, 2010a; Cerpa et al., 2014), all already presented in Thieulot et al. (2008) or Thieulot (2011). Note that they were nevertheless carried out and showed satisfactory results.

I have compiled the list of numerical experiments showed in this work in Table 2 and highlighted which aspects of the code they use/test.

Other benchmarks or numerical tests could have been envisaged, such as the dam break (Limache et al., 2007; Battaglia et al., 2008), the subduction zone cornerflow (van Keken et al., 2008), the 2-D thermal convection benchmark by Travis et al. (1990), the convergent channel flow (Mancktelow, 2008), the drag of a sphere in a viscoplastic medium (de Besses et al., 2004), the channel flow with a non-Newtonian rheology Gerya (2010a), etc ...

The following quantities are used throughout the presented numerical results:

\section{SED}

6, 1949-2096, 2014

\section{ELEFANT}

C. Thieulot

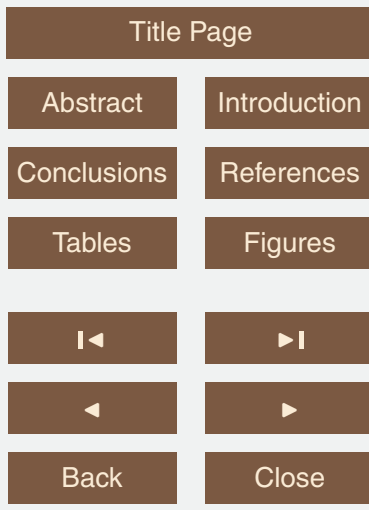

Full Screen / Esc

Printer-friendly Version

Interactive Discussion 
- the root-mean-square velocity $v_{\mathrm{rms}}$ in the domain as a function of time:

$$
v_{\mathrm{rms}}=\left(\frac{1}{V_{\Omega}} \int_{\Omega}|\boldsymbol{v}|^{2} \mathrm{~d} V\right)^{1 / 2}
$$

- the root-mean-square temperature $T_{\text {rms }}$ in the domain as a function of time:

$$
T_{\mathrm{rms}}=\left(\frac{1}{V_{\Omega}} \int_{\Omega} T^{2} \mathrm{~d} V\right)^{1 / 2}
$$

- the $L_{2}$-norm of a scalar function $q$ and a vector function $f$ :

$$
\begin{aligned}
& \|q\|_{L_{2}(\Omega)}=\left(\int_{\Omega} q^{2} \mathrm{~d} \Omega\right)^{1 / 2} \\
& \|f\|_{L_{2}(\Omega)}=\left(\int_{\Omega}\left(f_{x}^{2}+f_{y}^{2}+f_{z}^{2}\right) \mathrm{d} \Omega\right)^{1 / 2} .
\end{aligned}
$$

\subsection{Plasticity benchmarks}

4.1.1 The indenter

The punch benchmark is one of the few boundary value problems involving plastic solids for which there exists an exact solution. Such solutions are usually either for

Interactive Discussion

\section{ELEFANT}

C. Thieulot

\section{Title Page}

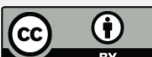


highly simplified geometries (spherical or axial symmetry, for instance) or simplified material models (such as rigid plastic solids) (Kachanov, 2004).

In this experiment, a rigid punch indents a rigid plastic half space; the slip line field theory gives exact solutions as shown in Fig. 8a. The plane strain formulation of the 5 equations and the detailed solution to the problem were derived in the Appendix of Thieulot et al. (2008) and are also presented in Gerbault et al. (1998).

The two dimensional punch problem has been extensively studied numerically for the past $40 \mathrm{yr}$ (Zienkiewicz et al., 1975, 1995; Christiansen and Pedersen, 2001; Christiansen and Andersen, 1999; Huh et al., 1999; Yu and Tin-Loi, 2006; Bui et al., 2008; 10 Rabczuk et al., 2007) and has been used to draw a parallel with the tectonics of eastern China in the context of the India-Eurasia collision (Tapponnier and Molnar, 1976; Molnar and Tapponnier, 1977). It is also worth noting that it has been carried out in one form or another in series of analogue modelling articles concerning the same region, with a rigid indenter colliding with a rheologically stratified lithosphere (Peltzer 15 and Tapponnier, 1988; Davy and Cobbold, 1988; Jolivet et al., 1990).

Numerically, the one-time step punch experiment is performed on a two-dimensional domain of purely plastic von Mises material. Given that the von Mises rheology yield criterion does not depend on pressure, the density of the material and/or the gravity vector is set to zero. Sides are set to free slip boundary conditions, the bottom to no 20 slip, while a vertical velocity $\left(0,-v_{p}\right)$ is prescribed at the top boundary for nodes whose $x$ coordinate is within $\left[L_{x} / 2-\delta, L_{x} / 2+\delta\right]$.

The following parameters are used: $L_{x}=1, L_{y}=0.5, \mu_{\min }=0.01, \mu_{\max }=10^{4}, \chi=$ $10^{-12}, v_{\mathrm{p}}=1, \delta=0.08$ and the yield value of the material is set to $k=1$.

The analytical solution predicts that the angle of the shear bands stemming from the sides of the punch is $\pi / 4$, that the pressure right under the punch is $1+\pi$, and that the velocity of the rigid blocks on each side of the punch is $v_{p} / \sqrt{2}$ (this is simply explained by invoking conservation of mass).

The results shown in Fig. 8 are obtained with a $1024 \times 512$ grid with the effective viscosity being directly computed at the quadrature points. We see that the obtained

SED

6, 1949-2096, 2014

\section{ELEFANT}

C. Thieulot

\section{Title Page}

Abstract Introduction

Conclusions

Tables

References

Figures

14

DI

4

Back

Close

Full Screen / Esc

Printer-friendly Version

Interactive Discussion

\section{ose}

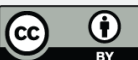


shear bands follow the expected distribution of slip lines and the measured angles are indeed $\pi / 4$. The three rigid blocks are recovered, as indicated by the three domains marked with letters $A, B, C$ in (c) with a high viscosity and a very low strain rate.

The (smoothed) pressure under the punch is measured at $p \simeq 4.76$, i.e. approx. $15 \%$ 5 error (left panel of Fig. 9) and the velocity of the rigid blocks is measured at $v_{b}=0.691$, i.e. approx $2 \%$ error. However, if one now only prescribes the vertical component under the punch (and lets the horizontal one free), the pressure under the punch is found to be approx. 4.16, i.e. an error of about $0.5 \%$ (right panel of Fig. 9).

Finally, switching from a von Mises to a Drucker-Prager yield criterion $\left(\phi=20^{\circ}\right)$ 10 yields the shear band geometry shown in Fig. 8e. The expected angle of the shear bands stemming from the sides of the punch is $\pi / 4+\phi / 2$ (Kachanov, 2004), i.e. $55^{\circ}$ which is indeed the recovered angle.

\subsubsection{The brick experiment}

The model domain is a rectangle of size $40 \mathrm{~km} \times 10 \mathrm{~km}$ and contains two materials: 15 a visco-plastic material of density $\rho=2700 \mathrm{~kg} \mathrm{~m}^{-3}$ characterised by a cohesion $c=$ $40 \mathrm{MPa}$, a variable angle of friction $\phi$ and a viscosity $\mu=10^{25} \mathrm{Pas}$; a linear viscous weak seed characterised by $\rho_{\mathrm{s}}=2700 \mathrm{~kg} \mathrm{~m}^{-3}$ and $\mu_{\mathrm{s}}=10^{20} \mathrm{~Pa} \mathrm{~s}$, as shown in Fig. 10 . The seed is placed at the bottom of the domain at location $x=L_{x} / 2$ and has a size $d \times h=800 \mathrm{~m} \times 400 \mathrm{~m}$. The gravity vector is given by $g=(0,-10) \mathrm{m} \mathrm{s}^{-2}$. Extensive or compressive boundary conditions are applied on the sides and result in a background strain rate value of $\pm 10^{-15} \mathrm{~s}^{-1}$, while free-slip is imposed at the bottom and the top boundary is free. Other parameters are as follows: $\mu_{\min }=10^{18} \mathrm{Pas}, \mu_{\max }=10^{25} \mathrm{~Pa} \mathrm{~s}$, $\lambda=10^{30} \mathrm{Pas}, \chi_{\mathrm{u}}=\chi_{\mathrm{v}}=\chi_{\mathrm{p}}=10^{-8}$.

This experiment has already been extensively investigated by many authors (Lemiale et al., 2008; Kaus, 2009; Maierová, 2012; Buiter, 2012; Glerum et al., 2014). The theory predicts that two shear bands will stem from the weak seed and that their angle with

\section{SED}

6, 1949-2096, 2014

\section{ELEFANT}

C. Thieulot

\section{Title Page}

Abstract Introduction

Conclusions

Tables

References

Figures

14

$>1$

4

Back

Close

Full Screen / Esc

Printer-friendly Version

Interactive Discussion 
respect to the $x$-axis will depend on the angle of friction $\phi$. However, as explained in Kaus (2009), this angle can take three acceptable values:

$\theta=45^{\circ} \pm \frac{\psi}{2} \quad$ (Roscoe angle)

$5 \quad \theta=45^{\circ} \pm \frac{\phi}{2} \quad$ (Coulomb angle)

$\theta=45^{\circ} \pm \frac{\phi+\psi}{4} \quad$ (Arthur angle)

where $\psi$ is the dilation angle which is taken to be 0 for rocks (Kaus, 2009). Angles outside the Roscoe-Coulomb angle are not expected to occur.

10 This experiment was carried out at the same resolution as Kaus (2009) $(400 \times 100$ elements) for angles of friction ranging from $0^{\circ}$ to $35^{\circ}$, both in extension and compression.

Similarly to Kaus (2009), the angle of the resulting shear bands is determined in an automated manner by computing the location of maximum strain rate invariant at 15 a distance of $d / 4$ and $d / 4+0.2$ from the sides of the inclusion. The average value from the left and right shear band is reported.

In in the absence of Newton-Raphson iterations it is expected that the Picard iterations converge very slowly and these results were typically obtained for a few hundreds nonlinear iterations, so that the system was allowed to reach the required convergence tolerances.

When $\phi=0^{\circ}$, the pressure is not coupled to the rheology, and the nature of the boundary conditions (compressive or extensive) does not influence the result and the predicted shear band angle of $45^{\circ}$ is recovered (Fig. 10b). Setting $\phi=20^{\circ}$ satisfactorily

ELEFANT

C. Thieulot

Title Page

Abstract

Introduction

Conclusions

Tables

References

Figures

14

$>$ I
4

Back

Close

Full Screen / Esc

Printer-friendly Version

Interactive Discussion

$>$

C

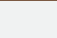

.


yields shear band angles of $\sim 35^{\circ}$ in compression and $\sim 55^{\circ}$ in extension (Fig. 10c and d). The results of the systematic study for $0 \leq \phi \leq 35^{\circ}$ are shown in Fig. 11 and it is found that the measured angles align well with the Coulomb angle values and fall within $\pm 1.5^{\circ}$ of this theoretical value.

\section{4.1.3 Shear bands fractals}

In the following experiment a $1 \times 1$ block of rigid-plastic material is submitted to pureshear boundary conditions: free slip is imposed on the $x=0$ and $y=0$ sides, while $u=-1$ is imposed on the $x=1$ side and $v=+1$ is imposed on the $y=1$ side (see Fig. 12a).

10 The material is characterised by a Drucker-Prager yield criterion with $c=1$ and $\phi=$ $35^{\circ}$. The resolution is varied between $50 \times 50$ and $400 \times 400$. Figure $12 \mathrm{~b}-\mathrm{g}$ shows the strain rate field after 1000 nonlinear iterations.

In the absence of prescribed weakness, the deformation localises on numerical noise and this explains the random character of the observed shear bands pattern. Note that the position and activities of single shear zones are not constant throughout the nonlinear iterations.

It is also worth mentioning that in the high resolution runs the shear band angles vary between $25^{\circ}$ and $29^{\circ}$ which is consistent with the expected Coulomb angle $\pi / 4-\phi / 2=$ $27.5^{\circ}$ (Lemiale et al., 2008; Kaus, 2009).

20 The system spontaneously organises in a network of thin shear bands which visually seems to be akin to fractals. This observation was the ground for the of Poliakov and Herrmann (1994), Poliakov et al. (1994) and Herrmann et al. (1996) hich looked at self-organised criticality of plastic shear bands in rocks, both numerically but also on the field by looking at outcrops in the Pyrenees.

25 Following the methodology presented in these articles, I have measured the normalised moments $m_{q}$ of the second invariant of the strain rate for all resolutions. They

\section{SED}

6, 1949-2096, 2014

\section{ELEFANT}

C. Thieulot

\section{Title Page}

Abstract

Introduction

Conclusions

Tables

References

Figures

14

$>1$

4

Back

Close

Full Screen / Esc

Printer-friendly Version

Interactive Discussion 
are calculated as follows:

$m_{q}=\left(M_{q} / M_{0}\right)^{1 / q}$

where $M_{q}$ is the $q$ th moment

$M_{\mathrm{q}}=\sum_{i=1}^{\text {ncell }} p_{\mathrm{i}}^{q} \quad$ and $\quad p_{i}=\frac{\dot{\epsilon}_{i}}{\sum_{j=1}^{\text {ncell }} \dot{\epsilon}_{j}}$

\section{ELEFANT}

C. Thieulot

Figure 13 shows the moments $q_{1}, q_{2}, q_{3}, q_{4}$ as a function of resolution ncell $x=$

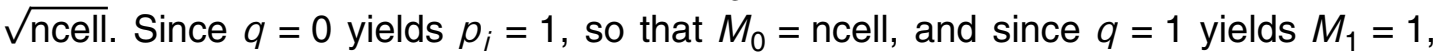
the normalised moment $m_{1}$ shows the expected scaling exponent of -2 . The other moments scaling exponents are around -1.7 which is consistent with the values of geometrical fractal dimension reported in Poliakov and Herrmann (1994) for both nu10 merical experiments and rocks.

\subsection{Rayleigh-Taylor instability growth}

This numerical experiment was first presented in van Keken et al. (1997) and has been consequently carried out in Tackley and King (2003); Samuel and Evonuk (2010); Suckale et al. (2010); Bourgouin et al. (2006); Leng and Zhong (2011); Fuchs and 15 Schmeling (2013); Choi et al. (2013). It consists of an isothermal Rayleigh-Taylor instability in a two-dimensional box of size $L_{x}=0.9142$ and $L_{y}=1$ (see Fig. 14).

Two Newtonian fluids are present in the system: the buoyant layer is placed at the bottom of the box and the interface between both fluids is given by

$y(x)=0.2+0.02 \cos \left(\frac{\pi x}{L_{x}}\right)$.

20 The bottom fluid is characterised by its mass density $\rho_{1}=1000$ and its viscosity $\mu_{1}=$ 100 , while the layer above is parametrised by $\rho_{2}=1010$ and $\mu_{2}=\mu_{1}$. No-slip boundary 
conditions are applied at the bottom and at the top of the box while free-slip boundary conditions are applied on the sides.

SED

The following quantities are measured:

- The maximum (or local maxima) of the $v_{\text {rms }}$ and its (their) corresponding time(s).

- The growth rate $\gamma$ of the instability at $t=0$, i.e. the slope of the $v_{\text {rms }}$ curve at startup.

- The total mass of the system $M(t)$ as a function of time. Since there is no chemical diffusion in the system (pure advection), the amount of material in the system is to remain constant, and therefore its mass:

$M(t)=\iint \rho(x, y, t) \mathrm{d} x \mathrm{~d} y$

computed as the sum over all elements of the average mass of tracers in each element. Given the layout described in the previous paragraph, the exact analytical initial mass $M_{0}$ of the system is given by

$M_{0}=0.9142 \times\left(0.2 \times \rho_{1}+0.8 \times \rho_{2}\right)=921.5136$

In what follows I measure the relative mass error as a function of time

$$
\delta M(t)=\frac{M(t)-M_{0}}{M_{0}}
$$

The time evolution of the system is shown in Fig. 14. The long-wavelength shape of the initial interface (i.e., the cosine used to describe the initial conditions in the input file) determines the rise of the first plume along the left edge of the domain (Fig. 14b).

20 A second plume follows and rises along the right edge. Its origin along the interface is much harder to trace - its position and the timing when it starts to rise is certainly not

ELEFANT

C. Thieulot

Title Page

Abstract

Introduction

Conclusions

Tables

References

Figures

14

$\Delta 1$

4

Back

Close

Full Screen / Esc

Printer-friendly Version

Interactive Discussion

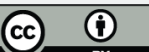


obvious from the initial location of the interface (Fig. 14c). Finally, (Fig. 14f) represents the state of the interface between the two fluids as shown in van Keken et al. (1997) at the end of the simulation $(t=2000)$ and one sees that the corresponding figure (Fig. 14e) as obtained with ELEFANT is remarkably similar to it.

$5 \quad$ In Fig. 15 is shown the $v_{\text {rms }}$ measurements for a $80 \times 80$ and $400 \times 400$ grids, alongside those from van Keken et al. (1997) and those obtained with ASPECT ${ }^{14}$. One sees that (a) the four curves match rather well (position and height of the two peaks); (b) the use of a higher resolution does not influence the results of the first peak but allows to better capture the height of the second. I have also investigated the influence of the advection scheme order and concluded that it has a limited effect on the $v_{\text {rms }}$ measurements (but has a consequence on mass conservation): there is a small difference between Runge-Kutta 1st and 2nd order, but virtually none between between those obtained with Runge-Kutta 2nd and 4th order and Dormand-Prince 8th-order schemes.

15 Values of $\delta M(t)$ were recorded for grid resolutions varying from $48 \times 48$ to $512 \times 512$ and were found to never exceed $\pm 0.001 \%$. Growth rate values were also measured and values ranged between 0.0106 and 0.0113 , which is extremely similar to those published by van Keken et al. (1997) and others, and differing by about $3 \%$ from the expected analytical value.

\subsection{Thin layer entrainment}

The second problem is a simulation to study the amount of entrainment by thermal convection of a dense, thin layer at the bottom of the model (van Keken et al., 1997). To the author's knowledge only one other publication (Tackley and King, 2003) has presented results pertaining to this benchmark but the authors did not show any quantitative re-

\section{SED}

6, 1949-2096, 2014

\section{ELEFANT}

C. Thieulot

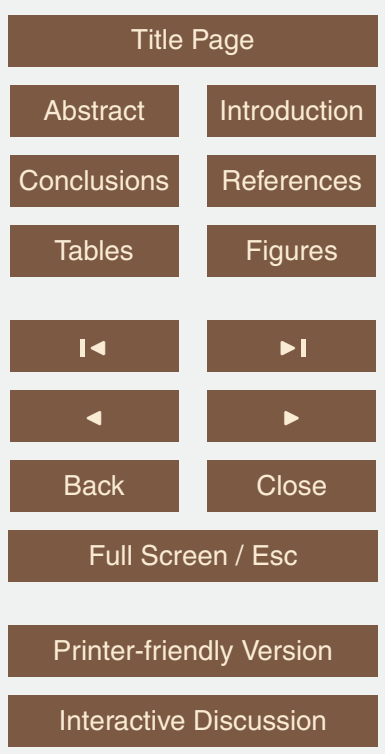

\footnotetext{
${ }^{14}$ See ASPECT manual for more details on the composition setup.
} 
The box is $2 \times 1$, and contains two fluids (see Fig. 16a). Fluid 1 has a density $\rho_{1}=1$ and a viscosity $\mu=1$. Fluid 2 is heavier $\left(\rho_{2}=\rho_{1}+\Delta \rho\right)$ but has the same viscosity. Both fluids have a thermal expansion coefficient $\alpha=10^{-10}$, a thermal conductivity $k=1$, and a heat capacity coefficient $c_{\mathrm{p}}=1$. Fluid 2 is placed at the bottom of the box $(0 \leq y \leq$ 5 0.025).

This experiment is parameterised by the thermal Rayleigh number $R a=300000$ and the compositional Rayleigh number $R b=450000$ which are defined as follows:

$R a=\frac{\alpha \rho g \Delta T L_{y}^{3}}{k \mu}=\frac{\alpha \rho^{2} g \Delta T L_{y}^{3} C_{\mathrm{p}}}{k \mu}=\alpha g$

$R b=\frac{\Delta \rho g L_{y}^{3}}{k \mu}=\frac{\rho \Delta \rho g L_{y}^{3} C_{\mathrm{p}}}{k \mu}=\Delta \rho g$

where I have used the relationship $k=k / \rho c_{\mathrm{p}}$. The gravity acceleration is therefore set to $g=10^{10} R a$ and this yields $\Delta \rho=R b / g=1.5 \times 10^{-10}$. Free-slip boundary conditions are imposed on all sides of the domain. Temperature boundary conditions are $T(x, y=$ $0)=1$ and $T(x, y=1)=0$. The analytical initial temperature field is given by

${ }_{15} T(x, y)=T_{\mathrm{u}}(x, y)+T_{1}(x, y)+T_{\mathrm{r}}(x, y)+T_{\mathrm{s}}(x, y)-\frac{3}{2}$

\section{SED}

6, 1949-2096, 2014

\section{ELEFANT}

C. Thieulot

\section{Title Page}

Abstract

Introduction

Conclusions

Tables

References

Figures

14

$\triangleright 1$

4

Back

Close

Full Screen / Esc

Printer-friendly Version

Interactive Discussion 
where

$T_{\mathrm{u}}(x, y)=\frac{1}{2} \operatorname{erf}\left(\frac{1-y}{2} \sqrt{\frac{u_{0}}{x}}\right)$

SED

$T_{1}(x, y)=1-\frac{1}{2} \operatorname{erf}\left(\frac{y}{2} \sqrt{\frac{u_{0}}{L_{x}-x}}\right)$

6, 1949-2096, 2014

$T_{\mathrm{r}}(x, y)=\frac{1}{2}+\frac{Q}{2 \sqrt{\pi}} \sqrt{\frac{u_{0}}{y+1}} \exp \left(-\frac{x^{2} u_{0}}{4 y+4}\right)$

${ }_{5} T_{\mathrm{s}}(x, y)=\frac{1}{2}-\frac{Q}{2 \sqrt{\pi}} \sqrt{\frac{u_{0}}{2-y}} \exp \left(-\frac{\left(L_{x}-x\right)^{2} u_{0}}{8-4 y}\right)$

with

$u_{0}=\frac{L_{x}^{7 / 3}}{\left(1+L_{x}^{4}\right)^{2 / 3}}\left(\frac{R a}{2 \sqrt{\pi}}\right)^{2 / 3} \quad Q=2 \sqrt{\frac{L_{x}}{\pi u_{0}}}$.

Using $L_{x}=2, R a=3 \times 10^{5}$, one gets $u_{0} \simeq 1469.315$ and $Q \simeq 0.0416305$.

Given the small thickness of the bottom layer, it seems quite legitimate to investigate 10 the influence of grid resolution on the simulation. I have therefore looked at the initial root mean square velocity measurement as a function of the element diagonal value (a proxy for the average resolution in the case where elements are not square). Results are shown in Fig. 17 and indeed confirm that the element size plays a non negligible role at startup on the dynamics of the system. I have tried a variety of resolutions and aspect ratios in order to assess the sensitivity of the initial velocity field to the numerical setup and I conclude that for grids with elements of size $\leq 0.01$ the initial $v_{\text {rms }}$ does not vary significantly anymore.

Superimposed on the figure are the measurements provided by Prof. van Keken (black squares in the gray box). They agree well with my measurements but also indi-

Title Page

ELEFANT

C. Thieulot

Abstract

Introduction

Conclusions

Tables

References

Figures

14

$\triangleright 1$

4

Back

Close

Full Screen / Esc

Printer-friendly Version

Interactive Discussion

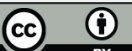



cate that none of the authors in the original study ran the experiment at a high-eno
resolution to start with (their results are therefore most likely resolution dependent)

Also, for a given resolution, measurements were carried out for the number of markers per element varying from 4 to 500 , and this translates into the pink "bars" in Fig. 17.

5 We see that this number is critical at low resolution but that it does not lead to significant velocity variations at high resolution.

In order to be able to compare my results with the published data, I have chosen to run this benchmark at similar resolutions as those in van Keken et al. (1997), i.e. $125 \times 40$ and $200 \times 48$.

10 The marker distribution and temperature field are shown in Fig. 16b-e for various times. As observed in van Keken et al. (1997), the dense layer is first swept into the lower left corner. Thermal instabilities then further develop in an asymmetrical way and entrain the dense material. Past $t \simeq 0.015$ the system becomes more and more chaotic with markers being randomly mixed in the system in a non-orderly fashion.

15 Looking at the root mean square velocity measurements of Fig. 18, we see that the measurements done with ELEFANT agree nicely, with those presented in van Keken et al. (1997). Past $t \simeq 0.015$, the curves diverge clearly across all codes and authors, so I only need to focus the comparison for times $t<0.015$. For the three tested resolutions, measurements agree well and fall within the grey curves representing all results of van Keken et al. (1997). Additional tests have been carried out concerning the value of the Courant number $(0.1$ to 0.25$)$ and the initial number of markers per element (100 or 200) and these parameters led to extremely similar results.

\subsection{Poiseuille flow}

The Poiseuille flow benchmark is a simple test of the fulfillment of the solenoidal con25 straint $\boldsymbol{\nabla} \cdot \boldsymbol{v}=0$.

This experiment, (and especially its time evolution in the context of Navier-Stokes flows) has been carried out by many authors using a wealth of methods: SPH (Morris et al., 1997; Sigalotti et al., 2003), Lattice Gas Automata (Kadanoff et al., 1987), Finite

\section{SED}

6, 1949-2096, 2014

\section{ELEFANT}

C. Thieulot
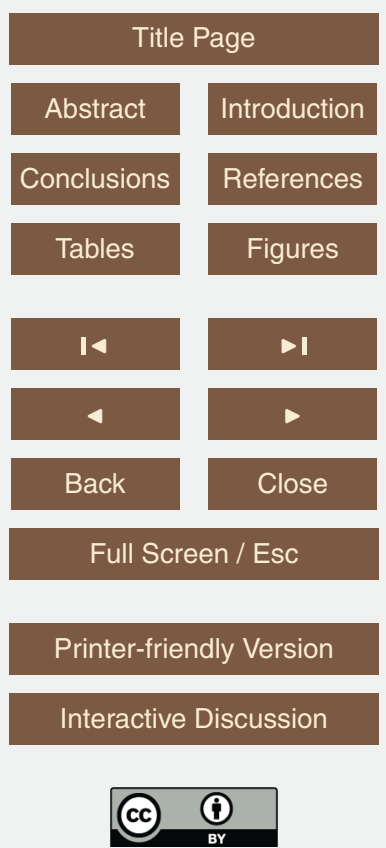
Differences (Bodoia and Osterle, 1961; Fukuchi, 2011), Finite Elements (Fortin et al., 1994; Fortin and Fortin, 1985), Finite Volumes (Gavarini et al., 2004), etc ...

Poiseuille flow (along with so-called Couette flow) is also relevant in the context of Earth Sciences, for instance when thin layers of ductile rocks (such as salt) flow be5 tween two more competent rock materials (Albertz et al., 2010; Gemmer et al., 2004), in subduction settings (Warren et al., 2008; Gerault et al., 2012), in magma transport in dykes (Yamato et al., 2012), in mantle convection (Höink et al., 2013), or even in biology (Meyer-Rochow and Gal, 2003).

The computational domain is a rectangle of size $L_{x}=2, L_{y}=1$ containing $40 \times 20$ 10 elements and the gravity acceleration is set to zero. A single fluid $(\rho=1, \mu=1)$ is present in the system and it is submitted to the following boundary conditions: no-slip is imposed at the bottom and at the top $(u=0, v=0)$ and a parabolic profile is imposed on the sides $(u=y(1-y), v=0)$. The penalty parameter is set to $\lambda=10^{8}$.

The analytical solution to this problem is given by the following field equations:

$15 \quad u(x, y)=y(1-y)$

$v(x, y)=0$

$p(x, y)=2 \mu\left(L_{x} / 2-x\right)$.

The computed velocity and pressure field are shown in Fig. 19a and b and one sees 20 that the parabolic and linear character of the velocity and pressure fields respectively is recovered.

In the case where no pressure iterations are carried out (standard penalty method) the divergence and pressure field are proportional through the penalty coefficient, which is visible in Fig. 19c. As a result, the incompressibility constraint is not respected exactly. Besides that, while increasing the penalty value would seem to be a way to improve the incompressibility performance, it also very fast leads to a numerically untractable linear system (even with direct solvers).

A single additional outer iteration is necessary to bring the system below a convergence tolerance of $10^{-15}$ and while the pressure field is virtually identical to the previ1993

\section{SED}

6, 1949-2096, 2014

\section{ELEFANT}

C. Thieulot

\section{Title Page}

Abstract Introduction

Conclusions

Tables

References

Figures

14

$>1$

4

Back

$>$

Close

Full Screen / Esc

Printer-friendly Version

Interactive Discussion 
ous case, one sees that the velocity divergence is now almost zero (down to machine precision).

\subsection{Subduction}

This benchmark is presented in Schmeling et al. (2008) and is also carried out in 5 Thieulot et al. (2014a) and Cerpa et al. (2014). A $3000 \mathrm{~km} \times 700 \mathrm{~km}$ domain contains three distinct materials. Material 1 is the sticky air $\left(\rho_{\text {air }}=0, \mu_{\text {air }}=10^{19}\right)$, material 2 is the lithosphere $\left(\rho_{\text {lith }}=3300, \mu_{\text {lith }}=10^{23}\right)$, and material 3 is the mantle $\left(\rho_{\mathrm{m}}=3200\right.$, $\mu_{\mathrm{m}}=10^{21}$ ). All materials are linear viscous and temperature is not taken into account. Free slip boundary conditions are applied on all sides of the domain. An average of 10100 markers is placed in each element at startup.

Figure 20 shows the material fields at various times with a $1000 \times 250$ grid and an arithmetic averaging of viscosities which are very similar to those in Schmeling et al. (2008).

The slab tip depth as a function of time is shown in Fig. 21. As documented in 15 Schmeling et al. (2008), the choice of viscosity averaging influences the dynamics of the system to first order. The curves obtained with ELEFANT fall very close to those in the original publication and illustrate the fact that the timing at which the slab tip reaches the bottom is inerasing with the averaging schemes in this order: harmonic, geometric, arithmetic.

\subsection{SolCx, SolKz and SolVi}

\subsubsection{SolCx}

The SolCx benchmark is intended to test the accuracy of the solution to a problem that has a large jump in the viscosity along a line through the domain. Such situations are common in geophysics: for example, the viscosity in a cold, subducting slab is much

\section{SED}

6, 1949-2096, 2014

\section{ELEFANT}

C. Thieulot
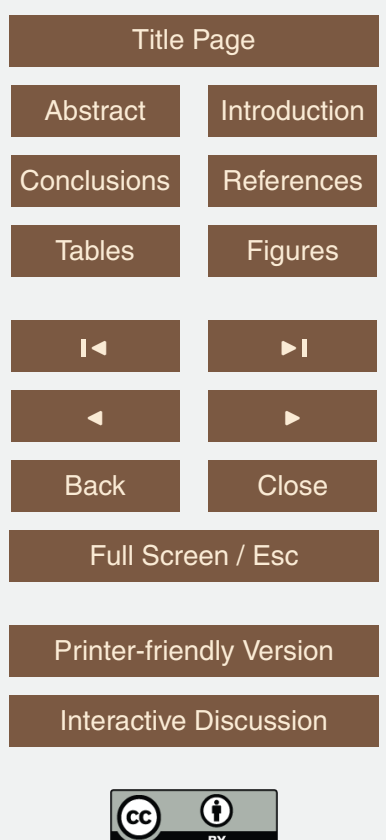
The SolCx benchmark computes the Stokes flow field of a fluid driven by spatial density variations, subject to a spatially variable viscosity. Specifically, the domain is $\Omega=[0,1]^{2}$, gravity is $g=(0,-1)^{T}$ and the density is given by

$\rho(x, y)=\sin (\pi y) \cos (\pi x)$.

5 Boundary conditions are free slip on all of the sides of the domain and the temperature plays no role in this benchmark. The viscosity is prescribed as follows:

$\mu(x, y)=\left\{\begin{array}{l}1 \text { for } x<0.5 \\ 10^{6} \text { for } x>0.5\end{array}\right.$.

Note the strongly discontinuous viscosity field yields a stagnant flow in the right half of the domain and thereby yields a pressure discontinuity along the interface.

The SolCx benchmark was previously used in Duretz et al. (2011) (references to earlier uses of the benchmark are available there) and its analytic solution is given in Zhong (1996). It has been carried out in Kronbichler et al. (2012) and Gerya et al. (2013). Note that the source code which evaluates the velocity and pressure fields for both SolCx and SolKz is distributed as part of the open source package Underworld 15 (Moresi et al. (2007), http://underworldproject.org).

In this particular example, the viscosity is computed analytically at the quadrature points (i.e. tracers are not used to attribute a viscosity to the element). If the number of elements is even in any direction, all elements (and their associated quadrature points) have a constant viscosity $\left(1\right.$ or $\left.10^{6}\right)$. If it is odd, then the elements situated at the viscosity jump have half their integration points with $\mu=1$ and half with $\mu=10^{6}$ (which is a pathological case since the used quadrature rule inside elements cannot represent accurately such a jump).

In all simulations the penalty coefficient was set to $\lambda^{\star}=10$, the convergence criteria set to $t o I_{\mathrm{u}}=t o I_{\mathrm{v}}=10^{-14}, t o I_{\mathrm{p}}=10^{-8}$ and $t o I_{\mathrm{d}}=10^{-11}$ and the iterative solver AGMG

\section{SED}

6, 1949-2096, 2014

\section{ELEFANT}

C. Thieulot

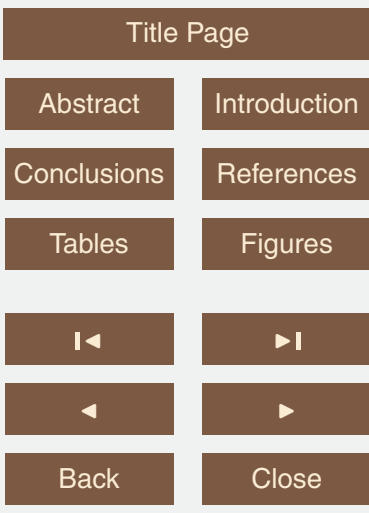

Full Screen / Esc

Printer-friendly Version

Interactive Discussion 
The viscosity distribution, velocity components and the pressure are shown in Fig. 22. The $L_{2}$-norm of the velocity and pressure error has been measured as a function of the element size for $16 \times 16$ to $1024 \times 1024$ grids and is shown in Fig. 23 . In the case of even numbers of elements, the convergence is found to be quadratic while odd 5 numbers lead to a linear convergence (Duretz et al., 2011).

In the case of the $1024^{2}$ grid $(N \simeq 2.1$ million dofs), 20 outer iterations were needed while the number of iterations within the solver steadily decreased from 211 to 1 and the solve time went from $69 \mathrm{~s}$ to $0.4 \mathrm{~s}$.

\subsubsection{SolKz}

10 The SolKz benchmark (Revenaugh and Parsons, 1987) is similar to the SolCx benchmark but the viscosity is now a function of the space coordinates:

$\mu(y)=\exp (2 B y) \quad$ with $\quad B=13.8155$.

It is however not a discontinuous function but grows exponentially with the vertical coordinate so that its overall variation is again $10^{6}$. The forcing is again chosen by

$\rho(x, y)=\sin (2 y) \cos (3 \pi y)$.

Free slip boundary conditions are imposed on all sides of the domain. This benchmark is presented in Zhong (1996) as well and is studied in Duretz et al. (2011) and Gerya et al. (2013).

The $L_{2}$-norm error of the velocity and pressure fields was computed for grids ranging from $16^{2}$ to $1250^{2}$ elements and is shown in Fig. 24. As opposed to the SolCx setup, the viscosity field is continuous so that no difference is observed for even or odd number of elements. The convergence is quadratic as observed in Duretz et al. (2011).

Here too, the penalty coefficient was set to $\lambda^{\star}=10$, the convergence criteria set to $25 t o I_{\mathrm{u}}=t o I_{\mathrm{v}}=10^{-14}, t o I_{\mathrm{p}}=10^{-8}$ and $t o I_{\mathrm{d}}=10^{-11}$ and the iterative solver AGMG was 1996
SED

6, 1949-2096, 2014

\section{ELEFANT}

C. Thieulot
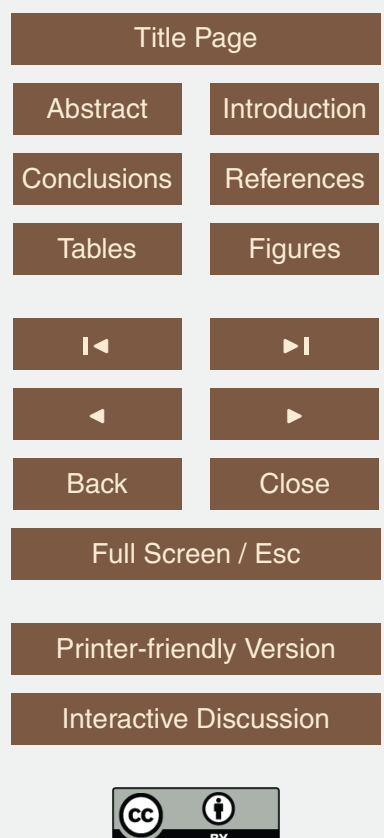
used. In the case of the $1250^{2}$ grid ( $N \simeq 3.1$ million dofs), 15 outer iterations were necessary to bring the system to convergence, while linear iterations within the solver went from 64 to 8 with an average solve time of $17 \mathrm{~s}$.

\subsubsection{SolVi}

5 Following SolCx and SolKz, the SolVi inclusion benchmark solves a problem with a discontinuous viscosity field, but in this case the viscosity field is chosen in such a way that the discontinuity is along a circle. Given the regular nature of the grid used by a majority of codes and the present one, this ensures that the discontinuity in the viscosity never aligns to cell boundaries. This in turns leads to almost discontinuous pressures along 10 the interface which are difficult to represent accurately. Schmid and Podlachikov (2003) derived a simple analytic solution for the pressure and velocity fields for a circular inclusion under simple shear and it was used in Deubelbeiss and Kaus (2008), Suckale et al. (2010), Duretz et al. (2011), Kronbichler et al. (2012) and Gerya et al. (2013).

Because of the symmetry of the problem, we only have to solve over the top right quarter of the domain (see Fig. 25a).

The analytical solution requires a strain rate boundary condition (e.g., pure shear) to be applied far away from the inclusion. In order to avoid using very large domains and/or dealing with this type of boundary condition altogether, the analytical solution is evaluated and imposed on the boundaries of the domain. By doing so, the trupantion error introduced while discretizing the strain rate boundary condition is removed 2

A characteristic of the analytic solution is that the pressure is zero inside the inclusion, while outside it follows the relation

$p_{\mathrm{m}}=4 \dot{\epsilon} \frac{\mu_{\mathrm{m}}\left(\mu_{\mathrm{i}}-\mu_{\mathrm{m}}\right)}{\mu_{\mathrm{i}}+\mu_{\mathrm{m}}} \frac{r_{\mathrm{i}}^{2}}{r^{2}} \cos (2 \theta)$

where $\mu_{\mathrm{i}}=10^{3}$ is the viscosity of the inclusion and $\mu_{\mathrm{m}}=1$ is the viscosity of the back25 ground media, $\theta=\tan ^{-1}(y / x)$, and $\dot{\epsilon}=1$ is the applied strain rate.

1997

\section{SED}

6, 1949-2096, 2014

\section{ELEFANT}

C. Thieulot

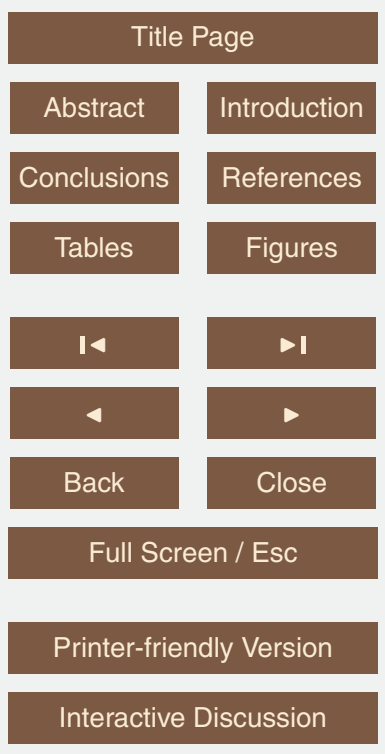


These experiments have been conducted with both direct and iterative solvers alike and with 100 markers per element. The measured velocity and pressure fields are shown in Fig. 25 and look similar to those shown in Deubelbeiss and Kaus (2008). In Fig. 26 are shown various pressure profiles measured at $y=0$. With increasing 5 resolution the measured pressures tend to conform better and better to the analytical profile, and error tends (quite predictably) to concentrate near the surface of the inclusion.

Finally, I have measured the convergence in the $L_{2}$-norm of the velocity and pressure fields errors for the three standard averaging schemes (arithmetic, geometric, - harmonic) and for both the elemental and nodal pressure fields. Results are shown in Fig. 27 for grids ranging from $32^{2}$ to $1024^{2}$. The velocity error is found to converge linearly with resolution while the pressure error displays large oscillations at relatively low resolution (especially for the arithmetic averaging case), due to the fact that the inclusion is under resolved and the interface matrix/inclusion is then discretised over very few elements. At high resolution, the oscillations cease and both pressures errors converge with an 1/2 exponent (only the elemental pressure error is shown for clarity).

Deubelbeiss and Kaus (2008) thoroughly investigated this problem with various numerical methods (FEM, FDM), with and without tracers, and conclusively showed how various averagings lead to different results. Duretz et al. (2011) obtained a first order convergence for both pressure and velocity, while Kronbichler et al. (2012) and Gerya et al. (2013) showed that the use of adaptive mesh refinement in respectively the FEM and FDM yields convergence rates which depend on refinement strategies.

\subsection{Topography evolution}

This benchmark was first presented in Crameri et al. (2012) and is also presented in 25 Hillebrand et al. (2014). It is designed to test the accuracy of the free surface representation in geodynamics code.

The model box spans $2800 \mathrm{~km}$ by $700-1100 \mathrm{~km}$ (greater model height is necessary when employing sticky air on top). The initial condition is specified by a man-

\section{SED}

6, 1949-2096, 2014

\section{ELEFANT}

C. Thieulot
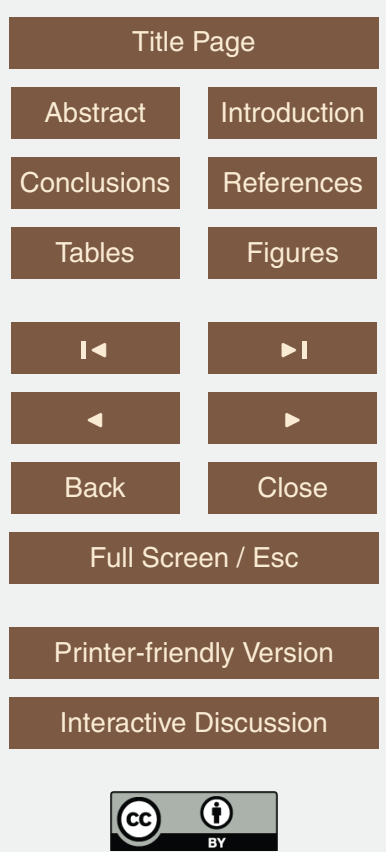
tle of $600 \mathrm{~km}$ thickness, overlain by a cosine shaped, 93-107 km-thick lithosphere (see Fig. 28). The sticky air layer has a thickness varying between 10 and $400 \mathrm{~km}$. The lithosphere is a highly viscous, dense medium $\left(\rho_{\mathrm{L}}=3300 \mathrm{~kg} \mathrm{~m}^{-3}, \mu_{\mathrm{L}}=10^{23} \mathrm{~Pa} \mathrm{~s}\right)$. The underlying ambient mantle has a density $\rho_{\mathrm{M}}=3300 \mathrm{~kg} \mathrm{~m}^{-3}$ and a viscosity $\mu_{\mathrm{M}}=$ $510^{21}$ Pas.

The sticky air layer on the top has a density $\rho_{\text {air }}=0 \mathrm{~kg} \mathrm{~m}^{-3}$ and a viscosity $\mu_{\text {air }}=$ $10^{18}-10^{20} \mathrm{Pas}$ and is bordered by a free-slip top boundary condition. Free slip is also imposed at the sides while the bottom boundary is set to no slip condition.

The setup for the real free-surface model is identical to the setup described above, but the weak surface layer is removed and replaced by zero normal stress boundary conditions.

An analytical solution is presented by Ramberg (1967): the maximum topography at time $t$ can be derived analytically using the relaxation rate $\gamma$ and from the initial maximum topography $h_{\text {init }}$ :

$15 \quad h_{\text {analytic }}=h_{\text {init }} \exp (\gamma t)$

where $t=14.825 \mathrm{kyr}$ is the characteristic relaxation time and $\gamma=-0.2139 \times 10^{-11} \mathrm{~s}^{-1}$ is the characteristic relaxation rate of the three-layer case at a given wavelength of $2800 \mathrm{~km}$. It should be noted that these values are valid for infinitesimal amplitudes, whereas deviations are to be expected for small but finite amplitudes. In particular, keeping the interface between the middle and lower layer flat and assuming a finite amplitude of the interface between the upper and middle layer implies that the thickness of the highly viscous middle layer varies laterally by $\pm 7 \%$ (in the case of an initial maximum topography of $7 \mathrm{~km}$ ). This variation increases the effective viscous flexural rigidity and leads to a slightly longer relaxation time. The system is let to relax over 25 time (typically $200 \mathrm{kyrs}$ ) and the position of the free surface is recorded over time. I hereafter show results done with both the sticky air approach and the free surface approach.

\section{SED}

6, 1949-2096, 2014

\section{ELEFANT}

C. Thieulot
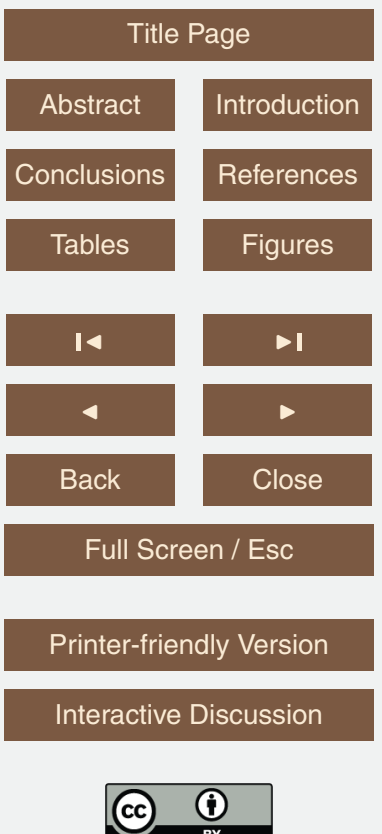


\subsubsection{Sticky air approach}

The following results have been obtained with a $400 \times 200$ grid. with an initial average of 100 markers per element. The Courant number is set to 0.05 and a set of markers are initially placed on the interface, advected and output every time step so that the

5 position of the free surface can be monitored over time. A fourth-order Runger-Kutta advection scheme is used.

The results obtained with ELEFANT are compared with those obtained with UNDERWORLD and SULEC as published in Crameri et al. (2012) in the case of a $100 \mathrm{~km}$ thick air layer and shown in Fig. 29. One sees that ELEFANT compares favourably with the others for all air viscosity values.

The vertical size of the elements close to the surface is about $2.8 \mathrm{~km}$. After full relaxation, it is observed that ELEFANT predicts an overshoot of the free surface (i.e. the excess depth to which the tracers goes below $y=700 \mathrm{~km}$ ) of about $0.02 \mathrm{~km}$, or less than $1 \%$ of an element height, which is negligible.

15 One can also zoom in on the results around the relaxation time, as in Fig. $2 b$ of Crameri et al. (2012) and results are shown in Fig. 30. Decreasing the sticky air value leads to a topography which tends towards the analytical result. Also, it can be noted that the curves for the three codes with the same air viscosity $\left(10^{18}\right)$ are remarkably similar.

\subsubsection{The ALE approach}

The same simulation was carried out using the ALE approach. Air is no more present in the system and the grid is initially stretched to conform to the sinusoidal perturbation. Elevation measurements are shown in Fig. 31 against those obtained with other ALE codes in Crameri et al. (2012) for later times ( $t>70$ Myrs). The grid resolution (and the order of the spline algorithm, not shown) used for the free surface interpolation algorithm was investigated and does not lead to substantial differences. After 2.5 Myr, the free surface elevation oscillates by $\pm 0.5 \mathrm{~m}$ around the $700 \mathrm{~km}$ horizontal line.

\section{SED}

6, 1949-2096, 2014

\section{ELEFANT}

C. Thieulot
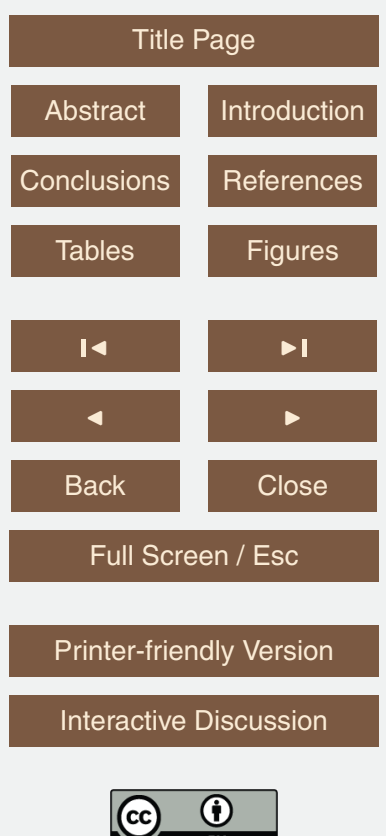


\subsection{Mantle convection benchmark}

\subsubsection{Two dimensions}

This benchmark deals with the 2-D thermal convection of a fluid of infinite Prandtl number in a rectangular closed cell. In what follows, I carry out the case $1 \mathrm{a}, 1 \mathrm{~b}$, and 1c

5 experiments as shown in Blankenbach et al. (1989): steady convection with constant viscosity in a square box.

The temperature is fixed to zero on top and to $\Delta T$ at the bottom, with reflecting symmetry at the sidewalls (i.e. $\partial_{x} T=0$ ) and there are no internal heat sources. Freeslip conditions are implemented on all boundaries.

The Rayleigh number is given by

$R a=\frac{\alpha g_{y} \Delta T h^{3}}{k V}=\frac{\alpha g_{y} \Delta T h^{3} \rho^{2} c_{\mathrm{p}}}{k \mu}$

In what follows, I use the following parameter values: $L_{x}=L_{y}=1, \rho_{0}=c_{\mathrm{p}}=k=\mu=$ $1, T_{0}=0, \alpha=10^{-10}, g=10^{10} R a$ and I run the model with $R a=10^{4}, 10^{5}$ and $10^{6}$.

The initial temperature field is given by

${ }_{15} T(x, y)=(1-y)-0.01 \cos (\pi x) \sin (\pi x)$.

The perturbation in the initial temperature fields leads to a perturbation of the density field and sets the fluid in motion.

Depending on the initial Rayleigh number, the system ultimately reaches a steady state after some time. The steady-state temperature fields of case 1a,b,c are shown in Fig. 32.

The root mean square of the velocity field in the whole domain was measured for a $100 \times 100$ grid resolution for all three cases and divided by the corresponding steady state values presented in Blankenbach et al. (1989). Results are shown in Fig. 33 and
SED

6, 1949-2096, 2014

\section{ELEFANT}

C. Thieulot

\section{Title Page}

Abstract

Introduction

Conclusions

Tables

References

Figures

14

$\rightarrow 1$

4

Back

Close

Full Screen / Esc

Printer-friendly Version

Interactive Discussion 
one sees that there is a very good agreement as all three curves ultimately converge to the expected value 1 .

The Nusselt number (i.e. the mean surface temperature gradient over mean bottom temperature) is computed as follows (Blankenbach et al., 1989):

\section{SED}

6, 1949-2096, 2014

$5 \mathrm{Nu}=L_{y} \frac{\int \frac{\partial T}{\partial y}\left(y=L_{y}\right) \mathrm{d} x}{\int T(y=0) \mathrm{d} x}$.

The case 1a results are shown in Fig. 34 for three grid resolutions. We see that the Nusselt number converges towards the expected value and that with increasing resolution the error decreases. The relative error on the Nusselt number has been measured for various grid resolutions with $R a=10^{4}$ and was found to decrease quadratically with the element size.

Finally, the steady state root mean square velocity and Nusselt number measurements are indicated in Table 3 alongside those of Blankenbach et al. (1989), Tackley (1994) and King (2009). (Note that this benchmark was also carried out and published in other publications (Trompert and Hansen, 1998; Albers, 2000; Gerya, 2010a; Davies 15 et al., 2011; Leng and Zhong, 2011) but since they did not provide a complete set of measurement values, they are not included in the table.) The results obtained with ELEFANT compare favourably to those initiall, published by Blankenbach et al. (1989) and fall within $1 \%$ of the expected values.

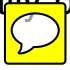

\subsubsection{Three dimensions}

20 This three-dimensional benchmark was first proposed by Busse et al. (1993). It has been subsequently presented in Tackley (1994); Trompert and Hansen (1998); Albers (2000); O'Neill et al. (2006); Davies et al. (2011); Kronbichler et al. (2012). We here focus on Case 1 of Busse et al. (1993): an isoviscous bimodal convection experiment at $R a=3 \times 10^{5}$.

25 The domain is of size $a \times b \times h$ with $a=1.0079 \mathrm{~h}, b=0.6283 \mathrm{~h}$ with $h=2700 \mathrm{~km}$. It is filled with a Newtonian fluid characterised by $\rho_{0}=3300 \mathrm{~kg} \mathrm{~m}^{-3}, \alpha=10^{-5} \mathrm{~K}^{-1}, \mu=$ 2002

ELEFANT

C. Thieulot

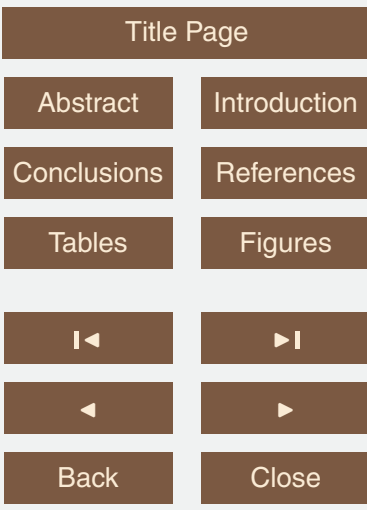

Full Screen / Esc

Printer-friendly Version

Interactive Discussion 
$8.0198 \times 10^{23} \mathrm{~Pa} \mathrm{~s}, k=3.564 \mathrm{~W} \mathrm{~m}^{-1} \mathrm{~K}^{-1}, c_{\mathrm{p}}=1080 \mathrm{~J} \mathrm{~K}^{-1} \mathrm{~kg}^{-1}$. The gravity vector is set to $g=(0,0,-10)^{T}$. The temperature is imposed at the bottom $\left(T=3700^{\circ} \mathrm{C}\right)$ and at the top $\left(T=0^{\circ} \mathrm{C}\right)$. This experiment was run with several resolutions, from $24 \times 14 \times 24$ to $48 \times$ $29 \times 48$. Tracers were not used and the density was computed directly at the integration 5 points.

In order to save computational time, and because only the steady state of the system is of interest, so-called Picard iterations were carried out: the mass matrix $\boldsymbol{M}_{\mathrm{c}}$ of the energy equation was set to zero, relaxation between two-consecutive iterations was implemented (relaxation factor set to 0.5) and a few dozen iterations were necessary 10 to obtained a steady state (see Appendix A.2 of van den Berg et al. (1993) for a similar approach). Note that in this case the value of the time step $\mathrm{d} t$ is irrelevant.

The various measurements presented in Busse et al. (1993) are listed hereafter:

- the Nusselt number Nu computed at the top surface following Eq. (69);

- the root mean square velocity $v_{\mathrm{rms}}$ and the temperature mean square velocity $T_{\text {rms }}$;

- the vertical velocity $w$ and temperature $T$ at points $x_{1}=\left(0,0, L_{z} / 2\right), x_{2}=$ $\left(L_{x}, 0, L_{z} / 2\right), x_{3}=\left(0, L_{y}, L_{z} / 2\right)$ and $x_{4}=\left(L_{x}, L_{y}, L_{z} / 2\right)$;

- the vertical component of the heat flux $Q$ at the top surface at all four corners.

Results obtained with ELEFANT are shown in Table 4 while temperature isocontours of the system at steady state are shown in Fig. 35. Note that they are presented in their dimensionless form, with the scaling factors obtained from Table 1 of Busse et al. (1993). In the table is also indicated the total number of degrees of freedom (velocity compoents, pressure and temperature) for various runs. One sees that ELEFANT yields rather accurate measurements (relative error less than $1 \%$ ) at a fraction of the number of degrees of freedom that ASPECT normally requires.

SED

6, 1949-2096, 2014

ELEFANT

C. Thieulot

\section{Title Page}

Abstract

Introduction

Conclusions

Tables

References

Figures

14

$\rightarrow 1$

4

Back

Close

Full Screen / Esc

Printer-friendly Version

Interactive Discussion 


\subsection{The lid driven cavity}

The lid driven cavity is a famous Computational Fluid Dynamics test case and has been studied in eountless, publications with a wealth of numerical techniques (see Erturk (2009) for a succinct review) and also in the laboratory (Koseff and Street, 1984).

5 It models a plane flow of an isothermal isoviscous fluid in a rectangular (usually square) lid-driven cavity. The boundary conditions are indicated in the Fig. 36a. The gravity is set to zero.

In the standard case, the upper side of the cavity moves in its own plane at unit speed, while the other sides are fixed. This thereby introduces a discontinuity in the boundary conditions at the two upper corners of the cavity and yields an uncertainty as to which boundary (side or top) the corner points belong to. We therefore avoid this issue altogether by prescribing the horizontal velocity of the lid as follows:

$u(x)=x^{2}(1-x)^{2}$.

In this case the velocity and its first derivative is continuous at the corners. This is the so-called regularised lid-driven cavity problem (Pinelli and Vacca, 1994).

This benchmark is usually dicussed in the context of low to very high Reynolds number with the full Navier-Stokes equations being solved (with the noticeable exception of Sani et al. (1981a, b); Chen et al. (1995); Eid (2005) which focus on the Stokes equation). In the case of the incompressible Stokes flow, the absence of inertia renders this problem instantaneous so that only one time step is needed. Since there is no analytical solution to this problem, and in order to compare my results to a reference, I have run the same setup with the mantle convection code ASPECT (Kronbichler et al., 2012) on a $2048 \times 2048$ grid with $Q_{2} Q_{1}$ elements, and thereafter use the obtained results as reference.

25 Figure $36 \mathrm{~b}$ and $\mathrm{c}$ show the horizontal and vertical components of the velocity for a $32 \times 32$ grid while Fig. 36 d exemplifies the so-called checkerboard pattern of the pressure. The (elemental) pressure field is perturbed by a spurious mode which must

\section{SED}

6, 1949-2096, 2014

\section{ELEFANT}

C. Thieulot

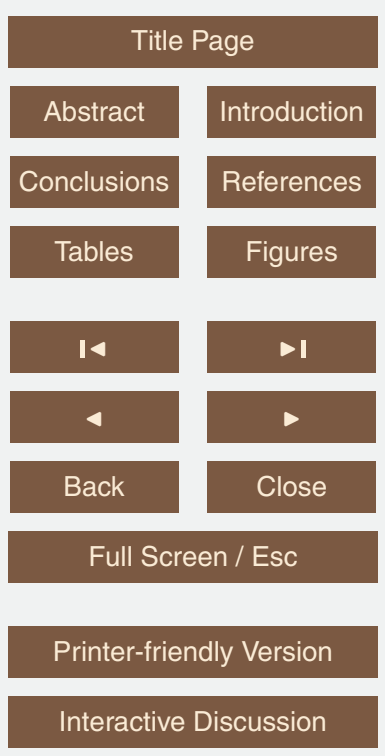


be filtered out. Having done so, one can compare the (filtered) nodal pressure with the pressure obtained with ASPECT (which is linear continuous). Isocontours of both fields overlay each other which demonstrates the accuracy of the filtered pressure.

Also, as discussed for instance in (Gresho and Sani, 2000), models with even num5 ber of elements in each direction are more prone to develop these spurious modes. When the same simulation is run with a $33 \times 33$ grid, the elemental pressure does not show any checkerboard pattern (see Fig. 36f).

\subsection{The falling sphere}

In 1851, George Gabriel Stokes derived an expression, now known as Stokes' law, for the frictional force (or drag force) exerted on a spherical object falling in an infinite continuous viscous fluid with a very low Reynolds number (Bachelor, 1967).

The analytic solution for the frictional drag on a sphere is

$F_{d}=6 \pi \mu_{\mathrm{f}} r w$

where $\mu_{\mathrm{f}}$ is the viscosity of the fluid, $r$ is the radius of the sphere, and $w$ is the velocity

of the sphere.

Also acting on the shere is the buoyancy force:

$F_{g}=\frac{4}{3} \pi r^{3}\left(\rho_{\mathrm{s}}-\rho_{\mathrm{f}}\right) g$

where $\rho_{\mathrm{f}}$ is the density of the fluid and $\rho_{\mathrm{s}}$ is the density of the sphere.

At terminal velocity, the frictional force $F_{d}$ on the sphere is balanced by the excess 20 force $F_{g}$ due its negative buoyancy. Solving for the velocity yields:

$w=\frac{2}{9} \frac{r^{2}}{\mu_{\mathrm{f}}}\left(\rho_{\mathrm{s}}-\rho_{\mathrm{f}}\right) g$.

When the boundaries are not infinitely far away, we can expand the solution in terms of the ratio of the radius of the sphere $(r)$ to the radius of the cylinder $(R)$ in which it 2005

\section{SED}

6, 1949-2096, 2014

\section{ELEFANT}

C. Thieulot

\section{Title Page}

\section{Abstract}

Introduction

Conclusions

Tables

References

Figures

14

$>$ I

4

Back

Close

Full Screen / Esc

Printer-friendly Version

Interactive Discussion
$>$ 
is contained. The solution by Habermann (see Lindgren, 1999) gives a corrected drag force

$F_{d}=6 \pi \mu_{\mathrm{f}} r w \frac{1-0.75857(r / R)^{5}}{1+f_{H}(r / R)}$

where

$5 \quad f_{H}(r / R)=-2.1050(r / R)+2.0865(r / R)^{3}$

$$
-1.7068(r / R)^{5}+0.72603(r / R)^{6} \text {. }
$$

Because of the symmetries of the problem we only have to simulate a quarter of the domain. The computational domain dimension was therefore chosen to be $4 \times 4 \times 8$, 10 with the center of the sphere at location $r_{c}=\left(0,0, L_{z} / 2\right)=(0,0,2)$ (see Fig. 37a). Free slip boundary conditions are used on the faces $x=0$ and $y=0$ while no-slip boundary conditions are used on all other boundaries. Zero velocities are imposed on all nodes of the FEM grid outside of the cylinder.

Choosing $\rho_{\mathrm{f}}=1, \rho_{\mathrm{s}}=2, \mu_{\mathrm{f}}=1, \mu_{\mathrm{s}}=10^{4}, r=1, R=4$ yields a terminal velocity of

$15 \quad W_{\text {th }} \simeq 0.11227847$.

The penalty parameter is set to $\lambda=10^{8}$ if the direct solver is used or set to $\lambda^{\star}=10$ if the iterative solver AGMG is used. Both density and viscosity are directly prescribed on the grid nodes.

The maximum downgoing velocity of the sphere was measured for regular grids ranging from $16 \times 16 \times 32$ elements $(N=26611)$ to $64 \times 64 \times 128(N=1635075)$ elements (see Fig. 37).

Relative velocity errors are shown in Fig. 38 and show that the error decreases nearly linearly with the decreasing element size. Also, I have made use of the grid stretching option in order to get a finer grid close to the sphere and results are systematically better than in the case of the regular grid, as expected. Conversely, the elemental 2006 
pressure at the top and bottom are found to be very close to -4 and +4 respectively as one expects.

In Fig. 39 is plotted the relative residual as output by AGMG in the case of the $32 \times 32 \times 64$ grid with and without using the diagonal preconditioner. One sees that this 5 simple preconditioner actually reduces the number of iterations by about $30 \%$, which shortens the solve time by approx. $20 \%$.

\subsection{3-D polynomial solution}

This benchmark begins by postulating a polynomial solution to the 3-D Stokes equation (Dohrmann and Bochev, 2004):

$10 \quad \boldsymbol{v}=\left(\begin{array}{c}x+x^{2}+x y+x^{3} y \\ y+x y+y^{2}+x^{2} y^{2} \\ -2 z-3 x z-3 y z-5 x^{2} y z\end{array}\right)$

and

$p=x y z+x^{3} y^{3} z-5 / 32$.

While it is then trivial to verify that this velocity field is divergence-free, the corresponding body force of the Stokes equation can be computed by inserting this solution into 15 the momentum equation with a given viscosity $\mu$ (constant or position/velocity/strain rate dependent) (see Appendix $\mathrm{D}$ ). The domain is a unit cube and velocity boundary conditions simply use Eq. (77). Following Burstedde et al. (2013), the viscosity is given by the smoothly varying function

$\mu=\exp (1-\beta(x(1-x)+y(1-y)+z(1-z)))$.

SED

6, 1949-2096, 2014

\section{ELEFANT}

C. Thieulot

\section{Title Page}

\section{Abstract}

Introduction

Conclusions

Tables

References

Figures

14

4

Back

Full Screen / Esc

Printer-friendly Version

Interactive Discussion

20 Choosing $\beta=0$ yields a constant velocity $\mu=e^{1}$ (and greatly simplifies the right-hand side). One can easily show that the ratio of viscosities $\mu^{\star}$ in the system follows $\mu^{\star}=$ 2007 
$\exp (-3 \beta / 4)$ so that choosing $\beta=10$ yields $\mu^{\star} \simeq 1808$ and $\beta=20$ yields $\mu^{\star} \simeq 3.269 \times$ $10^{6}$.

I have set $\lambda^{\star}=10, \chi_{\mathrm{u}}=\chi_{\mathrm{v}}=\chi_{\mathrm{w}}=10^{-12}$ and $\chi_{\mathrm{p}}=10^{-8}$ and ran this experiment on grids ranging from $8^{3}$ to $100^{3}\left(N \simeq 3.1 \times 10^{6}\right)$ for all three values of $\beta$. Both solvers

5 AGMG and WISMP were used and yielded nearly identical results, so that only results obtained with WISMP and for $\beta=20$ are shown in Fig. 40: the $L_{1}$ and $L_{2}$ errors for both pressure and velocity decrease quadratically with the element size. Overall a dozen of outer iterations were required to bring te system to convergence.

\section{An application to salt tectonics}

10 Evaporites are mineral sediments which form as a result of evaporation of an oversaturated aqueous solution. It forms salt layers which occur in many basins observed on Earth (Hudec and Jackson, 2007).

Because evaporite is weak (compared to the surrounding rock beds) and buoyant, it flows easily, be it horizontally or vertically, due to pressure differences caused by active 15 tectonics or overburden (Jackson et al., 1994; Brun and Fort, 2008, 2011). Salt layers are famous for their ability to form diapirs, which produce ideal locations for trapping petroleum. Indeed, salt is a low porosity medium which traps oil and gas during their migration towards the surface and a significant proportion of the world's hydrocarbon reserves is found in structures related to salt tectonics, including many in the Middle

20 East, the South Atlantic passive margins (Brazil, Gabon and Angola) and the Gulf of Mexico.

Understanding salt tectonics is therefore of great importance and the presence and effect of salt in stratigraphy has logically received attention from the numerical standpoint: from salt diapirs (Zaleski and Julien, 1992; van Keken et al., 1993; Poliakov et al., 1993b; Podlachikov et al., 1993; Ismail-Zadeh et al., 2004; Massimi et al., 2007) to the evolution of the Perdido Fold Belt in the Gulf of New Mexico (Gradmann et al., 2009; Gradmann and Beaumont, 2012), the evolution of the Scotian Basin (Albertz et al.,

SED

6, 1949-2096, 2014

\section{ELEFANT}

C. Thieulot

\section{Title Page}

Abstract

Introduction

Conclusions

Tables

References

Figures

14

$\Delta$

4

Back

Close

Full Screen / Esc

Printer-friendly Version

Interactive Discussion
$>$

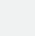

ion sion

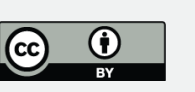


2010; Albertz and Beaumont, 2010) or the Zagros fold-and-thrust belt (Ghazian and Buiter, 2014) to cite but a few.

\section{SED}

6, 1949-2096, 2014 the Canyonlands of Utah, where grabens are found in the sediment cover that overlies 5 a basal salt layer (Trudgill and Cartwright, 1994). Two-dimensional (Schultz-Ela and Walsh, 2002) and recently three dimensional (Allken et al., 2013) numerical models of this area have been constructed and have shown the importance of the salt layer thickness and properties to understand the structural evolution of the area.

Another example would be the triassic salt horizons in north lberian basins which 10 acted as decollements for mesozoic (half-)grabens, and subsequently for thin-skinned thrusting during Iberia-Europe collision (McClay et al., 2004; Jammes et al., 2010; Ferrer et al., 2012).

Numerical modelling of salt units in large systems (taking the whole lithosphere into account) requires very high resolution and this has led the models to be of a few kilometers in the vertical direction (typically $\sim 10-15 \mathrm{~km}$ ), thereby neglecting or crudely approximating the behaviour of the underlying crustal rocks. I hereafter present a model of salt tectonics at the crustal scale which models the extension of a preexisiting basin filled with salt and sediments.

The setup is as follows: the computational domain represents a stretch of crust of size $150 \mathrm{~km} \times 35 \mathrm{~km}$. The crust is covered by a $1 \mathrm{~km}$ thick layer of salt itself covered by $2 \mathrm{~km}$ of sediments. Extensional boundary conditions are applied on each side of the system at $2 \mathrm{~cm} \mathrm{yr}^{-1}$.

Note that this setup does not necessarily aim at modelling true margins but rather aims at showcasing the code abilities to resolve salt tectonics on a larger scale than previously shown in the literature.

There are $1500 \times 250=375000$ elements in the system and a vertical stretching is applied so that the resolution in the salt and sediment layer is approximately $150 \mathrm{~m}$. An initial average of 100 markers per element is used so that there are about 37 million tracers in the system.

\section{ELEFANT}

C. Thieulot
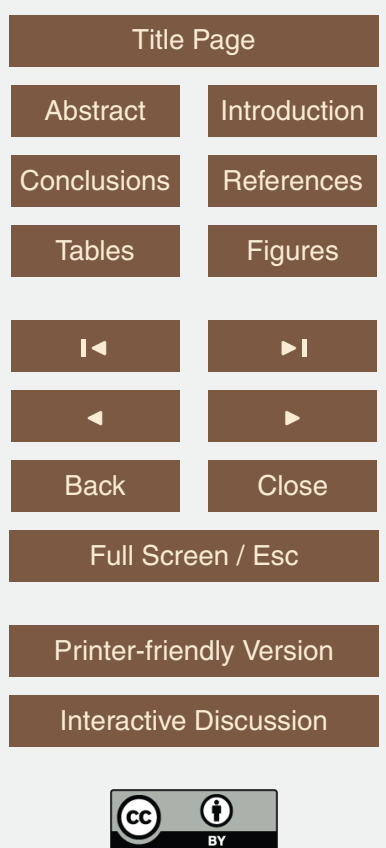
To illustrate the ease of use of the code I reproduce in Appendix $C$ the code instructions that the user needs to type in order to set the model up and run it succesfully.

The time evolution of the system over $0.6 \mathrm{Myr}$ is shown in Fig. 41. Contrary to many extensional numerical models, there is no weak seed or zone to root the deformation 5 at a given location in the domain. The random character of the tracer distribution and numerical roundoff errors lead to many angled shear zones in the upper brittle crust which progressively give way to more stable high-strain rate shear zones (Fig. 41f).

Note that in this model the absence of lithosphere and the flat impermeable lower boundary prevent any seaward margin tilt or large scale thermal/tectonic subsidence 10 which have been proven to play a major role in rifted continental margins (Goteti et al., 2013). Also, the absence of ongoing sedimentation (and surface processes as a whole) during the deformation prevents sediment loading from altering the salt flow. Nevertheless, typical structural features pertaining to salt tectonics are observed.

\section{Performance}

15 ELEFANT can be run on a variety of machines, from laptops to supercomputers. In order to assess its performance, I will first look at the case when the code runs on a single core and then look at the case when the code is ran in parallel on multicore machines.

Since most machines of today share rather common characteristics in terms of processor frequency and RAM memory speed, sequential measurements on a high-end laptop computer, a powerful multi-core desktop computer and a cluster proved to be very similar. In light thereof, all the following plots (sequential and parallel) are obtained with the University of Utrecht's Theoretical Geophysics group supercomputer GAIA ( 1000 cores at $2.34 \mathrm{GHz}, 2.88 \mathrm{~Tb}$ RAM memory, Qlogic InfiniBand). It is subdivided in 32 nodes containing each 32 cores. Some additional runs were carried on the

\section{SED}

6, 1949-2096, 2014

\section{ELEFANT}

C. Thieulot
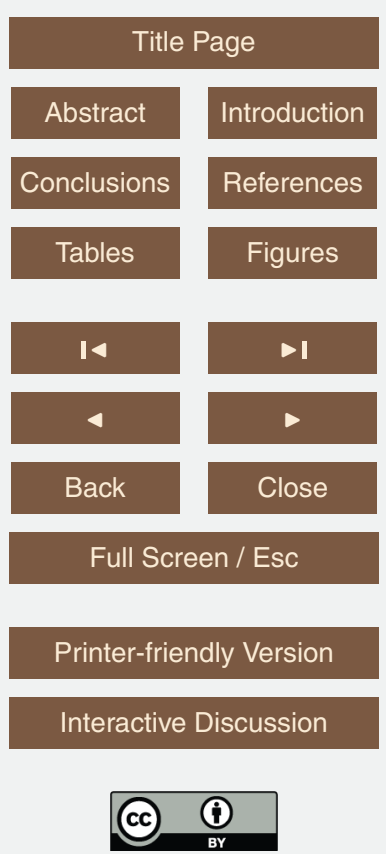

\footnotetext{
${ }^{15} \mathrm{http}: / /$ www.uio.no/english/services/it/research/hpc/abel/
} 
Note that all computations have been done with MUMPS 4.10.0 (using METIS 4.0.3) and that all libraries and the code itself were compiled with the gfortran 4.4 .6 compiler.

At this point, it is worth noticing that since between 60 and $80 \%$ of the CPU time of a typical sequential run is spent solving the Stokes Matrix (see Fig. 18 of Thieulot,

5 2011). I hereafter focus on the performance of the MUMPS solver alone which accounts for most of the code CPU time.

MUMPS provides several possibilities for inputting the matrix: the matrix can be supplied in elemental format and must then be input centrally on the host (some form of node connectivity is then provided to the solver and MUMPS does the assembly itself) 10 or it can be supplied in assembled format in coordinate form (the user needs to program the assembly process). Both methods are implemented in ELEFANT and tested hereafter. The first one is further discussed in Thieulot and L'Excellent (2014).

\subsection{Sequential performance}

In Fig. 42 is shown the time necessary to carry out one full solve (analysis + factori15 sation + backsubstitution) of the FEM matrix as a function of the number of degrees of freedom $N$ on both GAIA and ABEL. One sees that for a given number of dofs MUMPS solve time takes different values whether the matrix stems from two- or threedimensional simulations, which can be easily explained by their bandwidth differences (due to the stencil). The solve time for a 2-D problem scales like $N^{1.33}$ while the solve 20 time for a 3-D problem is proportional to $N^{1.67}$ (as observed in May et al., 2013).

The needed memory (as returned by MUMPS) to solve a system as a function of its size $N$ is shown in Fig. 43: the memory for a 2-D matrix scales like $N^{1.11}$ while the memory for a 3-D matrix scales like $N^{1.35}$. Also on the figure are shown various lines which indicates typical memory values which users might find relevant. For instance, 25 a computer with $2 \mathrm{~Gb}$ of RAM memory would allow at the very maximum 2-D systems with a grid of $800 \times 800$ elements $(N=1283202)$ or $3-D$ systems with a grid of $36 \times$ $36 \times 36$ elements $(N=151959)$. These values actually represent upper bounds since the operating system and the code itself also need a share of the computer memory.

SED

6, 1949-2096, 2014

\section{ELEFANT}

C. Thieulot
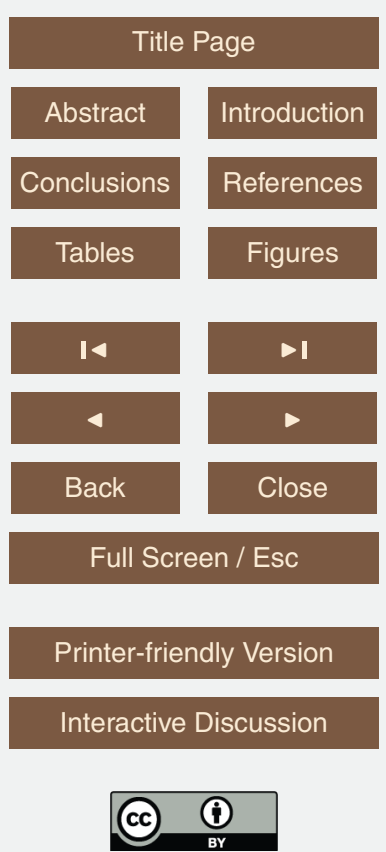
Finally, even though the sparsity pattern of the matrix changes with grid aspect ratios (both $20 \times 100$ and $4 \times 500$ grids contain the same number of degrees of freedom), I have not found a significant change in the solver's performance.

\subsection{Parallel performance}

5 In the current version of the code, parallelism is only present through the direct solver MUMPS, i.e. ELEFANT is not a massively parallel code: it is rather a sequential code which offers parallel matrix solve capabilities for improved performance.

In fact, ELEFANT is well suited for laptops, desktop computers or supercomputers up to a few dozen cores. Indeed, assuming that the total CPU time for a run can be decomposed as the sum of the time $T_{\mathrm{S}}$ spent in the solver and the time $T_{\mathrm{C}}$ spent in the rest of the code, and assuming a perfect scaling for the solver, the parallel total CPU time on nproc writes

$T($ nproc $)=\frac{T_{\mathrm{S}}}{\mathrm{nproc}}+T_{\mathrm{C}}$.

This is of course Amdahl's law (see for instance Eijkhout, 2014), which states that the 15 speedup of a program using multiple processors in parallel computing is limited by the time needed for the sequential fraction of the program. For nproc above a few dozen, the time spent in the solver becomes small compared to the rest and drops to a few percents of the total CPU time, thereby rendering the use of more processors useless.

MUMPS can be configured in such a way that the main thread does not participate 20 in the computations, a feature which can be useful if the main thread available memory is greatly reduced by the allocated memory needed to run the code or other tasks. This feature (made available to the user from the input file) was tested and no significant performance alteration was observed so that the host processor was set to participate in the all the calculations.

25 I focus in what follows on strong scaling measurements, i.e. the problem size stays fixed but the number of processing elements is increased.

2012
SED

6, 1949-2096, 2014

\section{ELEFANT}

C. Thieulot
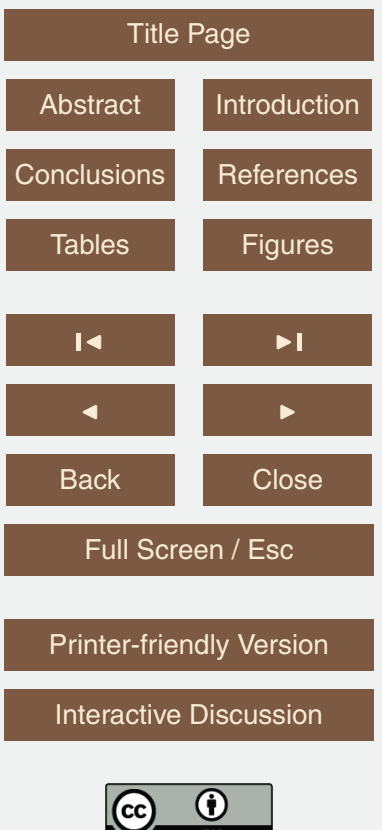
A MUMPS matrix solve is decomposed in three steps: analysis, factorisation and backsubstitution. At the time of writing, no domain decomposition is implemented in the code so that the matrix is built/assembled on the host processor. The analysis of the matrix is carried out sequentially on the host too and can take up to $\sim 100$ s for 5 very large systems. However the analysis is based on the matrix structure and not on its coefficients so that it only needs to be done once and thereby renders its cost negligible in the context of hundreds or even thousands of time steps.

The backsubstitution (also simply called solution) is carried out in parallel but its cost remains anyways negligible compared to the factorisation phase cost, and drops below 10 a second for the largest 3-D systems with more than 20 CPUs.

The factorisation is the one phase which is the most CPU and memory intensive, and its parallel scaling is therefore of paramount importance.

In Figs. 44-46 are shown the analysis, factorisation and solution times of various 2-D and 3-D matrices for numbers of CPUs ranging from 1 to 128 , as well as the average 15 allocated memory per process (Fig. 47).

In all cases, the FEM matrix is extremely sparse: the $2000 \times 2000$ grid leads to a matrix with $8008002^{\circ}$ of freedom but only counts 144048004 nonzero terms, which account for less than $0.0000022 \%$ of the matrix entries. In 3-D, there are approximately 64 million non-zero terms in the matrix corresponding to the $64 \times 64 \times 64$ grid which counts $823875^{\circ}$ of freedom, i.e. $\sim 10^{-8} \%$ of the matrix entries.

From all figures, it is clear that scaling is linear up to 32 cores. Past this value, the solver no more runs on a shared memory architecture since multiple nodes of the cluster are requested, connected through an infiniband interconnect. As a consequence, there is a jump observed in the curves at nproc $=32$.

Comparing the assembled and the elemental matrix input formats, one sees that (a) for the analysis the use of an already assembled matrix can be up to $50 \%$ faster than the use of the elemental format; (b) the factorisation phase is substantially faster when the elemental input is used.

\section{SED}

6, 1949-2096, 2014

\section{ELEFANT}

C. Thieulot

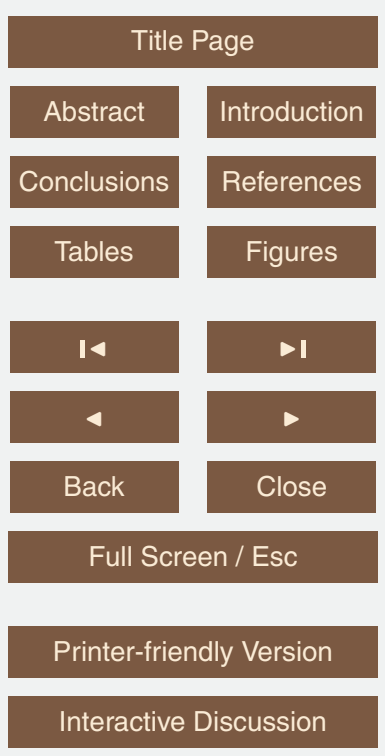


It is found that for both 2-D and 3-D matrices the factorisation phase scales like $N^{-0.7}$ and that the solution phase scales like $N^{-0.55}$. In 2-D, the average memory per processor scales like $N^{-0.73}$ while it scales like $N^{-0.85}$ in 3-D.

Note that MUMPS offers out-of-core capabilities which have not been tested.

5

\section{Conclusions}

In this work, I have presented the code ELEFANT, an ALE formulated thermomechanically coupled Finite Element code which uses the Marker-in-Cell approach.

It was found that ELEFANT passed all benchmarks which altogether tested the FEM implementation, the incompressible nature of the flow, the plasticity criterion, the thermo-mechanical coupling, the use of various iterative solvers and the implementation of the free surface. Even though the used finite element is know to yield potentially problematic pressure fields, these were shown to be usable is the context of pressuredependent plasticity criteria and to converge towards expected analytical solutions. The code was shown to converge when grid resolutions were increased and was found to 15 compare favourably with other codes.

I have further assessed the performance of the direct solver MUMPS used to solve the Stokes system. It was found to scale well in parallel and to allow for high resolution simulations in two-dimensions and somewhat limited resolution simulations in threedimensions.

20 It was finally shown how a simple salt tectonics experiment could be run and that the observed geological structures matched those observed on Earth to first order.

At the time of writing, ELEFANT is a platform on which future users can build. It already comes with an array of measurements (root mean square velocity and temperature, free surface elevation, slope, uplift rate, gravity anomaly calculations, heat flux, 25 pTt-paths, ...) which can be expanded to suite the user's needs.

When using a direct solver, ELEFANT is mostly limited in three dimensions by the memory requirements which, as shown in Sect. 6, grow extremely fast with resolution.

\section{SED}

6, 1949-2096, 2014

\section{ELEFANT}

C. Thieulot
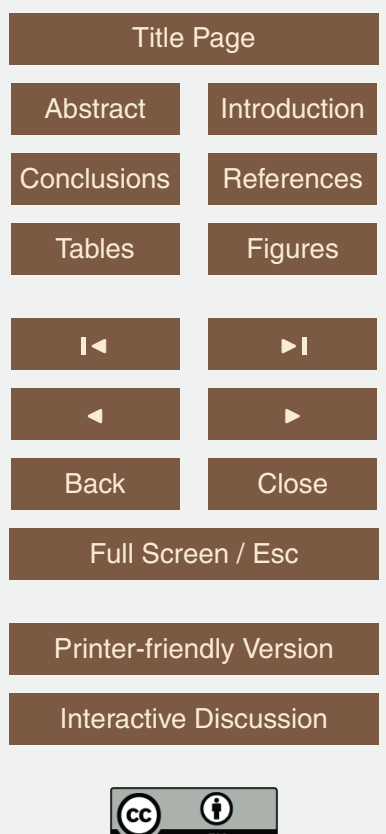
As it is, the code can easily run large simulations containing 512000 elements, which for instance could correspond to a $80^{3}$ or a $160 \times 160 \times 20$ grid (i.e. up to a $1.6-1.8$ million dofs). However, $100^{3}$ grids remain nearly intractable. When using an iterative solver, the memory limitation is alleviated but the outer iterations may converge very/too slowly 5 for practical use. Nevertheless, the presented 3-D benchmark with high viscosity ratios show that grids of the order of $128^{3}$ elements ( $~ 6.5$ million dofs) are tractable.

Other massively parallel codes, such as CITCOM, ASPECT, LAMEM, UNDERWORLD, PTATIN to cite a few can tackle much larger systems and I have listed in Table 5 a few dozens or so published articles of the past four years involving 3-D numerical modelling o at lithospheric-scale (typically involving rifting or subduction) alongside the resolution that was used (measured in elements or cells). While this list is not meant to be extensive, it represents fairly accurately the state-of-the-art and one sees that the algebraic system sizes used with ELEFANT in the present article compare nicely with those used in the current literature. The discussion on parallel scaling and total run times for these 15 models is however voluntarily left out as it would represent a substantial body of work which is outside of the scope of the present work.

The present article is intended to present the code in a thorough and centralised manner. ELEFANT has already been used in several scientific publications: it served as a representative code for the Marker-in-Cell technique in a work investigating the use of Level Set Functions in geodynamics (Hillebrand et al., 2014) and in another work about the ASPECT code (Thieulot et al., 2014a); it was used to carry out some simple modelling of the Ethiopian rift (Philippon et al., 2014), run benchmark subduction models Quinquis et al. (2014) and brittle wedges models (Buiter et al., 2014), and to look at subduction initiation near ocean ridges (Maffione et al., 2014); finally it was used alongside many other codes to carry out two- and three-dimensional slab detachment experiments (Thieulot et al., 2014b).

At the time of writing, ELEFANT is also being used in several Earth Science research institutes in Europe and North-America on problems such as rifting, subduction both in 2-D and 3-D, and at the Utrecht University for teaching/training purposes.

\section{SED}

6, 1949-2096, 2014

\section{ELEFANT}

C. Thieulot

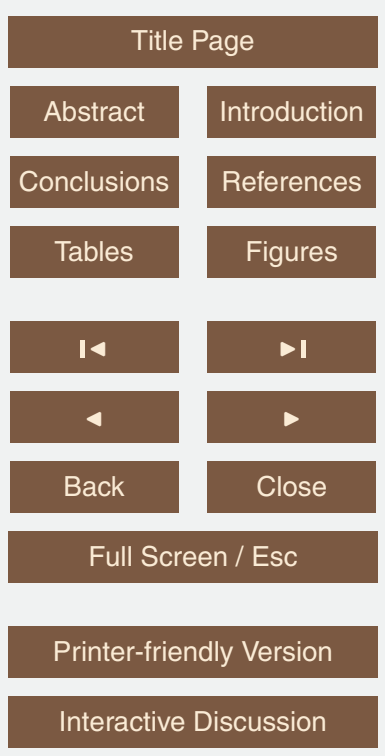




\subsection{ELEFANTs}

ELEFANT has recently been branched into ELEFANTS, which is a two-dimensional cylindrical geometry code destined to study mantle convection. It has been satisfactorily benchmarked against other well established mantle codes in Davies et al. (2014) for

5 the incompressible Boussinesq and Extended Boussinesq flow formulation.

ELEFANTS uses the same Finite Element algorithms as ELEFANT but due to the cylindrical geometry of the domain and the Cartesian coordinates on which the code relies, the normal and tangential vectors to the elements are not necessarily aligned with the coordinates system. The free slip boundary conditions for each node lying on the inner or outer boundary are therefore imposed by means of a local transformation. When needed, the rotational null mode is removed after each solve as explained in Zhong et al. (2008).

In Fig. 48 are shown time frames of a simple convection experiment analogous to the one in the Aspect's manual (http://aspect.dealii.org/).

\section{Appendix A: FEM formulation of equations}

The Galerkin finite element equation corresponding to Eq. (14) is

$\left(K_{\mu}+K_{\lambda}\right) \cdot V=G$

\section{SED}

6, 1949-2096, 2014

\section{ELEFANT}

C. Thieulot

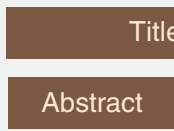

Title Page

A

Conclusions

Tables

Introduction

14

References

Figures

4

Back

Close

Full Screen / Esc

Printer-friendly Version

Interactive Discussion 
with

$\boldsymbol{K}_{\mu}=\int_{\Omega} \boldsymbol{B}^{T} \cdot \boldsymbol{D}_{\mu} \cdot \boldsymbol{B} \mathrm{d} \Omega$

SED

$K_{\lambda}=\int_{\Omega} B^{T} \cdot D_{\lambda} \cdot B \mathrm{~d} \Omega$

$\boldsymbol{G}=\int_{\Omega} \boldsymbol{N}^{T} \rho \boldsymbol{g} \mathrm{d} \Omega$

5 where in two dimensions (Schmalholz et al., 2008)

$D_{\mu}=\frac{1}{3} \mu\left(\begin{array}{ccc}4 & -2 & 0 \\ -2 & 4 & 0 \\ 0 & 0 & 3\end{array}\right) \quad D_{\lambda}=\lambda\left(\begin{array}{lll}1 & 1 & 0 \\ 1 & 1 & 0 \\ 0 & 0 & 1\end{array}\right)$

and where $\boldsymbol{N}$ is the vector of shape functions, and $\boldsymbol{B}$ is the matrix of spatial derivatives of the shape functions.

The finite element equation corresponding to the heat transfer equation is

$\boldsymbol{M}_{\mathrm{c}} \cdot \frac{\partial T}{\partial t}+\left(\boldsymbol{K}_{\mathrm{a}}+K_{\mathrm{d}}\right) \cdot \boldsymbol{T}=\boldsymbol{F}$

ELEFANT

C. Thieulot

Title Page

Abstract

Introduction

Conclusions

References

Tables

Figures

14

$>$ I

4

Back

Close

Full Screen / Esc

Printer-friendly Version

Interactive Discussion 
where

$$
\begin{aligned}
\boldsymbol{M}_{\mathrm{c}} & =\int_{\Omega} \boldsymbol{N}^{T} \rho c_{\mathrm{p}} \boldsymbol{N} \mathrm{d} \Omega \\
K_{\mathrm{a}} & =\int_{\Omega}\left(\boldsymbol{N}^{\star}\right)^{T} \rho c_{\mathrm{p}} \boldsymbol{V} \cdot \boldsymbol{B} \mathrm{d} \Omega \\
K_{\mathrm{d}} & =\int_{\Omega} \boldsymbol{B}^{T} k B \mathrm{~d} \Omega \\
F & =\int_{\Omega} \boldsymbol{N}^{T} H \mathrm{~d} \Omega
\end{aligned}
$$

and where $T$ is the vector of the nodal temperatures,

In the case where advection dominates over diffusion, the standard Galerkin approach of the advection term leads to problematic oscillations, and a stabilisation scheme is needed. A streamline-upwind Petrov-Galerkin (SUPG) method is therefore 10 implemented, which translates in the modified $\boldsymbol{N}^{*}$ term in Eq. (A8):

$$
\left(\boldsymbol{N}^{*}\right)^{T}=\boldsymbol{N}^{T}+\tau \boldsymbol{V} \cdot \boldsymbol{B}
$$

where $\tau$ a dimensionless parameter. The case $\tau=0$ is equivalent to the BubnovGalerkin method. The choice of the parameter $\tau$ in the context of FEM stabilisation schemes is discussed in Tezduyar and Osawa (2000) and is calculated as follows:

${ }_{15} \tau=\left(\frac{1}{\left(\tau_{1}\right)^{r}}+\frac{1}{\left(\tau_{2}\right)^{r}}+\frac{1}{\left(\tau_{3}\right)^{r}}\right)^{-1 / r}$

with often $r=1$ or $r=1 / 2$ and

$$
\tau_{1}=\frac{h}{2|\boldsymbol{v}|} \quad \tau_{2}=\theta \mathrm{d} t \quad \tau_{3}=\frac{h^{2} \rho c_{\mathrm{p}}}{k_{2018}}
$$

\section{SED}

6, 1949-2096, 2014

\section{ELEFANT}

C. Thieulot

\section{Title Page}

\section{Abstract}

Introduction

Conclusions

Tables

References

Figures

14

$\triangleright$ I

4

Back

Close

Full Screen / Esc

Printer-friendly Version

Interactive Discussion 
where $h$ is a measure of the element size and $\theta$ is related to the time discretisation scheme $(\theta=1 / 2$ in this case as it corresponds to the implemented mid-point implicit scheme, see for instance Braun, 2003).

\section{Appendix B: The Aspect and Sepran codes}

5 Aspect (short for Advanced Solver for Problems in Earth's ConvecTion) is a code intended to solve the equations that describe thermally driven convection with a focus on doing so in the context of convection in the Earth mantle (Kronbichler et al., 2012). Aspect solves a system of equations in a two- or three-dimensional domain that describes the motion of a highly viscous fluid driven by differences in the gravitational force due to a density that depends on the temperature. Aspect is built on numerical methods that are at the forefront of research in all areas (adaptive mesh refinement, linear and nonlinear solvers, stabilization of transport dominated processes). This implies complexity in the algorithms, but also guarantees highly accurate solutions while remaining efficient in the number of unknowns and with CPU and memory resources. Multiphase 15 flow and nonlinear visco-plastic rheologies have been recently implemented and tested (Glerum et al., 2014; Thieulot et al., 2014b).

SEPRAN (Segal and Praagman, 2005; van den Berg et al., 2012) is a Fortran-based multi-purpose Finite Element package developed by SEPRA engineering company in cooperation with the department of applied mathematics of Delft Technical University starting in the early 1980s. The package has been used for $25 \mathrm{yr}$ in the education and research program at Utrecht University and many students have used the package in their work dealing with numerical modelling in geodynamics. SEPRAN is available for a range of platforms including Linux/Unix and Microsoft Windows. It contains a mesh generator with a flexible scripting interface for general 2-D and 3-D mesh configura25 tions.

The package provides tools for a range of applications in science and engineering, including second order elliptic, parabolic and hyperbolic equations, suitable for mechani-

\section{SED}

6, 1949-2096, 2014

\section{ELEFANT}

C. Thieulot
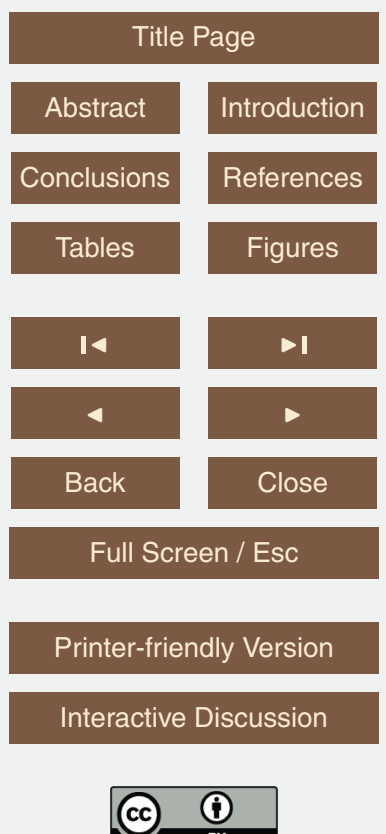
cal problems dealing with linear elasticity and for flow problems for both incompressible and compressible viscous media.

It has been recently coupled with a level set method algorithm (Hillebrand et al., 2014), has been used to study the effects of obliquity and curvature of subduction

5 zones (Bengtson and van Keken, 2012), the evolution of the slab in the western Mediterranean region (Chertova et al., 2014), and has been used in the study of slab detachments (Thieulot et al., 2014c).

\section{Appendix C: The salt tectonics input file}

What follows is a list of the necessary parameters to run the salt tectonics model of

$\mathrm{Lx}=150 . \mathrm{d} 3$

$L y=35 . d 3$

ncell $\mathrm{x}=800$

ncelly $=125$

penalt $\mathrm{y}=1 . \mathrm{d} 31$

15 nstep $=10000$

niter $=25$

use_courant $=$.true.

courant_nb $=0.1$

use_stretch_y=.true.

20

$$
\begin{array}{ll}
\text { alpha_y=0.6 } & \text { ! pertaining coefficient } \\
\text { tfinal=2.d6*year } & \text { ! model run time } \\
\text { vell=2.5d0*cm/year } & \text { ! applied vel bc } \\
\text { fix_bc1_u=.true. } & \text { ! left bc }
\end{array}
$$$$
\text { stretch_type_y }=3
$$

25 bc1_u=-vel1
! domain size

! nb of elements

! penalty coeff lambda

! max \# of time steps

! max \# nl iterations

! use Courant cond.

! Courant number

! allows stretching
SED

6, 1949-2096, 2014

ELEFANT

C. Thieulot

\section{Title Page}

Abstract

Introduction

Conclusions

References

Tables

Figures

14

$\triangleright$ I

4

$>$

Back

Close

Full Screen / Esc

Printer-friendly Version

Interactive Discussion 


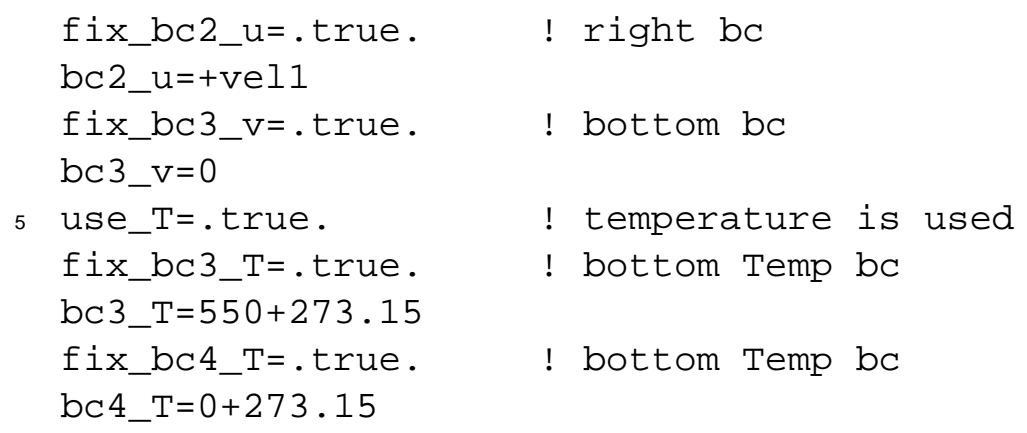

10 The list of materials must be specified in an other file as follows:

nmat $=3$

mat $(1)=$ sediment

mat $(2)=$ rocksalt

mat $(3)$ =wet quart $z$

\section{ELEFANT}

C. Thieulot

15 Note that these three material names correspond to a set of parameters (cohesion, angle of friction, density, activation energy, etc ...) taken from the literature and compiled into a library.

Their initial layout is carried out in a third routine which loops over all markers and assians them a material number, i.e. 1, 2, or 3. \\ Appendix D: Body force derivation of the 3-D polynomial solution benchmark}

The body forces corresponding to the prescribed velocity and pressure fields as specified in Sect. 4.11 are given by: 


$$
\begin{array}{r}
\boldsymbol{f}=-\left(\begin{array}{c}
y z+3 x^{2} y^{3} z \\
x z+3 x^{3} y^{2} z \\
x y+x^{3} y^{3}
\end{array}\right)+\mu\left(\begin{array}{c}
2+6 x y \\
2+2 x^{2}+2 y^{2} \\
-10 y z
\end{array}\right) \\
-(1-2 x) \beta \mu\left(\begin{array}{c}
2+4 x+2 y+6 x^{2} y \\
x+y+2 x y^{2}+x^{3} \\
-3 z-10 x y z
\end{array}\right) \\
-(1-2 y) \beta \mu\left(\begin{array}{c}
x+y+2 x y^{2}+x^{3} \\
2+2 x+4 y+4 x^{2} y \\
-3 z-5 x^{2} z \\
-3 z-10 x y z \\
-3 z-5 x^{2} z \\
-4-6 x-6 y-10 x^{2} y
\end{array}\right)
\end{array}
$$

\section{SED}

\section{ELEFANT}

C. Thieulot

\section{Title Page}

5 Acknowledgements. I wish to thank the following people for their input, their questions, their knowledge or their time which ultimately lead me to be able to carry out this work and make ELEFANT the tool that it is today. In alphabetical order: V. Allken, A. van den Berg, S. Strandskog Arnesen, W. Austmann, C. Beaumont, J. Braun, L. Cornelis, M. Dabrowski, R.S. Huismans, P. Fullsack, T. Geenen, R. Gray, B. Hillebrand, D.J.J. van Hinsbergen, S. Jammes, W. Landry, D. May, E. Mulyukova, M. Philippon, M. Quinquis, S. Schmalholz, W. Spakman, Ph. Steer, C. Warren, P. Yamato, T. van Zessen, and O. van Zomeren. F. Crameri, P. van Keken and $\mathrm{H}$. Schmeling are especially thanked for sharing their data. I am particularly indebted to A. Glerum, L. van de Wiel and I. van Zelst who read this work at various stages and helped improving it substantially. The author acknowledges support from ISES through the use of the GAIA supercomputer and benefitted of an ERC Advanced Investigator Grant awarded to Trond Torsvik \& CEED, Univ. of Oslo, Norway.

Conclusions

Tables

References

Figures

14

4

$>$

Back

Close

Full Screen / Esc

Printer-friendly Version

Interactive Discussion 


\section{References}

Albers, M.: A local mesh refinement multigrid method for 3D convection problems with strongly variable viscosity, J. Comp. Phys., 160, 126-150, 2000. 2002

Albertz, M. and Beaumont, C.: An investigation of salt tectonic structural styles in the Scotian 5 Basin, offshore Atlantic Canada: 2. Comparison of observations with geometrically complex numerical models, Tectonics, 29, TC4018, doi:10.1029/2009TC002540, 2010. 2009

Albertz, M., Beaumont, C., Shimeld, J., Ingsand, S., and Gradmann, S.: An investigation of salt tectonic structural styles in the Scotian Basin, offshore Atlantic Canada: Part 1, comparison of observations with geometrically simple numerical models, Tectonics, 29, TC4017, doi:10.1029/2009TC002539, 2010. 1993, 2008

Allken, V., Huismans, R., and Thieulot, C.: Three dimensional numerical modelling of upper crustal extensional systems, J. Geophys. Res., 116, B10409, doi:10.1029/2011JB008319, 2011. 1952, 2048

Allken, V., Huismans, R., and Thieulot, C.: Factors controlling the mode of rift interaction 15 in brittle-ductile coupled systems: a 3D numerical study, Geochem. Geophy. Geosy., 13, Q05010, doi:10.1029/2012GC004077, 2012. 1952, 2048

Allken, V., Huismans, R., Fossen, H., and Thieulot, C.: 3D numerical modelling of graben interaction and linkage: a case study of the Canyonlands grabens, Utah, Basin Research, 25, 1-14, 2013. 2009

20 Amestoy, P., Duff, I., J.Koster, and L'Excellent, J.-Y.: A fully asynchronous multifrontal solver using distributed dynamic scheduling, SIAM J. Matrix Anal. Appl., 23, 15-41, 2001. 1971

Amestoy, P., Guermouche, A., L'Excellent, J.-Y., and Pralet, S.: Hybrid scheduling for the parallel solution of linear systems, Parallel Comput., 32, 136-156, 2006. 1971

Anderson, J.: Computational Fluid Dynamics, McGraw-Hill, 1995. 1965

Babeyko, A., Sobolev, S., Trumbull, R., Oncken, O., and Lavier, L.: Numerical models of crustal scale convection and partial melting beneath the Altiplano-Puna plateau, Earth Planet. Sci. Lett., 199, 373-388, 2002. 1951, 1952

Bachelor, G.: An Introduction to Fluid Dynamics, Cambridge University Press, Cambridge, 1967. 2005

30 Ballmer, M., van Hunen, J., Ito, G., Tackley, P., and Bianco, T.: Non-hotspot volcano chains originating from small-scale sublithospheric convection, Geophys. Res. Lett., 34, doi:10.1029/2007GL031636, 2007. 1952

\section{SED}

6, 1949-2096, 2014

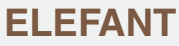

C. Thieulot
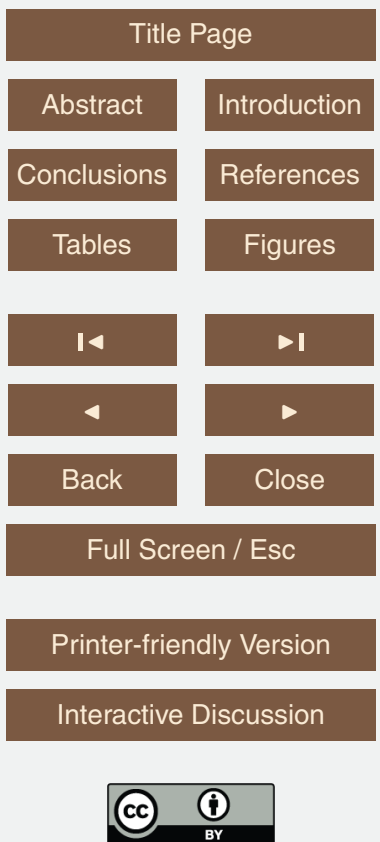
Ballmer, M., Ito, G., van Hunen, J., and Tackley, P.: Small-scale sublithospheric convection reconcilies geochemistry and geochronology of "Superplume" volcanism in th western and south pacific, Earth Planet. Sci. Lett., 290, 224-232, 2010. 2048

Bathe, K.-J.: Finite Element Procedures in Engineering Analysis, Prentice-Hall, 1982. 1957

5 Battaglia, L., Storti, M., and D'Elia, J.: An interface capturing finite element approach for free surface flows using unstructured grids, Mecanica Computational, XXVII, 33-48, 2008. 1967, 1981

Bengtson, A. and van Keken, P.: Three-dimensional thermal structure of subduction zones: effects of obliquity and curvature, Solid Earth, 3, 365-373, 2012. 2020

10 Benzi, M., Golub, G., and Liesen, J.: Numerical solution of saddle point problems, Acta Numerica, 14, 1-137, 2005. 1958, 1959

Betts, P., Mason, W., and Moresi, L.: The influence of a mantle plume head on the dynamics of a retreating subduction zone, Geology, 40, 739-742, 2012. 2048

Blankenbach, B., Busse, F., Christensen, U., Cserepes, L., Gunkel, D., Hansen, U., Harder, H., 15 Jarvis, G., Koch, M., Marquart, G., Moore, D., Olson, P., Schmeling, H., and Schnaubelt, T.: A benchmark comparison for mantle convection codes, Geophys. J. Int., 98, 23-38, 1989. 2001, 2002, 2046, 2081

Bodoia, J. and Osterle, J.: Finite difference analysis of plane Poiseuille and Couette flow developments, Appl. Sci. Res., 10, 265-276, 1961. 1993

20 Bourgouin, L., Mühlhaus, H.-B., Hale, A., and Arsac, A.: Towards realistic simulations of lava dome growth using the level set method, Acta Geotecnica, 1, 225-236, 2006. 1987

Bramley, R. and Wang, X.: SPLIB: a library of iterative methods for sparse linear systems, Tech. rep., Indiana University, 1995. 1972

Braun, J.: Three-dimensional numerical modelling of compressional orogens: thrust geometry and oblique convergence, Geology, 21, 153-156, 1993. 1951

Braun, J.: Three-dimensional numerical simulations of crustal-scale wrenching using a nonlinear failure criterion, J. Struct. Geol., 16, 1173-1186, 1994. 1952

Braun, J.: Pecube: a new finite-element code to solve the 3D heat transport equation including the effects of a time-varying, finite amplitude surface topography, Comput. Geosci., 29, 787794, 2003. 2019

Braun, J. and Beaumont, C.: Three-dimensional numerical experiments of strain partitioning at oblique plate boundaries: implications for contrasting tectonic styles in the southern Coast

\section{SED}

6, 1949-2096, 2014

ELEFANT

C. Thieulot

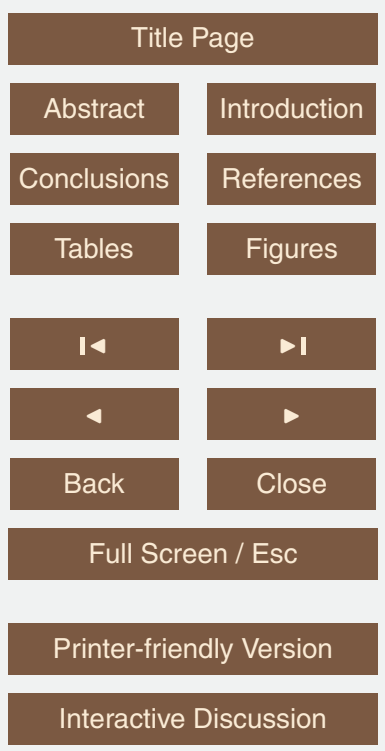


Ranges, California, and central South Island, New Zealand, J. Geophys. Res., 100, 1805918074, 1995. 1952

Braun, J. and Yamato, P.: Structural evolution of a three-dimensional, finite-width crustal wedge, Tectonophysics, 484, 181-192, doi:10.1016/j.tecto.2009.08.032, 2009. 1952

5 Braun, J., Thieulot, C., Fullsack, P., DeKool, M., and Huismans, R.: DOUAR: a new three-dimensional creeping flow model for the solution of geological problems, Phys. Earth. Planet. Inter., 171, 76-91, 2008. 1952, 1953, 1968, 1970

Brun, J.-P. and Fort, X.: Entre Sel et Terre: Structures et Mécanismes de la Tectonique Salifére, Vuibert, 2008. 2008

10 Brun, J.-P. and Fort, X.: Salt tectonics at passive margins: geology versus models, Marine Petrol. Geol., 28, 1123-1145, 2011. 2008

Brune, S. and Autin, J.: The rift to break-up evolution of the Gulf of Aden: insights from 3D numerical lithospheric-scale modelling, Tectonophysics, 607, 65-79, 2013. 1963, 2048

Brune, S., Popov, A., and Sobolev, S.: Modeling suggests that oblique extension facilitates rift15 ing and continental break-up, J. Geophys. Res., 117, B08402, doi:10.1029/2011JB008860, 2012. 2048

Brune, S., Popov, A., and Sobolev, S.: Quantifying the thermo-mechanical impact of plume arrival on continental break-up, Tectonophysics, 604, 51-59, 2013. 2048

Bui, H., Fukugawa, R., Sako, K., and Ohno, S.: Lagrangian meshfree particles method (SPH) for large deformation and failure flows of geomaterial using elastic-plastic soil constitutive model, Int. J. Numer. Anal. Geomech., 32, 1537-1570, 2008. 1983

Buiter, S.: A review of brittle compressional wedge models, Tectonophysics, 530, 1-17, 2012. 1984

Buiter, S., Babeyko, A., Ellis, S., Gerya, T., Kaus, B., Kellner, A., Schreurs, G., and Yamada, Y.: The numerical sandbox: comparison of model results for a shortening and an extension experiment, analogue and numerical modelling of crustal-scale processes, Geol. Soc., London, Spec. Publ., 253, 29-64, 2006. 1981

Buiter et al., S.: A comparison of numerical models of brittle wedges, in preparation, 2014. 2015

Bullen, P.: Handbook of Means and Their Inequalities, 2nd edition, Springer, 2003. 1969

30 Burov, E. and Cloetingh, S.: Erosion and rift dynamics: new thermomechanical aspects of postrift evolution of extensional basins, Earth Planet. Sci. Lett., 150, 7-26, 1997. 1957

Burstedde, C., Stadler, G., Alisic, L., Wilcox, L., Tan, E., Gurnis, M., and Ghattas, O.: Largescale adaptive mantle convection simulation, GJI, 192, 889-906, 2013. 2007

\section{SED}

6, 1949-2096, 2014

\section{ELEFANT}

C. Thieulot

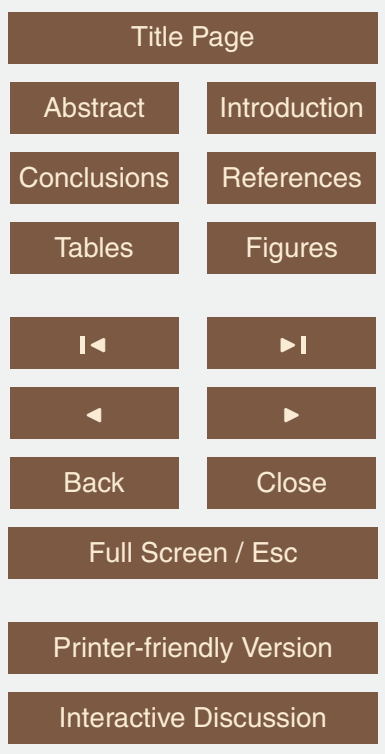

\section{5}


Busse, F., Christensen, U., Clever, R., Cserepes, L., Gable, C., Giannandrea, E., Guillou, L., Houseman, G., Nataf, H.-C., Ogawa, M., Parmentier, M., Sotin, C., and Travis, B.: 3D convection at infinite Prandtl number in Cartesian geometry - a benchmark comparison, Geophys. Astrophys. Fluid Dynamics, 75, 39-59, 1993. 2002, 2003

5 Butler, J., Beaumont, C., and Jamieson, R.: The Alps 1: A woring geodynamic model for burial and exhumation of (ultra)high-pressure rocks in Alpine-type orogens, Earth Planet. Sci. Lett., 337-378, 114-131, 2013. 1952

Capitanio, F. and Faccenda, M.: Complex mantle flow around heterogeneous subducting oceanic plates, Earth Planet. Sci. Lett., 353-354, 29-37, 2012. 2048

10 Capitanio, F. and Replumaz, A.: Subduction and slab breakoff controls on Asian indentation tectonics and Himalayan western syntaxis formation, Geochem. Geophy. Geosy., 14, 35153531, doi:10.1002/ggge.20171, 2013. 2048

Capitanio, F., Faccenna, C., Zlotnik, S., and Stegman, D.: Subduction dynamics and the origin of Andean orogeny and the Bolivian orocline, Nature, 480, 83-86, doi:10.1038/nature10596, 2011. 2048

Cerpa, N., Hassani, R., Gerbault, M., and Prévost, J.-H.: A fictitious domain method for lithosphere-asthenosphere interaction: Application to periodic slab folding in the upper mantle, Geochem. Geophy. Geosy., 15, doi:10.1002/2014GC005241, 2014. 1981, 1994

Chen, J., Pan, C., and Chang, T.: On the control of pressure oscillation in bilinear-displacement constant-pressure element, Comput. Methods Appl. Mech. Engrg., 128, 137-152, 1995. 2004

Chen, X. and Phoon, K.: Some numerical experiences on convergence criteria for iterative finite element solvers, Comput. Geotechn., 36, 1272-1284, 2009. 1970

Chertova, M., Geenen, T., van den Berg, A., and Spakman, W.: Using open sidewalls for modelling self-consistent lithosphere subduction dynamics, Solid Earth, 3, 313-326, 2012. 1962

Chertova, M., Spakman, W., Geenen, T., van den Berg, A., and van Hinsbergen, D.: Underpinning tectonic reconstructions of the western Mediterranean region with dynamic slab evolution from 3-D numerical modeling, J. Geophys. Res., doi:10.5194/se-3-313-2012, 2014. 1952, 1962, 2020

30 Choi, E., Lavier, L., and Gurnis, M.: Thermomechanics of mid-ocean ridge segmentation, Phys. Earth Planet. Interiors, 171, 374-386, 2008. 1952

\section{SED}

6, 1949-2096, 2014

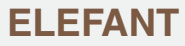

C. Thieulot

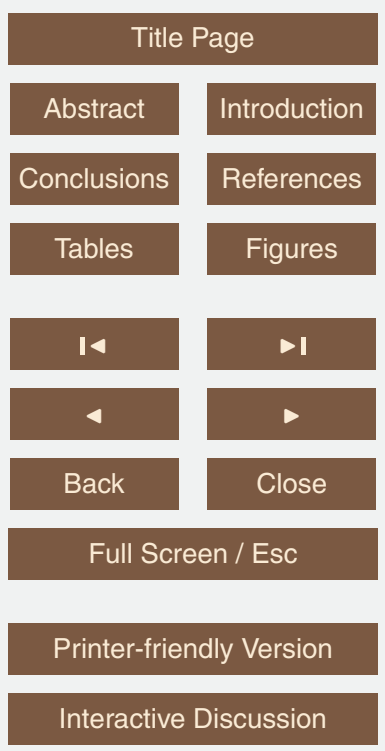


Choi, E., Tan, E., Lavier, L., and Calo, V.: DynEarthSol2D: An efficient unstructured finite element method to study long-term tectonic deformation, J. Geophys. Res., 118, 1-16, 2013. 1987

Chorin, A.: A numerical method for solving incompressible viscous flow problems, J. Comp. Phys., 2, 12-26, 1967. 1959

Christiansen, E. and Andersen, K. D.: Computation of collapse states with von mises type yield condition, Int. J. Numer. Methods Engin., 46, 1185-1202, 1999. 1983

Christiansen, E. and Pedersen, O. S.: Automatic mesh refinement in limit analysis, Int. J. Numer. Methods Engin., 50, 1331-1346, 2001. 1983

Č́žková, H., van den Berg, A., Spakman, W., and Matyska, C.: The viscosity of the earth's lower mantle inferred from sinking speed of subducted lithosphere, Phys. Earth. Planet. Inter., 200/201, 56-62, 2012. 1956

Crameri, F., Schmeling, H., Golabek, G., Duretz, T., Orendt, R., Buiter, S., May, D., Kaus, B., Gerya, T., and Tackley, P.: A comparison of numerical surface topography calculations in geodynamic modelling: an evaluation of the "sticky air" method, Geophy. J. Int., 189, 38-54, 2012. 1998, 2000, 2077, 2078

Currie, C., Beaumont, C., and Huismans, R.: The fate of subducted sediments: a case for backarc intrusion and underplating, Geology, 35, 1111-1114, 2007. 1952

Cuvelier, C., Segal, A., and van Steenhoven, A.: Finite Element Methods and Navier-Stokes Equations, D. Reidel Publishing Company, 1986. 1958

Dabrowski, M., Krotkiewski, M., and Schmid, D.: MILAMIN: Matlab based finite element solver for large problems, Geochem. Geophy. Geosy., 9, Q04030, doi:10.1029/2007GC001719, 2008. 1952, 1953, 1960, 1964

Davies, D., Wilson, C., and Kramer, S.: Fluidity: A fully unstructured anisotropic adaptive mesh computational modeling framework for geodynamics, Geochem. Geophy. Geosy., 12, Q06001, doi:10.1029/2011GC003551, 2011. 1951, 2002

Davies, D., Kramer, S., Wilson, C., Tosi, N., Besserer, J., and Huettig, C.: A community benchmark for compressible mantle convection in a two-dimensional cylindrical domain, in preparation, 2014. 2016

30 Davy, P. and Cobbold, P.: Indentation tectonics in nature and experiment. 1. Experiments scaled for gravity, Bull. Geol. Inst. Uppsala, 14, 129-141, 1988. 1983

de Besses, B. D., Magnin, A., and Jay, P.: Sphere drag in a viscoplastic fluid, AIChE J., 50, 2627-2629, 2004. 1981

\section{SED}

6, 1949-2096, 2014

\section{ELEFANT}

C. Thieulot

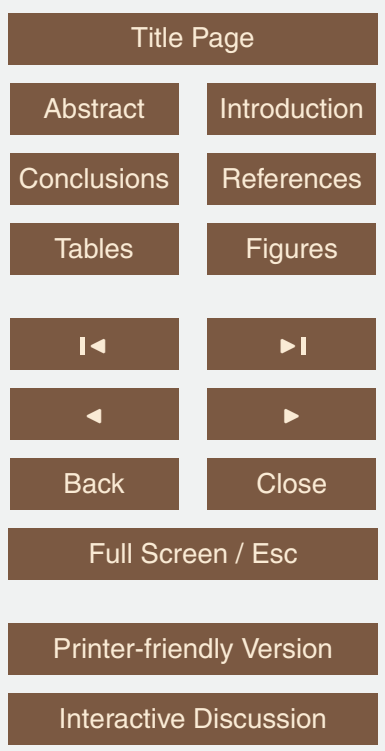


Deubelbeiss, Y. and Kaus, B.: Comparison of Eulerian and Lagrangian numerical techniques for the Stokes equations in the presence of strongly varying viscosity, Phys. Earth Planet. Interiors, 171, 92-111, 2008. 1968, 1981, 1997, 1998

Dohrmann, C. and Bochev, P.: A stabilized finite element method for the Stokes problem based on polynomial pressure projections, Int. J. Num. Meth. Fluids, 46, 183-201, 2004. 2007

Donea, J. and Huerta, A.: Finite Element Methods for Flow Problems, John Wiley \& Sons, New York, 2003. 1958, 1960

Donea, J., Huerta, A., Ponthot, J., and Rodriguez-Ferran, A.: Arbitrary Lagrangian-Eulerian methods, Encyclop. Comput. Mechan., 1, 2004. 1966

Dormand, J. and Prince, P.: A reconsideration of some embedded Runge-Kutta formulae, J. Comput. Appl. Math., 15, 203-211, 1986. 1967

Dunbar, J. and Sawyer, D.: Three-dimensional dynamical model of continental rift propagation and margin plateau formation, J. Geophys. Res., 101, 27845-27863, 1996. 1952

Duretz, T., May, D., Gerya, T., and Tackley, P.: Discretization errors and free surface stabilisation in the finite difference and marker-in-cell method for applied geodynamics: a numerical study, Geochem. Geophy. Geosy., 12, 2011 Q07004, doi:10.1029/2011GC003567, 2011. 1968, 1995, 1996, 1997, 1998

Egholm, D. L.: A new strategy for discrete element numerical models: 1. Theory, J. Geophys. Res., 112, B05203, doi:10.1029/2006JB004557, 2007. 1952

20 Egholm, D. L., Sandiford, M., Clausen, O. R., and Nielsen, S. B.: A new strategy for discrete element numerical models: 2. Sandbox applications, J. Geophys. Res., 112, B05204, doi:10.1029/2006JB004558, 2007. 1952

Eid, R.: Higher order isoparametric finite element solution of Stokes flow, Appl. Math. Comput., 162, 1083-1101, 2005. 2004

Eijkhout, V.: Introduction to High Performance Scientific Computing, Creative Commons Licence, 2014. 2012

Ellis, S., Little, T., Wallace, L., Hacker, B., and Buiter, S.: Feedback between rifting and diapirism can exhume ultrahigh-pressure rocks, Earth Planet. Sci. Lett., 311, 427-438, 2011. 1962, 2048

30 England, P.: Some numerical investigations of large scale continental deformation, in: Mountain Building Processes, Academic Press, 129-189, 1982. 1951

Erturk, E.: Discussions on Driven Cavity Flow, Int. J. Num. Meth. Fluids, 60, 275-294, 2009. 2004

\section{SED}

6, 1949-2096, 2014

\section{ELEFANT}

C. Thieulot

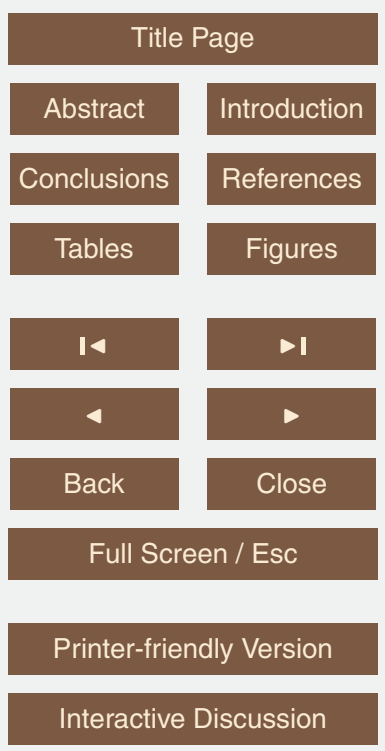


Faccenda, M.: Mid mantle seismic anisotropy around subduction zones, Phys. Earth. Planet. Inter., 227, 1-19, 2014. 1952, 2048

Faccenda, M. and Capitanio, F.: Seismic anisotropy around subduction zones: insights from three-dimensional modeling of upper mantle deformation and SKS splitting calculations,

$5 \quad$ Geochem. Geophy. Geosy., 14, doi:10.1029/2012GC004451, 2013. 2048

Fehlberg, E.: Some old and new Runge-Kutta formulas with stepsize control and their error coefficients, Computing, 34, 265-270, 1985. 1967

Fernandez, N. and Kaus, B.: Fold interaction and wavelength selection in 3D models of multilayer detachment folding, Tectonophysics, doi:10.1016/j.tecto.2014.06.013, 2014. 2048

10 Ferrer, O., Jackson, M., Roca, E., and Rubinat, M.: Evolution of salt structures during extension and inversion of the Offshore Parentis Basin (Eastern Bay of Biscay), salt tectonics, sediments and prospectivity, Geol. Soc., London, Spec. Publ., 363, 361-379, 2012. 2009

Fortin, A., Jardak, M., Gervais, J., and Pierre, R.: Old and new results on the two-dimensional poiseuille flow, J. Comp. Phys., 115, 455-469, 1994. 1993

15 Fortin, M.: Old and new finite elements for incompressible flows, Int. J. Num. Meth. Fluids, 1, 347-364, 1981. 1978

Fortin, M. and Fortin, A.: Experiments with several elements for viscous incompressible flows, Int. J. Num. Meth. Fluids, 5, 911-928, 1985. 1993

Fuchs, L. and Schmeling, H.: A new numerical method to calculate inhomogeneous and timedependent large deformation of two-dimensional geodynamic flows with application to diapirism, Geophy. J. Int., 194, 623-639, 2013. 1987

Fukuchi, T.: Numerical calculation of fully-developed laminar flows in arbitrary cross-sections using finite difference method, AIP Advances, 1, 042109, 2011. 1993

Fullsack, P.: An arbitrary Lagrangian-Eulerian formulation for creeping flows and its application in tectonic models, Geophy. J. Int., 120, 1-23, 1995. 1951

Gavarini, M., Bottaro, A., and Nieuwstad, F.: The initial stage of transition in pipe flow: role of optimal base-flow distortions, J. Fluid. Mechanics, 517, 131-165, 2004. 1993

Geenen, T., ur Rehman, M., MacLahlan, S., Segal, G., Vuik, C., van den Berg, A., and Spakman, W.: Scalable robust solvers for unstructured FE geodynamic modeling applications: 30 solving the Stokes equation for models with large localized viscosity contrasts, Geochem. Geophy. Geosy., 10, 2009. 1970

\section{SED}

6, 1949-2096, 2014

\section{ELEFANT}

C. Thieulot

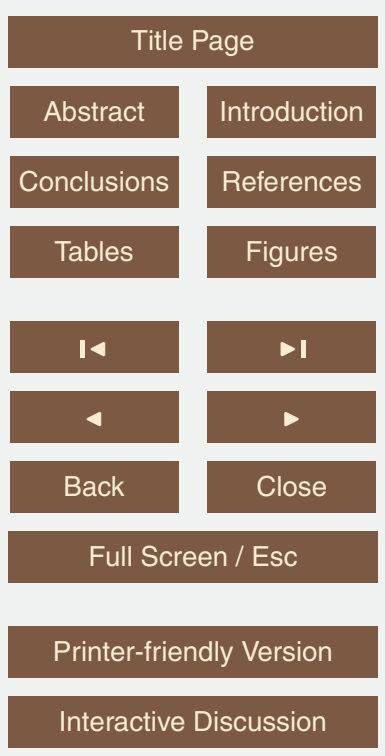

Interactive Discussion 
Gemmer, L., Ings, S., Medvedev, S., and Beaumont, C.: Salt tectonics driven by differential sediment loading: stability analysis and finite-element experiments, Basin Res., 16, 199218, 2004. 1993

Gerault, M., Becker, T., Kaus, B., Faccenna, C., Moresi, L., and Husson, L.: The role of slabs and oceanic plate geometry in the net rotation of the lithosphere, trench motions, and slab return flow, Geochem. Geophy. Geosy., 13, Q04001, doi:10.1029/2011GC003934, 2012. 1993

Gerbault, M., Poliakov, A., and Daignieres, M.: Prediction of faulting from the theories of elasticity and plasticity: what are the limits?, J. Struct. Geol., 20, 301-320, 1998. 1983

Gerbault, M., Cembrano, J., Mpodozis, C., Farias, M., and Pardo, M.: Continental margin deformation along the Andean subduction zone: thermo-mechanical models, Phys. Earth. Planet. Inter., 177, 180-205, 2009. 1952

Gerya, T.: Numerical Geodynamic Modelling, Cambridge University Press, Cambridge, 2010a. 1951, 1963, 1967, 1981, 2002

Gerya, T.: Dynamical instability produces transform faults at mid-ocean ridges, Science, 329, 1047-1050, 2010b. 1952

Gerya, T.: Future directions in subduction modeling, J. Geodynam., 52, 344-378, 2011. 1952

Gerya, T. and Yuen, D.: Characteristics-based marker-in-cell method with conservative finitedifferences schemes for modeling geological flows with strongly variable transport properties, Phys. Earth. Planet. Inter., 140, 293-318, 2003. 1951

20 Gerya, T. and Yuen, D.: Robust characteristics method for modelling multiphase visco-elastoplastic thermo-mechanical problems, Phys. Earth. Planet. Inter., 163, 83-105, 2007. 1951

Gerya, T., May, D., and Duretz, T.: An adaptive staggered grid finite difference method for modeling geodynamic Stokes flows with strongly variable viscosity, Geochem. Geophy. Geosy., 14, 1200-1225, 2013. 1995, 1996, 1997, 1998

Ghazian, R. and Buiter, S.: Numerical modelling of the role of salt in continental collision: An application to the southeast Zagros fold-and-thrust belt, Tectonophysics, in press, 2014. 2009

Gleason, G. C. and Tullis, J.: A flow law for dislocation creep of quartz aggregates determined with the molten salt cell, Tectonophysics, 247, 1-23, 1995. 2089

Glerum, A., Thieulot, C., and Spakman, W.: Complex rheologies in Aspect: application to subduction, in preparation, 2014. 1984, 2019

Glowinski, R.: Handbook of Numerical Analysis, vol IX: Numerical methods for fluids, NorthHolland, 2003. 1959, 1960

\section{SED}

6, 1949-2096, 2014

\section{ELEFANT}

C. Thieulot

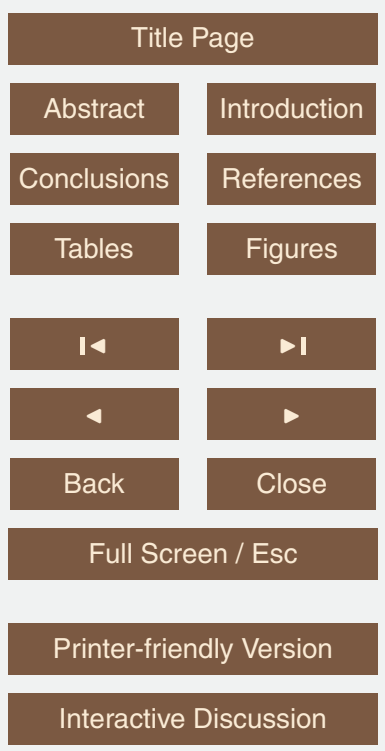


Golub, G. and van Loan, C.: Matrix Computations, 4th edition, John Hopkins University Press, 2013. 1959

Goteti, R., Beaumont, C., and Ings, S.: Factors controlling early stage salt tectonics at rifted continental margins and their thermal consequences, J. Geophys. Res., 117, 1-31, 2013. 52010

Gould, N., Hu, Y., and Scott, J.: A numerical evaluation of sparse direct solvers for the solution of large sparse, symmetric linear systems of equations, Tech. Rep. RAL-TR-2005-005, CCLRC, 2005. 1970

Gradmann, S. and Beaumont, C.: Coupled fluid flow and sediment deformation in margin-scale salt-tectonic systems: 2. Layered sediment models and application to the northwestern Gulf of Mexico, Tectonics, 31, TC4011, doi:10.1029/2011TC003035, 2012. 2008, 2089

Gradmann, S., Beaumont, C., and Albertz, M.: Factors controlling the evolution of the Perdido Fold Belt, northwestern Gulf of Mexico, determined from numerical models, Tectonics, 28, TC2002, doi:10.1029/2008TC002326, 2009. 2008

Gray, R. and Pysklywec, R.: Geodynamic models of Archean continental collision and the formation of mantle lithosphere keels, Geophys. Res. Lett., 37, L19301, doi:10.1029/2010GL043965, 2010. 1952

Gresho, P. and Sani, R.: On pressure boundary conditions for the incompressible NavierStokes equations, Int. J. Num. Meth. Fluids, 7, 1111-1145, 1987. 1962

20

Gresho, P. and Sani, R.: Incompressible Flow and the Finite Element Method, Vol. II, John Wiley and Sons, Ltd, New York, 2000. 2005

Gunzburger, M.: Finite Element Methods for Viscous Incompressible Flows: A Guide to Theory, Practice and Algorithms, Academic, Boston, 1989. 1958, 1960

Gupta, A.: WSMP: Watson Sparse Matrix Package (Part-I: Direct solution of symmetric sparse systems), Tech. Rep. RC 21886, IBM T. J. Watson Research Center, Yorktown Heights, NY, http://www.research.ibm.com/projects/wsmp, 2000. 1971

Gupta, A.: WSMP: Watson Sparse Matrix Package (Part-III: Iterative solution of sparse systems), Tech. Rep. RC 24398, IBM T. J. Watson Research Center, Yorktown Heights, NY, http://www.research.ibm.com/projects/wsmp, 2007. 1973

30 Gupta, A., Koric, S., and George, T.: Sparse matrix factorization on massively parallel computers, in: SC09 (International Conference for High Performance Computing, Networking, Storage and Analysis), 2009. 1971

\section{SED}

6, 1949-2096, 2014

\section{ELEFANT}

C. Thieulot
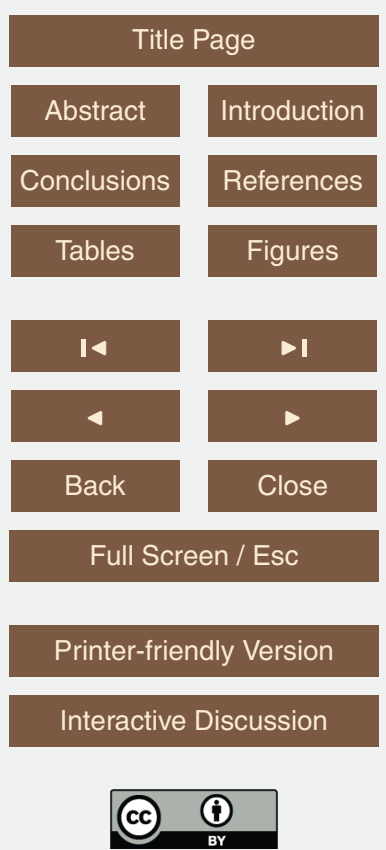
Hansen, D.: A meshless formulation for geodynamic modeling, J. Geophys. Res., 108, 2549, doi:10.1029/2003JB002460, 2003. 1952

Hartz, E. and Podlachikov, Y.: Toasting the jelly sandwich: the effect of shear heating on lithospheric geotherms and strength, Geology, 36, 331-334, 2008. 1955

5 Hassani, R., Jongmans, D., and Chéry, J.: Study of plate deformation and stress in subduction processes using two-dimensional numerical models, J. Geophys. Res., 102, 17951-17965, 1997. 1951

Heine, C. and Brune, S.: Oblique rifting of the Equatorial Atlantic: why there is no Saharan Atlantic Ocean, Geology, 42, 211-214, 2014. 2048

10 Herrmann, H., Poliakov, A., and Tzschichholz, F.: Examples of fractals in rock mechanics, in: Size Scale Effects in the Failure Mechanisms of Materials and Structures, edited by Carpinteri, A., E \& FN Spon, London, 1996. 1986

Hetényi, G., Godard, V., Cattin, R., and Connolly, J.: Incorporating metamorphism in geodynamic models: the mass conservation problem, Geophy. J. Int., 186, 6-10, 2011. 1956

Hillebrand, B., Thieulot, C., Geenen, T., van den Berg, A., and Spakman, W.: Geodynamical modeling of multi-material flows and Earth's free surface using the level set method, Solid Earth, in review, 2014. 1998, 2015, 2020

Hoffman, J. D.: Numerical Methods for Engineers and Scientists, McGraw-Hill, Inc., 1992. 1967

Höink, T., Lenardic, A., and Jellinek, A.: Earth's thermal evolution with multiple convection modes: a Monte-Carlo approach, Phys. Earth. Planet. Inter., 221, 22-26, 2013. 1993

Houseman, G. and England, P.: Crustal thickening versus lateral expulsion in the Indian-Asian continental collision, J. Geophys. Res., 98, 12333-12249, 1993. 1951

Hudec, M. and Jackson, M.: Terra infirma: understanding salt tectonics, Earth-Sci. Rev., 82, 1-28, 2007. 2008

Hughes, T. J.: The Finite Element Method. Linear Static and Dynamic Finite Element Analysis, Dover Publications, Inc., 2000. 1957, 1960

Hughes, T. J. R., Liu, W., and Brooks, A.: Finite element analysis of Incompressible viscous flows by the penalty function formulation, J. Comp. Phys., 30, 1-60, 1979. 1958

Huh, H., Lee, C. H., and Yang, W. H.: A general algorithm for plastic flow simulation by finite element limit analysis, Int. J. Solids Struct., 36, 1193-1207, 1999. 1983

Huismans, R. S. and Beaumont, C.: Symmetric and asymmetric lithospheric extension: Relative effects of frictional-plastic and viscous strain softening, J. Geophys. Res., 108, B10, doi:10.1029/2002JB002026, 2003. 1952, 1956, 1976

\section{SED}

6, 1949-2096, 2014

\section{ELEFANT}

C. Thieulot

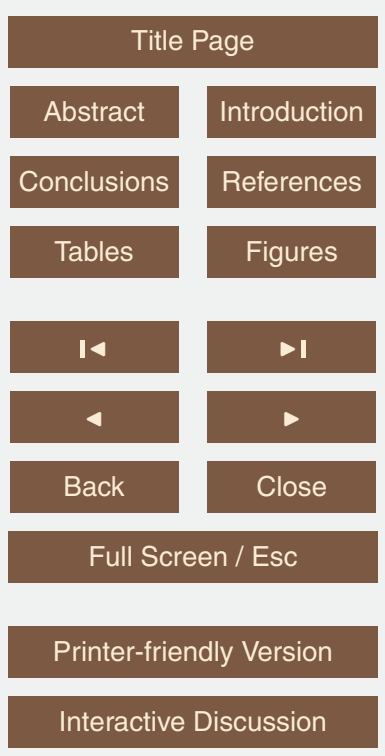


Huismans, R. S. and Beaumont, C.: Roles of lithospheric strain softening and heterogeneity in determining the geometry of rifts and continental margins, in: Imaging, Mapping and Modelling Continental Lithosphere Extension and Breakup, vol. 282, Geological Society, London, Special Publications, 282, 111-138, 2007. 1952

5 Ismail-Zadeh, A. and Tackley, P.: Computational Methods for Geodynamics, Cambridge University Press, Cambridge, 2010. 1951

Ismail-Zadeh, A., Sepelev, I., Talbot, C., and Korotkii, A.: Three-dimensional forward and backward modelling of diapirism: numerical approach and its applicability to the evolution of salt structures in the Priscaspian basin, Tectonophysics, 387, 81-103, 2004. 2008

10 Ismail-Zadeh, A., Honda, S., and Tsepelev, I.: Linking mantle upwelling with the lithosphere descent and the Japan Sea evolution: a hypothesis, Sci. Rep., 3, doi:10.1038/srep01137, 2013. 1962

Jackson, M., Vendeville, B., and Schultz-Ela, D.: Structural dynamics of salt systems, Annu. Rev. Earth Planet. Sci., 22, 93-117, 1994. 2008

Jadamec, M. and Billen, M.: The role of rheology and slab shape on rapid mantle flow: threedimensional numerical models of the Alaska slab edge, J. Geophys. Res., 117, B02304, doi:10.1029/2011JB008563, 2012. 2048

Jammes, S. and Huismans, R.: Structural styles of mountain building: controls of lithospheric rheologic stratification and extensional inheritance, J. Geophys. Res., 117, B10403, doi:10.1029/2012JB009376, 2012. 1962

Jammes, S., Manatschal, G., and Lavier, L.: Interaction between prerift salt and detachment faulting in hyperextended rift systems: the example of the Parentis and Mauléon basins (Bay of Biscay and western Pyrenees), AAPG Bulletin, 94, 957-975, 2010. 2009

J. B. Ruh, T. Gerya and Burg, J.-P.: High-resolution 3D numerical modeling of thrust wedges: Influence of décollement strength on transfer zones, Geochem. Geophy. Geosy., 14, 11311155, 2014. 1952, 2048

Jolivet, L., Davy, P., and Cobbold, P.: Right-lateral shear along the Northwest Pacific margin and the India-Eurasia collision, Tectonics, 9, 1409-1419, 1990. 1983

Kachanov, L.: Fundamentals of the Theory of Plasticity, Dover Publications, Inc., 2004. 1955, 1975, 1983, 1984

Kadanoff, L., McNamara, G., and Zanetti, G.: A Poiseuille viscometer for lattice gas automata, Complex Syst., 1, 791-803, 1987. 1992

\section{SED}

6, 1949-2096, 2014

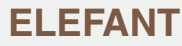

C. Thieulot
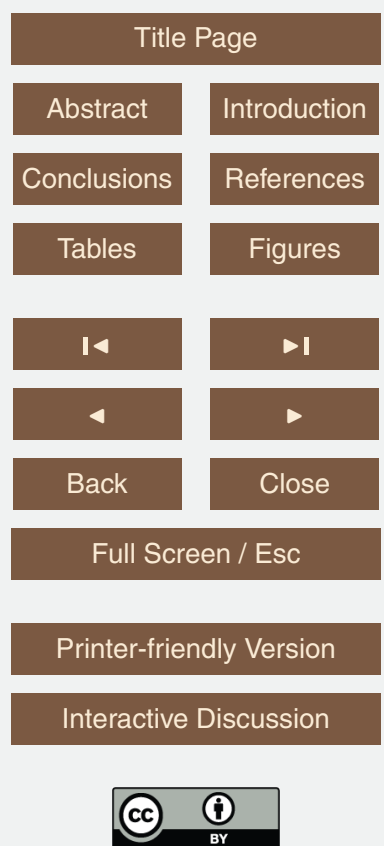
Karato, S.-I.: Deformation of Earth Materials, Cambridge University Press, Cambridge, 2008. 1954

Kaus, B.: Modelling approaches to geodynamic processes, PhD thesis, ETH Zurich, Zurich, 2005. 1951

5 Kaus, B.: Factors that control the angle of shear bands in geodynamic numerical models of brittle deformation, Tectonophysics, 484, 36-47, 2009. 1984, 1985, 1986

Kaus, B., Steedman, C., and Becker, T.: From passive continental margin to mountain belt: insights from analytical and numerical models and application to Taiwan, Phys. Earth. Planet. Inter., 171, 235-251, 2008. 1952

10 Kaus, B., Mühlhaus, H., and May, D.: A stabilization algorithm for geodynamic numerical simulations with a free surface, Phys. Earth. Planet. Inter., 181, 12-20, 2010. 1977, 1978

King, S.: On topography and geoid from 2-D stagnant lid convection calculations, Geochem. Geophy. Geosy., 10, Q03002, doi:10.1029/2008GC002250, 2009. 2002, 2046

Komzsik, L. and Poschmann, P.: Iterative solution techniques for finite element applications,

15 Finite Elem. Anal. Des., 14, 373-379, 1993. 1961

Koseff, J. and Street, R.: The lid-driven cavity flow: a synthesis of qualitative and quantitative observations, J. Fluids Eng., 106, 390-398, 1984. 2004

Kronbichler, M., Heister, T., and Bangerth, W.: High accuracy mantle convection simulation through modern numerical methods, Geophy. J. Int., 191, 12-29, 2012. 1995, 1997, 1998, 2002, 2004, 2019, 2047

Lavier, L., Buck, W., and Poliakov, A.: Factors controlling normal fault offset in an ideal brittle layer, J. Geophys. Res., 105, 23431-23442, 2000. 1952

Lechmann, S., Schmalholz, S., Hetenyi, G., May, D., and Kaus, B.: Quantifying the impact of mechanical layering and underthrusting on the dynamics of the modern India-Asia collisional system with 3D numerical models, J. Geophys. Res., doi:10.1002/2012JB009748, 2013. 2048

Lemiale, V., Mühlhaus, H.-B., Moresi, L., and Stafford, J.: Shear banding analysis of plastic models formulated for incompressible viscous flows, Phys. Earth. Planet. Inter., 171, 177186, 2008. 1984, 1986

30 Leng, W. and Gurnis, M.: Dynamics of subduction initiation with different evolutionary pathways, Geochem. Geophy. Geosy., 12, Q12018, doi:10.1029/2011GC003877, 2011. 1962

SED

6, 1949-2096, 2014

ELEFANT

C. Thieulot

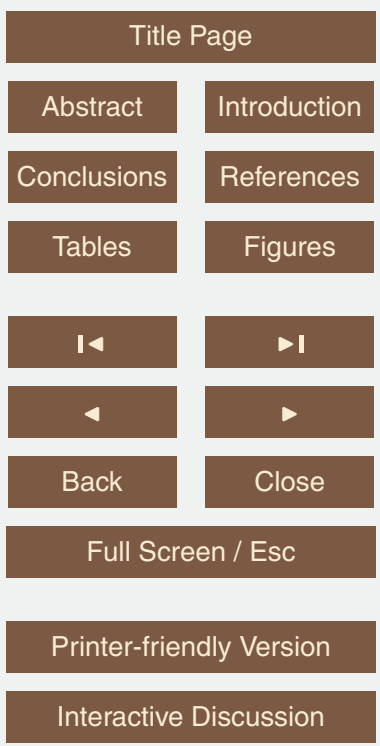

2034 
Leng, W. and Zhong, S.: Implementation and application of adaptive mesh refinement for thermochemical mantle convection studies, Geochem. Geophy. Geosy., 173, 693-702, 2011. 1987, 2002

Lewis, R., Nithiarasu, P., and Seetharamu, K.: Fundamentals of the Finite Element Method for Heat and Fluid Flow, John Wiley \& Sons, Ltd., New York, 2004. 1961

$\mathrm{Li}, \mathrm{Z}$.-H., Xu, Z., Gerya, T., and Burg, J.-P.: Collision of continental corner from 3-D numerical modeling, Earth Planet. Sci. Lett., 380, 98-111, 2013. 1952, 2048

Limache, A., Idelsohn, S., Rossi, R., and Oñate, E.: The violation of objectivity in Laplace formulations of the Navier-Stokes equations, Int. J. Num. Meth. Fluids, 54, 639-664, 2007. 1981

Lindgren, E. R.: The motion of a sphere in an incompressible viscous fluid at Reynolds numbers considerably less than one, Phys. Scr., 60, 97-110, 1999. 2006

Loiselet, C., Braun, J., Husson, L., Le Carlier de Veslud, C., Thieulot, C., Yamato, P., and Grujic, D.: Subducting slabs: Jellyfishes in the Earth's mantle, Geochem. Geophy. Geosy., 11, Q08016, doi:10.1029/2010GC003172, 2010. 1952

Maffione, M., Thieulot, C., van Hinsbergen, D., Morris, A., Plümper, O., and Spakman, W.: Subduction initiation at oceanic detachment faults and the formation of forearc ophiolites, submitted, 2014. 2015

Maierová, P.: Evolution of the Bohemian Massif: Insights from numerical modeling, Ph.D. thesis, Charles University in Prague, Prague, 2012. 1984

Malatesta, C., Gerya, T., Crispini, L., Federico, L., and Capponi, G.: Oblique subduction modelling indicates along-trench tectonic transport of sediments, Nature Commun., 4, doi:10.1038/ncomms3456, 2013. 2048

Malkus, D. and Hughes, T.: Mixed finite element methods - reduced and selective integration techniques: a unification of concepts, Comput. Meth. Appl. Mech. Eng., 15, 63-81, 1978. 1958

Mancktelow, N.: Tectonic pressure: theoretical concepts and modelled examples, Lithos, 103, 149-177, 2008. 1981

Mason, W., Moresi, L., Betts, P., and Miller, M.: Three-dimensional numerical models of the 30 influence of a buoyant oceanic plateau on subduction zones, Tectonophysics, 483, 71-79, 2010. 2048

Massimi, P., Quarteroni, A., Saleri, F., and Scrofani, G.: Modeling of salt tectonics, Comput. Methods Appl. Mech. Engrg., 197, 281-293, 2007. 2008

\section{SED}

6, 1949-2096, 2014

ELEFANT

C. Thieulot

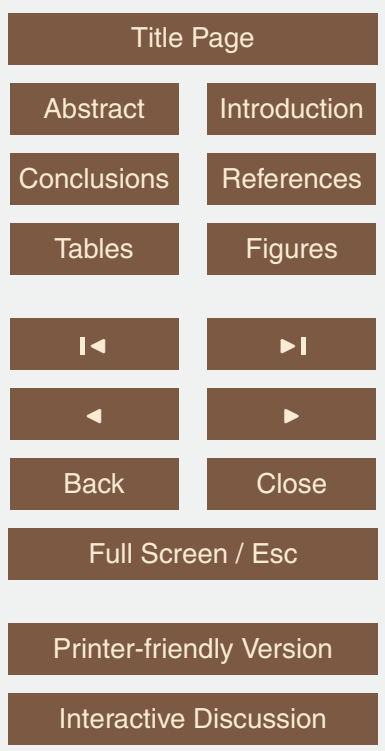


May, D. and Moresi, L.: Preconditioned iterative methods for Stokes flow problems arising in computational geodynamics, Phys. Earth. Planet. Inter., 171, 33-47, 2008. 1970

May, D., Schellart, W., and Moresi, L.: Overview of adaptive finite element analysis in computational geodynamics, J. Geodynam., 70, 1-20, 2013. 2011

5 McClay, K., Muñoz, J.-A., and García-Senz, J.: Extensional salt tectonics in a contractional orogen: a newly identified tectonic event in the Spanish Pyrenees, Geology, 32, 373-740, 2004. 2009

Meyer-Rochow, V. and Gal, J.: Pressures produced when penguins pooh-calculations on avian defaecation, Polar Biol., 27, 56-58, 2003. 1993

10 Molnar, P. and Tapponnier, P.: Relation of the tectonics of eastern China to the India-Eurasia collision: Application of the slip-line field theory to large-scale continental tectonics, Geology, 5, 212-216, 1977. 1983

Montgomery, D. and Brandon, M.: Topographic controls on erosion rates in tectonically active mountain ranges, Earth Planet. Sci. Lett., 201, 481-489, 2002. 1957

Moresi, L.-N. and Solomatov, V.: Numerical investigation of 2D convection with extremely large viscosity variations, Phys. Fluids, 7, 2154-2162, 1995. 1970

Moresi, L., Dufour, F., and Muhlhaus, H.: A Lagrangian integration point finite element method for large deformation modeling of visco-elastic geomaterials, J. Comp. Phys., 184, 476-497, 2003. 1968

20 Moresi, L., Quenette, S., Lemiale, V., Mériaux, C., Appelbe, B., and Mühlhaus, H.-B.: Computational approaches to studying non-linear dynamics of the crust and mantle, Phys. Earth. Planet. Inter., 163, 69-82, 2007. 1952, 1995

Moresi, L., Betts, P., Miller, M., and Cayley, R.: Dynamics of continental accretion, Nature, doi:10.1038/nature13033, 2014. 2048

Morris, J., Fox, P., and Zhu, Y.: Modeling Low Reynolds Number Incompressible Flows Using SPH, J. Comp. Phys., 136, 214-226, 1997. 1992

Napov, A. and Notay, Y.: An algebraic multigrid method with guaranteed convergence rate, SIAM J. Sci. Comput., 34, A1079-A1109, 2012. 1972

Notay, Y.: An aggregation-based algebraic multigrid method, Electron. Trans. Numer. Anal., 37, 123-146, 2010. 1972

Notay, Y.: Aggregation-based algebraic multigrid for convection-diffusion equations, SIAM J. Sci. Comput., 34, A2288-A2316, 2012. 1972

\section{SED}

6, 1949-2096, 2014

\section{ELEFANT}

C. Thieulot
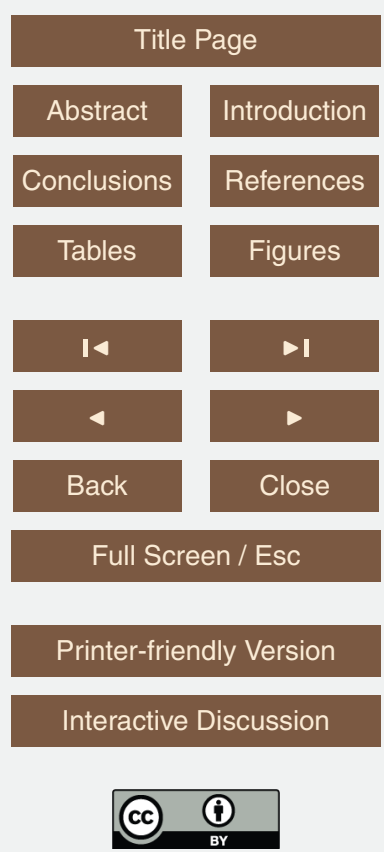
O'Neill, C., Moresi, L., Müller, D., Albert, R., and Dufour, F.: Ellipsis 3D: a particle-in-cell finite element hybrid code for modelling mantle convection and lithospheric deformation, Comp. Geosci., 32, 1769-1779, 2006. 1952, 2002, 2047

Owen, D. and Hinton, E.: Finite Elements in Plasticity, Pineridge Press, 1980. 1974

5 OzBench, M., Regenauer-Lieb, K., Stegman, D., Morra, G., Farrington, R., Hale, A., May, D., Freeman, J., Bourgoin, L., Mühlhaus, H.-B., and Moresi, L.: A model comparison study of large-scale mantle-lithosphere dynamics driven by subduction, Phys. Earth. Planet. Inter., 171, 224-234, 2008. 1952

Peltzer, G. and Tapponnier, P.: Formation and evolution of strike-slip faults, rifts, and basins during the india-asia collision: an experimental approach, J. Geophys. Res., 93, 1508515177, 1988. 1983

Petrunin, A. and Sobolev, S.: Three-dimensional numerical models of the evolution of pull-apart basins, Phys. Earth. Planet. Inter., 171, 387-399, 2008. 1952

Philippon, M., Thieulot, C., Brun, J., Sokoutis, D., Willingshofer, E., and Cloetingh, S.: Structure of the main Ethiopian rift, in preparation, 2014. 2015

Pietro, D. D., Forte, S. L., and Parolini, N.: Mass preserving finite element implementations of the level set method, Appl. Numer. Math., 56, 1179-1195, 2006. 1967

Pinelli, A. and Vacca, A.: Chebyshev collocation method and multidomain decomposition for the incompressible Navier-Stokes equations, Int. J. Numer. Methods Fluids, 18, 781-799, 1994. 2004

Pini, G. and Gambolati, G.: Is a simple diagonal scaling the best preconditioner for conjugate gradients on supercomputers?, Ad. Water Resources, 13, 147-153, 1991. 1962

Podlachikov, Y., Talbot, C., and Poliakov, A.: Numerical models of complex diapirs, Tectonophysics, 228, 189-198, 1993. 2008

Poliakov, A. and Herrmann, H.: Self-organized criticality of plastic shear bands in rocks, Geophys. Res. Lett., 21, 2143-2146, 1994. 1986, 1987

Poliakov, A., Cundall, P., Podlachikov, P., and Lyakhovsky, V.: An explicit inertial method for the simulation of viscoelastic flow: an evaluation of elastic effects on diapiric flow in two- and three-layers models, in: Flow and Creep in the Solar System: Observations, Modeling and theory, Kluwer Academic Publishers, 175-195, 1993a. 1951

Poliakov, A., van Balen, R., Podladchikov, Y., Daudre, B., Cloetingh, S., and Talbot, C.: Numerical analysis of how sedimentation and redistribution of surficial sediments affects salt diapirism, Tectonophysics, 226, 199-216, 1993b. 2008

\section{SED}

6, 1949-2096, 2014

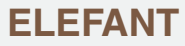

C. Thieulot

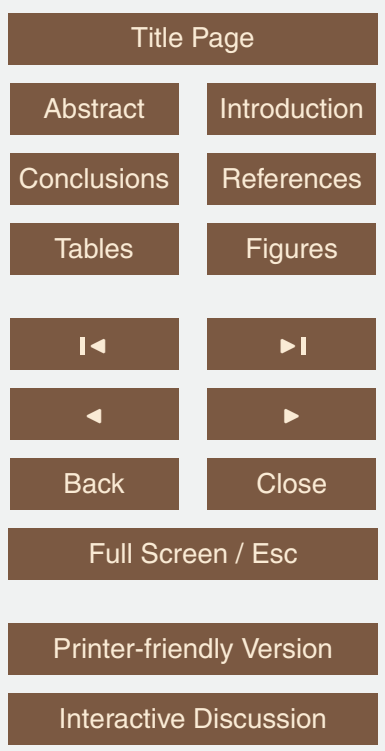


Poliakov, A., Herrmann, H., and Podladchikov, Y.: Fractal plastic shear bands, Fractals, 2, 567581, 1994. 1986

Popov, A. and Sobolev, S.: SLIM3D: a tool for three-dimensional thermomechanical modelling of lithospheric deformation with elasto-visco-plastic rheology, Phys. Earth. Planet. Inter., 171, 5 55-75, 2008. 1952

Pourhiet, L. L., Huet, B., May, D., Labrousse, L., and Jolivet, L.: Kinematic interpretation of the 3D shapes of metamorphic core complexes, Geochem. Geophy. Geosy., 13, doi:10.1029/2012GC004271, 2012. 2048

Prince, P. and Dormand, J.: High order embedded Runge-Kutta formulae, J. Comput. Appl. Math., 7, 67-75, 1981. 1967

Püthe, C. and Gerya, T.: Dependence of mid-ocean ridge morphology on spreading rate in numerical 3-D models, Gondwana Res., 25, 270-283, 2014. 1952, 2048

Pysklywec, R., Ellis, S., and Gorman, A.: Three-dimensional mantle lithosphere deformation at collisional plate boundaries: a subduction scissor across the South Island of New Zealand,

15 Earth Planet. Sci. Lett., 289, 334-346, 2010. 2048

Quinquis, M. E., Buiter, S. J., and Ellis, S.: The role of boundary conditions in numerical models of subduction zone dynamics, Tectonophysics, 497, 57-70, 2011. 1951, 1977

Quinquis, M. E. T., Buiter, S., Tosi, N., Thieulot, C., Maierova, P., Quinteros, J., Dolejs, D., and Ellis, S.: A numerical comparison study of thermo-mechanical subduction, in preparation., 2014. 2015

Quinteros, J., Sobolev, S., and Popov, A.: Viscosity in transition zone and lower mantle: Implications for slab penetration, Geophys. Res. Lett., 37, L09307, doi:10.1029/2010GL043140, 2010. 1962

Rabczuk, T., Areias, P., and Belytschko, T.: A simplified mesh-free method for shear bands with cohesive surfaces, Int. J. Num. Meth. Eng., 69, 993-1021, 2007. 1983

Ramberg, H.: Gravity, deformation, and the Earth's Crust: In Theory, Experiments and Geological Application, Academic Press, London, 214 pp., 1967. 1999

Ramberg, H.: Instability of layered systems in the field of gravity, Phys. Earth Planet. Interiors, 1, 427-447, 1968. 1981

30 Ranalli, G.: Rheology of the Earth, Springer, 1995. 1974

Reddy, J.: On penalty function methods in the finite element analysis of flow problems, Int. J. Num. Meth. Fluids, 2, 151-171, 1982. 1958

\section{SED}

6, 1949-2096, 2014

\section{ELEFANT}

C. Thieulot

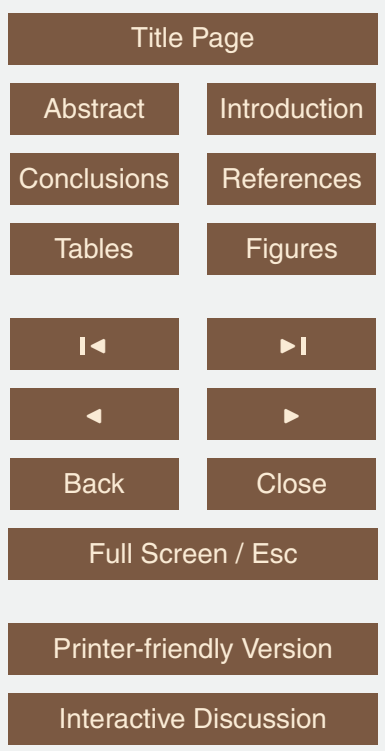


Revenaugh, J. and Parsons, B.: Dynamic topography and gravity anomalies for fluid layers whose viscosity varies exponentially with depth, Geophys. J. Roy. Astron. Soc., 90, 349368, 1987. 1996

Samuel, H. and Evonuk, M.: Modeling advection in geophysical flows with particle level sets, $5 \quad$ Geochem. Geophy. Geosy., 11, Q08020, doi:10.1029/2010GC003081, 2010. 1987

Sani, R., Gresho, P., Lee, R., and Griffiths, D.: The cause and cure (?) of the spurious pressures generated by certain FEM solutions of the incompressible Navier-Stokes equations: part 1, Int. J. Num. Meth. Fluids, 1, 17-43, 1981a. 1978, 1979, 2004

Sani, R., Gresho, P., Lee, R., Griffiths, D., and Engelman, M.: The cause and cure (?) of the spurious pressures generated by certain FEM solutions of the incompressible Navier-Stokes equations: part 2, Int. J. Num. Meth. Fluids, 1, 171-204, 1981b. 1979, 2004

Schellart, W. and Moresi, L.: A new driving mechanism for backarc extension and backarc shortening through slab sinking induced toroidal and poloidal mantle flow: results from dynamic subduction models with an overriding plate, J. Geophys. Res., 118, 1-28, 2013. 2048

Schenk, O., Wächter, A., and Hagemann, M.: Matching-based preprocessing algorithms to the solution of saddle-point problems in large-scale nonconvex interior-point optimization, Comput. Opt. Appl., 36, 321-341, 2007. 1971

Schenk, O., Bollhoefer, M., and Roemer, R.: On large-scale diagonalization techniques for the Anderson model of localization, SIAM Rev., 50, 91-112, 2008. 1971

20

Schmalholz, S. and Podlachikov, Y.: Tectonic overpressure in weak crustal-scale shear zones and implications for the exhumation of high-pressure rocks, Geophys. Res. Lett., 40, 1-5, 2013. 1979

Schmalholz, S., Schmid, D., and Fletcher, R.: Evolution of pinch-and-swell structures in a power-law layer, J. Struct. Geol., 30, 649-663, 2008. 1964, 2017

Schmeling, H., Babeyko, A., Enns, A., Faccenna, C., Funiciello, F., Gerya, T., Golabek, G., Grigull, S., Kaus, B., Morra, G., Schmalholz, S., and van Hunen, J.: A benchmark comparison of spontaneous subduction models - towards a free surface, Phys. Earth. Planet. Inter., 171, 198-223, 2008. 1952, 1969, 1994

Schmid, D. and Podlachikov, Y.: Analytical solutions for deformable elliptical inclusions in general shear, Geophy. J. Int., 155, 269-288, 2003. 1997

Schöberl, J.: Robust multigrid methods for parameter dependent problems, Ph.D. thesis, Johannes Kepler Universität Linz, Linz, 1999. 1970

\section{SED}

6, 1949-2096, 2014

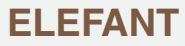

C. Thieulot

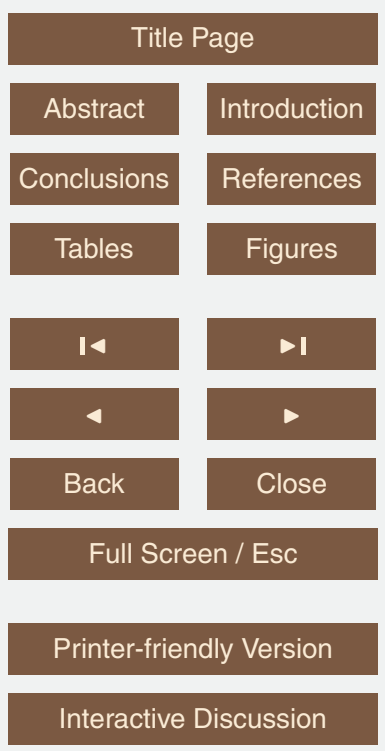


Schott, B., Yuen, D., and Schmeling, H.: The significance of shear heating in continental delamination, Phys. Earth. Planet. Inter., 118, 273-290, 2000. 1955

Schultz-Ela, D. and Walsh, P.: Modeling of grabens extending above evaporites in Canyonlands National Park, Utah, J. Struct. Geol., 24, 247-275, 2002. 2009

5 Scott, J. and Hu, Y.: Experiences of sparse direct symmetric solvers, Tech. Rep. RAL-TR-2005014, CCLRC, 2005. 1970

Segal, A. and Praagman, N.: The Sepran FEM package, Technical Report, Ingenieursbureau Sepra, the Netherlands. http://ta.twi.tudelft.nl/sepran/sepran.html, 2005. 2019

Sigalotti, L. D. G., Klapp, J., Sira, E., Melean, Y., and Hasmy, A.: SPH simulations of timedependent Poiseuille flow at low Reynolds numbers, J. Comp. Phys., 191, 622-638, 2003. 1992

Stegman, D., Schellart, W., and Freeman, J.: Competing influences of plate width and far-field boundary conditions on trench migration and morphology of subducted slabs in the upper mantle, Tectonophysics, 483, 46-57, 2010. 2048

Suckale, J., Nave, J.-C., and Hager, B.: It takes three to tango: 1. Simulating buoyancydriven flow in the presence of large viscosity contrasts, J. Geophys. Res., 115, B07409, doi:10.1029/2009JB006916, 2010. 1987, 1997

Sussman, M. and Puckett, E.: A coupled level set and volume-of-fluid method for computing 3D and axisymmetric incompressible two-phase flows, J. Comp. Phys., 162, 301-337, 2000.

$20 \quad 1967$

Tackley, P.: Three-dimensional models of mantle convection: influence of phase transitions and temperature-dependent viscosity, Ph.D. thesis, California Institute of Technology, 1994. 2002, 2046

Tackley, P.: Self-consistent generation of tectonic plates in three-dimensional mantle convection, Earth Planet. Sci. Lett., 157, 9-22, 1998. 1976

Tackley, P. and King, S.: Testing the tracer ratio method for modeling active compositional fields in mantle convection simulations, Geochem. Geophy. Geosy., 4, 8302, doi:10.1029/2001GC000214, 2003. 1987, 1989

Tapponnier, P. and Molnar, P.: Slip-line field theory and large-scale continental tectonics, Nature, 264, 319-324, 1976. 1983

Tezduyar, T. E. and Osawa, Y.: Finite element stabilization parameters computed from element matrices and vectors, Comp. Methods Appl. Mech. Engin., 190, 411-430, 2000. 2018 
Thielmann, M. and Kaus, B.: Shear heating induced lithospheric-scale localization: does it result in subduction?, Earth Planet. Sci. Lett., 359-360, 1-13, 2012. 1955

Thieulot, C.: FANTOM: two- and three-dimensional numerical modelling of creeping flows for the solution of geological problems, Phys. Earth. Planet. Inter., 188, 47-68, 2011. 1951, 1953, 1963, 1966, 1975, 1979, 1980, 1981, 2011

Thieulot, C. and L'Excellent, J.-Y.: Using the elemental format of the MUMPS direct solver in a geodynamics code: a simple bridge between sequential and parallel computing, in preparation, 2014. 1971, 1980, 2011

Thieulot, C., Fullsack, P., and Braun, J.: Adaptive octree-based finite element analysis 10 of two- and three-dimensional indentation problems, J. Geophys. Res., 113, B12207, doi:10.1029/2008JB005591, 2008. 1952, 1978, 1979, 1981, 1983

Thieulot, C., Glerum, A., Fraters, M., Bangerth, W., Heister, T., Rose, I., Austmann, J., Dannberg, J., Stamps, D., Gassmoeller, R., and Spakman, W.: Geodynamical modelling using ASPECT, in preparation, 2014a. 1994, 2015

Thieulot, C., Schmalholz, S., Glerum, A., Hillebrand, B., van Hinsbergen, D., Schmeling, H., Quinteros, J., Brune, S., Pourhiet, L. L., May, D., and Spakman, W.: A two- and threenumerical comparison study of slab detachment, in preparation, 2014b. 2015, 2019

Thieulot, C., Steer, P., and Huismans, R.: Three-dimensional numerical simulations of crustal systems undergoing orogeny and subjected to surface processes, in review, 2014b. 1956, $20 \quad 2020,2048$

Travis, B., Anderson, C., Baumgardner, J., Gable, C., Hager, B., O'Connell, R., Olson, P., Raefsky, A., and Schubert, G.: A benchmark comparison of numerical methods for infinite Prandtl number thermal convection in two-dimensional Cartesian geometry, Geophys. Astrophys. Fluid Dynam., 55, 137-160, 1990. 1981

Trompert, R. and Hansen, U.: On the Rayleigh number dependence of convection with a strongly temperature-dependent viscosity, Phys. Fluids, 10, 351-360, 1998. 2002, 2047

Trudgill, B. and Cartwright, J.: Relay-ramp forms and normal-fault linkages, Canyonlands National Park, Utah, Geol. Soc. Am. B., 106, 1143-1157, 1994. 2009

van den Berg, A., van Keken, P., and Yuen, D.: The effects of a composite non-Newtonian and Newtonian rheology on mantle convection, Geophy. J. Int., 115, 62-78, 1993. 2003

van den Berg, A., Segal, G., and Yuen, D.: SEPRAN: A Versatile Finite-Element Package for Realistic Problems in Geosciences, International Workshop of Deep Geothermal Systems, Wuhan, China, 29-30 June 2012. 2019

\section{SED}

6, 1949-2096, 2014

\section{ELEFANT}

C. Thieulot
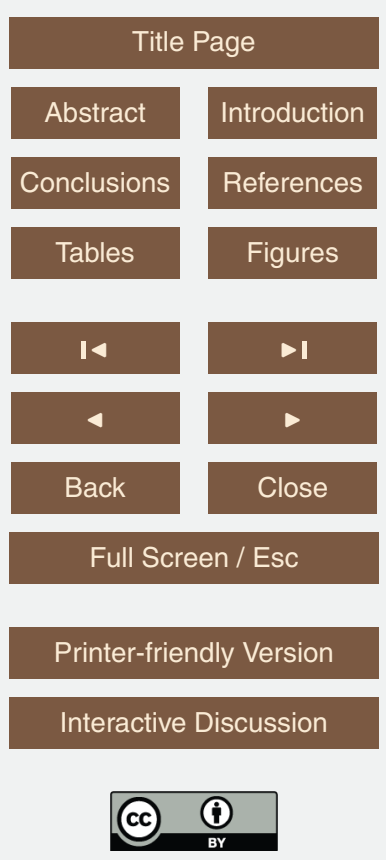
van Keken, P., spiers, C., van den Berg, A., and Muyzert, E.: The effective viscosity of rocksalt: implementation of steady-state creep laws in numerical models of salt diapirism, Tectonophysics, 225, 457-476, 1993. 2008

van Keken, P., King, S., Schmeling, H., Christensen, U., Neumeister, D., and Doin, M.-P.: A 5 comparison of methods for the modeling of thermochemical convection, J. Geophys. Res., 102, 22477-22495, 1997. 1987, 1989, 1992, 2062, 2066

van Keken, P. E., Currie, C., King, S., Behn, M., Cagnioncle, A., Hee, J., Katz, R., Lin, S.-C., Parmentier, E., Spiegelman, M., and Wang, K.: A community benchmark for subduction zone modelling, Phys. Earth. Planet. Inter., 171, 187-197, 2008. 1981

10 van Wijk, J., Baldridge, W., van Hunen, J., Goes, S., Aster, R., Coblentz, D., Grand, S., and Ni, J.: Small-scale convection at the edge of the Colorado Plateau: implications for topography, magmatism, and evolution of Proterozoic lithosphere, Geology, 38, 611-614, 2010. 1952

Virgo, S., Abe, S., and Urai, J.: Extension fracture propagation in rocks with veins: Insight into the crack-seal process using Discrete Element Method modeling, J. Geophys. Res., 118, 15 5236-5251, 2013. 1952

Warren, C., Beaumont, C., and Jamieson, R.: Formation and exhumation of ultra-high-pressure rocks during continental collision: role of detachment in the subduction channel, Geochem. Geophy. Geosy., 9, Q04019, doi:10.1029/2007GC001839, doi:10.1029/2007GC001839, 2008. 1956, 1993

20

Wathen, A. and Silvester, D.: Fast iterative solution of stabilised Stokes systems. Part I: using simple diagonal preconditioners, SIAM J. Numer. Anal., 3, 630-649, 1993. 1961

Whipp, D., Beaumont, C., and Braun, J.: Feeding the "aneurysm": Orogen-parallel mass transport into Nanga Parbat and the western Himalayan syntaxis, J. Geophys. Res., 119, doi:10.1002/2013JB010929, 2014. 1952, 2048

Willett, S.: Dynamic and kinematic growth and change of a Coulomb wedge, in: Thrust Tectonics, edited by McClay, K., Chapman and Hall, 19-31, 1992. 1975

Willett, S. D.: Rheological dependence of extension in wedge models of convergent orogens, Tectonophysics, 305, 419-435, 1999. 1952

Willett, S. D. and Pope, D. C.: Thermo-mechanical models of convergent orogenesis: Thermal and rheologic dependence of crustal deformation, in: Rheology and Deformation of the Lithosphere at Continental Margins, Columbia University Press, 166-222, 2003. 1951

Yamato, P., Burov, E., Agard, P., Le Pourhiet, L., and Jolivet, L.: HP-UHP exhumation during slow continental subduction: self-consistent thermodynamically and thermomechanically

\section{SED}

6, 1949-2096, 2014

\section{ELEFANT}

C. Thieulot

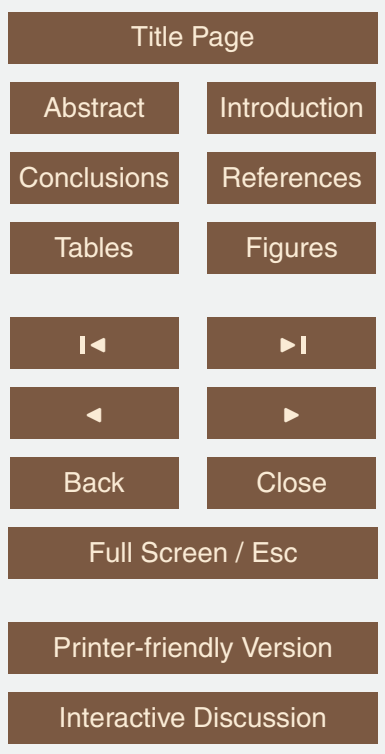

2042 
coupled model with application to the Western Alps, Earth Planet. Sci. Lett., 271, 63-74, 2008. 1952

Yamato, P., Husson, L., Braun, J., Loiselet, C., and Thieulot, C.: Influence of surrounding plates on 3D subduction dynamics, Geophys. Res. Lett., 36, L07303, doi:10.1029/2008GL036942, 2009. 1952

Yamato, P., Tartese, R., Duretz, T., and May, D.: Numerical modelling of magma transport in dykes, Tectonophysics, 526-529, 97-109, 2012. 1993

Yoshida, M., Tajima, F., Honda, S., and Morishige, M.: The 3D numerical modeling of subduction dynamics: Plate stagnation and segmentation, and crustal advection in the wet mantle transition zone, J. Geophys. Res., 117, B04104, doi:10.1029/2011JB008989, 2012. 1952

$\mathrm{Yu}, \mathrm{X}$. and Tin-Loi, F.: A simple mixed finite element for static limit analysis, Comput. Struct., 84, 1906-1917, 2006. 1983

Zalesak, S.: Fully multidimensional flux-corrected transport algorithms for fluids, J. Comp. Phys., 31, 335-362, 1979. 1967

Zaleski, S. and Julien, P.: Numerical simulation of Rayleigh-Taylor instability for single and multiple salt diapirs, Tectonophysics, 206, 55-69, 1992. 2008

Zhong, S.: Analytic solutions for Stokes' flow with lateral variations in viscosity, Geophys. J. Int., 124, 18-28, 1996. 1995, 1996

Zhong, S., McNamara, A., Tan, E., Moresi, L., and Gurnis, M.: A benchmark study on mantle convection in a 3-D spherical shell using CITCOMS, Geochem. Geophy. Geosy., 9, Q10017, doi:10.1029/2008GC002048, 2008. 2016

Zhu, G., Gerya, T., Yuen, D., Honda, S., Yoshida, T., and Connolly, T.: Three-dimensional dynamics of hydrous thermal-chemical plumes in oceanic subduction zones, Geochem. Geophy. Geosy., 118, 4682-4698, doi:10.1029/2009GC002625, 2009. 1952

Zhu, G., Gerya, T., Tackley, P., and Kissling, E.: Four-dimensional numerical modeling of crustal growth at active continental margins, J. Geophys. Res., 118, 4682-4698, 2013. 2048

Zienkiewicz, O. and Taylor, R.: The Finite Element Method. Vol. 1,2,3, Butterworth and Heinemann, 2002. 1960, 1974

Zienkiewicz, O., Humpheson, C., and Lewis, R.: Associated and non-associated visco-plasticity and plasticity in soil mechanics, Géotechnique, 25, 671-689, 1975. 1983

Zienkiewicz, O., Huang, M., and Pastor, M.: Localization problems in plasticity using Finite Elements with adaptive remeshing, Int. J. Numer. Anal. Methods Geomech., 19, 127-148, 1995. 1983 


\section{SED}

Table 1. Nomenclature.

\begin{tabular}{ll}
\hline Symbol & Meaning and dimension \\
\hline$A$ & power-law initial constant $\left(\mathrm{Pa}^{-n} \mathrm{~s}^{-1}\right)$ \\
$c_{\mathrm{p}}$ & heat capacity $\left(\mathrm{J} \mathrm{kg}^{-1} \mathrm{~K}^{-1}\right)$ \\
$\boldsymbol{g}$ & gravity acceleration vector $\left(\mathrm{m} \mathrm{s}^{-2}\right)$ \\
$H$ & heat production $\left(\mathrm{W} \mathrm{m}^{-3}\right)$ \\
$k$ & heat conductivity $\left(\mathrm{W} \mathrm{m}^{-1} \mathrm{~K}^{-1}\right)$ \\
$L_{x}, L_{y}, L_{z}$ & domain size $(\mathrm{m})$ \\
$n$ & power-law creep exponent \\
$p$ & pressure $(\mathrm{Pa})$ \\
$R$ & gas constant $\left(\mathrm{J} \mathrm{K}^{-1} \mathrm{~mol}^{-1}\right)$ \\
$\boldsymbol{s}$ & deviatoric stress vector $(\mathrm{Pa})$ \\
$T, T_{0}$ & temperature $(\mathrm{K})$ \\
$\boldsymbol{v}=(u, v, w)$ & velocity (m s $\left.{ }^{-1}\right)$ \\
$V$ & power-law activation volume $\left(\mathrm{m}^{3} \mathrm{~mol}^{-1}\right)$ \\
$\alpha$ & thermal expansion coefficient $\left(\mathrm{K}^{-1}\right)$ \\
$\mathrm{d} t$ & time step (s) \\
$\dot{\boldsymbol{\epsilon}}$ & strain rate tensor $\left(\mathrm{s}^{-1}\right)$ \\
$\epsilon, \epsilon_{1}, \epsilon_{2}$ & strain \\
$\lambda$ & penalty coefficient (Pas) \\
$\mu, \mu_{\min }, \mu_{\max }, \mu_{\text {eff }}$ & viscosity (Pas) \\
$\phi, \phi_{\infty}$ & angle of internal friction \\
$\rho, \rho_{0}$ & mass density (kg m $\left.{ }^{-3}\right)$ \\
$\sigma$ & stress tensor (Pa) \\
$c, c_{\infty}$ & cohesion (Pa) \\
\hline &
\end{tabular}

\section{ELEFANT}

C. Thieulot

\section{Title Page}

Abstract Introduction

Conclusions

References

Tables

Figures

14

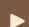

Back

Close

Full Screen / Esc

Printer-friendly Version

Interactive Discussion

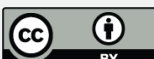




\section{SED}

6, 1949-2096, 2014

\section{ELEFANT}

C. Thieulot

Table 2. List of numerical models and experiments run.

\begin{tabular}{|c|c|c|c|c|c|c|c|c|}
\hline $\begin{array}{l}\text { Experiments and } \\
\text { models }\end{array}$ & $\# \operatorname{dim}$ & $\begin{array}{l}\text { nonlinear } \\
\text { material(s) }\end{array}$ & $\begin{array}{c}\text { free } \\
\text { surface }\end{array}$ & $\begin{array}{c}\text { temperature } \\
\text { solve }\end{array}$ & $\begin{array}{l}\text { multi- } \\
\text { phase }\end{array}$ & $\begin{array}{l}\text { large } \mu \\
\text { contrast }\end{array}$ & $\begin{array}{l}\text { analytical } \\
\text { solution }\end{array}$ & $\begin{array}{c}\text { numerical } \\
\text { comparison }\end{array}$ \\
\hline Indenter & 2 & $\checkmark$ & & & & $\checkmark$ & $\checkmark$ & \\
\hline Brick & 2 & $\checkmark$ & $\checkmark$ & & $\checkmark$ & $\checkmark$ & $\checkmark$ & $\checkmark$ \\
\hline Shear bands fractals & 2 & $\checkmark$ & & & & $\checkmark$ & & $\checkmark$ \\
\hline Rayleigh-Taylor instability & 2 & & & & $\checkmark$ & & & $\checkmark$ \\
\hline Thin layer entrainment & 2 & & & $\checkmark$ & $\checkmark$ & & & $\checkmark$ \\
\hline Poiseuille flow & 2 & & & & & & $\checkmark$ & \\
\hline Subduction & 2 & & & & $\checkmark$ & $\checkmark$ & & $\checkmark$ \\
\hline SolCx, SolKz, SolVi & 2 & & & & $\checkmark$ & $\checkmark$ & $\checkmark$ & \\
\hline Topography evolution & 2 & & $\checkmark$ & & $\checkmark$ & $\checkmark$ & $\checkmark$ & $\checkmark$ \\
\hline Mantle convection & 2 and 3 & & & $\checkmark$ & & & & $\checkmark$ \\
\hline Lid driven cavity & 2 & & & & & & & $\checkmark$ \\
\hline Falling sphere & 3 & & & & $\checkmark$ & $\checkmark$ & $\checkmark$ & \\
\hline Salt tectonics (Sect. 5) & 2 & $\checkmark$ & $\checkmark$ & $\checkmark$ & $\checkmark$ & $\checkmark$ & & \\
\hline 3-D polynomial solution & 3 & & & & & $\checkmark$ & $\checkmark$ & \\
\hline
\end{tabular}

\begin{tabular}{|c|c|}
\hline \multicolumn{2}{|c|}{ Title Page } \\
\hline Abstract & Introduction \\
\hline Conclusions & References \\
\hline Tables & Figures \\
\hline I4 & \\
\hline 4 & \\
\hline Back & Close \\
\hline Full Screen / Esc \\
\hline Printer-friendly Version
\end{tabular}




\section{SED}

6, 1949-2096, 2014

\section{ELEFANT}

C. Thieulot

Table 3. Steady state Nusselt number and $V_{\text {rms }}$ measurements as reported in the literature and obtained with ELEFANT on a $200 \times 200$ grid.

\begin{tabular}{clcccc}
\hline & & Blankenbach et al. (1989) & Tackley (1994) & King (2009) & ELEFANT \\
\hline$R a=10^{4}$ & $V_{\text {rms }}$ & $42.864947 \pm 0.000020$ & $42.775(0.2 \%)$ & $42.867(0.005 \%)$ & $42.867(0.01 \%)$ \\
& $\mathrm{Nu}$ & $4.884409 \pm 0.000010$ & $4.878(0.1 \%)$ & $4.885(0.02 \%)$ & $4.882(0.05 \%)$ \\
$R a=10^{5}$ & $V_{\text {rms }}$ & $193.21454 \pm 0.00010$ & $193.11(0.05 \%)$ & $193.248(0.02 \%)$ & $193.255(0.02 \%)$ \\
& $\mathrm{Nu}$ & $10.534095 \pm 0.000010$ & $10.531(0.03 \%)$ & $10.536(0.02 \%)$ & $10.507(0.26 \%)$ \\
$R a=10^{6}$ & $V_{\text {rms }}$ & $833.98977 \pm 0.00020$ & $833.55(0.05 \%)$ & $834.353(0.04 \%)$ & $834.712(0.08 \%)$ \\
& $\mathrm{Nu}$ & $21.972465 \pm 0.000020$ & $21.998(0.1 \%)$ & $21.981(0.04 \%)$ & $21.695(1.2 \%)$ \\
\hline
\end{tabular}

Abstract

Title Page

Conclusions

Tables

References

Figures

14

$\rightarrow 1$

Back

Close

Full Screen / Esc

Printer-friendly Version

Interactive Discussion

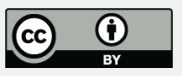




\section{SED}

6, 1949-2096, 2014

\section{ELEFANT}

C. Thieulot

Table 4. Velocity and temperature measurements in dimensionless form as published by various authors and obtained with ELEFANT for various resolutions. (Note that O'Neill et al. (2006) do carry out the benchmark but do not provide actual numbers.) Tr. and $\mathrm{H}$. stands for Trompert and Hansen (1998). The authors state: "[...] a $32 \times 32 \times 32$ grid is used, uniform in the horizontal directions and nonuniform vertically, with refinement in the thermal boundary layers where the largest cell size is $0.0425,3.5$ times larger than the smallest". Kr. et al. stands for Kronbichler et al. (2012). These authors report that the mesh leads to about $570 \mathrm{k}$ temperature dofs, implying that second order elements were used.

\begin{tabular}{|c|c|c|c|c|c|c|}
\hline \# dofs & B. et al. & $\begin{array}{c}\text { Tr. and } \mathrm{H} \text {. } \\
32 \times 32 \times 32\end{array}$ & $\begin{array}{c}\text { Kr. et al. } \\
48 \times 30 \times 48 \\
570 \mathrm{k}\end{array}$ & $\begin{array}{c}24 \times 14 \times 24 \\
9 \mathrm{k}\end{array}$ & $\begin{array}{c}\text { ELEFANT } \\
32 \times 19 \times 32 \\
21 \mathrm{k}\end{array}$ & $\begin{array}{c}48 \times 29 \times 48 \\
71 \mathrm{k}\end{array}$ \\
\hline $\mathrm{Nu}$ & 3.5374 & 3.545 & 3.5397 & 3.509 (0.8\%) & 3.510 (0.7\%) & $3.511(0.7 \%)$ \\
\hline$v_{\text {rms }}$ & 40.999 & 41.09 & 40.999 & $41.062(0.2 \%)$ & $41.126(0.3 \%)$ & $41.172(0.4 \%)$ \\
\hline$w(0,0, h / 2)$ & 116.625 & 116.79 & 116.623 & $114.716(1.6 \%)$ & $115.172(1.2 \%)$ & $115.503(0.9 \%)$ \\
\hline$T(0,0, h / 2)$ & 0.80130 & 0.7997 & 0.80129 & 0.797 (0.5\%) & 0.798 (0.4\%) & 0.799 (0.3\%) \\
\hline$Q(0,0, h)$ & 6.7127 & 6.7767 & 6.7189 & $6.594(1.8 \%)$ & $6.600(1.7 \%)$ & 6.604 (1.6\%) \\
\hline$Q(a, b, h)$ & 0.7140 & 0.7120 & 0.7174 & $0.706(1.1 \%)$ & $0.712(0.3 \%)$ & $0.716(0.3 \%)$ \\
\hline
\end{tabular}

C. Thieulot

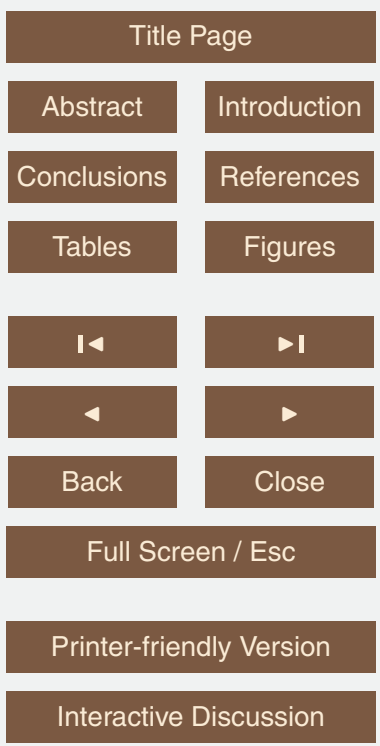


Table 5. List of authors, publication topics and corresponding grid resolutions. This list is not exhaustive.

\begin{tabular}{|c|c|c|}
\hline Author(s) & topic & resolution \\
\hline Ballmer et al. (2010) & Small-scale sublithospheric convection in the Pacific & $448 \times 56 \times 64$ \\
\hline Stegman et al. (2010) & Migration and morphology of subducted slabs in the upper mantle & $50 \times 50 \times 25$ \\
\hline Pysklywec et al. (2010) & Subduction scissor across the South Island of New Zealand & $17 \times 9 \times 9$ \\
\hline Mason et al. (2010) & Influence of a buoyant oceanic plateau on subduction zones & $80 \times 40 \times 80$ \\
\hline Capitanio et al. (2011) & Subduction dynamics, origin of Andean orogeny and the Bolivian orocline & $96 \times 96 \times 64$ \\
\hline Ellis et al. (2011) & Feedback between rifting and diapirism, ultrahigh-pressure rocks exhumation & $100 \times 64 \times 20$ \\
\hline Allken et al. (2011) & Numerical modeling of upper crustal extensional systems & $160 \times 160 \times 12$ \\
\hline Allken et al. (2012) & Rift interaction in brittle-ductile coupled systems & $160 \times 160 \times 23$ \\
\hline Pourhiet et al. (2012) & Kinematic interpretation of the 3-D shapes of metamorphic core complexes & $67 \times 67 \times 33$ \\
\hline Jadamec and Billen (2012) & Role of rheology and slab shape on rapid mantle flow: the Alaska slab edge & $960 \times 648 \times 160$ \\
\hline Capitanio and Faccenda (2012) & Complex mantle flow around heterogeneous subducting oceanic plates & $96 \times 96 \times 64$ \\
\hline Brune et al. (2012) & Oblique rifting and continental break-up & $150 \times 50 \times 30$ \\
\hline Betts et al. (2012) & Influence of mantle plume head on dynamics of a retreating subduction zone & $80 \times 40 \times 80$ \\
\hline Brune and Autin (2013) & Rift to break-up evolution of the Gulf of Aden & $83 \times 83 \times 40$ \\
\hline Brune et al. (2013) & Thermo-mechanical impact of plume arrival on continental break-up & $100 \times 70 \times 20$ \\
\hline Capitanio and Replumaz (2013) & Subduction and slab breakoff controls on Asian indentation tectonics & $96 \times 96 \times 64$ \\
\hline Faccenda and Capitanio (2013) & Modeling of upper mantle deformation and SKS splitting calculations & $96 \times 64 \times 96$ \\
\hline Schellart and Moresi (2013) & Backarc extension/shortening, slab induced toroidal/poloidal mantle flow & $352 \times 80 \times 64$ \\
\hline Malatesta et al. (2013) & Sediment transports in the context of oblique subduction modelling & $500 \times 164 \times 100$ \\
\hline Zhu et al. (2013) & Crustal growth at active continental margins & $404 \times 164 \times 100$ \\
\hline Lechmann et al. (2013) & Dynamics of India-Asia collision & $257 \times 257 \times 33$ \\
\hline Whipp et al. (2014) & Strain-partitioning in the Himalaya & $256 \times 256 \times 40$ \\
\hline Li et al. (2013) & Collision of continental corner from 3-D numerical modeling & $500 \times 340 \times 164$ \\
\hline Püthe and Gerya (2014) & Dependence of mid-ocean ridge morphology on spreading rate & $196 \times 196 \times 100$ \\
\hline Faccenda (2014) & Mid mantle seismic anisotropy around subduction zones & $197 \times 197 \times 53$ \\
\hline Heine and Brune (2014) & Oblique rifting of the Equatorial Atlantic & $120 \times 80 \times 20$ \\
\hline Moresi et al. (2014) & Dynamics of continental accretion & $256 \times 96 \times 96$ \\
\hline Ruth et al. (2014) & Thrust wedges: infl. of decollement strength on transfer zones & $309 \times 85 \times 149$ \\
\hline Thieulot et al. (2014c) & modelled crustal systems undergoing orogeny and subjected to surface processes & $96 \times 32 \times 14$ \\
\hline Fernandez and Kaus (2014) & Fold interaction and wavelength selection in 3-D models of multilayer folding & $257 \times 257 \times 13$ \\
\hline this work & 3-D polynomial solution, falling sphere & $100 \times 100 \times 100$ \\
\hline
\end{tabular}

\section{ELEFANT}

\section{Thieulot}

\section{Title Page}

Abstract

Introduction

Conclusions

References

Tables

Figures

14

$>$ I

4

$\triangleright$

Back

Close

Full Screen / Esc

Printer-friendly Version

Interactive Discussion 


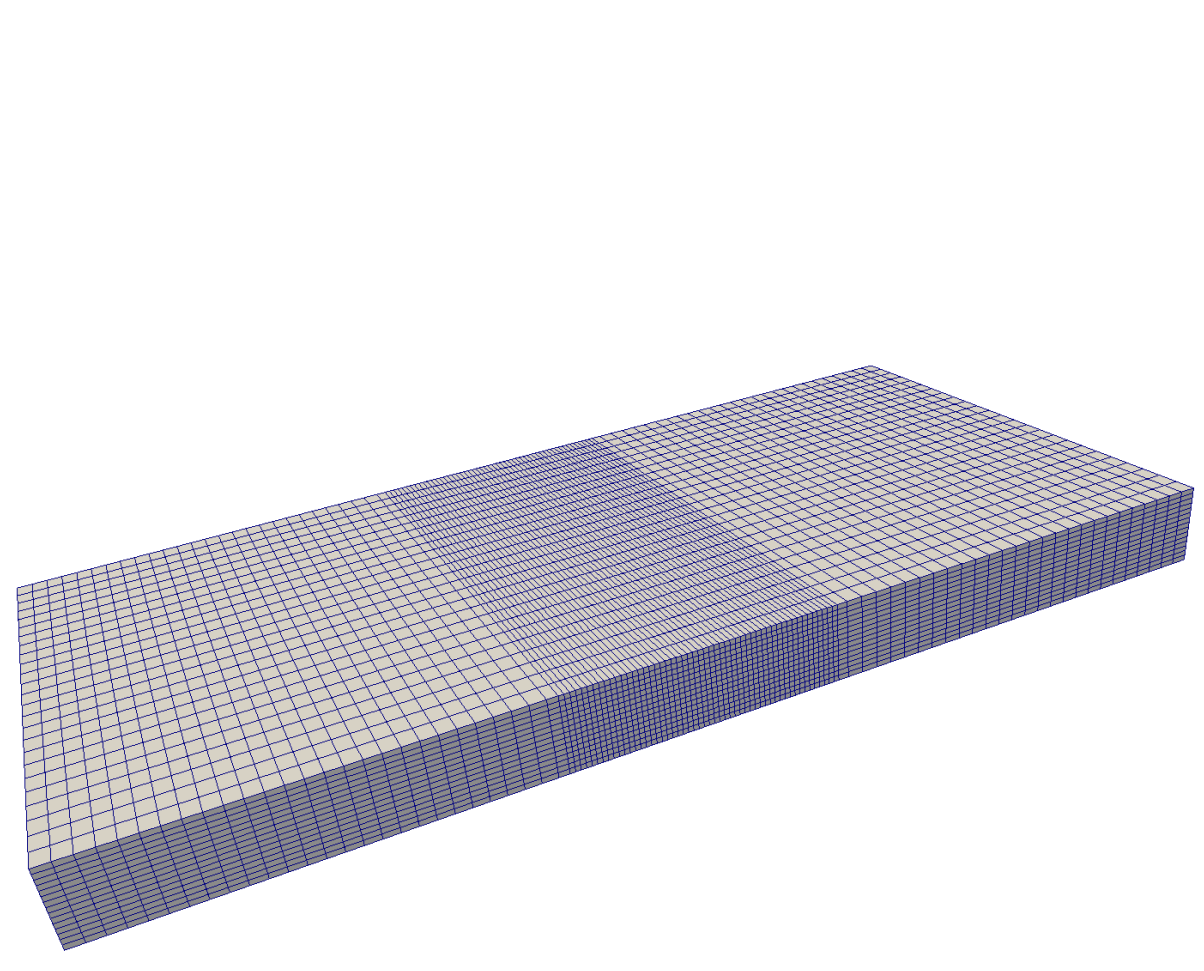

Figure 1. Examples of grid stretching which allows for a much higher resolution in a targetted area of the computational domain.

\section{SED}

6, 1949-2096, 2014

\section{ELEFANT}

C. Thieulot

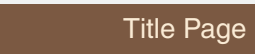

Abstract

Introduction

Conclusions References

Tables

Figures

14

$>$ I

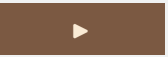

Back

Close

Full Screen / Esc

Printer-friendly Version

Interactive Discussion 


\section{SED}

6, 1949-2096, 2014

\section{ELEFANT}

C. Thieulot
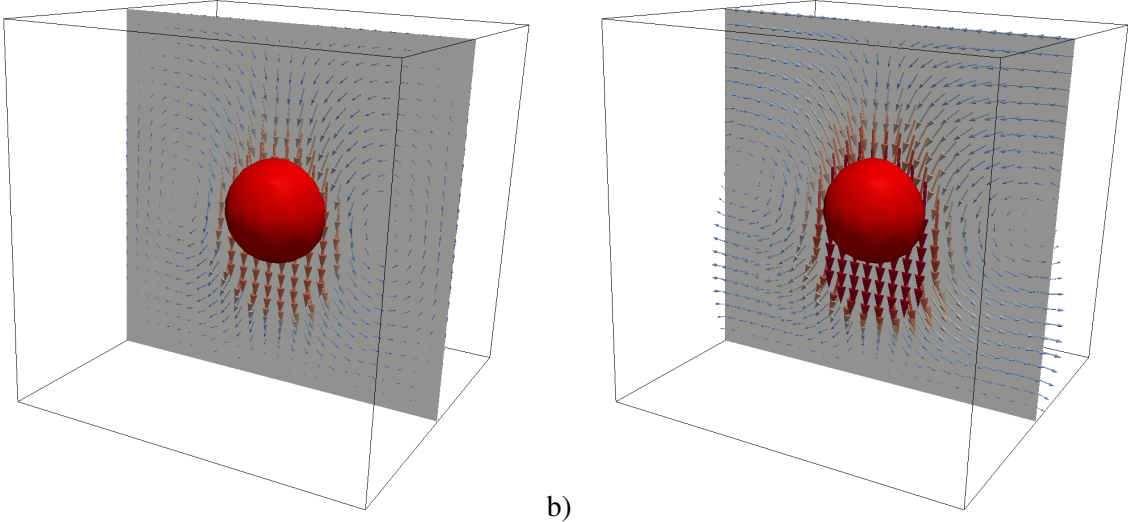

Title Page

Abstract

Introduction

Conclusions

References

Tables

Figures

a)

$>$ I

4

$\triangleright$

Back

Close

Full Screen / Esc boundary conditions on all sides; (b) both $y=0$ and $y=L_{y}$ walls are subjected to open boundary conditions.

Printer-friendly Version

Interactive Discussion 


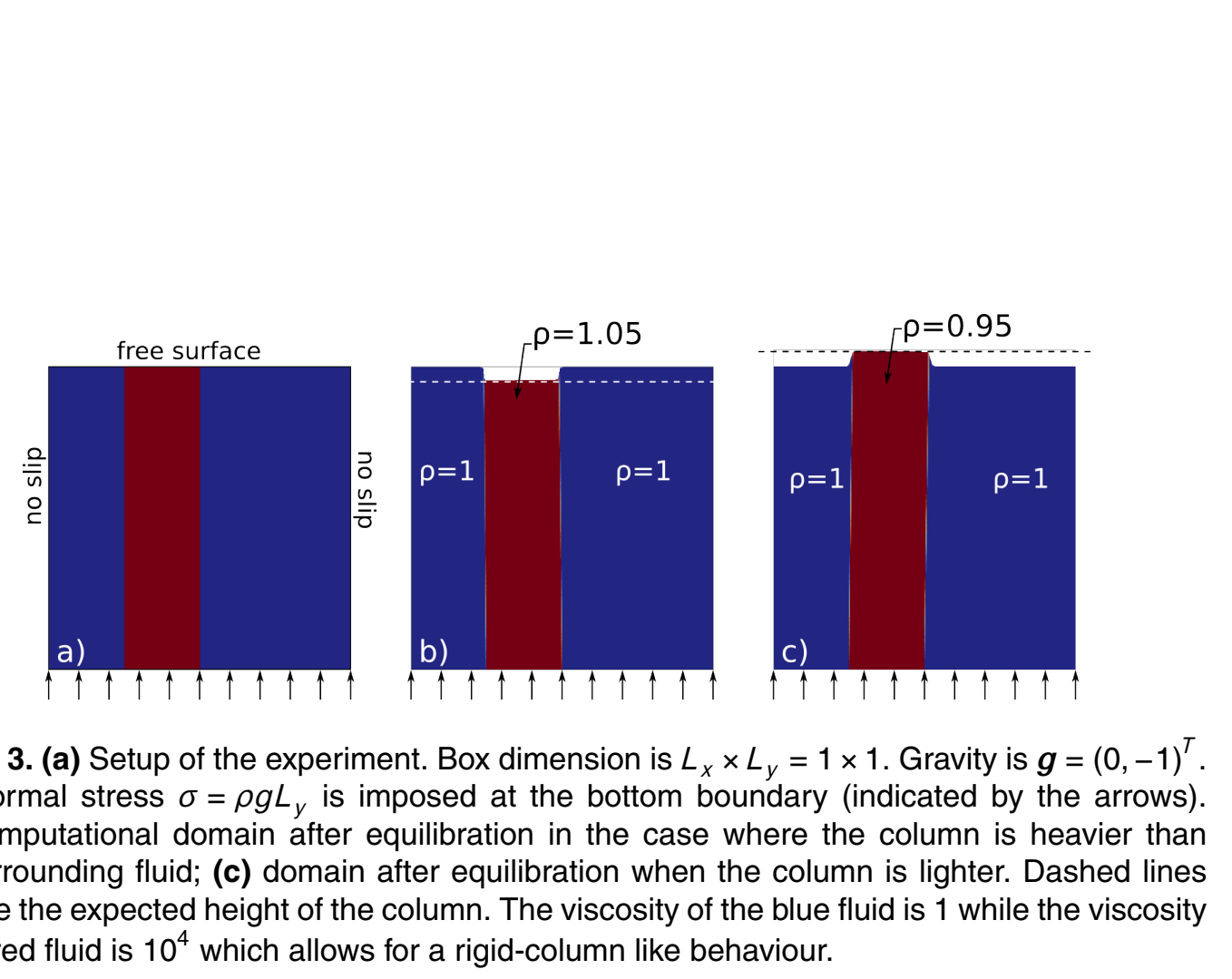

SED

6, 1949-2096, 2014

\section{ELEFANT \\ C. Thieulot}

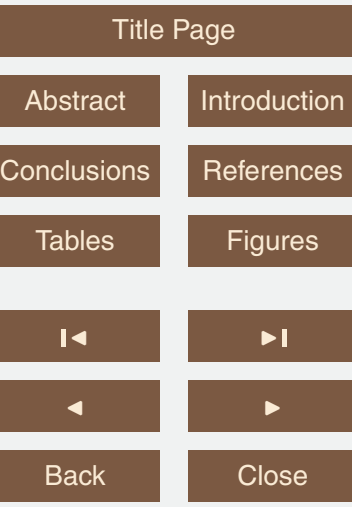

Full Screen / Esc indicate the expected height of the column. The viscosity of the blue fluid is 1 while the viscosity of the red fluid is $10^{4}$ which allows for a rigid-column like behaviour.

Printer-friendly Version

Interactive Discussion 

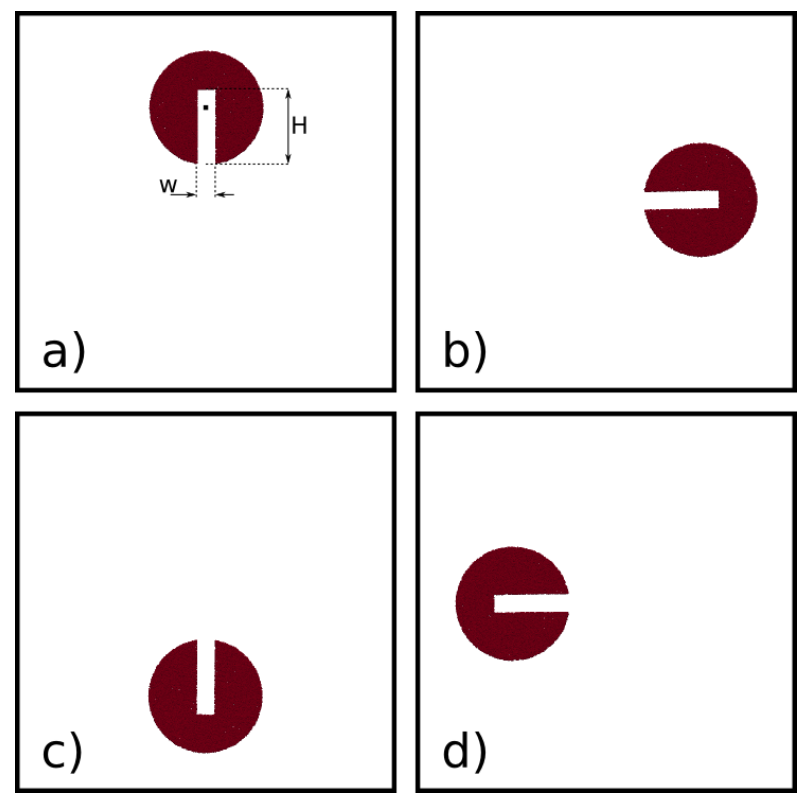

Figure 4. Zalesak disk experiment at times (a) $t=0$, (b) $t=0.25$, (c) $t=0.5$, (d) $t=0.75$ with $W=0.05, H=0.2$. The disk is centered at location $\left(x_{0}, y_{0}\right)=(0.5,0.75)$ and has a radius $R=$ 0.15 . Only the very dense cloud of markers tracking the disk are shown. The domain size is $L_{x}=L_{y}=1$. A grid of $100 \times 100$ elements is used, and the Courant number is fixed to $C=0.5$. 100 markers per element are initially prescribed.

\section{ELEFANT}

C. Thieulot

\section{Title Page}

Abstract

Introduction

Conclusions

References

Tables

Figures

14

$>$ I

4

Back

Close

\section{Full Screen / Esc}

Printer-friendly Version

Interactive Discussion

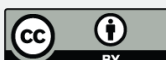




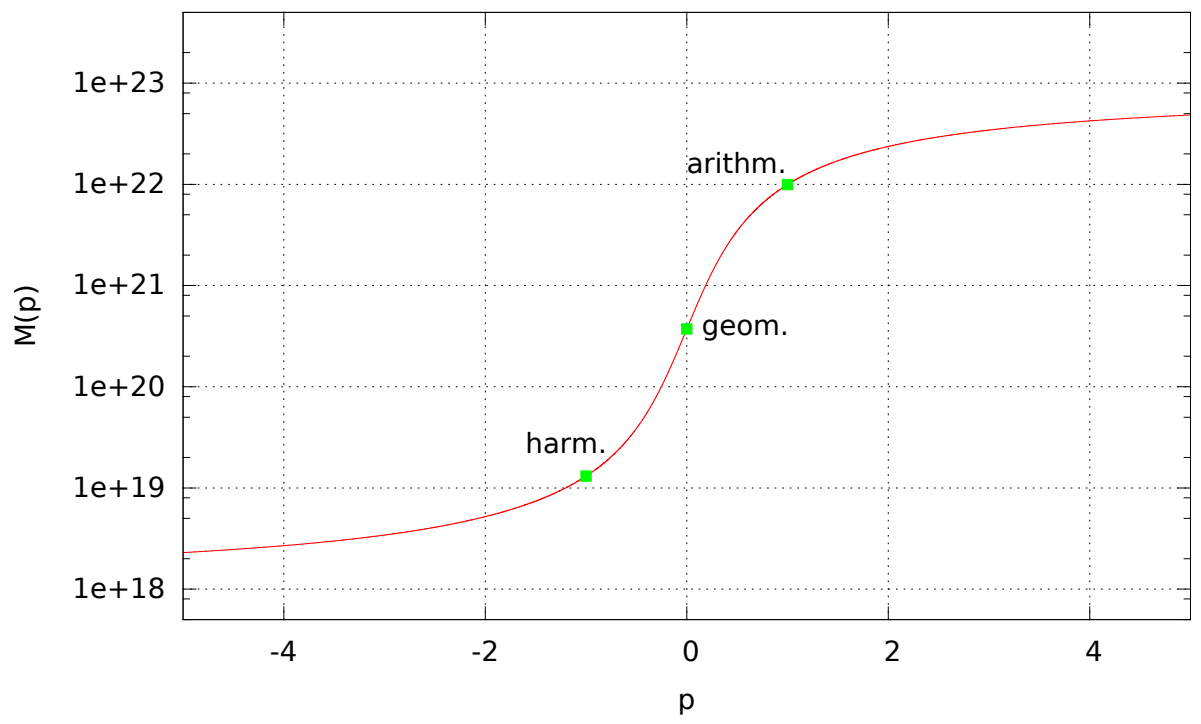

SED

6, 1949-2096, 2014

\section{ELEFANT}

C. Thieulot

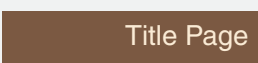

\section{Abstract}

Introduction

Conclusions References

Tables

Figures

14

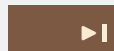

4

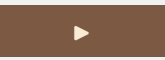

Back

Close

Full Screen / Esc

Figure 5. Computed generalised average of randomly generated viscosities.

Printer-friendly Version

Interactive Discussion

() (1) 


\section{SED}

6, 1949-2096, 2014
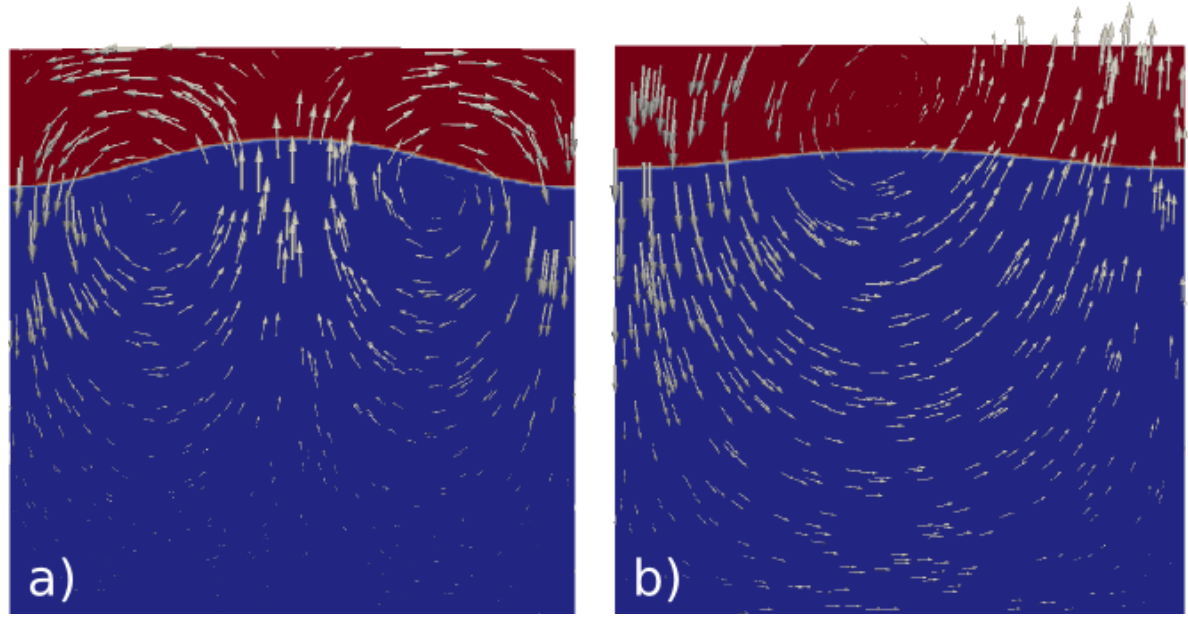

Figure 6. (a) Material and velocity fields at $t=2 \mathrm{Myr}$ with $\delta t=1000 \mathrm{yr}$; (b) material and velocity fields at $t=0.5 \mathrm{Myr}$ with $\delta t=4000 \mathrm{yr}$ in the absence of stabilisation. ALE algorithm is used and stabilisation is applied to the upper row of elements. The red fluid is characterised by $\rho=3300 \mathrm{~kg} \mathrm{~m}^{-3}$ and $\mu=10^{21} \mathrm{~Pa}$ and overlays the blue fluid characterised by $\rho=3200 \mathrm{~kg} \mathrm{~m}^{-3}$ and $\mu=10^{20} \mathrm{Pas}$. The domain is $500 \mathrm{~km} \times 500 \mathrm{~km}$ and the initial interface is a sinusoidal shape of $5 \mathrm{~km}$ amplitude. Lateral boundary conditions are free slip, bottom is no-slip and the top boundary is a free surface. The grid counts $200 \times 200$ elements and each element counts an average of 16 markers.

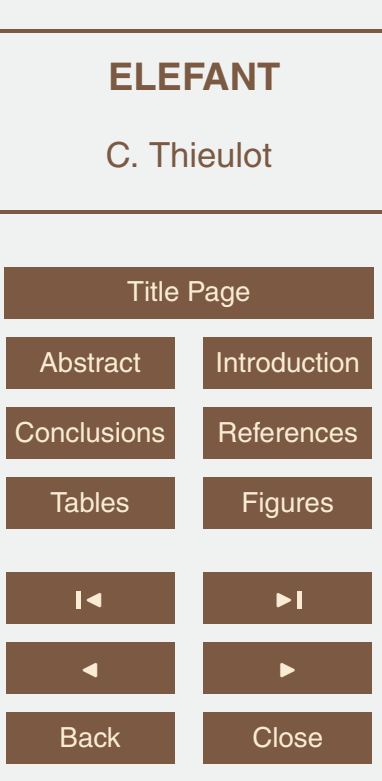

Full Screen / Esc

Printer-friendly Version

Interactive Discussion 


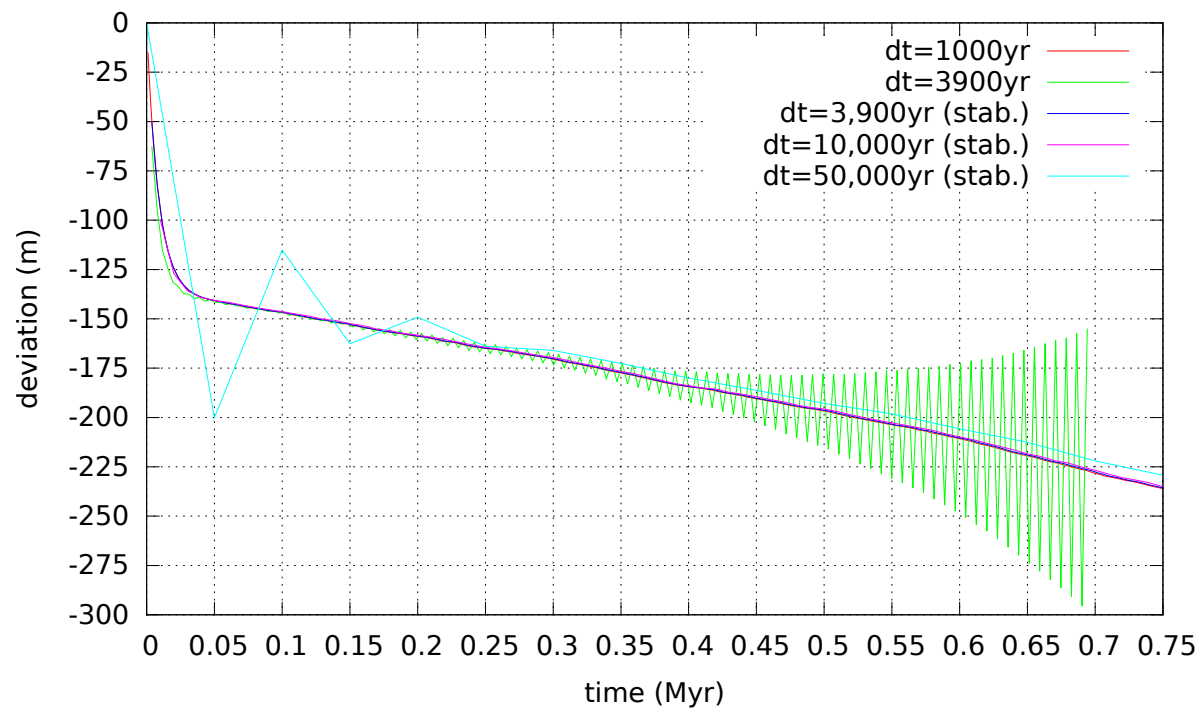

SED

6, 1949-2096, 2014

\section{ELEFANT}

C. Thieulot

Title Page

Abstract

Introduction

Conclusions References

Tables

Figures

14

$>$ I

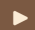

Back

Close

Full Screen / Esc

Figure 7. Time evolution of the vertical coordinate of the free surface point most right as a function of time and for various time steps.

Printer-friendly Version

Interactive Discussion

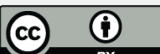



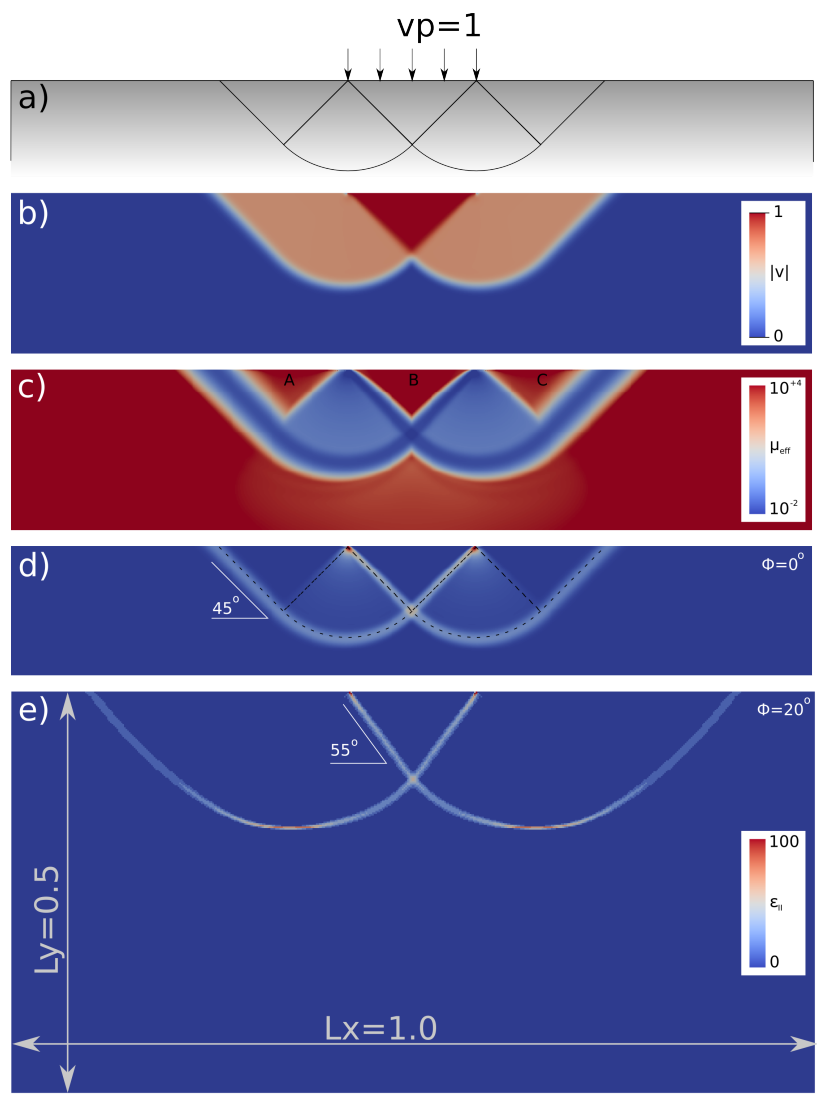

SED

6, 1949-2096, 2014

\section{ELEFANT \\ C. Thieulot}

Title Page

\section{Abstract}

Conclusions

Tables

14

Back

Full Screen / Esc

Printer-friendly Version

Interactive Discussion

Figure 8. Indenter experiment: (a) sketch of the applied boundary conditions and the expected slip-lines; (b) velocity vector magnitude; (c) effective viscosity; (d) strain rate field (square root of the second invariant) in the case $\phi=0^{\circ}$; (e) strain rate field when the angle of friction is set to $20^{\circ}$. 


\section{SED}

6, 1949-2096, 2014

pressure under the punch rough punch

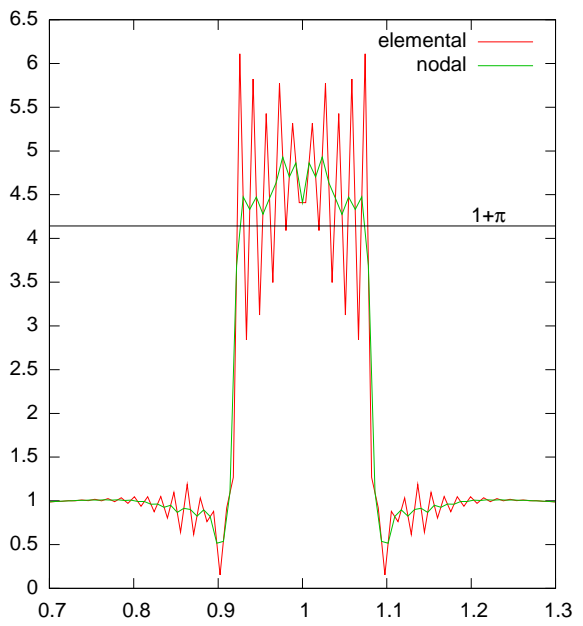

smooth punch

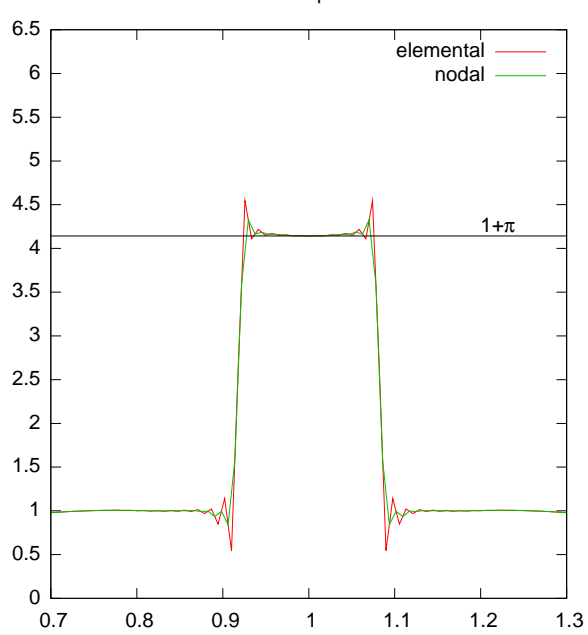

Figure 9. Indenter experiment: the left panel shows the elemental and nodal pressure values measured at the free surface in the case of a so-called rough punch (vertical component of the velocity under the punch set to zero), while the right panel shows the same fields in the case of a smooth punch (vertical component of the velocity under the punch left free).

\section{ELEFANT}

C. Thieulot

\section{Title Page}

Abstract

Introduction

Conclusions

References

Tables

Figures

14

$>$ I

Back

Close

Full Screen / Esc

Printer-friendly Version

Interactive Discussion 

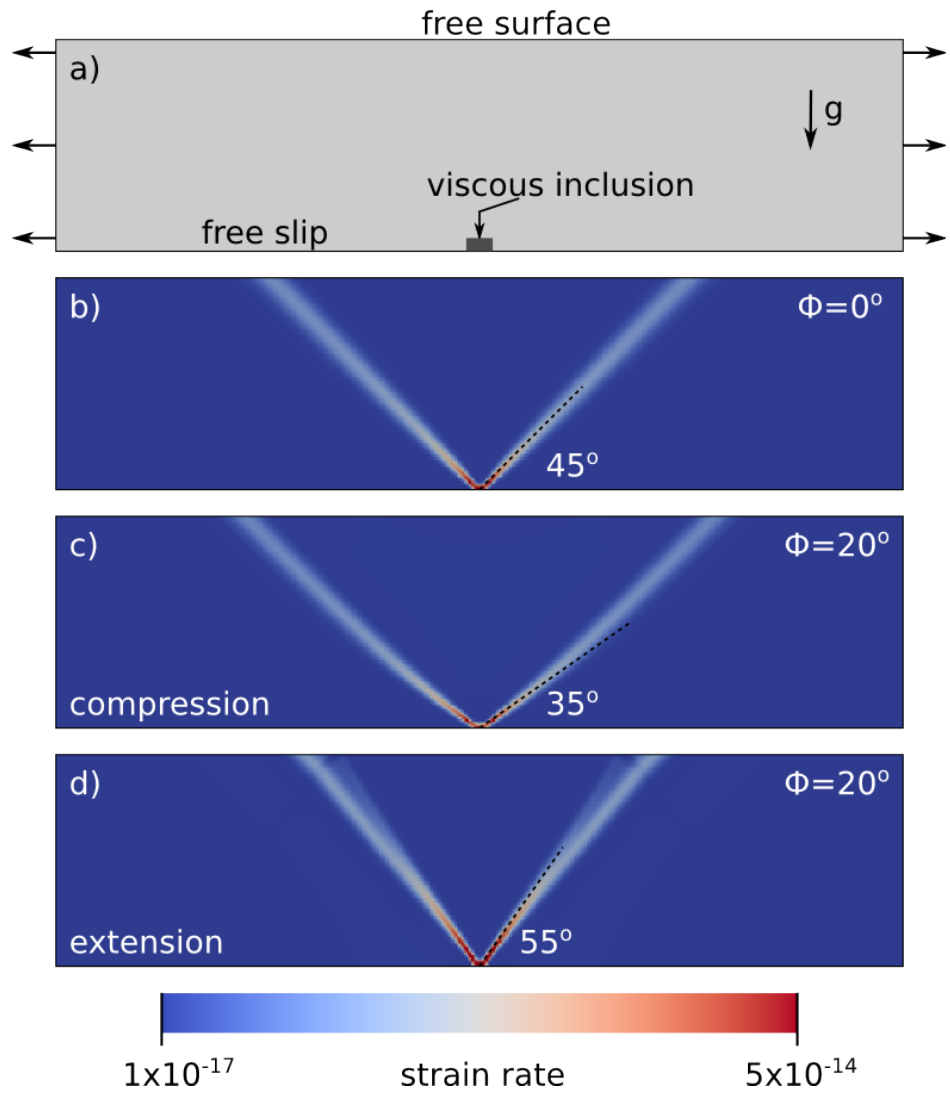

Figure 10. (a) Setup of the brick experiment; (b) shear bands for $\phi=0^{\circ}$; (c) shear bands for $\phi=20^{\circ}$ in a system in compression; (d) shear bands for $\phi=20^{\circ}$ in a system in extension.

\section{SED}

6, 1949-2096, 2014

\section{ELEFANT \\ C. Thieulot}

Title Page

Abstract

Introduction

Conclusions

References

Tables

Figures

14

$>$ I

4

Back

Close

Full Screen / Esc

Printer-friendly Version

Interactive Discussion 


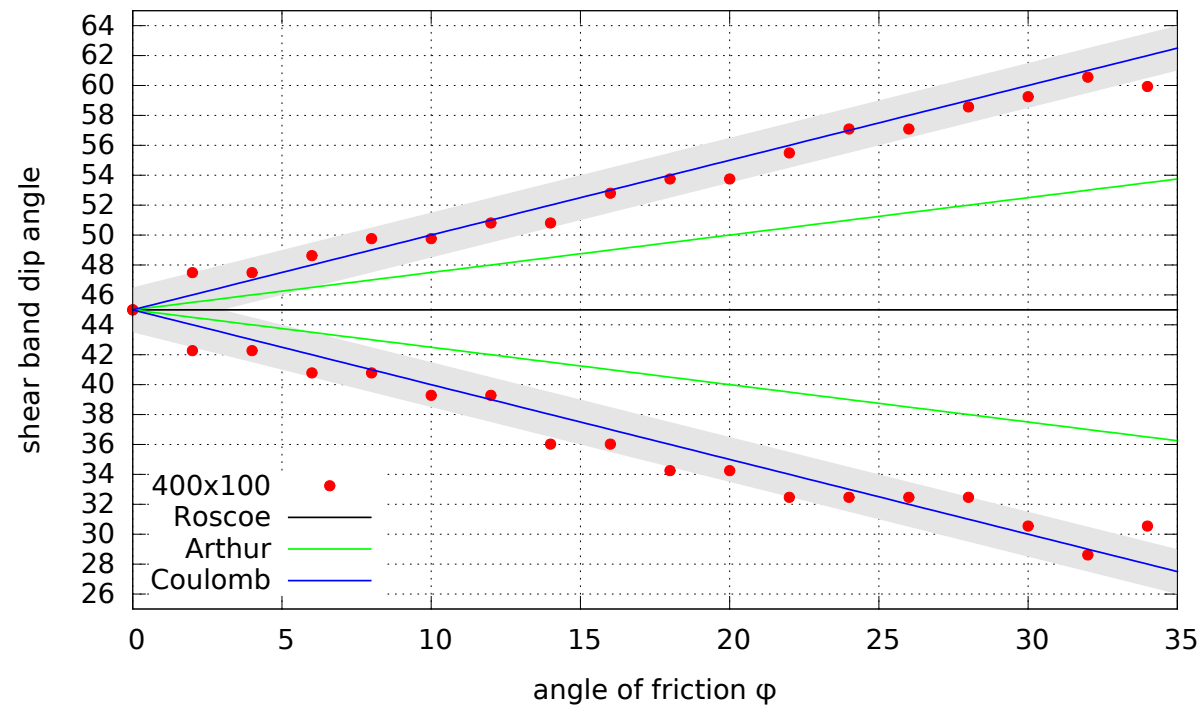

SED

6, 1949-2096, 2014

\section{ELEFANT}

C. Thieulot

\section{Title Page}

\section{Abstract}

Introduction

Conclusions

References

Tables

Figures

14

$>$ I

Back

Close

Full Screen / Esc

Figure 11. Brick experiment: effect of friction angle on resulting shear band angle. The grey area indicates $\mathrm{a} \pm 1.5^{\circ}$ domain around the analytical Coulomb value.

Printer-friendly Version

Interactive Discussion

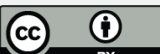




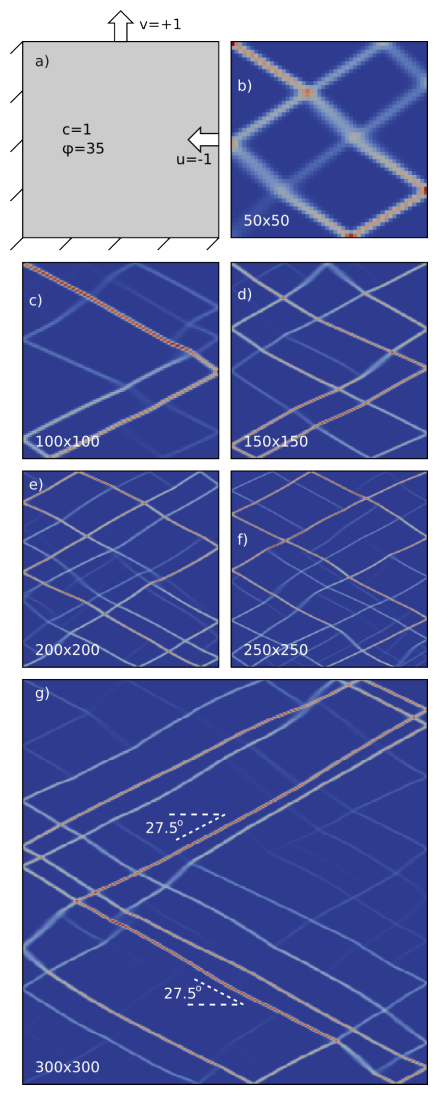

\section{SED}

6, 1949-2096, 2014

\section{ELEFANT}

C. Thieulot

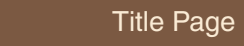

Abstract

Introduction

Conclusions

References

Tables

Figures

14

$>$ I

$>$

Back

Close

Full Screen / Esc

Printer-friendly Version

Interactive Discussion

Figure 12. Shear bands fractals experiment: (a) setup of the experiment; (b-g) shear band networks for various resolutions. 


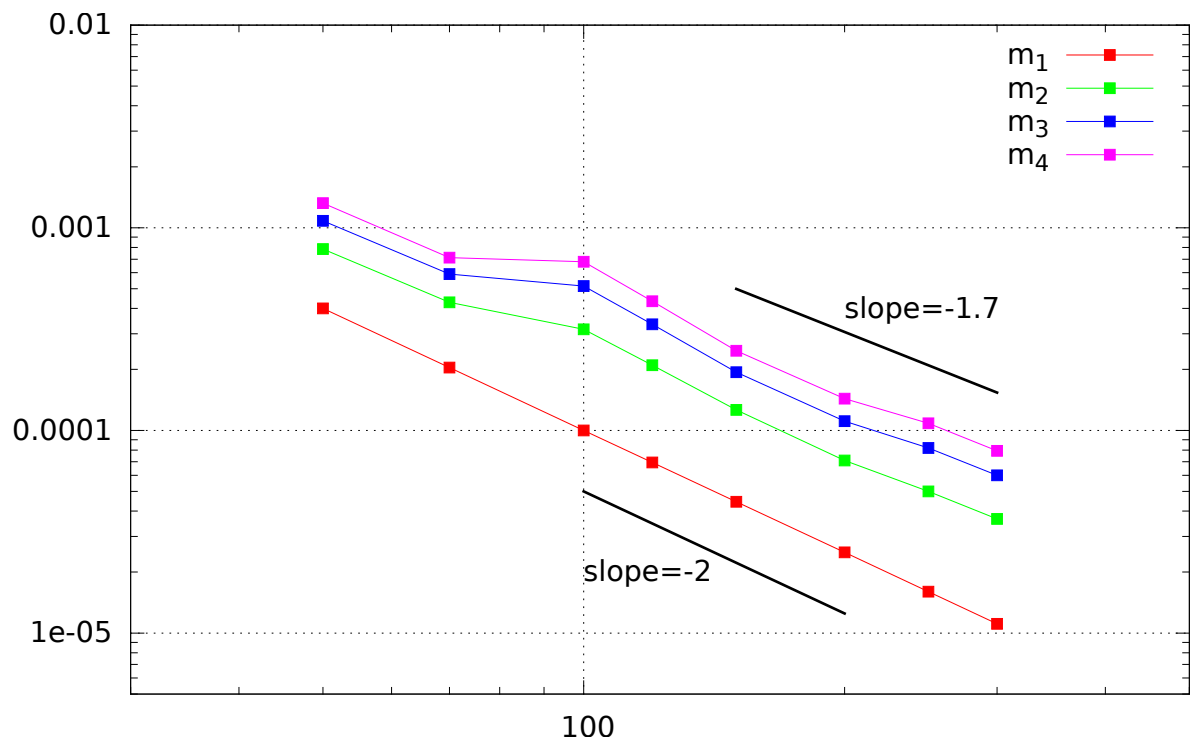

SED

6, 1949-2096, 2014

\section{ELEFANT}

C. Thieulot

\section{Title Page}

Abstract

Introduction

Conclusions

References

Tables

Figures

14

$\rightarrow 1$

$\rightarrow$

Back

Close

Full Screen / Esc

Figure 13. Shear bands fractals experiment: first, second, third and fourth normalised moments measured as a function of resolution.

Printer-friendly Version

Interactive Discussion

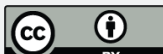



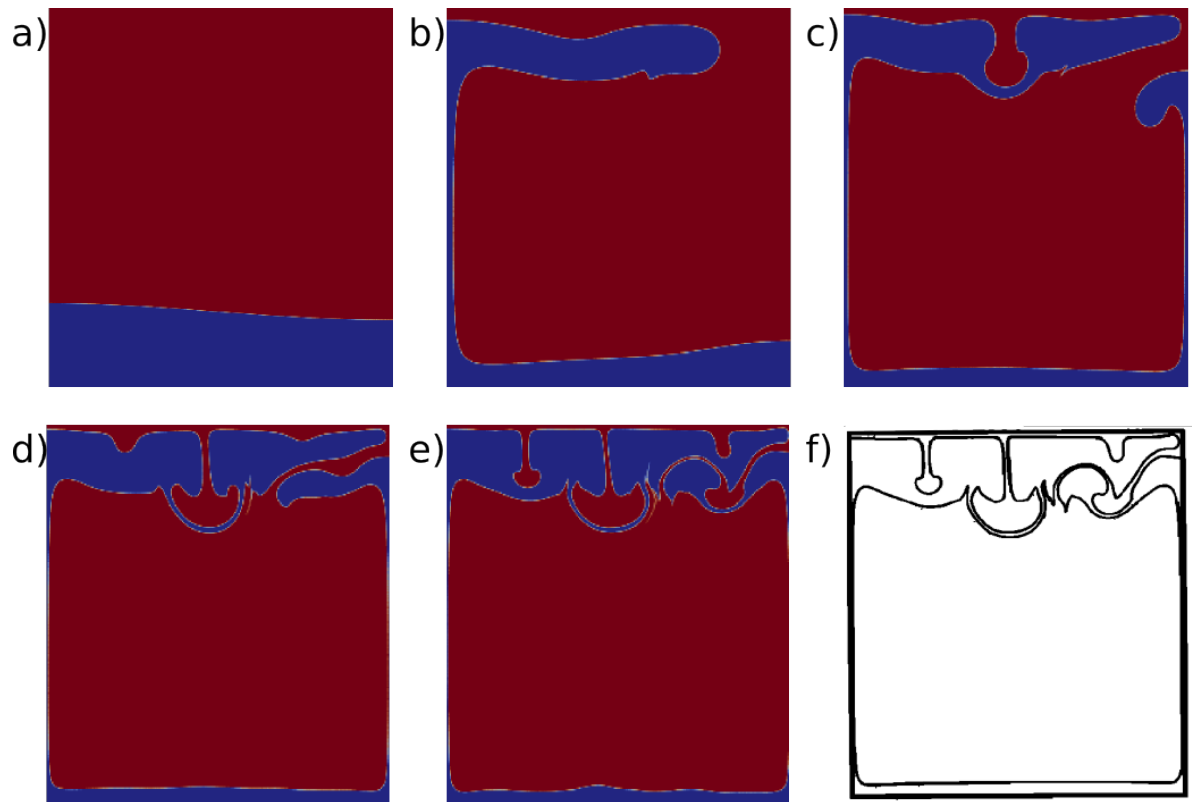

Figure 14. Rayleigh-Taylor instability experiment: (a-e) time evolution of the Rayleigh-Taylor instability experiment $(t=0,500,1000,1500,2000$ respectively); (f) fluids interface as shown in van Keken et al. (1997) at time $t=2000$.

\section{SED}

6, 1949-2096, 2014

\section{ELEFANT \\ C. Thieulot}

Title Page

\section{Abstract}

Introduction

Conclusions

References

Tables

Figures

14

$\triangleright 1$

4

Back

Close

Full Screen / Esc

Printer-friendly Version

Interactive Discussion 


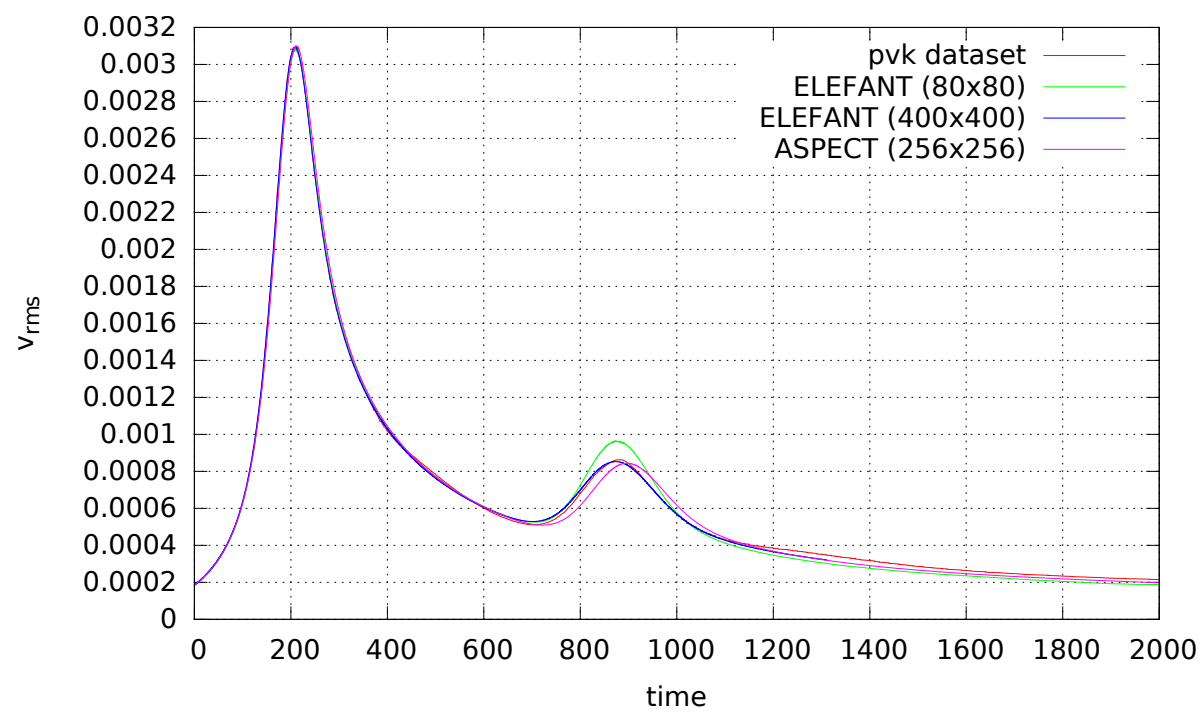

Figure 15. Rayleigh-Taylor instability experiment: root mean square velocity as a function of time.

\section{SED}

6, 1949-2096, 2014

\section{ELEFANT}

C. Thieulot

\section{Title Page}

Abstract

Introduction

Conclusions

References

Tables

Figures

14

$\rightarrow 1$

$\triangleright$

Back

Close

Full Screen / Esc

Printer-friendly Version

Interactive Discussion 


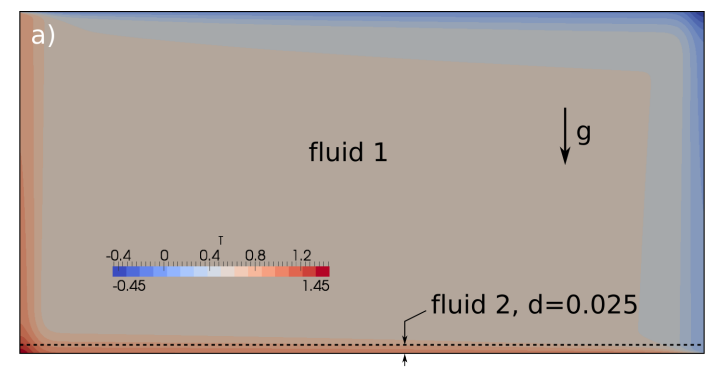

\section{SED}

6, 1949-2096, 2014

\section{ELEFANT \\ C. Thieulot}

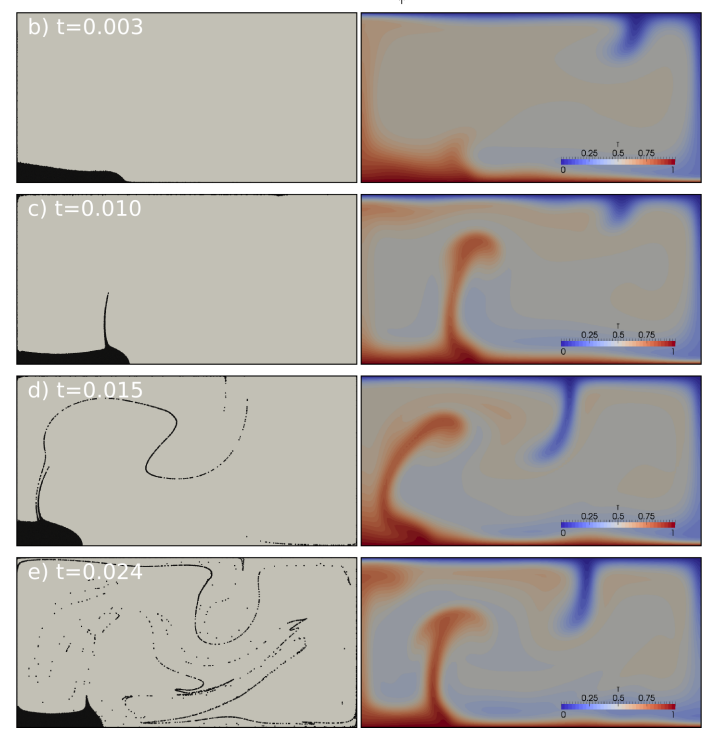

Title Page

Abstract

Introduction

Conclusions References

Tables

Figures

14

4

Back

$>$

Full Screen / Esc

Printer-friendly Version

Interactive Discussion

Figure 16. Thin layer entrainment experiment: (a) thermal setup of the experiment. (b-e) snapshots of the tracer distribution and temperature field in the $120 \times 60$ grid experiment. 


\section{SED}

6, 1949-2096, 2014

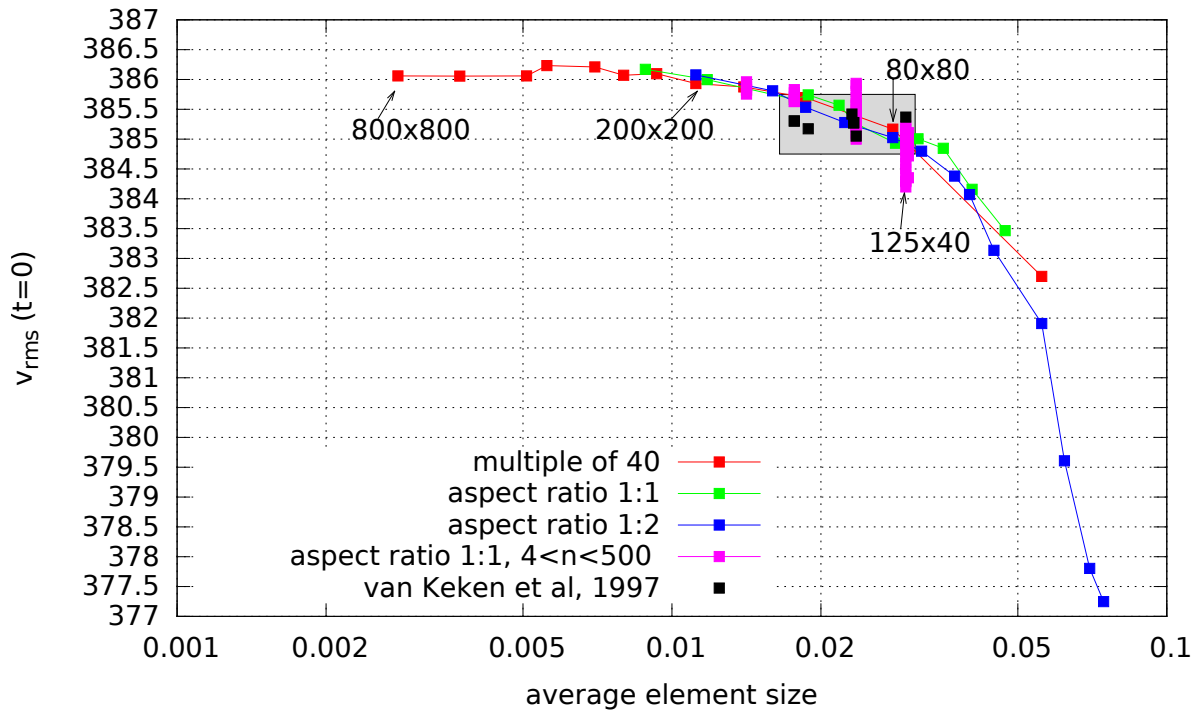

\section{ELEFANT}

C. Thieulot

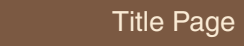

Abstract

Introduction

Conclusions

References

Tables

Figures

14

$>$ I

$\triangleright$

Back

Close

Full Screen / Esc

Printer-friendly Version

Interactive Discussion

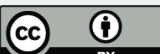




\section{SED}

6, 1949-2096, 2014

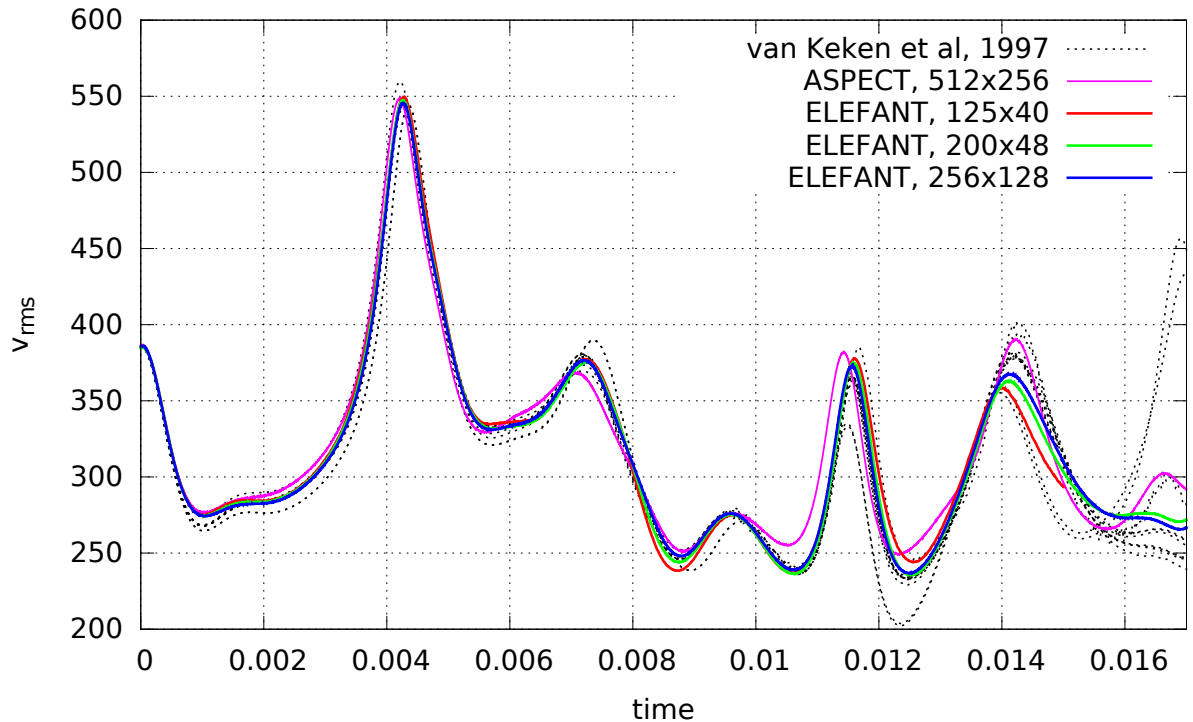

\section{ELEFANT}

C. Thieulot

\section{Title Page}

Abstract

Introduction

Conclusions

References

Tables

Figures

14

$>1$

$\checkmark$

Back

Close

Full Screen / Esc

Figure 18. Thin layer entrainment experiment. Root mean square velocity as a function of time. All results presented in van Keken et al. (1997) are collapsed in dashed lines. All simulations were run with an initial marker density of 100 markers per element and with a Courant number of 0.25 .

Printer-friendly Version

Interactive Discussion 


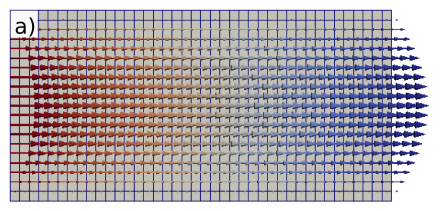

b)

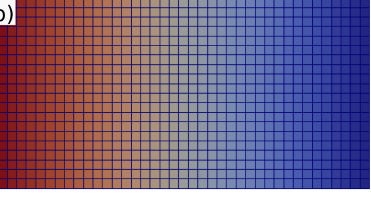

pressure
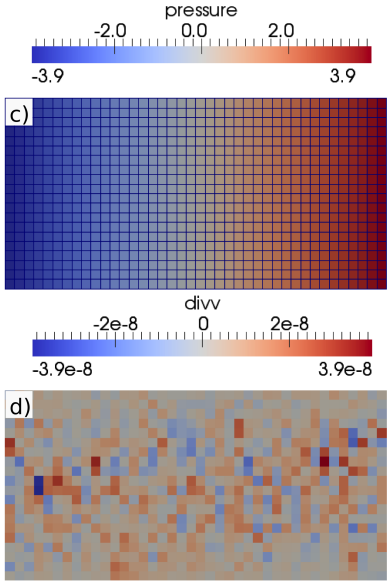

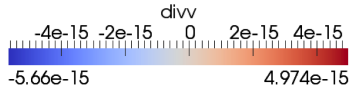

Figure 19. Poiseuille flow experiment: (a) velocity field; (b) computed pressure; (c) divergence field (no pressure iteration); (d) divergence field (1 pressure iteration).
SED

6, 1949-2096, 2014

\section{ELEFANT}

C. Thieulot

Title Page

Abstract

Introduction

Conclusions

References

Tables

Figures

14

Back

Close

Full Screen / Esc

Printer-friendly Version

Interactive Discussion 


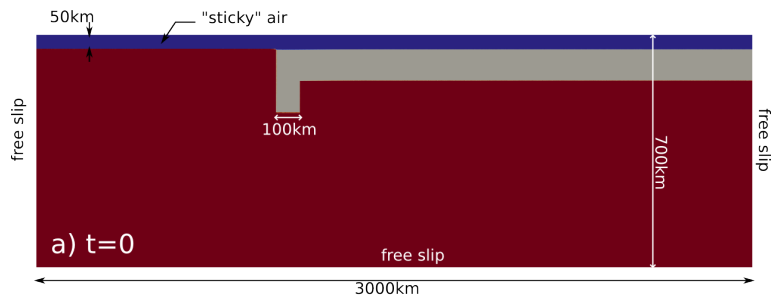

SED

6, 1949-2096, 2014

\section{ELEFANT \\ C. Thieulot}

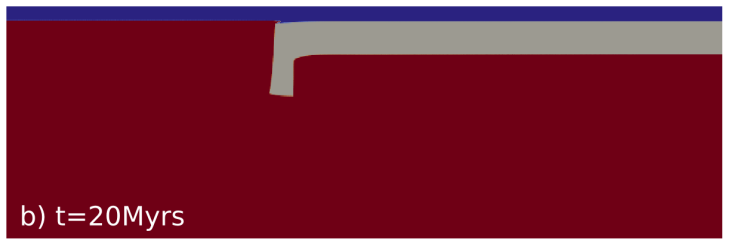

Title Page

Abstract

Introduction

Conclusions References

Tables

Figures

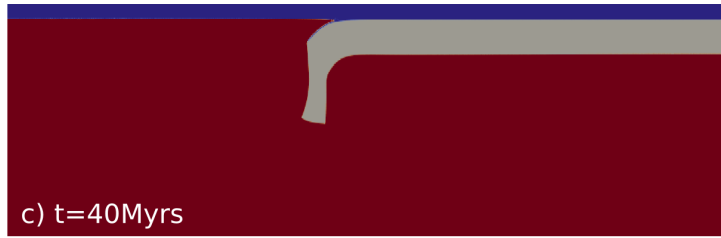

14

4

Back

Close

Full Screen / Esc

Printer-friendly Version

Interactive Discussion

(ब) (1) 

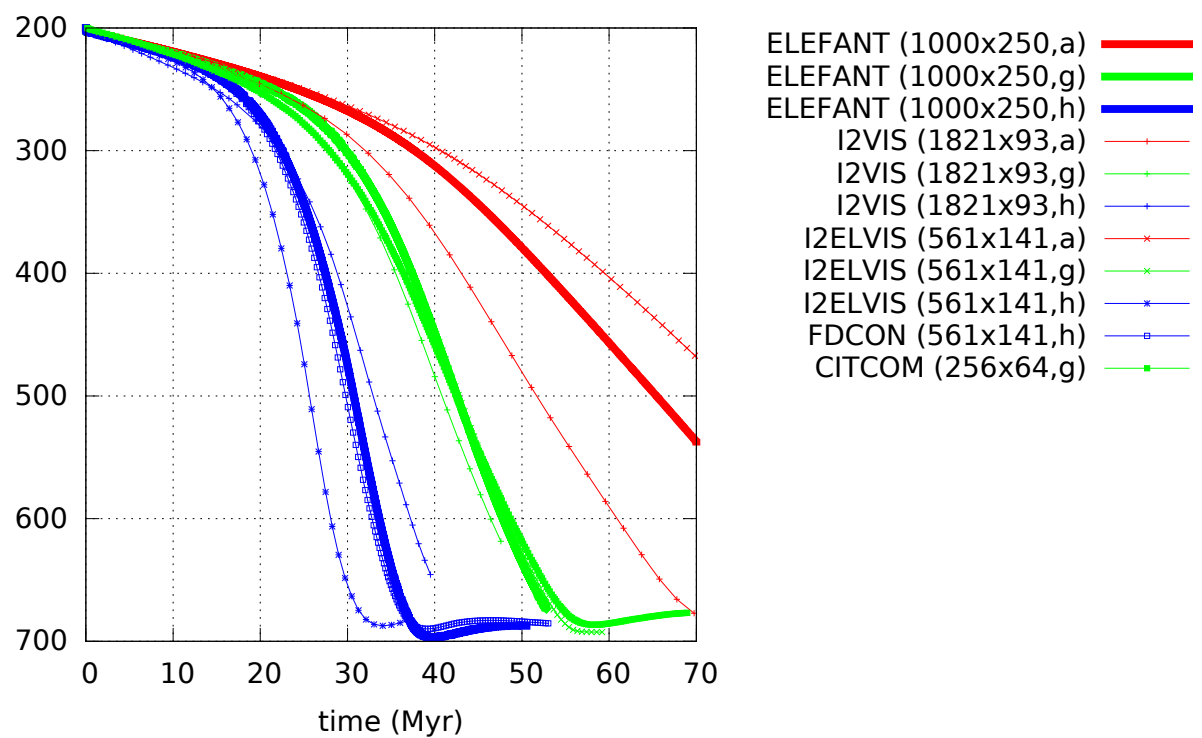

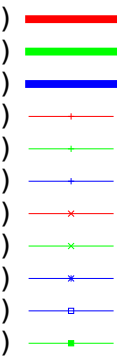

Figure 21. Subduction benchmark: slab tip depth as a function of time. "a" stands for arithmetic averaging, "g" for geometric and " $h$ " for harmonic.
SED

6, 1949-2096, 2014

\section{ELEFANT}

C. Thieulot

\section{Title Page}

Abstract

Introduction

Conclusions

References

Tables

Figures

14

$\triangleright$ I

4

Back

Close

Full Screen / Esc

Printer-friendly Version

Interactive Discussion 

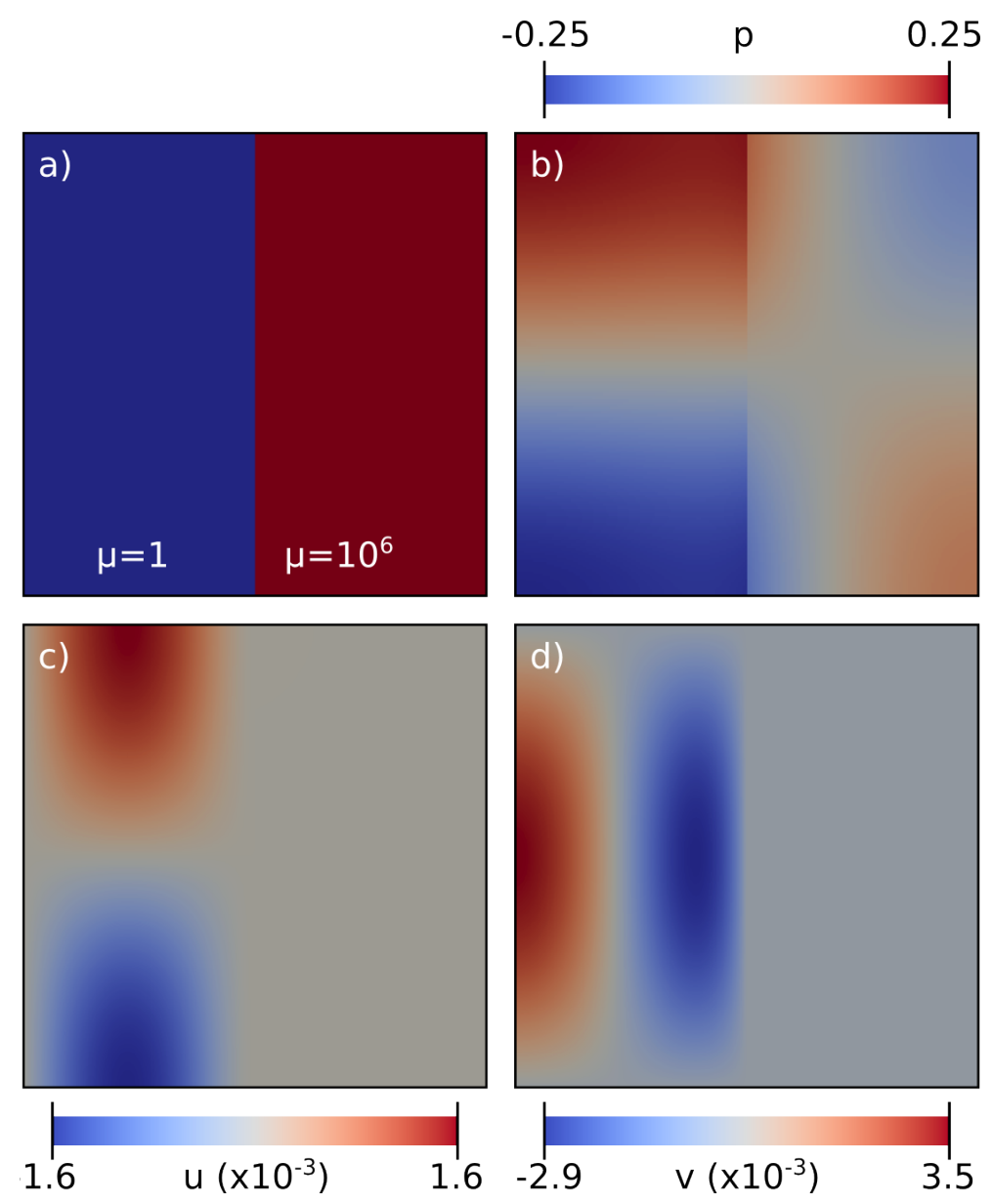

SED

6, 1949-2096, 2014

\section{ELEFANT \\ C. Thieulot}

Title Page

Abstract

Introduction

Conclusions

References

Tables

Figures

14

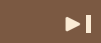

4

Back

Close

Full Screen / Esc

Printer-friendly Version

Interactive Discussion

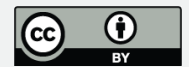

Figure 22. SolCx experiment: (a) viscosity field; (b) pressure field; (c) horizontal velocity field $u$; (d) vertical velocity field $v$. 


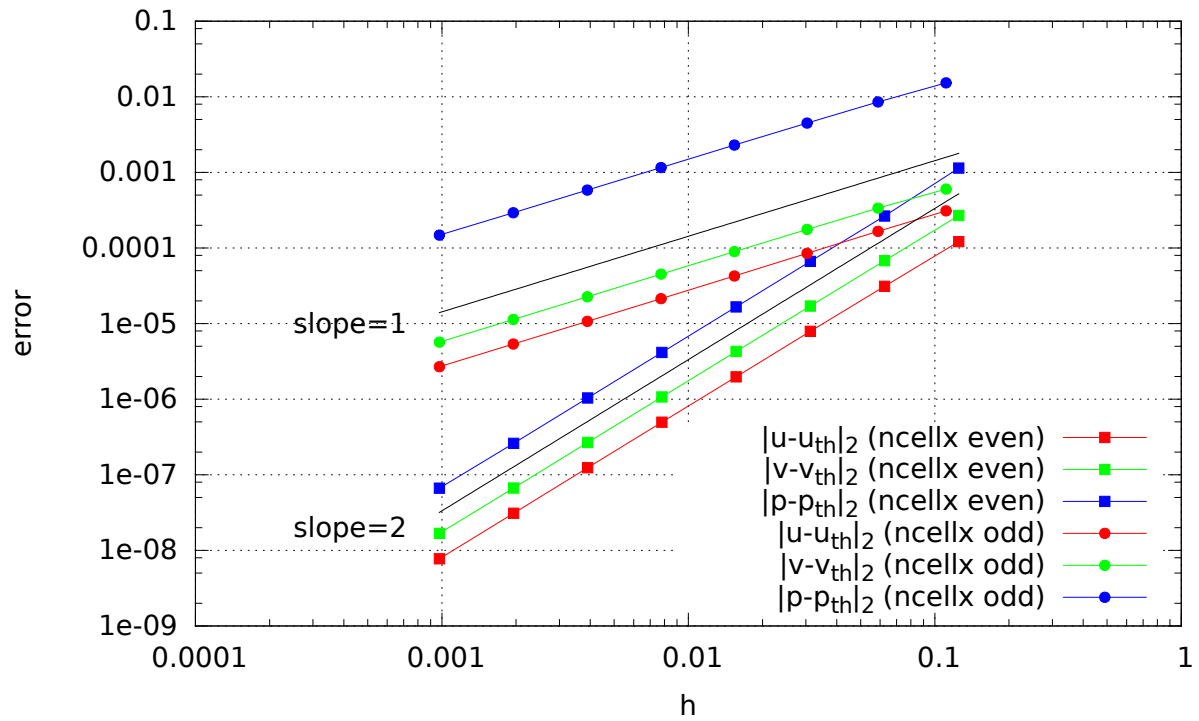

SED

6, 1949-2096, 2014

\section{ELEFANT}

C. Thieulot

\section{Title Page}

\section{Abstract}

Introduction

Conclusions

References

Tables

Figures

14

Back

Close

Full Screen / Esc

Figure 23. SolCx experiment: $L_{2}$ errors for various fields as a function of the elements size (grids ranging from $8 \times 8$ to $1024 \times 1024$ ).

Printer-friendly Version

Interactive Discussion

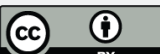




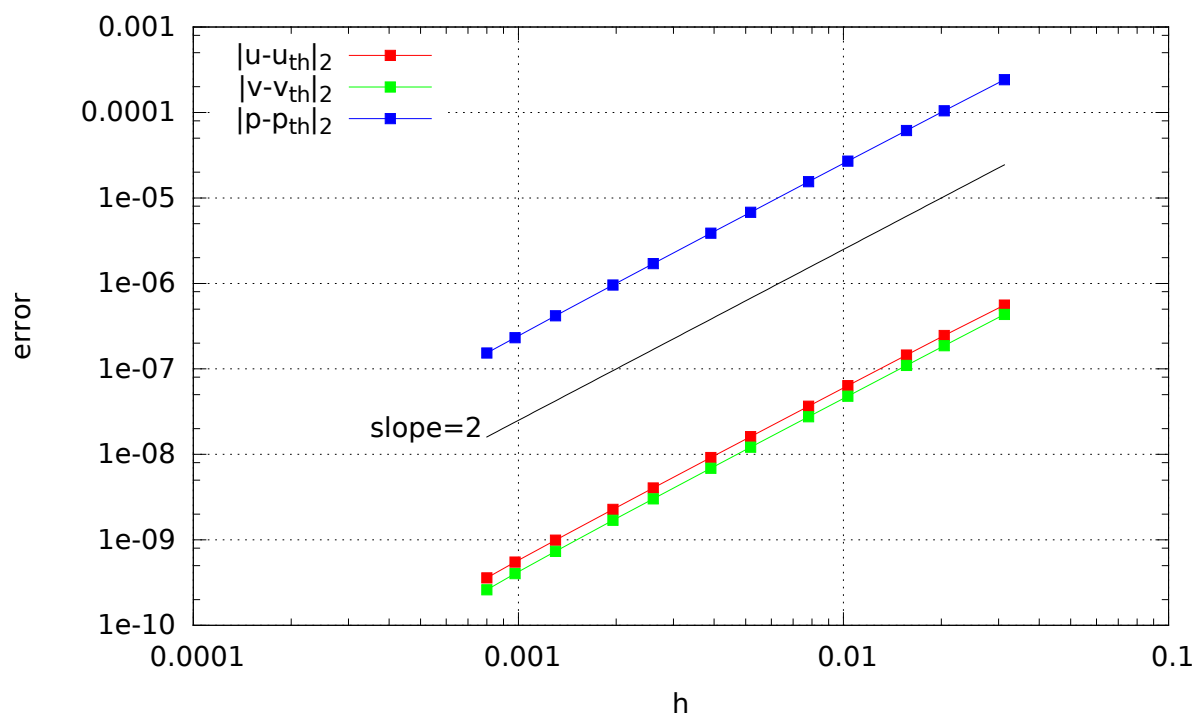

SED

6, 1949-2096, 2014

\section{ELEFANT}

C. Thieulot

Title Page

Abstract

Introduction

Conclusions

References

Tables

Figures

14

$\rightarrow 1$

4

$\checkmark$

Back

Close

Full Screen / Esc

Figure 24. SolKz experiment: absolute errors for various fields as a function of the elements size (grids ranging from $16 \times 16$ to $1250 \times 1250$ ).

Printer-friendly Version

Interactive Discussion

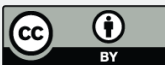



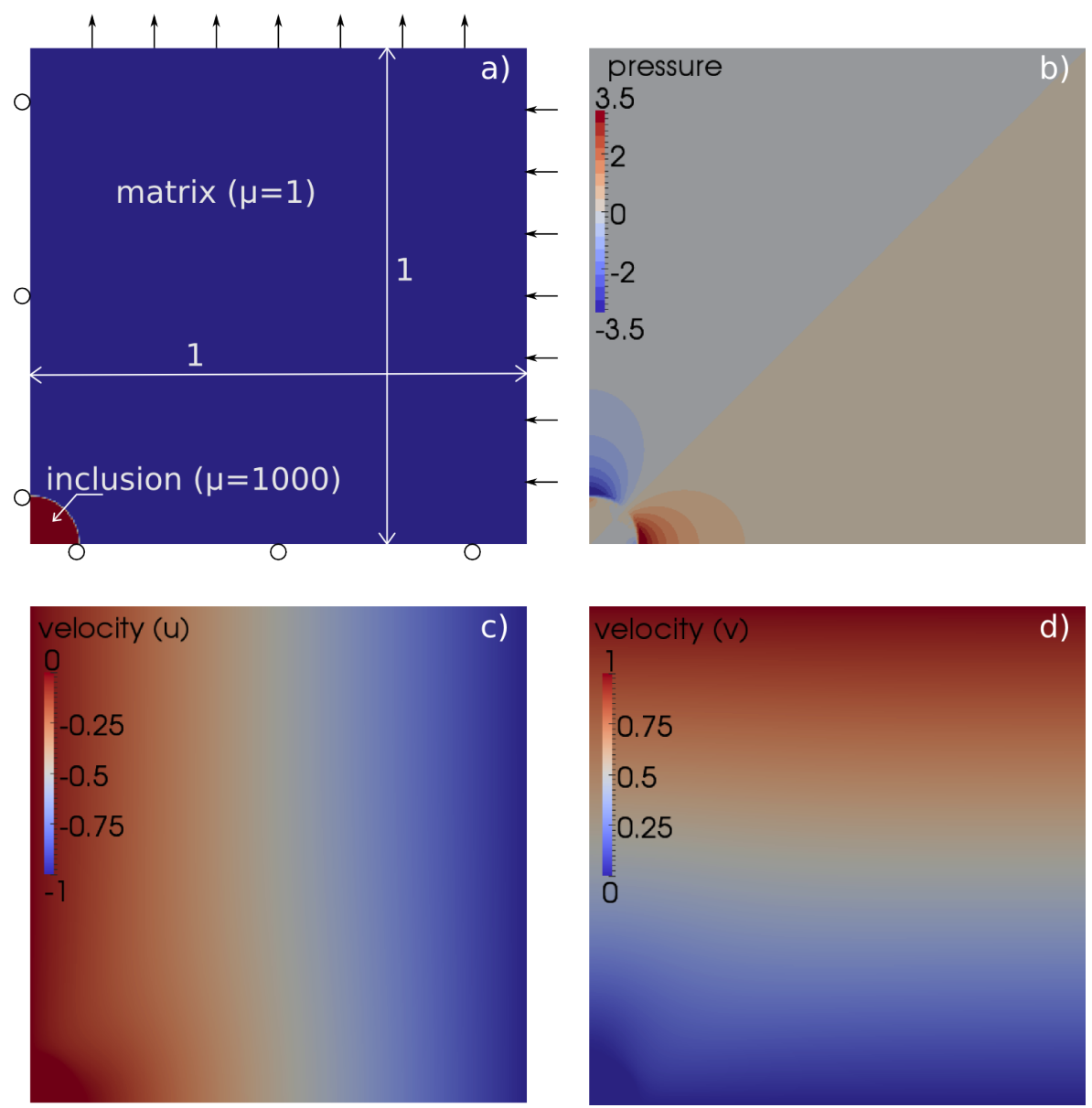

Figure 25. SolVi experiment: (a) setup; (b) nodal pressure field; (c) horizontal velocity field; (d) vertical velocity field.

\section{SED}

6, 1949-2096, 2014

\section{ELEFANT \\ C. Thieulot}

Title Page

Abstract

Introduction

Conclusions

References

Tables

Figures

14

$>$ I

4

Back

Close

Full Screen / Esc

Printer-friendly Version

Interactive Discussion 


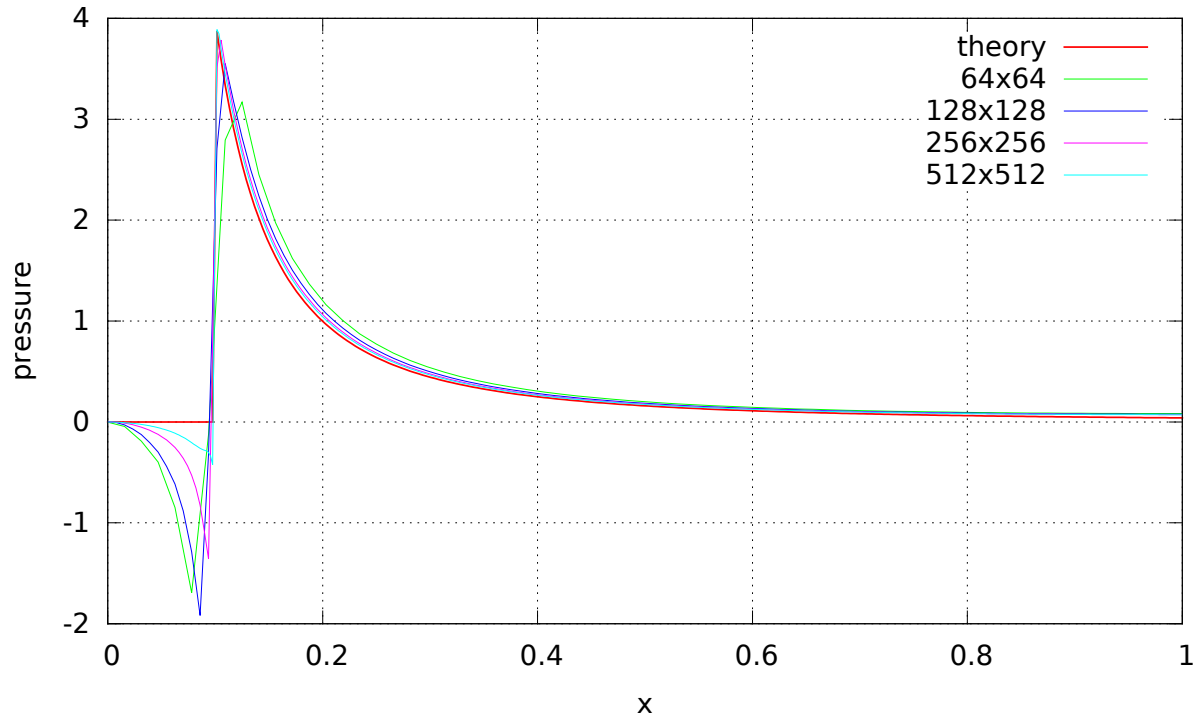

Figure 26. SolVi experiment: pressure measurements at $y=0$ for various resolutions.

\section{SED}

6, 1949-2096, 2014

\section{ELEFANT}

C. Thieulot

\section{Title Page}

Abstract

Introduction

Conclusions

References

Tables

Figures

14

$>$ I

Back

Close

Full Screen / Esc

Printer-friendly Version

Interactive Discussion 


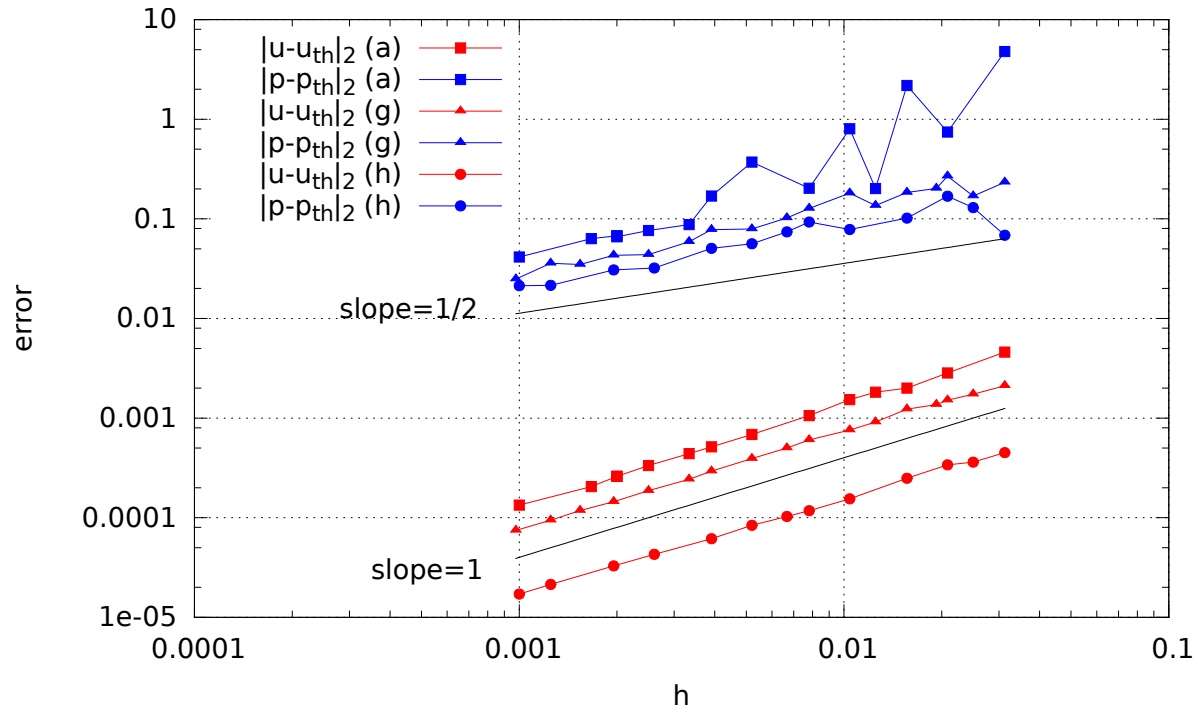

Figure 27. SolVi experiment: horizontal velocity component $u$ and elemental pressure error measurements in the $L_{2}$-norm as a function of the element size $h$. (a) stands for arithmetic averaging, $(\mathrm{g})$ for geometric and $(\mathrm{h})$ for harmonic.

\section{SED}

6, 1949-2096, 2014

\section{ELEFANT}

C. Thieulot

\section{Title Page}

\section{Abstract}

Introduction

Conclusions

References

Tables

Figures

14

$\triangleright$ I

$\checkmark$

Back

Close

Full Screen / Esc

Printer-friendly Version

Interactive Discussion 


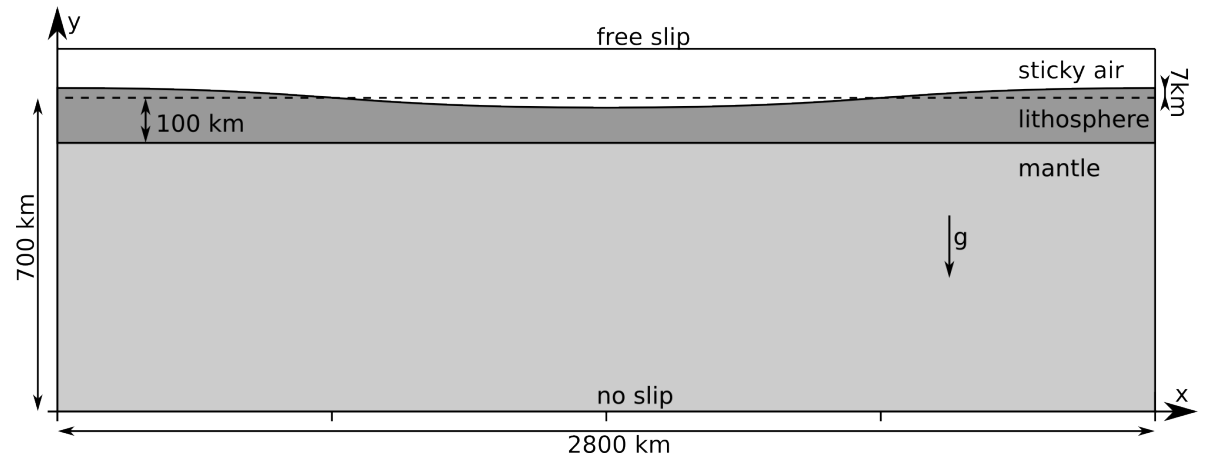

Figure 28. Setup of the free surface relaxation benchmark.

SED

6, 1949-2096, 2014

\section{ELEFANT}

C. Thieulot

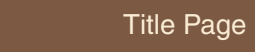

\section{Abstract}

Introduction

Conclusions

References

Tables

Figures

14

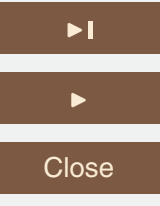

Back

Full Screen / Esc

Printer-friendly Version

Interactive Discussion

(c) (i) 


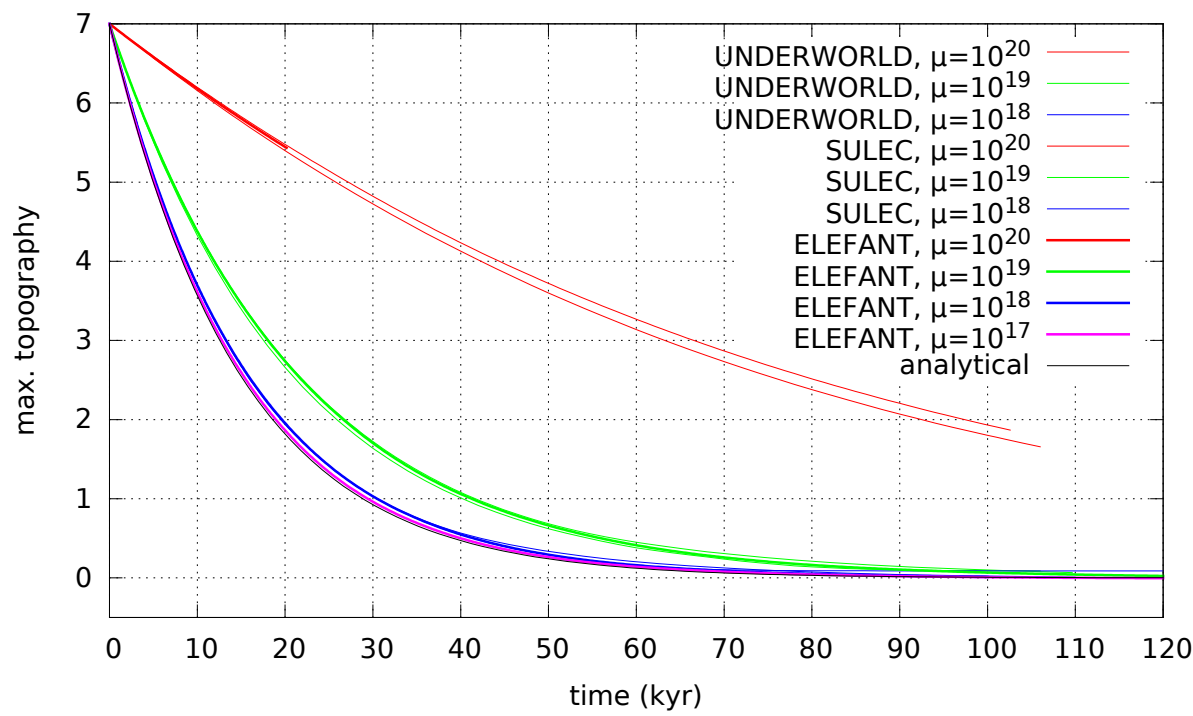

Figure 29. Free surface relaxation benchmark: time evolution of the maximum of the topography for various sticky air viscosities for ELEFANT and two others codes (SULEC and UNDERWORLD, data from Crameri et al., 2012). Curves have been colored by viscosity and thick lines represent the results obtained with ELEFANT which mostly overlap the other curves, especially at low air viscosities.

\section{ELEFANT}

C. Thieulot

\section{Title Page}

Abstract

Introduction

Conclusions

References

Tables

Figures

14

$>$ I

Back

Close

\section{Full Screen / Esc}

Printer-friendly Version

Interactive Discussion 


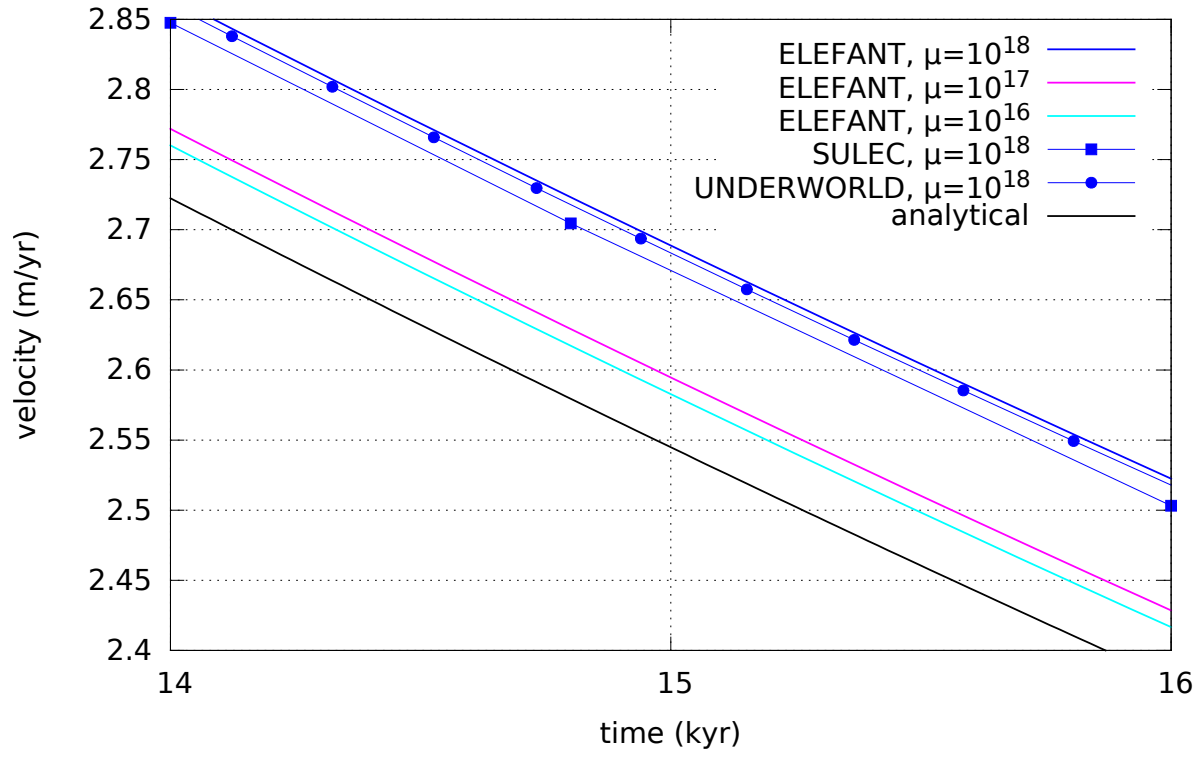

SED

6, 1949-2096, 2014

\section{ELEFANT}

C. Thieulot

\section{Title Page}

Abstract

Introduction

Conclusions

References

Tables

Figures

14

$>$ I

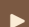

Back

Close

Full Screen / Esc

Printer-friendly Version

Interactive Discussion

(c) (i) 


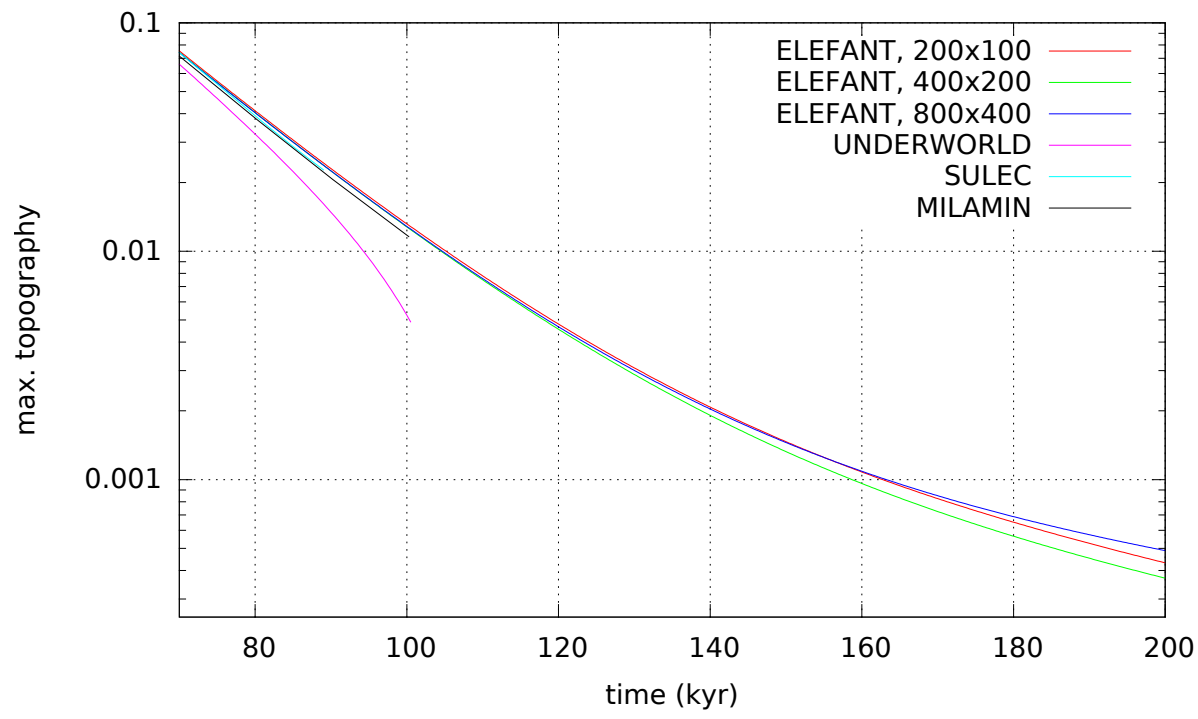

Figure 31. Free surface relaxation benchmark: late stage of the topography as a function of time in the case of ALE.

\section{SED}

6, 1949-2096, 2014

\section{ELEFANT}

C. Thieulot

\section{Title Page}

\section{Abstract}

Introduction

Conclusions

References

Tables

Figures

14

$\rightarrow 1$

Back

Close

Full Screen / Esc

Printer-friendly Version

Interactive Discussion 


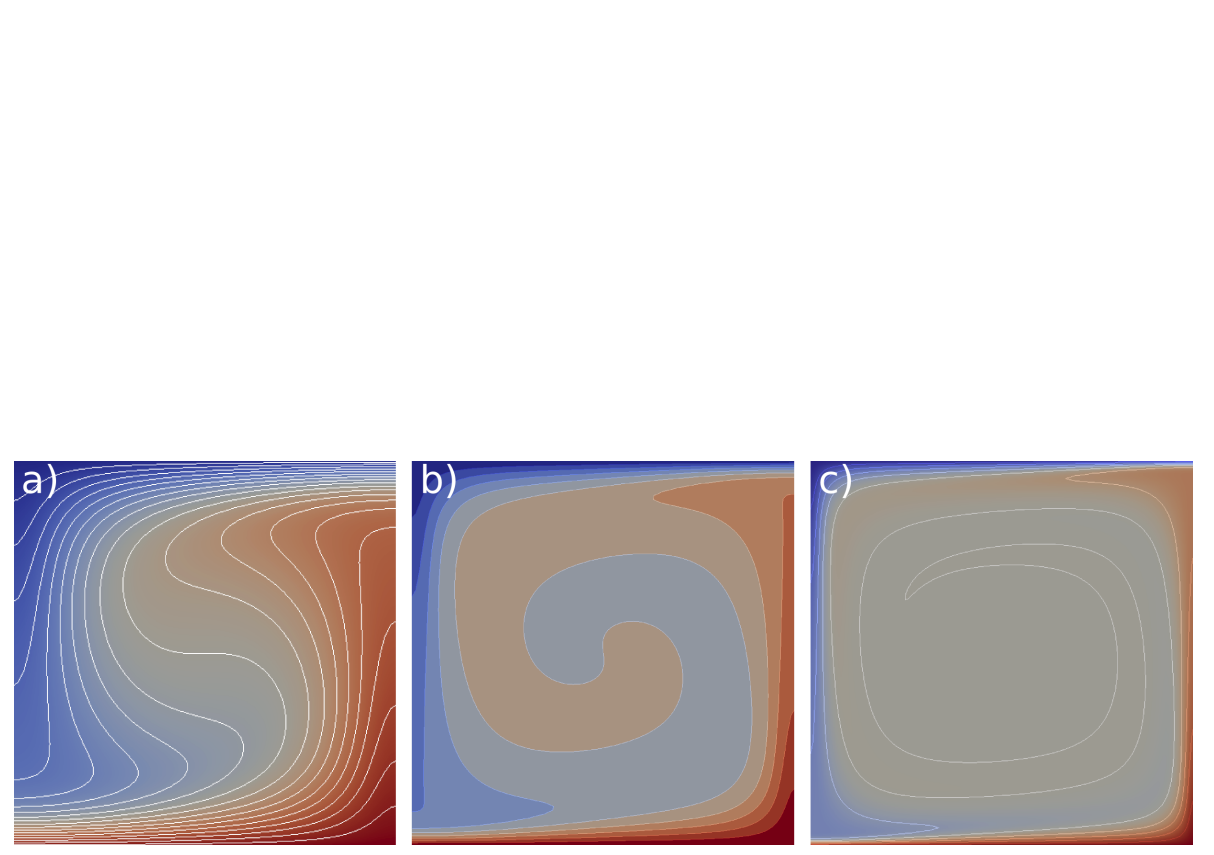

SED

6, 1949-2096, 2014

\section{ELEFANT}

C. Thieulot

\section{Title Page}

Abstract

Introduction

Conclusions

References

Tables

Figures

14 DI

4

Back

Close

White lines correspond to temperature $0.1-0.9$ isocontours.

Full Screen / Esc

Printer-friendly Version

Interactive Discussion

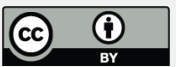




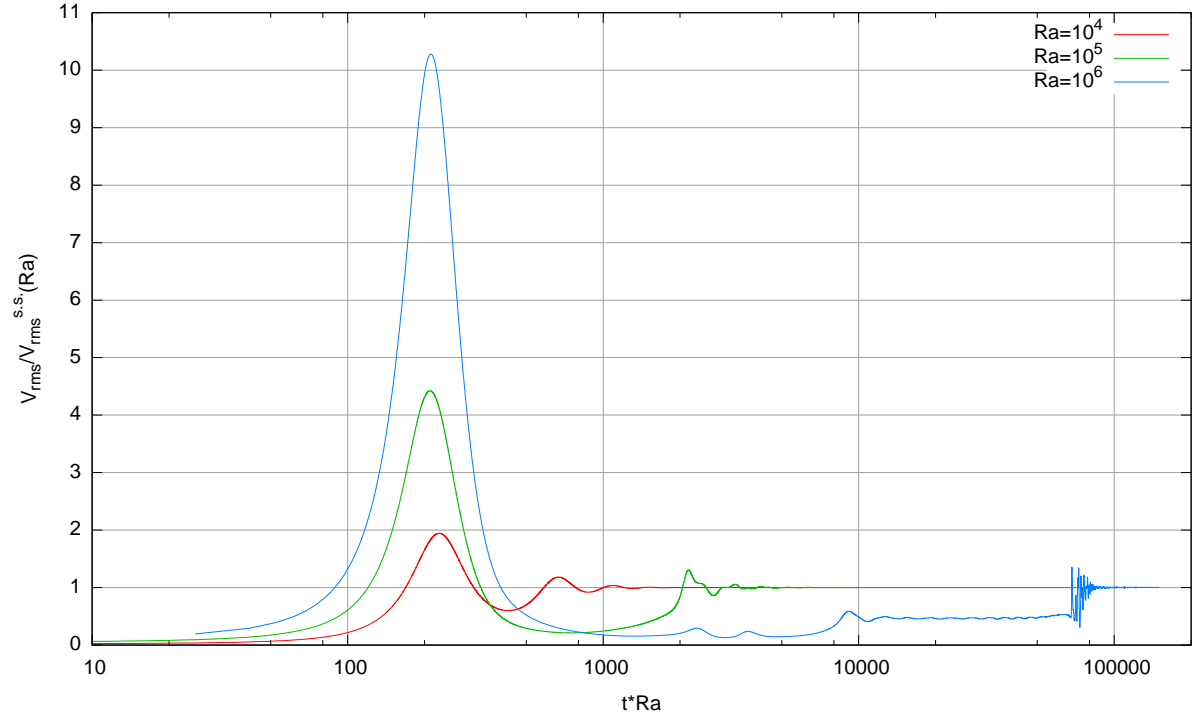

Figure 33. 2-D mantle convection benchmark: root mean square velocity as a function of time. Velocities have been adimensionalised by the reported steady state $V_{\text {rms }}$ obtained in Blankenbach et al. (1989) and times are multiplied by the Rayleigh number of each experiment for ease of plotting.
SED

6, 1949-2096, 2014

\section{ELEFANT}

C. Thieulot

\section{Title Page}

Abstract

Introduction

Conclusions

References

Tables

Figures

14

$>$ I

Back

Close

Full Screen / Esc

Printer-friendly Version

Interactive Discussion 


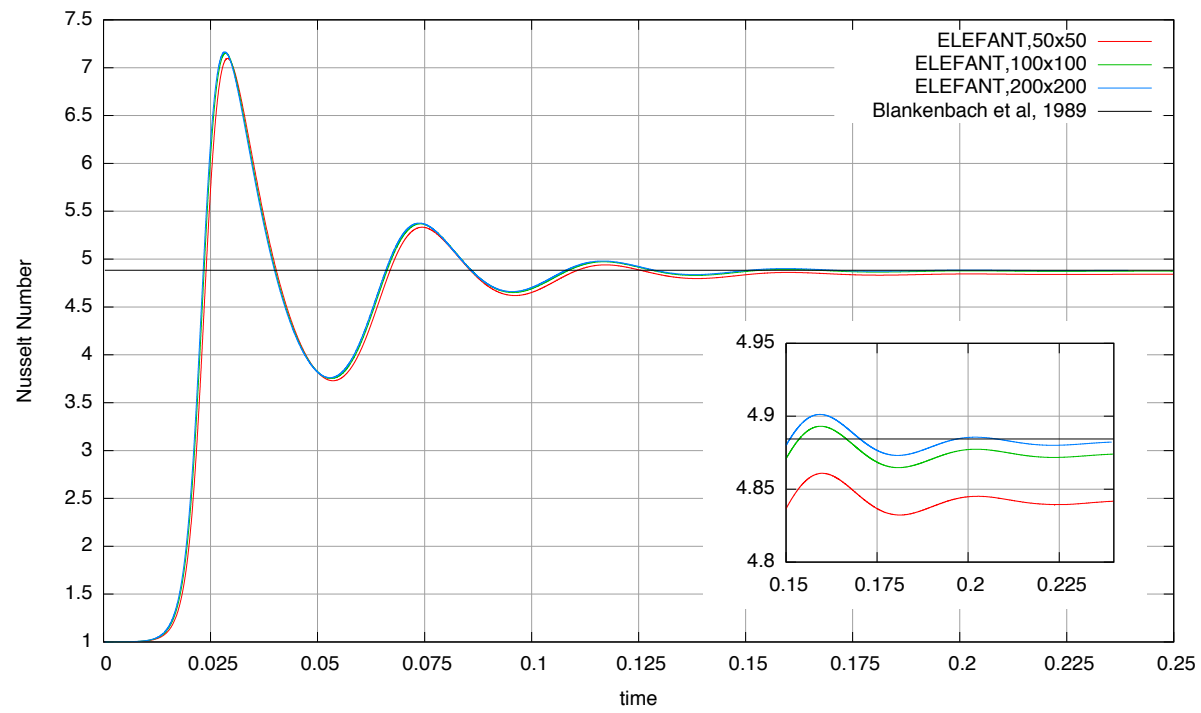

\section{SED}

6, 1949-2096, 2014

\section{ELEFANT}

C. Thieulot

\section{Title Page}

\section{Abstract}

Introduction

Conclusions

References

Tables

Figures

14

$>$

Back

Close

Full Screen / Esc

Figure 34. 2-D mantle convection benchmark: Nusselt number as a function of time for various grid resolutions (case 1a).

Interactive Discussion

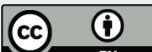




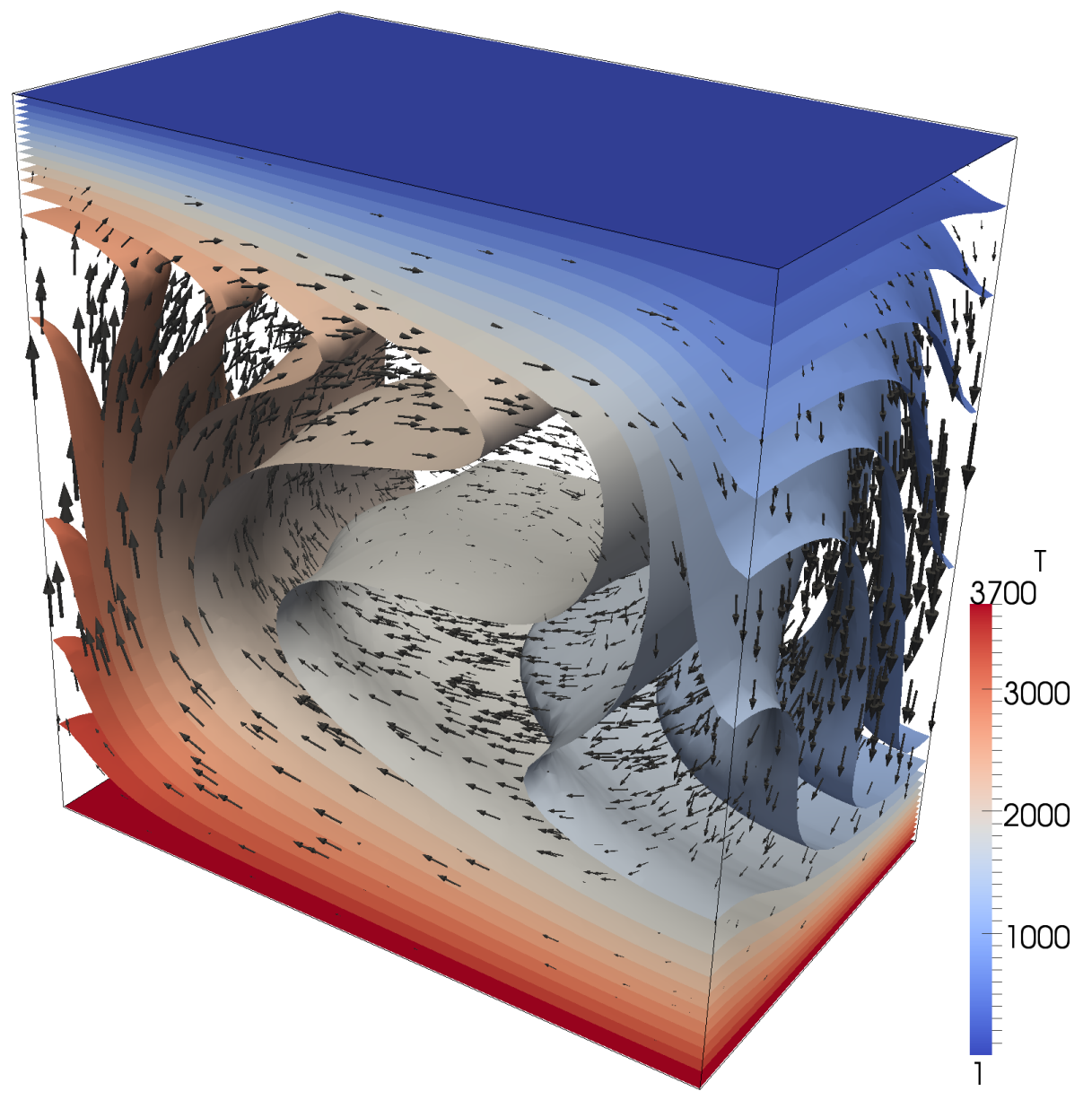

SED

6, 1949-2096, 2014

\section{ELEFANT \\ C. Thieulot}

Title Page

Abstract

Introduction

Conclusions

References

Tables

Figures

14

$\rightarrow 1$

4

Back

$\triangleright$

\section{Full Screen / Esc}

Printer-friendly Version

Interactive Discussion

Figure 35. Temperature isocontours and velocity field for the 3-D convection benchmark. 

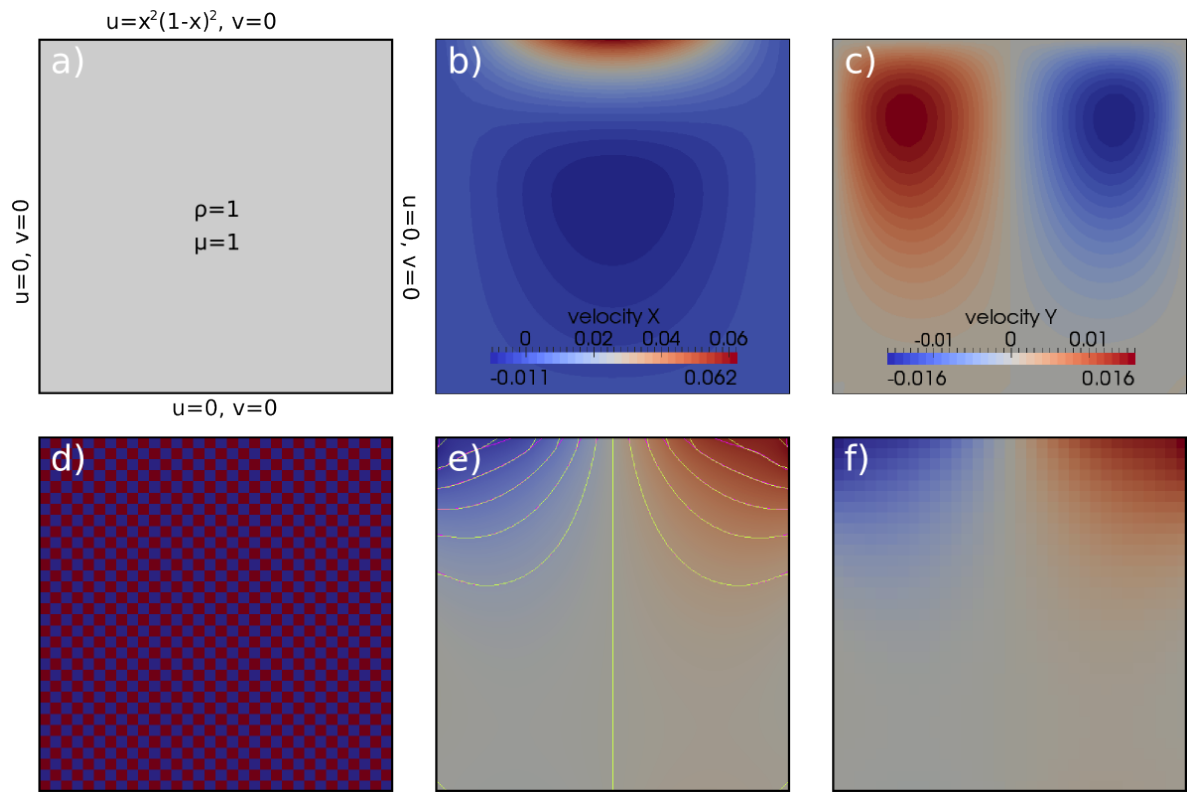

Figure 36. Lid driven cavity experiment: (a) setup of the experiment; (b) and (c) horizontal and vertical velocity components on a $256 \times 256$ grid; (d) elemental pressure on a $32 \times 32$ grid; (e) smoothed pressure isocontours of ELEFANT (green), and pressure field and isocontours of ASPECT (pink); (f) elemental pressure field with a $33 \times 33$ grid.
SED

6, 1949-2096, 2014

\section{ELEFANT}

C. Thieulot

Title Page

\section{Abstract}

Introduction

Conclusions

References

Tables

Figures

14

DI

Back

Close

Full Screen / Esc

Printer-friendly Version

Interactive Discussion 

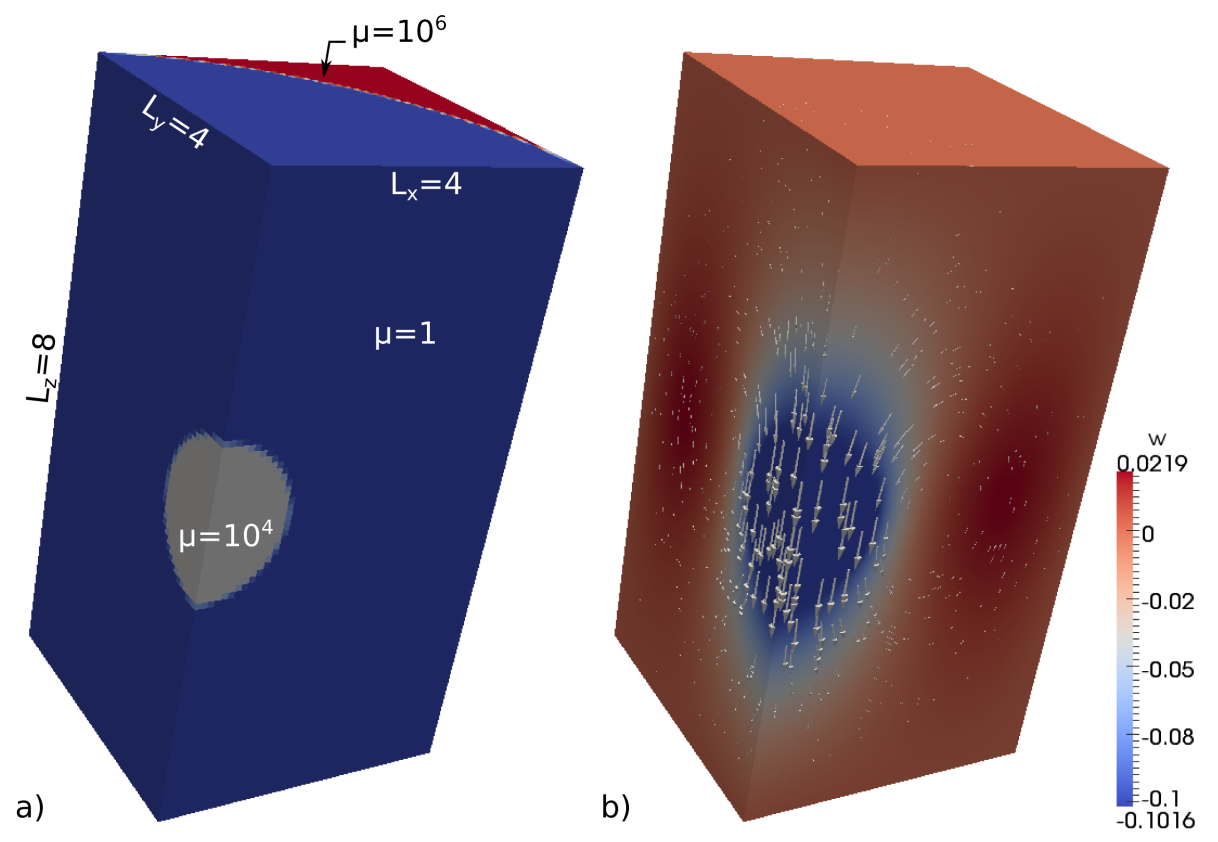

Figure 37. (a) Materials in the computational domain; (b) vertical velocity field $w$.

\section{SED}

6, 1949-2096, 2014

\section{ELEFANT \\ C. Thieulot}

Title Page

Abstract

Introduction

Conclusions

References

Tables

Figures

14

4

Back

Close

Full Screen / Esc

Printer-friendly Version

Interactive Discussion 


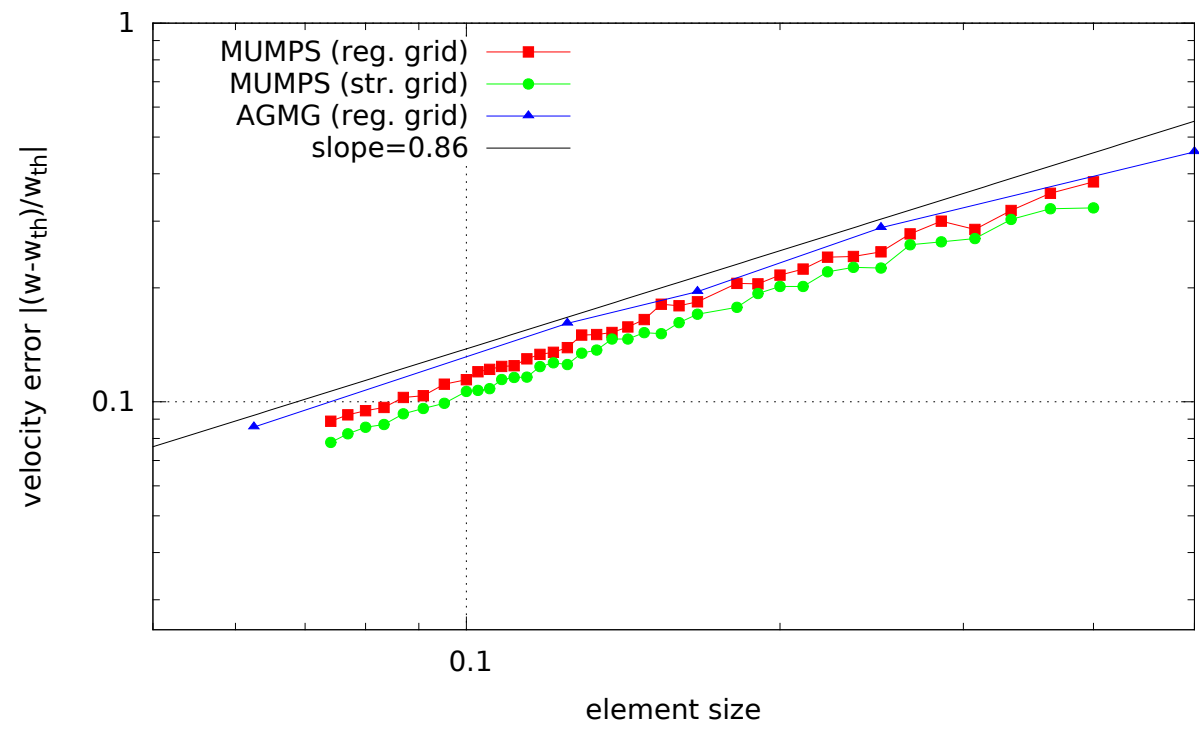

SED

6, 1949-2096, 2014

\section{ELEFANT}

C. Thieulot
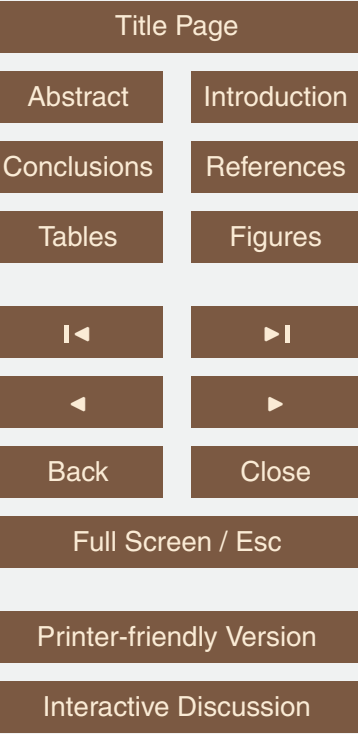

Figure 38. Measured sphere velocity relative error as a function of the element size. Results are obtained with MUMPS (constant penalty parameter) for both a regular and a stretched grid, and with AGMG (variable penalty parameter).

Interactive Discussion 


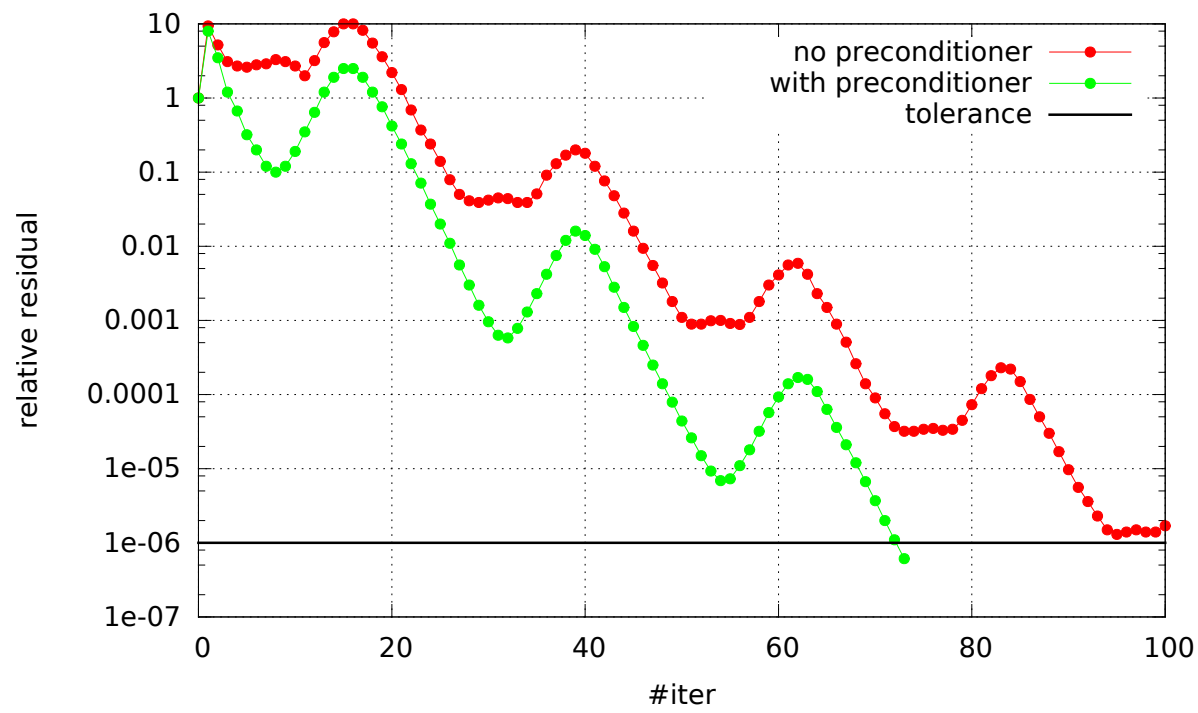

SED

6, 1949-2096, 2014

\section{ELEFANT}

C. Thieulot

\section{Title Page}

\section{Abstract}

Introduction

Conclusions

References

Tables

Figures

14

$>$ I

Back

Close

Full Screen / Esc

Figure 39. Relative residual as output by AGMG with a $32 \times 32 \times 64$ grid for the first outer iteration with and without simple diagonal preconditioner.

Printer-friendly Version

Interactive Discussion

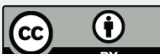




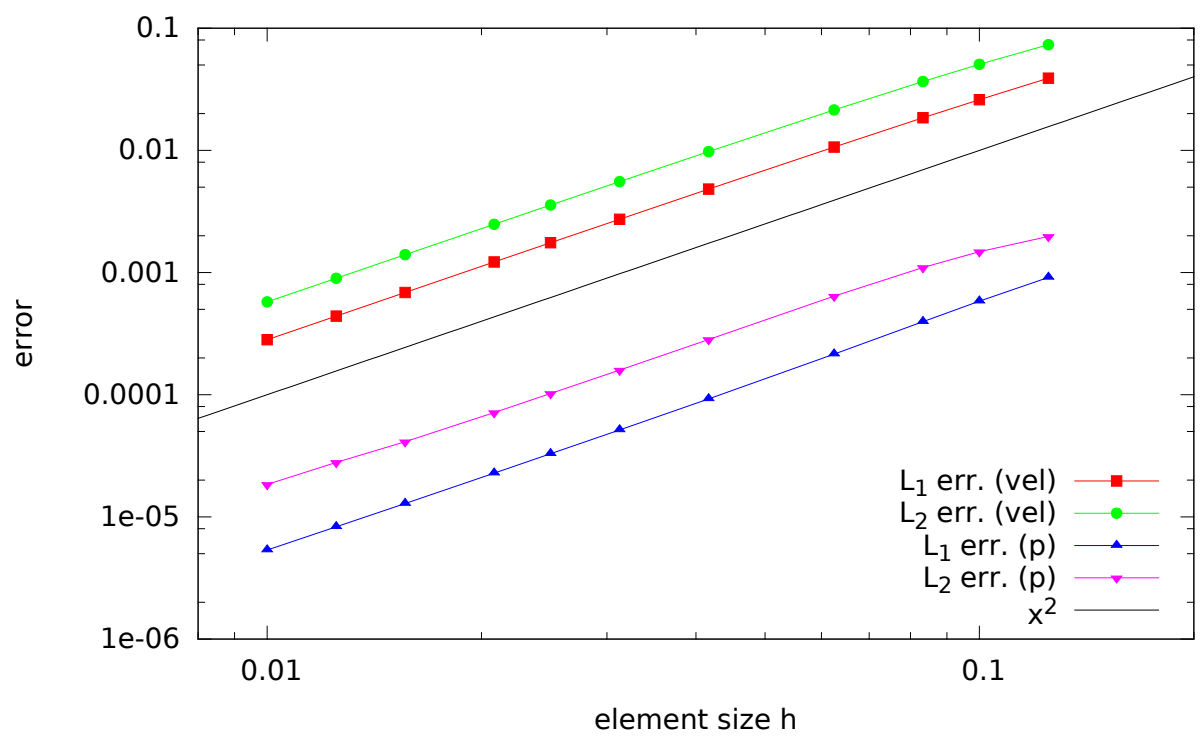

SED

6, 1949-2096, 2014

\section{ELEFANT}

C. Thieulot

Title Page

\begin{tabular}{c|c}
\hline Abstract & Introduction \\
\hline Conclusions & References \\
\hline Tables & Figures \\
\hline I4 & $\triangleright$ I \\
\hline 4 & $\triangleright$ \\
\hline Back & Close \\
\hline
\end{tabular}

Full Screen / Esc

Figure 40. 3-D polynomial solution: velocity and pressure errors in both $L_{1}$ and $L_{2}$ norms for $\beta=20$.

Printer-friendly Version

Interactive Discussion

(c) 


\section{SED}

6, 1949-2096, 2014
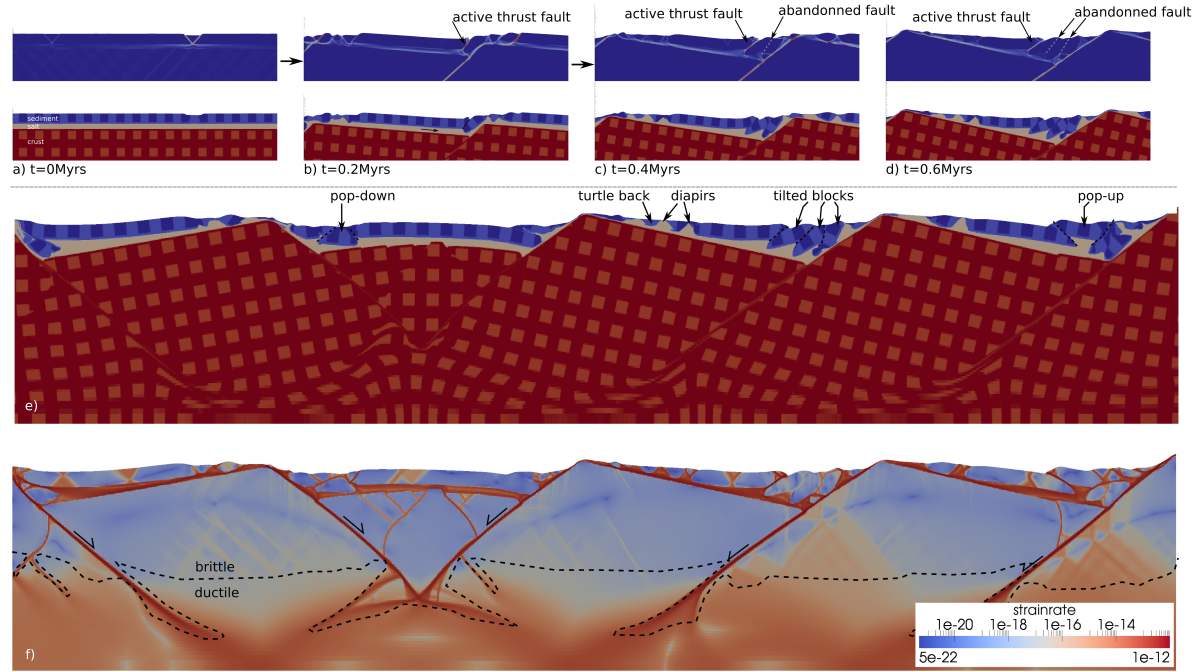

Figure 41. (a-d) Zoom of the strain rate and material fields at $t=0,0.2,0.4$, and 0.6 Myrs. $(e, f)$ Material and strain rate fields for the whole system where tectonic structures and the brittle-ductile transition have been highlighted. Crustal material rheology is of wet quartz type (Gleason and Tullis, 1995), salt and sediments properties are similar to those in Gradmann and Beaumont (2012).

\section{ELEFANT \\ C. Thieulot}

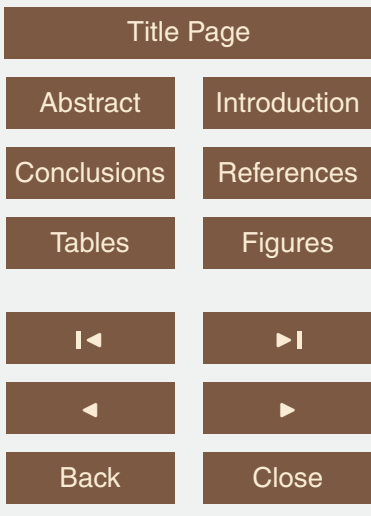

Full Screen / Esc

Printer-friendly Version

Interactive Discussion 


\section{SED}

6, 1949-2096, 2014

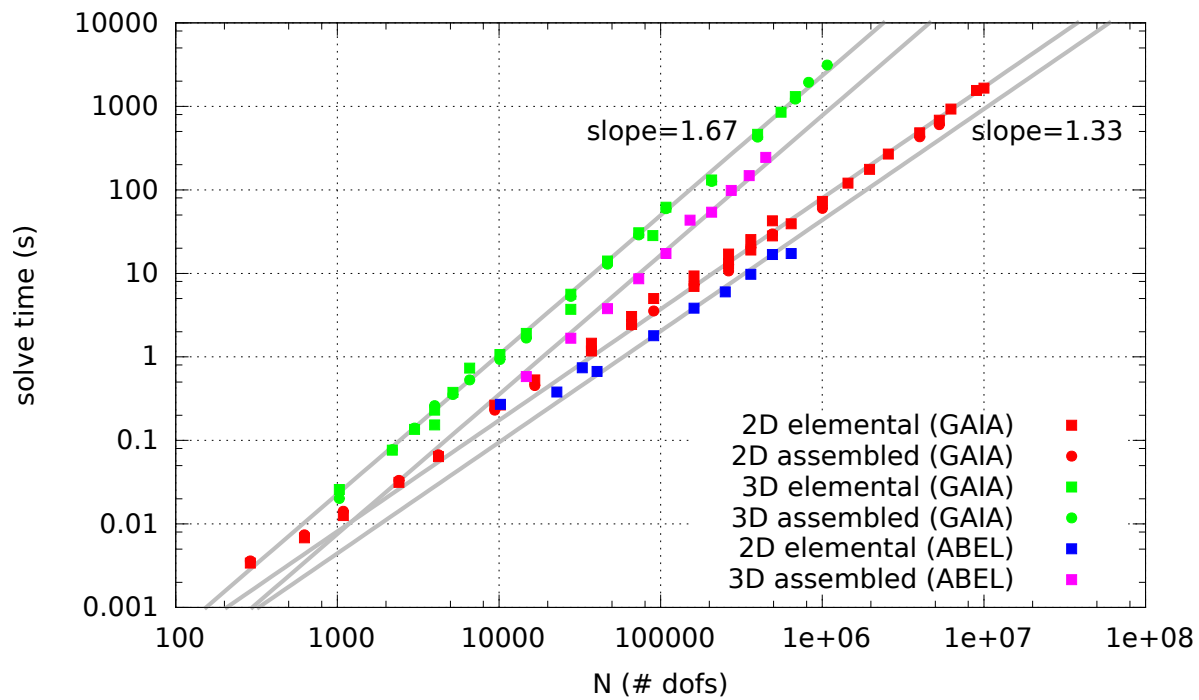

\section{ELEFANT}

C. Thieulot

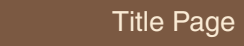

Abstract

Introduction

Conclusions

References

Tables

Figures

14

$>1$

Back

Close

Full Screen / Esc

Figure 42. Solve time (analysis + factorisation + backsubstitution) as a function of the number of degrees of freedom $N$ for both MUMPS formats as measured on GAIA and ABEL.

Printer-friendly Version

Interactive Discussion

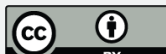




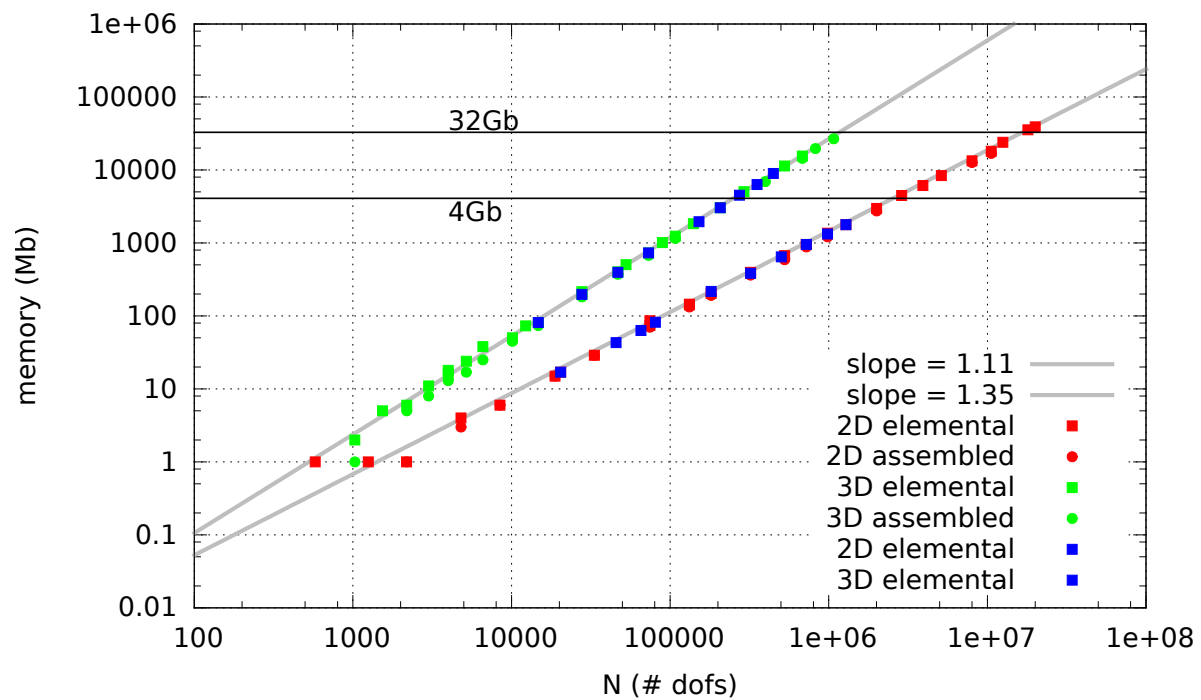

Figure 43. Memory needed by MUMPS as a function of the number of degrees of freedom $N$.

\section{SED}

6, 1949-2096, 2014

\section{ELEFANT}

C. Thieulot

\section{Title Page}

\section{Abstract}

Introduction

Conclusions

References

Tables

Figures

14

$>$ I

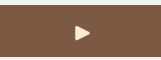

Back

Close

Full Screen / Esc

Printer-friendly Version

Interactive Discussion 


\section{SED}

6, 1949-2096, 2014
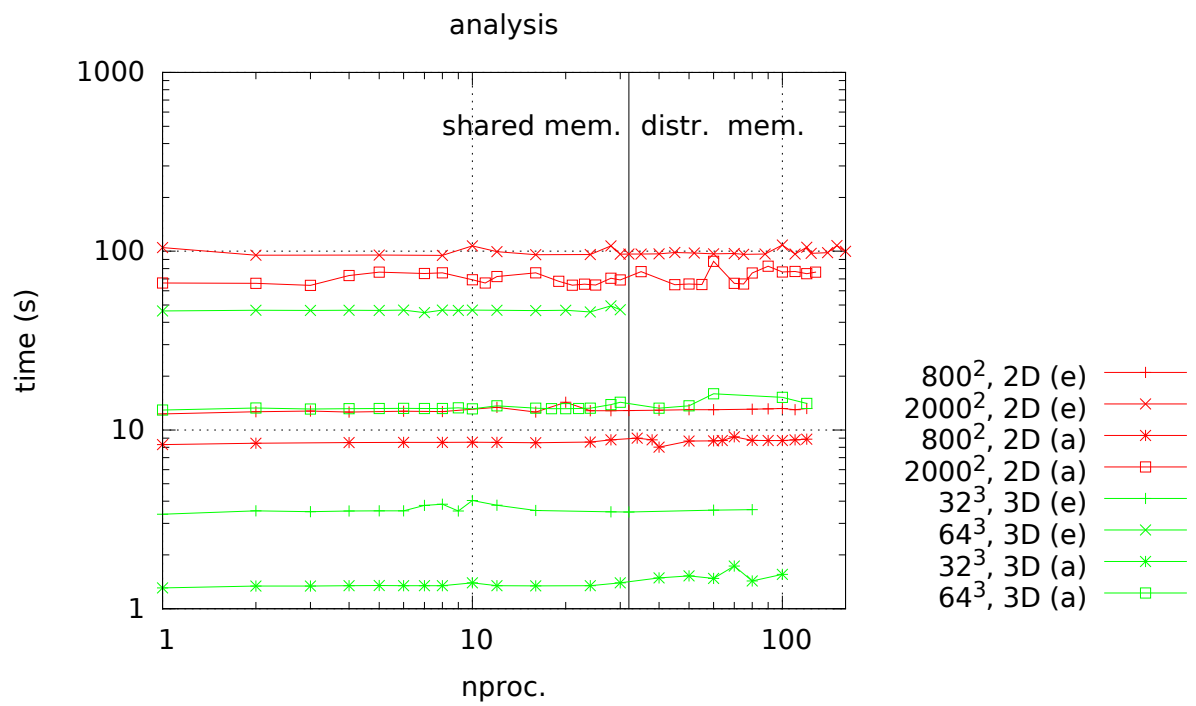

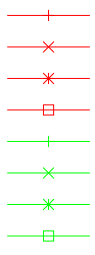

\section{ELEFANT}

C. Thieulot

\section{Title Page}

Abstract

Introduction

Conclusions

References

Tables

Figures

14

$>$

Back

Close

Full Screen / Esc

Figure 44. Strong scaling measurements for the analysis for various 2-D and 3-D systems: $800^{2}$ $(N=1283202), 2000^{2}(N=8008002), 32^{3}(N=107811)$, and $64^{3}(N=823875)$. "e" stands for elemental matrix input format while "a" stands for assembled matrix input format.

Printer-friendly Version

Interactive Discussion 


\section{SED}

6, 1949-2096, 2014

\section{ELEFANT}

C. Thieulot

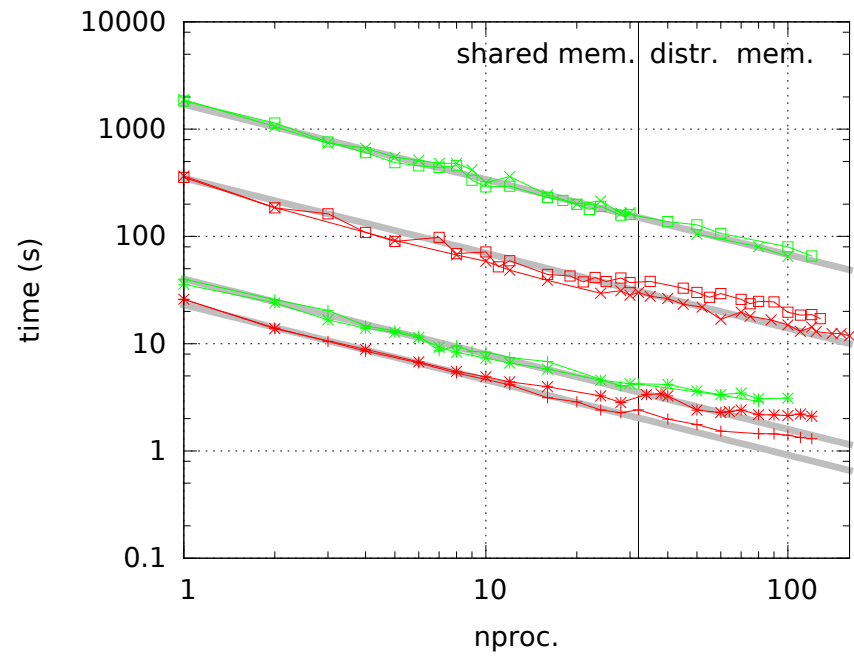

slope $=-0.7$

$800^{2}, 2 \mathrm{D}(\mathrm{e})$

$2000^{2}, 2 \mathrm{D}(\mathrm{e})$

$800^{2}, 2 \mathrm{D}(\mathrm{a})$

$2000^{2}, 2 \mathrm{D}(\mathrm{a})$

$32^{3}, 3 \mathrm{D}(\mathrm{e})$

$64^{3}, 3 \mathrm{D}(\mathrm{e})$

$32^{3}, 3 \mathrm{D}(\mathrm{a})$

$64^{3}, 3 \mathrm{D}(\mathrm{a})$

nproc.

Figure 45. Strong scaling measurements for the factorisation for various 2-D and 3-D systems: $800^{2}(N=1283202), 2000^{2}(N=8008002), 32^{3} \quad(N=107811)$, and $64^{3} \quad(N=823875)$. "e" stands for elemental matrix input format while"a" stands for assembled matrix input format.

\section{Title Page}

Abstract

Introduction

Conclusions

References

Tables

Figures

14

$\triangleright$ I

4

Back

Close

Full Screen / Esc

Printer-friendly Version

Interactive Discussion 


\section{SED}

6, 1949-2096, 2014

\section{ELEFANT}

C. Thieulot

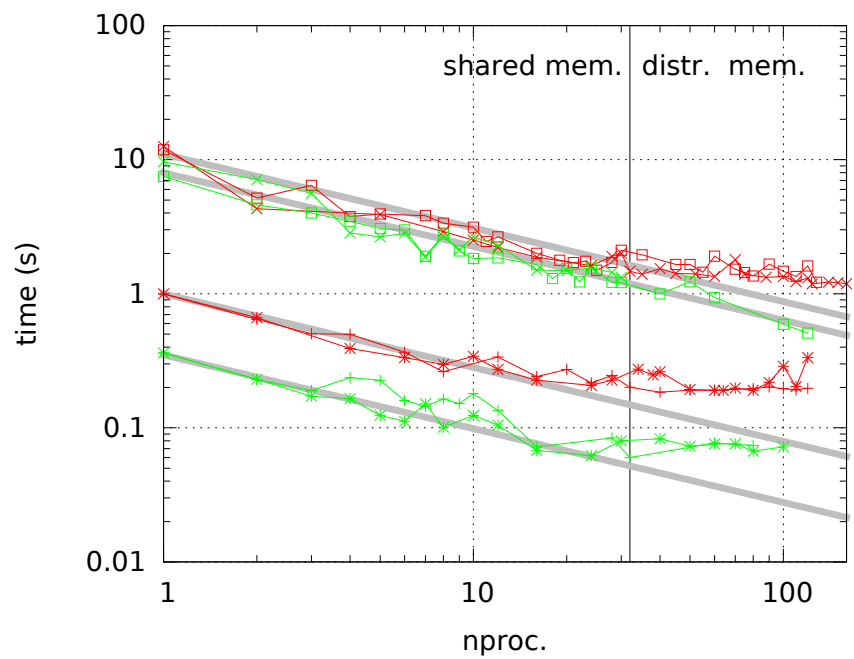

slope $=-0.55$ $800^{2}, 2 \mathrm{D}(\mathrm{e})$ $2000^{2}, 2 \mathrm{D}(\mathrm{e})$ $800^{2}, 2 \mathrm{D}(\mathrm{a})$ $2000^{2}, 2 \mathrm{D}(\mathrm{a})$ $32^{3}, 3 \mathrm{D}(\mathrm{e})$

$64^{3}, 3 \mathrm{D}(\mathrm{e})$

$32^{3}, 3 \mathrm{D}(\mathrm{a})$

$64^{3}, 3 \mathrm{D}(\mathrm{a})$

nproc.

Figure 46. Strong scaling measurements for the backsubstitution phases for various 2-D and 3-D systems: $800^{2}(N=1283202), 2000^{2}(N=8008002), 32^{3}(N=107811)$, and $64^{3}(N=$ 823875). "e" stands for elemental matrix input format while"a" stands for assembled matrix input format.

\section{Title Page}

Abstract

Introduction

Conclusions

References

Tables

Figures

14

$\rightarrow 1$

4

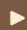

Back

Close

Full Screen / Esc

Printer-friendly Version

Interactive Discussion 


\section{SED}

6, 1949-2096, 2014
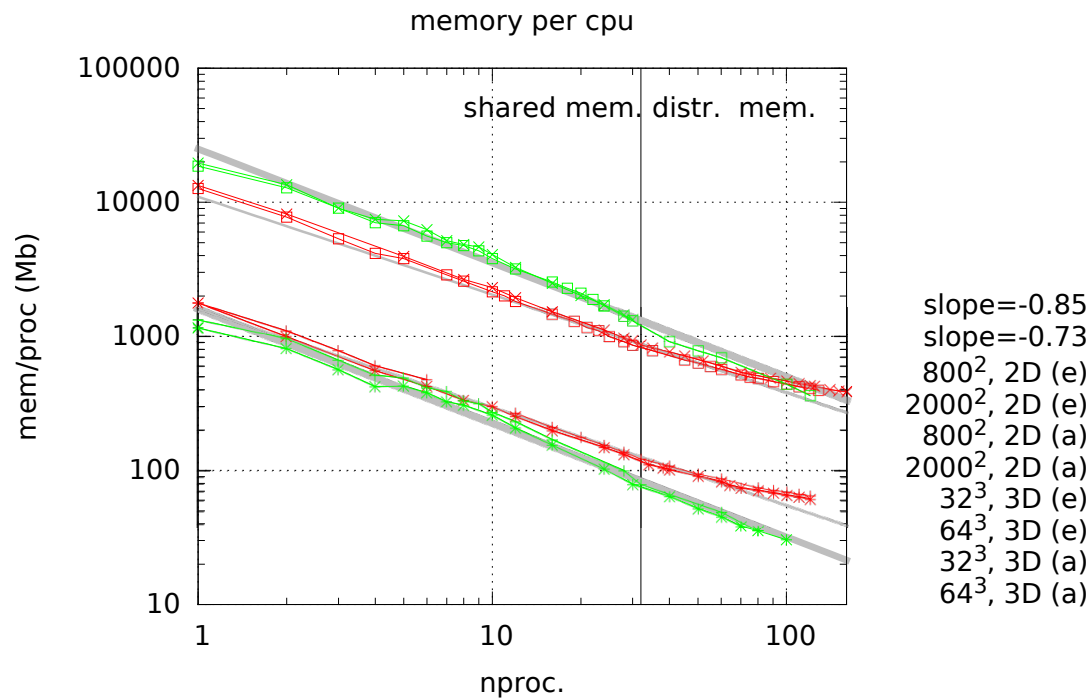

nproc.

Figure 47. Strong scaling measurements for the used memory per thread for various $2-D$ and 3-D systems: $800^{2}(N=1283202), 2000^{2}(N=8008002), 32^{3}(N=107811)$, and $64^{3}(N=$ 823875)."e" stands for elemental matrix input format while"a" stands for assembled matrix input format. 


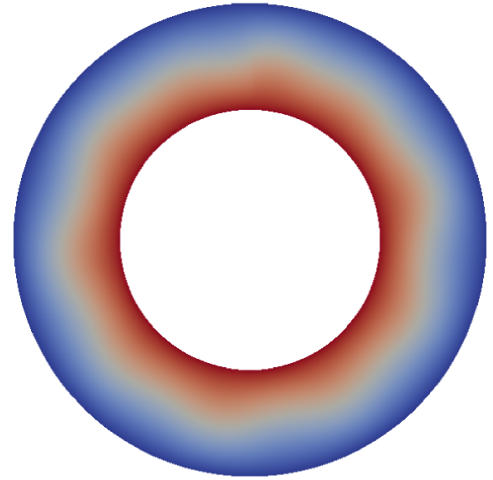

Time: $45.541000 \mathrm{Myr}$

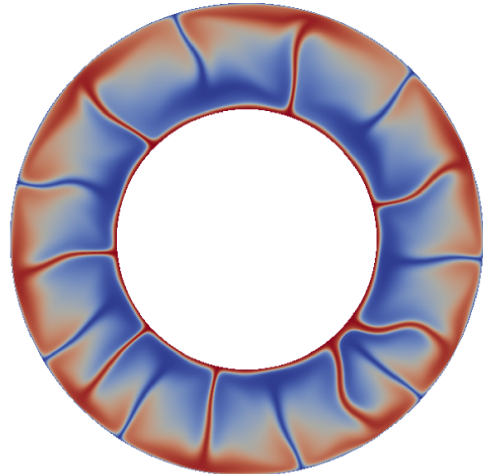

Time: $201.120000 \mathrm{Myr}$

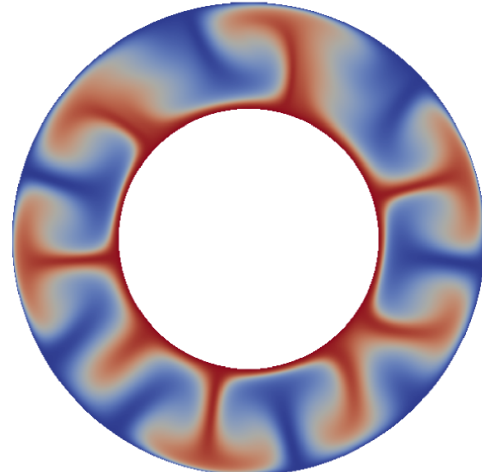

Time: $100.230000 \mathrm{Myr}$

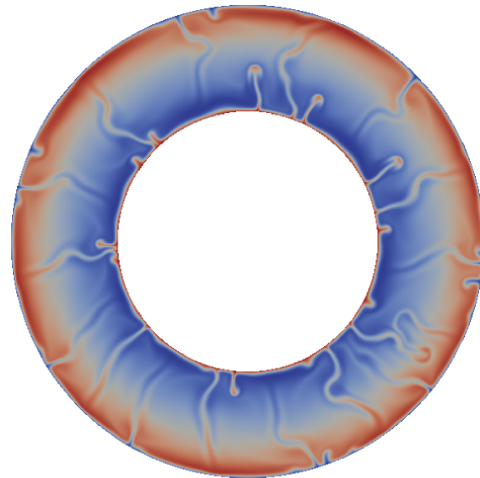

Time: $663.450000 \mathrm{Myr}$

Figure 48. Initial temperature gradient is linear between $T=973 \mathrm{~K}$ at the surface and $4273 \mathrm{~K}$ at the bottom. A small 6 -lobed perturbation is added in order to onset convection. Inner radius is $3481 \mathrm{~km}$, outer radius is $6336 \mathrm{~km}$, the grid is $480 \times 1115, \alpha=4 \times 10^{-5} \mathrm{~K}^{-1}, \mu=10^{22} \mathrm{~Pa} \mathrm{~s}$, $\lambda=10^{28} \mathrm{Pas}, T_{0}=273 \mathrm{~K}, \rho_{0}=3300 \mathrm{~kg} \mathrm{~m}^{-3}, k=5 \mathrm{~W} \mathrm{~m}^{-1} \mathrm{~K}^{-1}, c_{\mathrm{p}}=1200 \mathrm{~J} \mathrm{~kg}^{-1} \mathrm{~K}^{-1}, C=0.2, g=$ $10 \mathrm{~m} \mathrm{~s}^{-2}$.

SED

6, 1949-2096, 2014

\section{ELEFANT}

C. Thieulot

\section{Title Page}

\section{Abstract}

Introduction

Conclusions

References

Tables

Figures

14

$>$ I

4

Back

Close

Full Screen / Esc

Printer-friendly Version

Interactive Discussion 